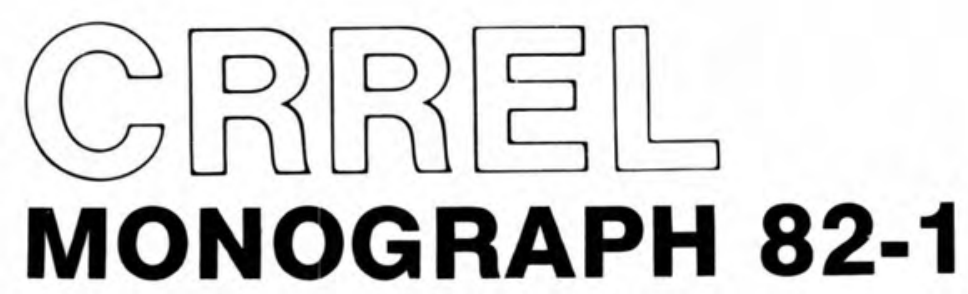

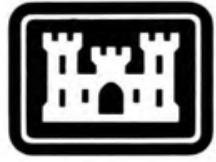

US Army Corps of Engineers

Cold Regions Research \& Engineering Laboratory

The growth, structure, and properties of sea ice
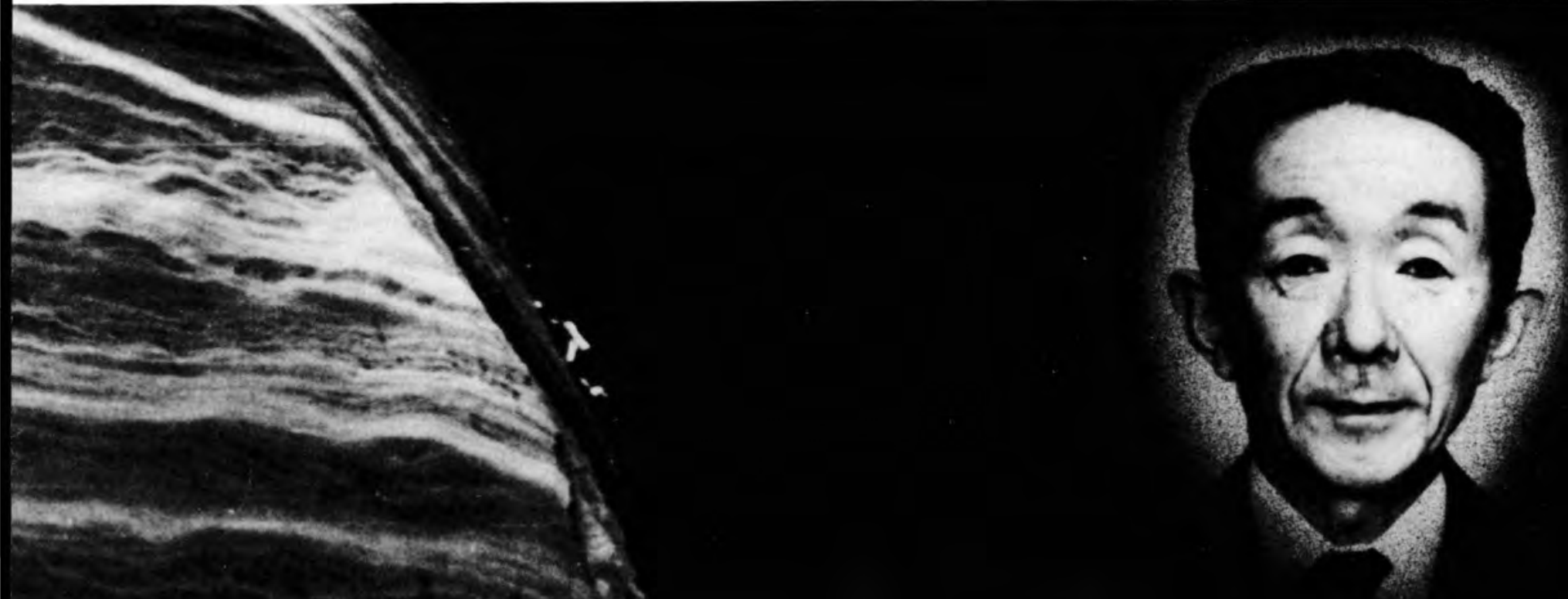
For conversion of SI metric units to U.S./British customary units of measurement consult ASTM Standard E380, Metric Practice Guide, published by the American Society for Testing and Materials, 1916 Race St., Philadelphia, Pa. 19103.

Cover: The authors dedicate this Monograph to the memory of Professor Tadashi Tabata, a dedicated student of sea ice and a close friend.

The photograph is a vertical aerial view from an altitude of 200 meters of frazil ice forming along the edge of an ice floe (also composed of frazil ice) in the northern Bering Sea. The changes in whiteness result from changes in ice thickness and variations in how tightly the crystals are packed to. gether. 


\section{CRREL Monograph 82-1}

November 1982

The growth, structure, and properties of sea ice

W.F. Weeks and S.F. Ackley 


\begin{tabular}{|c|c|}
\hline REPORT DOCUMENTATION PAGE & $\begin{array}{c}\text { READ INSTRUCTIONS } \\
\text { BEFORE COMPLETING FORM }\end{array}$ \\
\hline $\begin{array}{l}\text { 1. REPORT NUMBER } \\
\text { CRREL Monograph } 82-1\end{array}$ & 3. RECIPIENT'S CATALOG NUMBER \\
\hline \multirow[t]{2}{*}{$\begin{array}{l}\text { 4. TITLE (and Subtitie) } \\
\text { THE GROWTH, STRUCTURE, AND PROPERTIES OF SEA ICE }\end{array}$} & 5. TYPE OF REPORT \& PERIOD COVERED \\
\hline & 6. PERFORMING ORG. REPORT NUMBER \\
\hline $\begin{array}{l}\text { 7. AUTHOR(s) } \\
\text { W. F. Weeks and S.F. Ackley }\end{array}$ & 8. CONTRACT OR GRANT NUMBER(s) \\
\hline $\begin{array}{l}\text { 9. PERFORMING ORGANIZATION NAME AND ADDRESS } \\
\text { U.S. Army Cold Regions Research and } \\
\text { Engineering Laboratory } \\
\text { Hanover, New Hampshire } 03755\end{array}$ & $\begin{array}{l}\text { 10. PROGRAM ELEMENT, PROJECT, TASK } \\
\text { AREA \& WORK UNIT NUMBERS }\end{array}$ \\
\hline \multirow{2}{*}{$\begin{array}{l}\text { 11. CONTROLLING OFFICE NAME AND ADDRESS } \\
\text { U.S. Army Cold Regions Research and } \\
\text { Engineering Laboratory } \\
\text { Hanover, New Hampshire } 03755\end{array}$} & $\begin{array}{l}\text { 12. REPORT DATE } \\
\text { NoVember } 1982 \\
\end{array}$ \\
\hline & $\begin{array}{l}\text { 13. NUMBER OF PAGES } \\
136\end{array}$ \\
\hline \multirow[t]{2}{*}{ 14. MONITORING AGENCY NAME A ADORESS(If different from Controlling Office) } & $\begin{array}{l}\text { 15. SECURITY CLASS. (of thle roport) } \\
\text { Unclassified }\end{array}$ \\
\hline & $\begin{array}{l}\text { 15a. DECLASSIFICATION/DOWNGRADING } \\
\text { SCHEDULE }\end{array}$ \\
\hline \multicolumn{2}{|l|}{$\begin{array}{l}\text { 16. DISTRIBUTION STATEMENT (of thia Roport) } \\
\text { Approved for pub1ic release; distribution unlimited. }\end{array}$} \\
\hline \multicolumn{2}{|l|}{ 17. DISTRIBUTION STATEMENT (of the abetract onterod in Block 20, If different from Report) } \\
\hline \multicolumn{2}{|l|}{ 18. SUPPLEMENTARY NOTES } \\
\hline \multicolumn{2}{|l|}{$\begin{array}{l}\text { 19. KEY WORDS (Continuo on revers } \\
\text { Electrical properties } \\
\text { Ice } \\
\text { Mechanical properties } \\
\text { Salinity }\end{array}$} \\
\hline \multicolumn{2}{|c|}{ 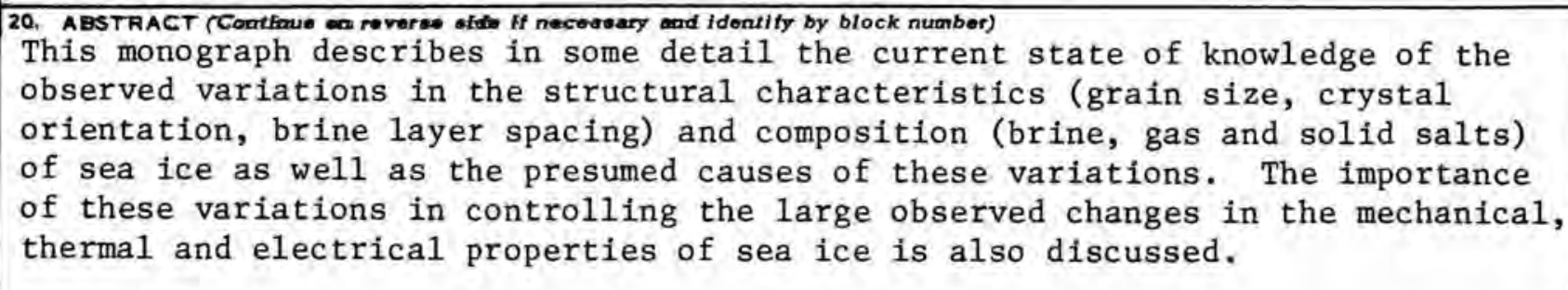 } \\
\hline
\end{tabular}


PREFACE

This Monograph was prepared by Dr. W.F. Weeks, Glaciologist, Snow and Ice Branch, Research Division, U.S. Army Cold Regions Research and Engineering Laboratory, and S.F. Ackley, Chief of the Snow and Ice Branch.

The work on which a portion of this paper is based has taken place over a number of years. The authors particularly thank the Oceanic Processes Branch of NASA, the Arctic Program of the Office of Naval Research, the Division of Polar Programs of the National Science Foundation, and the Arctic Program of the Outer Continental Shelf Environmental Assessment Program of NOAA for their support and patience. The OCSEAP program was supported by the Bureau of Land Management and is a multiyear program responding to needs of petroleum development of the Alaskan Continental Shelf.

Technical review of the manuscript was performed by Dr. Anthony J, Gow and Jacqueline A. Richter of CRREL. 


\section{CONTENTS}

Abstract--

Preface--

Introduction-- 1

The atomic structure of ice-1

The sea ice phase diagram-_- 4

Formation of the initial ice cover- 12

The transition zone-- 23

The columnar zone-- 29

Substructure--

Constitutional supercooling-_- 41

Variations-_- 47

Directional c-axis alignments-_ 47

Frazil ice-- 52

Multiyear ice- 63

The salinity profile- 69

Observations-- 69

Initial salt entrapment-- 74

Brine drainage mechanisms- 78

Solid salt crystals- 88

Relationships between sea ice structure and properties------ 90

Models for the variation in the mechanical properties of sea ice-- 90

Models for the variation in the thermal properties of sea ice-_- 98

Electrical properties of sea ice in the 0.1 - to $40-\mathrm{GHz}$ range-- 103

Concluding statement- 117

Literature cited-- 117

\section{ILLUSTRATIONS}

Figure

1. Structure of ice I

2. A portion of the phase diagram $\mathrm{NaCl}_{-} \mathrm{H}_{2} \mathrm{O}-\cdots$

3. Freezing point of brine as a function of the ratio of

the weight of dissolved salts to pure water----- 7

4. Phase relations for "standard" sea ice-___ 8

5. Relative water content in percent versus temperature for sea ice-- 10

6. Probabilities of values for $D_{C}$ for various ions------ 11

7. Temperature of the density maximum and of the freezing point for seawater of different salinities-------

8. Growth sequence for ice crystals in bulk water-------

9. Initial discs during the freezing of seawater------

10. Stellar ice crystals growing in seawater----

11. Stellar ice crystals grown from seawater--

12. Initial ice crystal formation in calm seawater-------

13. A needle surrounded by crystals with their c-axes vertical-_- 
14. Inked copy of a surface rubbing of an ice skim-_-_- 17

15. The relation between the ice surface topography produced by etching and the lines on a rubbing-...-.- 18

16. Grease ice forming on the surface of a lead-_-_-..-19

17. Pancake ice forming from frazil crystals-_._-_._- 20

18. Composite ice sheet of pancakes and sheet ice---------- 21

19. Aerial photograph of grease ice-_ 22

20. Schematic drawing of the general effect of Langmuir circulation on grease and pancake ice-- 23

21. Rubbing of the bottom of an ice skim-- 24

22. Photomicrograph of the lower surface of sea ice--.-- 24

23. Orientation of the c-axes of sea ice crystals from different depths-_-_-_- 26

24. Histograms showing the relative percentage of different c-axis orientations-_-_-

25. Schematic diagram showing the process of geometric selection according to Perey and Pounder-........-.

26. c-axis orientation in a healed crack--

27. Rubbing from just below the transition layer on an ice sheet--.--

28. Histogram giving the angles between the c-axes of neighboring ice crystals-

29. Vertical rubbing of columnar zone ice--

30. The distribution of $c-$ and a-axis orientations in the upper and lower portions of thin ice sheets------

31. Lengths and widths of ice crystals at different levels in a sea ice sheet-- 32

32. Increase in crystal size with distance below the surface of an ice sheet-_ 32

33. Plot of change in grain size with distance below the upper ice surface-_- 34

34. Histograms of crystal diameters at different levels in an ice sheet---

35. Horizontal thin section of sea ice from below the upper ice surface--

36. Photographs of two thin sections showing cellular substructure in sea ice---

37. Plot of $-\log \left(a_{0} v\right)$ versus $(\log 1 / v)^{2}$

38. Profiles of growth rate, salinity and brine layer spacing--- - -

39. Plot of average brine layer spacing versus corresponding rate of growth-_ 40

40. Vertical thin section of sea ice from the lower portion of the core from site J-9, Ross Ice Shelf --_-.---

41. Steady-state distribution of solute in the liquid ahead of an advancing solid/1iquid interface-_-_-_-_--.--

42. Constitutionally supercooled zone of liquid ahead of an advancing interface----

43. A plot of the boundaries that separate growth conditions where a planar interface is stable and where it is unstable--

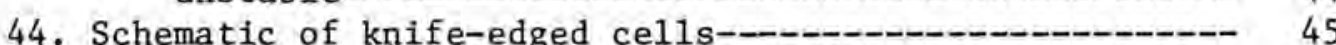

45. The c-axis orientations as determined by Cherepanov in the Kara Sea-_-_- 
Figure

46. Sample site locations, mean c-axis alignments, and in-

Page stantaneous current directions determined along the coast of the Beaufort Sea-_.

47. Schmidt net plots of individual c-axis orientations for

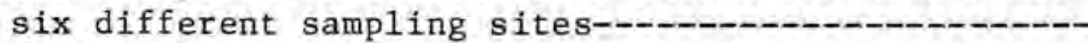

48. Mean crystal orientation in the horizontal plane, and the standard deviation as a function of vertical location in the ice sheet-...-.

49. Histogram showing the relative frequency of different deviations between the observed instantaneous current direction and the mean c-axis direction-..-...-..--

50. Sketch showing the interface geometry of two crystals---

51. Site locations for sea ice core sampling from the USCGC Polar Sea-

52. Salinity, structure and thin section photos from selected depths for Floe 42-A-1 -

53. Salinity, structure and thin section photos from Floe 43-A-2--

54. Salinity, structure and thin section photos from Floe 44-G-3-.........

55. Salinity, structure and thin section photos from Floe 49-G-2--

56. Salinity, structure and thin section photos from Floe 61-G-2-_-

57. Congelation ice vs ice thickness for all cores obtained in the Weddell Sea-_-

58. Profiles of seasonal changes of temperature with depth in the water column typical of the Antarctic and the Arctic-_-

59. Cross section of a multi-year floe--

60. Winter's increment of ice growth plotted against the number of annual layers measured from the top of the floe--

61. The distribution of salinity, temperature and the resultant density caused by the diffusion of a freshwater layer over a saltwater layer--.--

62. Salinity profiles of ice of Eclipse Sound at intervals of two weeks during the winter of 1977-78----

63. Average salinity of ice sheet at Hopedale, Labrador-----

64. Average salinity of sea ice as a function of ice thickness----

65. Average multiyear salinity profiles for hummocked and depressed areas---

66. A cross section of an area of multiyear ice showing the variation of salinity with topography-_.-.

67. Average salinity of sea ice as a function of ice thickness for warm sea ice--..--

68. Plot of $\ln (1 / \mathrm{k}-1)$ versus $\mathrm{v}$ using the salinity entrapment data of Cox and Weeks-_-

69. Plot of $k$ vs $\delta v / D$ for the salinity entrapment data of Cox and Weeks-_-

70. Plot of $\ln (1 / k-1)$ versus $v$ for columnar-grained sea ice71. Stable salinity or $k$ versus growth rate--

72. Relation between brine pocket migration velocity and ice temperature - 
Figure

Page

73. Relation between the temperature gradient in the ice and the brine pocket migration rate---

74. Comparison between experimental salinity curves and theoretical salinity curves determined from a brine expulsion mode1--

75. Plot of rate of change of salinity due to gravity drainage versus brine volume for different temperature gradients--

76. Plot of rate of change of salinity due to gravity drainage versus low brine volumes for different temperature gradients--

77. Schematic drawing of a cut through a brine drainage channel--_-_-

78. Number of brine drainage channels developed in thin ice sheets versus the average growth rate---

79. Relationship of maximum brine volume and salt advection required to maintain the steady-state salinity profile--.---_-

80. Scanning electron micrographs of a vertical section of a brine pocket at $-30^{\circ} \mathrm{C}$, second replica--_-_-_--

81. Rubbing of a broken segment of sea ice-_-

82. Idealized diagram of the shape of the brine inclusions in sea and $\mathrm{NaCl}$ ice-_-

83. An idealization of the structure of sea ice used in calculating its elastic modulus--

84. Thermal conductivity of pure ice as a function of temperature---

85. Thermal conductivity of sea ice-_.

86. Density and thermal conductivity of bubbly ice as a function of the fractional air content--

87. Effective thermal conductivity of sea ice as a function of temperature for various salinities and densities-

88. Thermal conductivity of sea ice calculated using Ono's model-

89. Thermal diffusivity of sea ice-_-

90. Real and imaginary parts of the dielectric constant for brine and pure water--_-

91. Brine layers at the bottom of the ice sheet showing necking off as the temperature is lowered--------

92. Ice salinity, temperature and brine volume profile from the Alaskan Arctic-_-_-_-_-_-

93. Computed depth-dielectric constant profiles--

94. Simulated returned power/incident power vs depth-_-_---

95. Scattering albedo vs scatterer size to wavelength ratio for ice overlying fresh water--

89

96. Changes in brightness temperature plotted against scattering albedo with the layer thickness to wavelength ratio as a parameter---

\section{TABLES}

Table

1. Some properties of the solid salts presumed to occur in

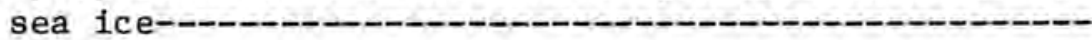




\title{
THE GROWTH, STRUCTURE, AND PROPERTIES OF SEA ICE
}

\author{
W.F. Weeks and S.F. Ackley
}

\section{INTRODUCTION}

On the geophysical scale sea 1 ce is a thin, fragile, dynamic, solid layer that forms under the thermodynamic conditions that occur near the Poles. There it serves as a boundary between two much larger fluid bodles - the ocean and the atmosphere. Typical scales of interest would be $10^{3}$ to $10^{6} \mathrm{~m}$. In the present paper we take a more detailed view, focusing on the ice itself at scales ranging between $10^{0}$ and $10^{-3} \mathrm{~m}$, with an occasional glimpse at a scale of $10^{-10} \mathrm{~m}$. It is our purpose to help the reader understand the internal structure of sea ice, how this structure develops, and how it affects the bulk properties of the ice. Although this is a subject that has recelved little attention in comparison to similar studies of metals and ceramics, it is, in our view, very important, as many details in the behavior of sea tce are structurally controlled. The variations in structure are, in turn, determined by the environmental conditions under which the ice has formed.

In the following, we will take many observations and theories based on studies of other materials and apply them to sea ice. This is a natural progression, in that it moves from the well studied to the little studied. The reader should, however, be warned that such transfers of ideas are, many times, far from straightforward. In fact, it is to be hoped that in the long run the study of sea ice as a material will be able to contribute as much to the study of other materials as 1t receives. The reasons for this optimism are several. First, the natural range of temperatures at which sea ice exists is just a few degrees of $f$ its melting point. In fact, sea ice normally is only partially solidified in that it contains melt inclusions. Second, this temperature range is one in which man can operate without special precautions or equipment. Therefore, experiments on sea lce are much easier than experiments on most metals and ceramics studied at similar near-melting temperatures. Finally, pure 1ce, the primary phase composing sea ice, is transparent. This makes it relatively easy to look inside the ice and to observe what is actually occurring. This is a luxury rarely available to workers in metallurgy and ceramics.

THE ATOMIC STRUCTURE OF ICE

One of the unusual characteristics of ordinary ice is that it is less dense than its melt. Geophysically this low density is quite important in that it causes ice to float on the surface of lakes and seas. If 1 ce sank into its melt, as do most solids, there would be a tendency for natural water bodies to freeze completely to their beds, a situation hardly conducive to the development of aquatic $11 \mathrm{fe}$ in either temperate or polar regions. 

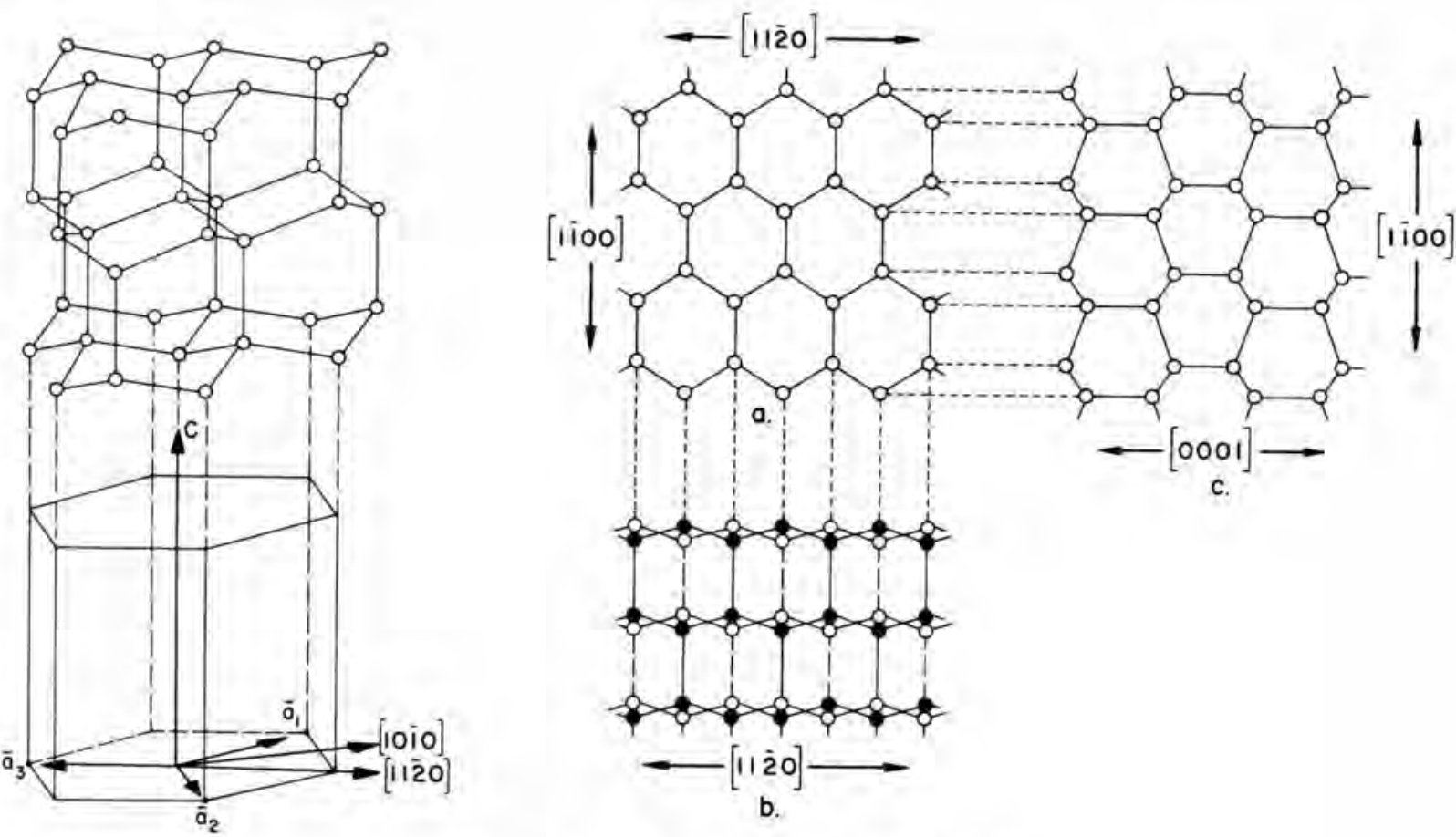

Figure 1. Structure of ice I.

The fact that ordinary ice is such an open, low density solid also suggests that there may be other, more compact atomic arrangements of $\mathrm{H}$ and 0 that would result in $\mathrm{H}_{2} \mathrm{O}$ polymorphs with a higher density. There are, in fact, at least nine other polymorphs of $\mathrm{H}_{2} \mathrm{O}$ (Hobbs 1974) that can be produced. However, ordinary ice (ice I) is the only one of these that exists in significant quantities under the physical conditions encountered at the earth's surface. In the remainder of this paper, when ice is referred to, the ice polymorph will always be ice I.

The geometric arrangement of the oxygen atoms, which in the ice structure are the principal diffracting centers for X-rays, is well understood, as ice was one of the first substances to have its structure determined (Bragg 1922, Lonsdale 1958, Owston 1958, Hobbs 1974). The results of these studies are shown in Figure 1 . Each oxygen atom is located at the center of a tetrahedron with four other oxygen atoms located at each of the apices. The $0-0$ distance is $0.276 \mathrm{~nm}$ at $0^{\circ} \mathrm{C}$, resulting in an open, low-density structure. The tetrahedral coordination of the oxygen atoms results in a crystal structure possessing hexagonal symmetry, a fact that will affect many of the large scale characteristics of ice. An important feature of the structure of ice I is that the oxygen atoms are concentrated close to a series of parallel planes that are referred to as the basal planes. The direction perpendicular to these planes is referred to as the principal hexagonal or caxis. The arrangement is such that, in any unit cell which contains four oxygen atoms, fracture along the basal or (0001)* plane involves

* The parentheses around the Miller indices signify a single plane or a set of planes; Indices of a direction are given in brackets, i.e. $[11 \overline{2} 0]$, and the full set of equivalent directions of a form are indicated by carets, 1.e. $\langle 1120\rangle$ (Barrett 1952, p. 8-12). 
the rupture of only two bonds. On the other hand, fracture along any plane normal to this plane requires the breaking of at least four bonds. Therefore, the fact that ice glides and cleaves readily on the basal plane can be easily rationalized in terms of its atomistic structure. When the positions of the oxygen atoms are projected parallel to the [0001] direction, the resulting hexagonal array (Figure la) can be seen to be composed of three close-packed rows of atoms. These rows lie in the $\langle 11 \overline{2} 0\rangle$ direction parallel to the three secondary or a-axes. As will be seen, the a-axis directions, which are, of course, all equivalent, correspond to the directions of the arms of a) dendritic sea ice crystals growing from the melt, b) snowflakes growing from the vapor, and c) internal melt features that form inside ice crystals as the result of absorbed solar radiation; again all are external manifestations of the atomic structure.

This highly regular net of oxygen atoms is bonded together by a series of hydrogen bonds. The positions of the hydrogen atoms in these bonds are disordered and obey the so-called Berna1-Fowler rules: 1) two hydrogens are near each oxygen atom and 2) only one hydrogen atom can be on or near the line connecting two neighboring oxygen atoms. Within the constraints of these rules all configurations are considered to be equally probable. The average structure that results can be specified by assigning hypothetical "half-hydrogen" atoms to each of the $4 \mathrm{~N}$ sites contained in any array of $\mathrm{N}$ oxygen atoms. Therefore each oxygen atom is tetrahedrally surrounded by four "half-hydrogens." This arrangement of "half-hydrogens" is in good agreement with both the observed zero-point entropy of ice (Pauling 1935, Nagle 1966, Suzuki 1967) and the results of single-crystal neutron diffraction studies (Peterson and Levy 1957). Any violation of the Bernal-Fowler rules can be considered as producing a defect in the ice structure, with a violation of rule 1 resulting in an Ionic defect: an oxygen atom surrounded by three protons produces a positive ion $\left(\mathrm{H}_{3} \mathrm{O}\right)^{+}$while one with only one proton produces the negative ion $(\mathrm{OH})^{-}$. When rule 2 is violated, a Bjerrum defect results: when two protons occur on the bond a so-called D-defect results, while a bond with no protons gives an L-defect.

Although beyond the scope of the present paper, an understanding of the nature of the hydrogen bonding in ice is certainly necessary to the study of its electrical, diffusive, thermodynamic and mechanical behavior. For instance, it is the nature of the highly directional hydrogen bond that is responsible for the anomalous physicochemical properties of ice and water. As was mentioned, the density of 1 ce at $0^{\circ} \mathrm{C}$ is less than that of water at the same temperature, with the density of water increasing to a maximum at $+4^{\circ} \mathrm{C}$. The low density of ice is the result of the tetrahedral coordination of each water molecule by hydrogen bonding causing a very open structure. On melting, some of the hydrogen bonds are broken, allowing the molecules to assume a more closely packed structure with an associated increase in density. This process of further bond breakage and compaction of molecules continues with rising temperature until a point is reached $\left(+4^{\circ} \mathrm{C}\right)$ when density increases are more than compensated for by thermal expansion. 
Now that we have a general knowledge of the structure of pure ice, we next need information on the phase relations of the ice-salt and ice-seawater systems that are of concern in the study of sea ice. By phase relations we refer to information that specifies the different phases that coexist at equilibrium at different temperatures and pressures in a system with a known bulk composition. One of the first questions that must be considered here is "Does the ice that forms from freezing salt solutions incorporate salt in solid solution?" Here by solid solution we refer to the process when the impurity atoms actually occupy lattice sites in the atomic structure of the ice crystal. Solid solutions form most readily when the foreign atoms have the right size to fit into the host structure, tend to form a similar type of chemical bond, and have an appropriate charge to maintain electrostatic neutrality. Impurities fulfilling these requirements for substitution into ice are rare. Because the ionic and atomic radii of fluorine and nitrogen are similar to those of oxygen, $\mathrm{F}^{-}, \mathrm{HF}, \mathrm{NH}_{4}^{+}$, and $\mathrm{NH}_{3}$ are likely candidates to replace some of the water molecules in the ice structure. Other possibilities are $\mathrm{NH}_{4} \mathrm{OH}, \mathrm{NH}_{4} \mathrm{~F}$, and the hydrohalogen acids ( $\mathrm{HCl}$, $\mathrm{HBr}$, and $\mathrm{HL})$. In all of the above cases some limited substitution in the ice structure is observed. Maximum substitution occurs at a concentration of $10^{-2} \mathrm{~mol} / \mathrm{L}$, which corresponds to a molar ratio of about 1 in 5000. However, none of the above materials are present in significant quantities in seawater.

How much of the common components of seawater enter substitutionally into ice crystals grown from it? There is, to our knowledge, no precise information on the subject, although the amounts would appear to be extremely small. Harrison and Tiller (1963) estimate that for most solutes in ice the equilibrium solute partition coefficient $k_{0}\left(k_{0}=x_{A}^{s} / x_{A}^{\ell}\right.$ where $x_{A}^{S}$ and $x_{A}^{\ell}$ are the mole fraction of solute $A$ in the solid and liquid respectively) is less than $k_{0} \leq 10^{-4}$. In short, although thermodynamic arguments can be made that suggest that at equilibrium a finite amount of impurity should exist in the ice structure, this amount is apparently so small that for most purposes the ice can be considered as a pure phase. Therefore, as ice forms from a salt or seawater solution essentially all the solute is rejected back into the liquid or melt. So, as more and more ice forms with gradually decreasing temperature the melt that coexists in equilibrium with the ice becomes saltier and saltier. The phase relations simply specify the number and composition of the different phases (brine, ice, solid salts) that coexist at the different temperatures and pressures. Although, in principle, it is possible to calculate the phase relations from thermodynamic information, in fact phase diagrams, and particularly those for complex systems such as seawater, are invariably determined experimentally. The results of such experimentation are then displayed in the form of a phase diagram.

For example, Figure 2 shows the water-rich portion of the $\mathrm{H}_{2} \mathrm{O}$ NaC1 phase diagram, which is the simple two-component system that most closely approximates seawater. What happens when we start with an $\mathrm{NaCl}$ solution and gradually cool it down past its freezing point until it becomes completely solidified can be seen on this diagram. Consider an 


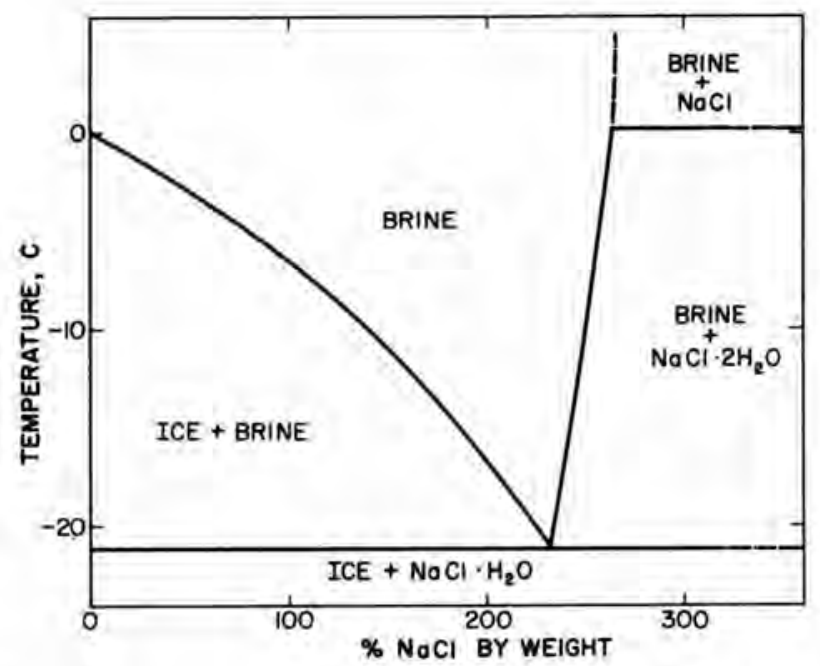

Figure 2. A portion of the phase diagram $\mathrm{NaCl}-\mathrm{H}_{2} \mathrm{O}$.

$\mathrm{NaCl}$ solution with a composition of $35 \%$ o $\mathrm{NaCl}$ at a temperature of $+5^{\circ} \mathrm{C}$. The phase rule is $\mathrm{P}+\mathrm{F}=\mathrm{C}+2$, where $\mathrm{P}$ is the number of phases that coexist, $\mathrm{C}$ is the number of components, and $\mathrm{F}$ is the number of degrees of freedom (for details refer to any standard physical chemistry text). However, in our case we have fixed one degree of freedom by the fact that our experiment was carried out at a constant pressure of 1 atmosphere and, therefore, the appropriate formulation of the phase rule becomes $\mathrm{P}+\mathrm{F}=\mathrm{C}+1$. We have a two-component system, $\mathrm{H}_{2} \mathrm{O}$ and $\mathrm{NaC1}$ (so $C=2)$, with only one phase (the brine solution) present $(P=1)$. Therefore, $F=2$ and two variables (temperature and bulk composition) must be specifled to $\mathrm{fix}$ the state of the system. Figure 2 shows that experimenta11y ice is observed to start forming from a $35 \%$ oo NaC1 solution at $-2.0^{\circ} \mathrm{C}$. Once ice forms $P$ becomes $2, \mathrm{C}$ remains 2 , and $\mathrm{F}=1$, indicating that the system is now univariate. Therefore, as long as ice and brine coexist it is only necessary to specify the temperature or the bulk composition to $\mathrm{flx}$ the state of the system. In our case we 1 nitially specified the composition of the system, so if we additionally specify the temperature we have also fixed the composition of the brine that can coexist in equilibrium with the ice. The liquidus curve, in fact, gives the composition of the $\mathrm{NaCl}$ brine that is in equilibrium with ice at different temperatures. As the system continues to cool, more and more pure ice forms from the brine, causing the remaining brine to decrease in volume and become more saline. For example, at $-5^{\circ} \mathrm{C} 1 \mathrm{ce}$ coexists with a brine containing $80 \%$ o $\mathrm{NaCl}$, while at $-10^{\circ}$ and $-20^{\circ} \mathrm{C}$ the brine compositions are respectively 140 and $225 \% \% 0^{\circ}$ If cooling is continued to $-21.2^{\circ} \mathrm{C}$ a third phase (the solid salt $\mathrm{NaCl} \cdot 2 \mathrm{H}_{2} \mathrm{O}$ ) is observed to form. Now $P$ has become $3, C$ remalns 2 , and $F$ must equal 0 . The system is now referred to as being invariate, and this point (where the curve giving the composition of the brines that are in equilibrium with ice meets the curve giving the composition of the brines that are in equilibrium with $\mathrm{NaCl} \cdot 2 \mathrm{H}_{2} \mathrm{O}$ ) is called the eutectic point. As the system is invariate further cooling cannot continue until one of the phases disappears. Solidification continues at the eutectic temperature, with the two solids ice $+\mathrm{NaCl} \cdot 2 \mathrm{H}_{2} \mathrm{O}$ crystallizing unt11 all of the remaining brine has disappeared. The system is now composed of a 
mixture of the two solids ice $+\mathrm{NaCl} \cdot 2 \mathrm{H}_{2} \mathrm{O}$, and a further decrease in temperature can proceed.

The above can be summarized as follows. When an $\mathrm{NaCl}$ solution with a composition similar to seawater $(35 \%$ o salt) is frozen, the first ice crystals start to form at $-2.0^{\circ} \mathrm{C}$. As freezing proceeds, more and tore pure ice forms, with the remaining brine gradually becoming saltier and saltier. As long as ice and brine coexist the composition of the brine at each temperature is fixed. The formation of ice continues with further cooling, and the amount of brine becomes less and less until at a temperature of $-21.2{ }^{\circ} \mathrm{C}$ the eutectic point is reached and an additional phase, the sodium chloride dihydrate, is formed. At temperatures below the eutectic temperature all brine has solidified and only the two phases ice and $\mathrm{NaCl} \cdot 2 \mathrm{H}_{2} \mathrm{O}$ exist.

When seawater is frozen a similar but more complex series of events occur. In this case we are dealing with an eight-component system for artificial seawater and a greater-than-eight-component system for natural seawater. Therefore, these systems never become invariate exhibiting eutectic points. With cooling, ice forms and the remaining brine becomes more saline. As cooling continues, different solid salts also precipitate from the brine. However they precipitate over a temperature range as opposed to a fixed eutectic temperature. At a temperature of $-70^{\circ} \mathrm{C}$ there is still a measurable amount of brine believed to be present in the ice (Richardson and Keller 1966), and at least five solid salts are presumed to be present $\left(\mathrm{CaCO}_{3} \cdot 6 \mathrm{H}_{2} \mathrm{O}, \mathrm{Na}_{2} \mathrm{SO}_{4} \cdot 10 \mathrm{H}_{2} \mathrm{O}, \mathrm{NaCl} \cdot 2 \mathrm{H}_{2} \mathrm{O}, \mathrm{KCl}\right.$, $\mathrm{MgCl}_{2} \cdot 12 \mathrm{H}_{2} \mathrm{O}$ ).

Present phase information on sea ice is largely based on three different experimental studies (Ringer 1906, Gitterman 1937, Nelson and Thompson 1954). All these contributions are very creditable, but the first two works are old and the investigators were not aware of many potential problems that must be overcome in any proper determination of the phase relations (Tsurikov and Tsurikova 1972). Also, the Nelson and Thompson study was not focused on sea ice (they were interested in the possiblity of the formation of sulfate deposits by freezing) and, therefore, certain desirable parameters of importance in the study of sea ice were not determined.

Without going into details concerning who did what and why, we feel that current deficiencies in the experimental studies of the sea ice phase diagram are as follows:

1. There has never been a direct determination of the composition of the solid salts that form in sea ice (their composition has always been inferred from changes in the composition of the brine).

2. Although equilibrium is always assumed in such studies, there does not appear to have been any attempt to verify this assumption by approaching the same state via different cooling (and heating) paths.

3. It is very important in phase studies to assure that the liquid phase is always compositionally homogeneous and can react with all the solid phases in the system. It is almost certain that this was not true in the three studies we mentioned. The general experimental technique 


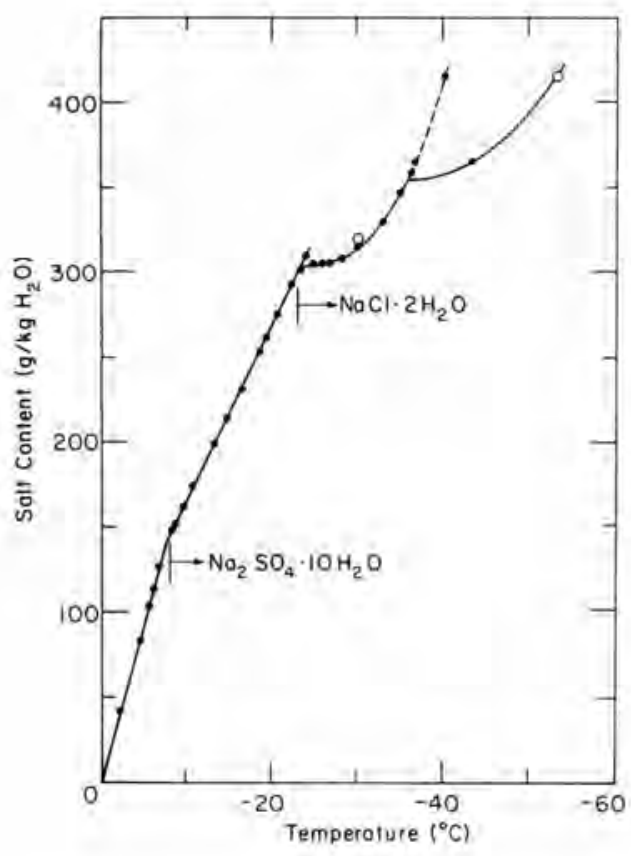

Figure 3. Freezing point of brine as a function of the ratio of the weight of dissolved salts to pure water (linear relations used to $\left.-24^{\circ} \mathrm{C}\right)$. Solid dots computed from data of Nelson and Thompson (1954). Open circles computed from Ringer (1906). The dashed line indicates a possible path if salts precipitate in a different order (after Assur 1958).

has been to freeze a solution to a desired temperature, remove the 1 ce from the brine, and if necessary prepare a new solution for further freezing based on the composition of the remaining brine. This is an excellent procedure as long as the brine remains homogeneous and is in continuous contact with all the phases present. However, if isolated brine pockets form in the ice phase then the liquid and solids in these pockets can no longer react with the bulk liquid. This problem becomes particularly pronounced if there are reactions between the brine and previously formed solid phases. Several such reactions have been suggested by Gitterman and also by Savel'ev (1963), although the evidence for their occurrence cannot at present be considered conclusive.

4. All experimental work to date has ignored the carbonate content of the brine, although $\mathrm{CaCO}_{3} \cdot 6 \mathrm{H}_{2} \mathrm{O}$ would appear to be the first solid salt to form during the formation of sea $1 \mathrm{ce}$.

Considering the above problems, is our present knowledge of the phase diagram useful or just misleading? We feel that in most cases it 1s useful. The phase diagram as commonly utilized was worked out by Assur (1958), based on the work of Nelson and Thompson and of Ringer. Figure 3 shows the freezing point of the brine derived from standard seawater as a function of 1 ts composition (expressed as grams of salt per kilogram of $\mathrm{H}_{2} \mathrm{O}$ ). The different experimental determinations are in good agreement. Note that there are pronounced breaks in slope at temperatures where major solid salts start to crystallize. Figure 4 presents the phase diagram for standard sea 1ce, which is defined as sea ice of such a composition that its meltwater will have the same relative concentration of lons (to each other) as normal seawater (Assur 1958). The idea of standard sea ice is a useful one and is an extension of the observation that although the absolute amounts of salt in seawater may vary widely, the ratios of the lons relative to each other remain surprisingly constant. How applicable this observation is to sea ice will be examined later. It should be noted here that if the ratios of the 


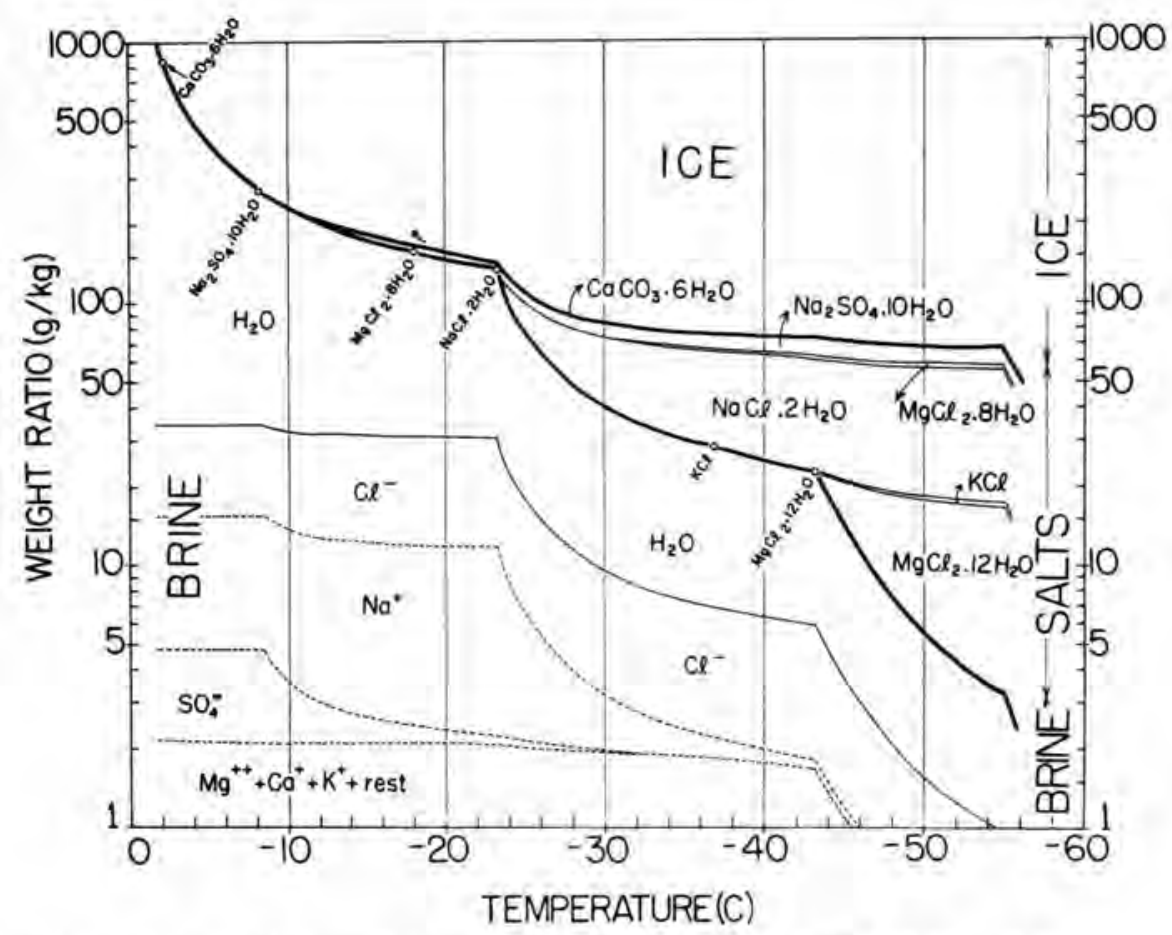

Figure 4. Phase relations for "standard" sea ice. Circles on the brine-salt line indicate temperatures at which solid salts precipitate (Assur 1958).

Ions were to change, the crystallization temperatures of the solid salts would also be changed.

Figure 4 shows that at $-10^{\circ} \mathrm{C} 1000 \mathrm{~g}$ of standard sea ice with a salinity of $34.325 \%$ is composed of $768 \mathrm{~g}$ of ice, $4.2 \mathrm{~g}$ of solid salt ( $4.0 \mathrm{~g}$ of $\mathrm{Na}_{2} \mathrm{SO}_{4} \cdot 10 \mathrm{H}_{2} \mathrm{O}+0.2 \mathrm{~g} \mathrm{CaCO}{ }_{3} \cdot 6 \mathrm{H}_{2} \mathrm{O}$ ) and $228 \mathrm{~g}$ of brine composed of $195 \mathrm{~g} \mathrm{H}_{2} \mathrm{O}$ and $32 \mathrm{~g}$ of various ions. At $-30^{\circ} \mathrm{C}$, on the other hand, the amount of ice and of solid salt present has risen to 917.0 and 43.4 , respectively $\left(76 \%\right.$ of the solid salt is $\left.\mathrm{NaCl} \cdot 2 \mathrm{H}_{2} \mathrm{O}\right)$, while the amount of brine has decreased to $39.5 \mathrm{~g}$ (the exact figures can be found in Assur (1958)). The Initial temperatures of crystallization of the various solid salts believed to be present in sea ice are given in Table 1. Also listed are some other characteristics of these salts, including their eutectic temperatures in pure salt $-\mathrm{H}_{2} \mathrm{O}$ solutions. The differences in these temperatures are the results of the presence of the other ions in seawater brine that are not present in the aqueous solutions of the individual salts.

To change precisely from measurements of the weight of brine per kilogram of sample to the volume of brine per kilogram of sample, accurate measurements must be available of the density of the seawater brine coexisting with ice at different temperatures. As Nelson and Thompson only reported brine densities at $+4^{\circ} \mathrm{C}$, this calculation cannot be made with the confidence desired. A table of the estimated values of the relative volume of brine (usually indicated by the symbol $\nu_{b}$ ) for standard sea ice is given in Assur (1958) for the temperature range of -0.1 to $-54^{\circ} \mathrm{C}$. In sea ice with a salinity of $1 \%$ only $0.075 \%$ of brine remains at $-54^{\circ} \mathrm{C}$ as compared with $24 \%$ oo existing at $-2.0^{\circ} \mathrm{C}$ (a 
Table 1. Some properties of the solid salts presumed to occur in sea ice.

\begin{tabular}{|c|c|c|c|c|c|}
\hline $\begin{array}{c}\text { Salt } \\
\text { Composition }\end{array}$ & $\begin{array}{l}\text { Mineral } \\
\text { Name }\end{array}$ & $\begin{array}{l}\text { Crystal } \\
\text { System }\end{array}$ & $\begin{array}{l}\text { Density } \\
\left(\mathrm{Mg} / \mathrm{m}^{3}\right)\end{array}$ & $\begin{array}{c}\text { Eutectic Temperature } \\
\text { of the Salt in an } \\
\text { Aqueous Solution }\left({ }^{\circ} \mathrm{C}\right)\end{array}$ & $\begin{array}{l}\text { Temperature of Initial } \\
\text { Salt Formation In Sea- } \\
\text { water BrIne }\left({ }^{\circ} \mathrm{C}\right)\end{array}$ \\
\hline $\mathrm{CaCO}_{3} \cdot 6 \mathrm{H}_{2} \mathrm{O}$ & & Monoclinle & 1.771 & ? & -2.2 \\
\hline $\mathrm{Na}_{2} \mathrm{SO}_{4} \cdot 10 \mathrm{H}_{2} \mathrm{O}$ & Mirabilite & Monoclinle & 1.464 & -3.6 & -8.2 \\
\hline $\mathrm{MgCl}_{2} \cdot 8 \mathrm{H}_{2} \mathrm{O}^{2}$ & & & & -33.6 & -18.0 \\
\hline $\mathrm{NaCl} 1 \cdot 2 \mathrm{H}_{2} \mathrm{O}$ & Hydrohallte & Monoclinte & $1.630\left(0^{\circ} \mathrm{C}\right)$ & -21.1 & -22.9 \\
\hline $\mathrm{KCI}$ & silvite & Cubic & 1.984 & -11.1 & -36.8 \\
\hline $\mathrm{MgCl}_{2} \cdot 12 \mathrm{H} 2 \mathrm{O}$ & & Monoclinic & $(1.24)$ & -33.6 & -43.2 (erratic) \\
\hline $\mathrm{CaCl}_{2} \cdot 6 \mathrm{H}_{2} \mathrm{O}$ & Antarcticlte & Hexagonal & $1.718\left(4^{\circ} \mathrm{C}\right)$ & -55.0 & $<-55.0$ \\
\hline
\end{tabular}

320-fold increase). In most applications where extreme accuracy is not deemed essential, the fact that $\nu_{b}$ can be linearized as a function of $1 / \theta$ and $S_{i}$, where $\theta$ is the temperature and $S_{i}$ is the salinity of the $1 \mathrm{ce}$, is utilized, and the empirical equations developed by Frankenstein and Garner (1967)

$$
v_{b}=s_{i}\left(\frac{45.917}{\theta}+0.930\right) \quad-8.2 \leq \theta \leq 2.0^{\circ} \mathrm{C}
$$

and

$$
\nu_{b}=s_{1}\left(\frac{43.795}{\theta}+1.189\right) \quad-22.9 \leq \theta \leq-8.2^{\circ} \mathrm{C}
$$

are used (note that different relations are used on the opposite sides of the $\mathrm{Na}_{2} \mathrm{SO}_{4} \cdot 10 \mathrm{H}_{2} \mathrm{O}$ crystallization temperature). At temperatures above and below the stated ranges it is necessary to refer directly to Assur's original table. It should be noted that both Assur's table and the above equations assume that sea ice has a constant density of 0.926 $\mathrm{Mg} / \mathrm{m}^{3}$. Therefore, to determine the applicable brine volume for sea ice having a known bulk density of $\rho$, the calculated brine volume should be multiplied by $(\rho / 0.926)$. Equations incorporating this density change and allowing the calculation of both the brine and the gas volumes in sea Ice of known densities can be found in Cox and Weeks (1982).

The best check on the adequacy of Assur's brine volume diagram is a study by Richardson and Keller (1966) in which the amount of liquid water present in artificially frozen seawater was determined as a function of temperature by the use of nuclear magnetic resonance (NMR) techniques. These values were then compared with a curve of the same parameter based on Nelson and Thompson's chemical measurements. The results are shown in Figure 5. The agreement is very good at temperatures above $-43^{\circ} \mathrm{C}$ (the $\mathrm{MgCl}_{2} \cdot 12 \mathrm{H}_{2} \mathrm{O}$ crystallization temperature). At lower temperatures systematic differences were noted, with NMR giving the higher water contents. Fortunately, natural sea ice rarely exists at temperatures below $-40^{\circ} \mathrm{C}$.

Based on the NMR study can one assume that the phase relations pub1ished by Assur are adequate at temperatures above $-40^{\circ} \mathrm{C}$ ? This is a hard question to answer at present. The problems arise in two different but similar ways. First, as was mentioned, brine pockets may form, 


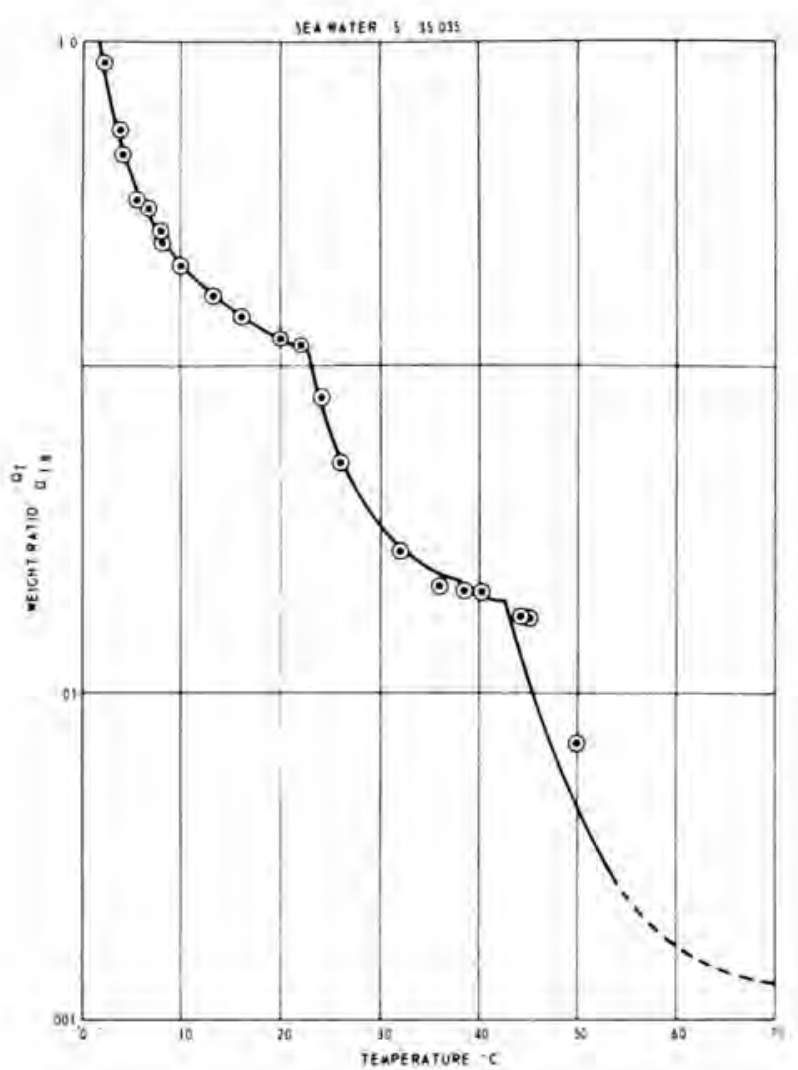

Figure 5. Relative water content in percent versus temperature for sea ice (sea-water sample $35.035 \%$ salinity). The curve is based on Nelson and Thompson's analytical data. The points are measured by NMR techniques (after Richardson and Keller 1966).

isolating portions of the brine and solid salts, and changing the sequence of possible reactions between these phases and the 1ce. Second, and probably more important, it is possible that as sea ice ages and brine drainage proceeds, the solid salts will remain fixed in the ice. This process would result in the enrichment of ions that are present in the early-formed solid phases. For instance, if the upper surface of sea ice were to be maintained at a temperature of $-20^{\circ} \mathrm{C}$ for a long period of time, $\mathrm{CaCO}_{3} \cdot 6 \mathrm{H}_{2} \mathrm{O}$ and $\mathrm{Na}_{2} \mathrm{SO}_{4} \cdot 10 \mathrm{H}_{2} \mathrm{O}$ would form while all the $\mathrm{Cl}^{-}$ ion would remain in the brine. If brine drainage were to proceed, this could produce changes in the $\mathrm{SO}_{4}=/ \mathrm{Cl}^{-}$and $\mathrm{CO}_{3}=/ \mathrm{Cl}^{-}$ratios. If these changes were large enough the standard sea 1ce phase diagram of Assur would no longer be applicable, with appreciably different phase relations being exhibited by ices that have had different thermal histories. As the thermal history of most pack ice is relatively unknown, we would be reduced to either performing a complete chemical analysis on each sea ice specimen or developing a technique that could easily be used to determine brine volume directly. Both of these methods would presumably be much more time consuming than the present technique of determining the salinity, density and temperature of a sample and determining the amount of brine, gas and solid salt in the 1ce from Assur's tables or Cox and Weeks' equations.

Do significant changes occur in the ratios of the fons in sea ice? The evidence is mixed. In newly formed ice, and in first-year ice that has not been subject to low temperatures for long periods of time, most measurements (Bennington 1963b, Blinov 1965, Addison 1977) suggest that major changes in the ion ratios are smal1. For thicker ice, and particularly for multiyear ice where the changes in ion ratios would be expected to be largest, experimental results are quite variable. The most 

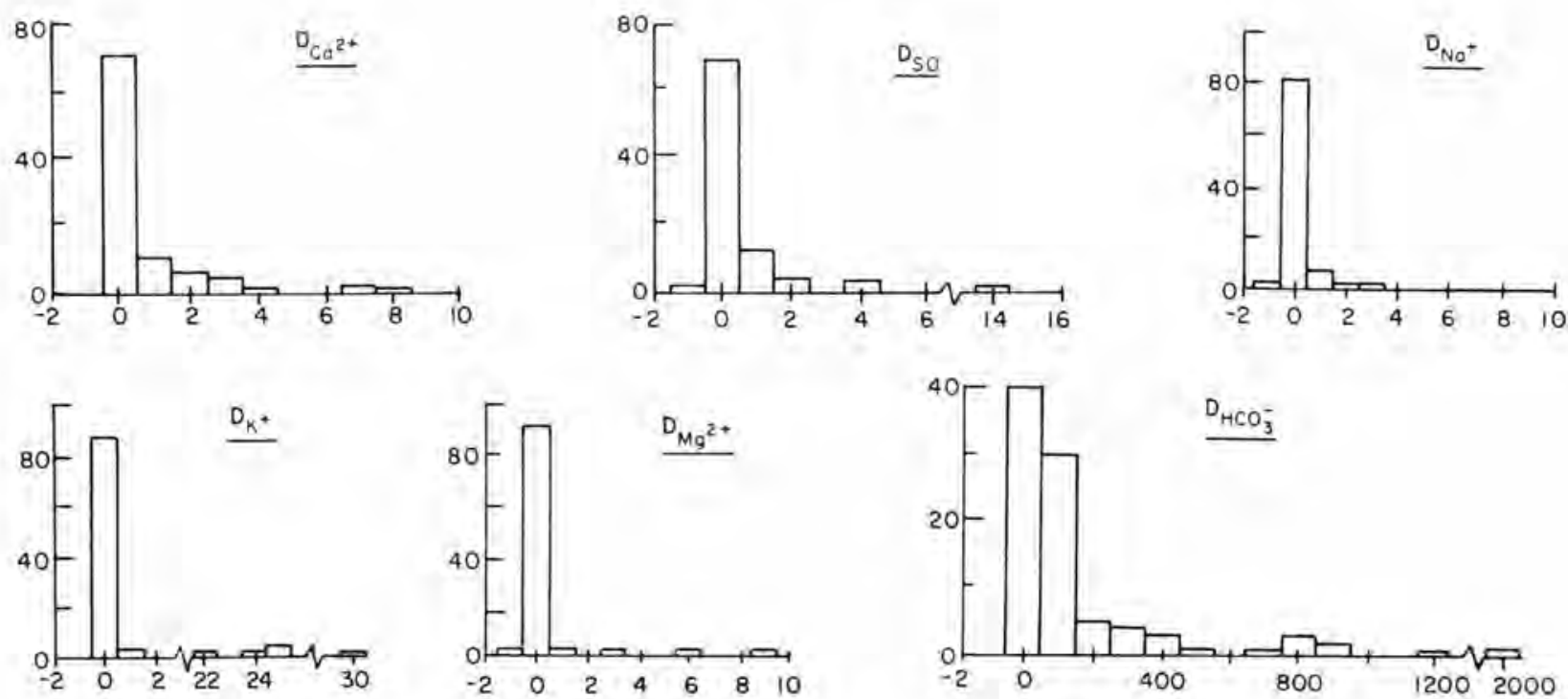

Figure 6. Probabilities (expressed as percentage) of values for $D_{c}$ for various ions (Tsurikov 1974).

thorough study of the problem is by Tsurikov (1974, 1976), who calculated the ratio

$$
D_{c}=\frac{(c / C 1)_{1}-(c / C 1)_{W}}{(c / C 1)_{W}}
$$

where $\mathrm{c}$ is the concentration of the ion of interest and $i$ and $w$ indicate ice and water respectively. Positive values of $D_{c}$ indicate that the content of ion $c$ in the ice is higher than in the water. The chloride ion was chosen as the "standard" as it is retained completely within the brine at temperatures above $-22.9^{\circ} \mathrm{C}$ and, therefore, should show extensive depletion via drainage. Figure 6 shows the relative frequencies of the $D_{c}$ values calculated for several different ions. Although negative $D_{c}$ values do occur, all the histograms show pronounced positive skews. The most interesting case is that of $\mathrm{D}_{\mathrm{HCO}_{3}}$; only $60 \%$ of the samples showed non-zero $\mathrm{DHCO}_{3}$ values indicating measurable changes in the relative ratios of $\left(\mathrm{HCO}_{3}^{-} / \mathrm{Cl}\right)$ in the $1 \mathrm{ce}$ as compared to the seawater from which the ice formed. One sample showed a 2000-fold enrichment in $\mathrm{HCO}_{3}^{-}$and several values near 800 were observed. That higher values might be observed for $\mathrm{D}_{\mathrm{HCO}_{3}}$ is not too surprising as $\mathrm{CaCO}_{3} \cdot 6 \mathrm{H}_{2} \mathrm{O}$ is the first solid salt to form in sea ice $\left(-2.2^{\circ} \mathrm{C}\right)$ which would presumably tend to immobilize the $\mathrm{CO}_{3}=$ ion, resulting in enrichment. However, such large values would appear difficult to explain. The other histograms show similar but much less striking trends, with near-zero values occurring in excess of $70 \%$ of the time. A $14-f$ old enrichment was noted for $\mathrm{D}_{\mathrm{SO}_{4}}$, which is not surprising. However, a 30-fold enrichment was observed for $D_{K}$, which is surprising in that the first $K$ salt (KC1) does not form until $-36.8^{\circ} \mathrm{C}$ and therefore $\mathrm{K}^{+}$should be more mobile than $\mathrm{Cl}^{-}$. The effects of these ratio changes on the sea ice phase relations, and in particular on current techniques for estimating brine volume, are not presently clear. Certainly this is an area worthy of further study. To add to the confusion, the most recent paper on the subject (Reeburgh and Young, in press) obtalned data that suggest an initial change in the 
$\mathrm{SO}{ }_{4} / \mathrm{CI}^{-}$ratio during the formation of Eirst-year ice but no change in the ratio for multiyear ice. As in most of the previous studies, the sampling was sparse ( 1 first-year and 1 multiyear site).

FORMATION OF THE INITIAL ICE COVER

In comparison to the rather voluminous literature devoted to the freezing of bodies of "fresh" water, little attention has been paid to the initial formation of sea $1 \mathrm{ce}$. It is possible, however, by piecing together the available information on sea ice and comparing it with the "fresh" water observations, to arrive at a fairly complete qualitative picture of the gross features of the process. This initial crystal formation is unique in that, although the cold source is the overlying air, the velocity of crystal growth is probably largely limited by the rate of heat and solute dissipation through the liquid. It is, therefore, the only portion of the growth of a sea ice sheet that can be considered as true dendritic growth, i.e. that type of branched external crystal morphology that is characteristic of growth into "thermally" supercooled melts.

Because norma1 seawater has a salinity greater than $24.7 \%$, therefore possessing a freezing point higher than its temperature of maximum density (Fig. 7), surface cooling creates an unstable vertical density distribution, causing convective mixing. This process transports the sensible heat stored in the lower layers of the water to the surface where it is dissipated. At the time of initial ice formation a several-meter-thick upper layer of the sea will have been lowered to or slightly below the freezing point.

The amount of supercooling necessary to initiate ice formation in seawater has apparently not been investigated. Considering the large number of solid impurities in any small volume of natural seawater, it is almost certain that homogeneous nucleation never occurs. Also, in polar regions snow crystals are fairly continuously being deposited on the upper water surface, providing nuclei for further growth. The amount of supercooling is probably a few hundredths to tenths of a degree Celsius.

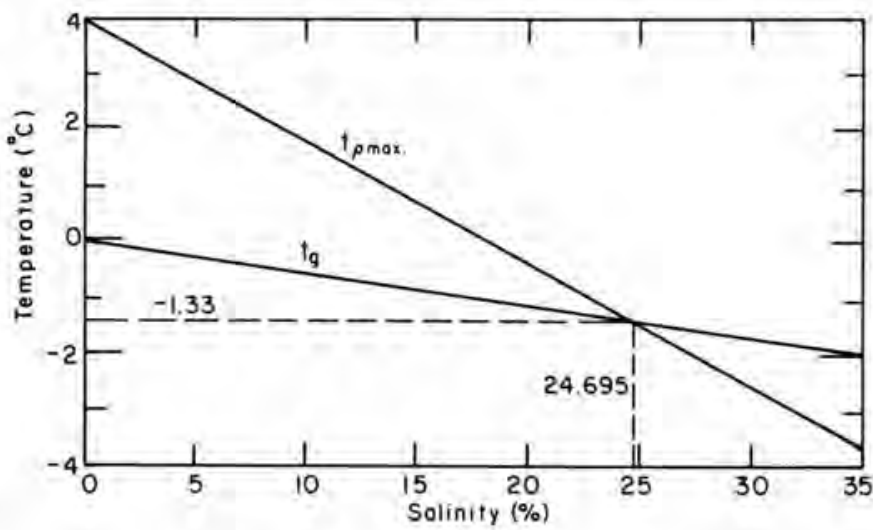

Figure 7. Temperature of the density maximum $t_{\rho \max }$ and of the freezing point $t_{g}$ for seawater of different salinities. 
In genera1, the freezing of seawater appears to be similar to that of fresh water, and it is reasonable to assume that the first crystals to form will be minute spheres of pure ice (Hobbs 1974). Growth rapidiy changes these spheres into thin circular discs in the general growth sequence spheres to discs to hexagonal dendritic stars, as shown schematically in Figure 8 (Arakawa 1954). The disc-1ike shape is the result of a highly anisotropic surface energy of ice which, although specifying a planar form, does not specify any particular growth direction in this plane. At small undercoolings, when heat and solute dissipation problems are not important, the growing disc can minimize its surface-tovolume ratio by maintaining a circular outline. That the growth rate of ice is strongly dependent on the growth direction is well known (Hillig 1958,1959 , Macklin and Ryan 1966). In ice discoids this plane of maximum growth is the (0001) or basal plane, which is the plane of maximum reticular atomic density in an ice crystal (Owston 1958). Therefore, ice growth can be sald to be well described by Bravals' law: the smaller the reticular density of a crystal surface, the faster it grows normal to itself. The final crystal consists only of those surfaces showing the slowest normal growth, the close-packed surfaces (Rosenberg and Tiller 1957). Crystal growth parallel to the c-axis is orders of magnitude slower than growth in the (0001) plane, and the resulting kinetics are consistent with the classical Volmer-Stranski models, which are based on the assumption that two-dimensional nucleation and growth is the rate-controlling mechanism (Hillig 1958).

The maximum diameter to which discs grow is, at least in fresh water, on the order of 2 to $3 \mathrm{~mm}$, and is a function of the supercooling. A discussion of the morphological stability of such disc crystals, including a specific discussion of ice discs growing in pure water, is given by Fujioka and Sekerka (1974). Related work concerning the morphological stability of ice cylinders freezing from aqueous solutions has been published by Hardy and Coriell (1973).

Figure 9 shows a large number of such discs developing in the upper centimeter of seawater (observations were made at Thule, Greenland). Note the characteristic notched edges on several of the tilted plates. Limited experimental observations (Kumai and Itagaki 1953) indicate that under comparable growth conditions the maximum disc size is depressed by the presence of an appreciable amount of solute in the water. Discs did, however, form in all cases when inorganic solutes were used (Arakawa and Higuchi 1954). This decrease in maximum disc size is quite

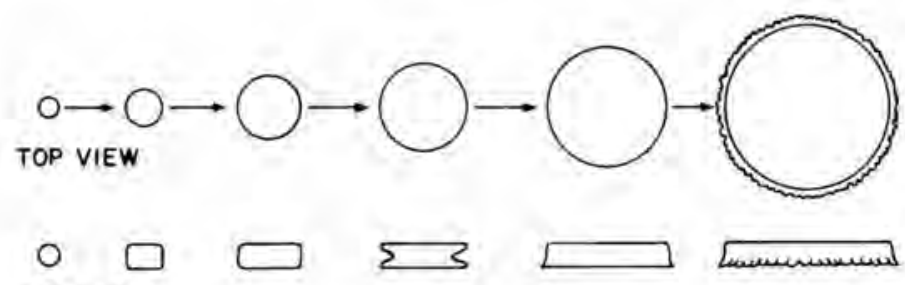

SIDE VIEW

Figure 8. Growth sequence for ice crystals in bulk water (Arakawa 1954). 


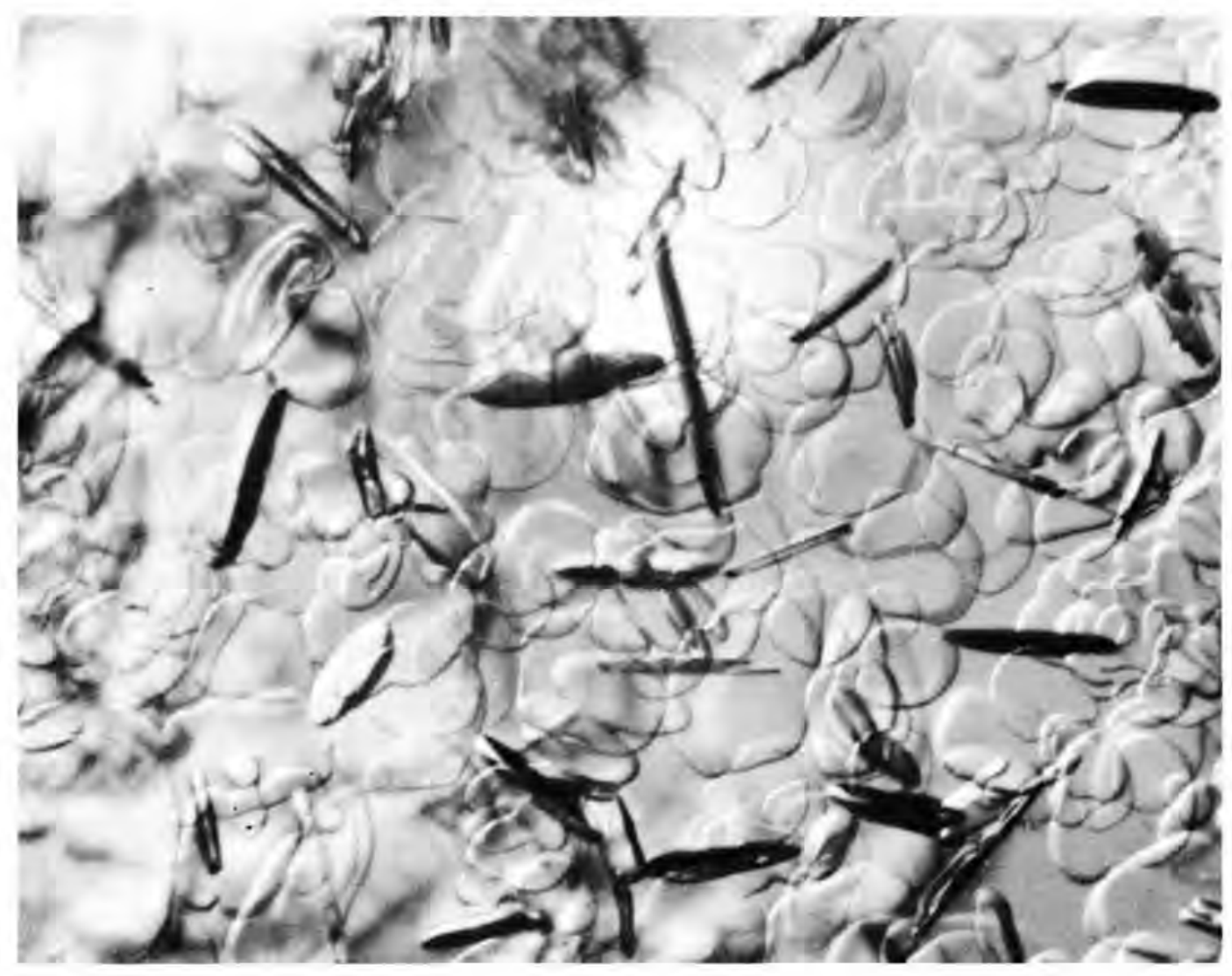

Figure 9. Initial discs during the freezing of seawater. Disc size is approximately $1 \mathrm{~mm}$ (Thule, Greenland).

reasonable since it is necessary for an ice crystal growing in seawater to dissipate both heat and solute into the surrounding liquid. As the radius of curvature of the disc increases, the ease of heat and solute dissipation decreases, until at some critical radius -- determined by the thermal conductivity of the melt, the diffusion coefficient of the solute in the melt, and the growth velocity (Glen 1955) -- the discoidal growth form becomes unstable, breaking up into a hexagonal dendritic star which again offers a much smaller tip radius of curvature. A1though the change to a stellar form causes an increase in the relative amount of surface, this is apparently compensated for by the fact that the crystal is now more readily able to dispose of heat and solute at the advancing interface (the so-called "point effect of diffusion"). The disc-to-star transition is therefore marked by an appreciable increase in the growth velocity (Kumai and Itagaki 1953). That most, if not all, of the stellar crystals initially went through a discoidal stage can be seen by examining the centers of the stars under a high magnification (Fig. 10 and 11). The arms of the stars form parallel to the a-axis direction $\langle 11 \overline{2} 0\rangle$ in the ice crystal, which, as was mentioned, is the shortest lattice vector in the (0001) plane.

Optically, these initial crystals, both discoidal and stellar, show a small but definite biaxiality. Optic angles of 3 to 5 degrees were observed in crystals from ice skims formed at Hopedale, Laborador, and Thule, Greenland. Golovkov (1936) reported 2V values as great as 20 degrees from crystals of Kara Sea ice. This biaxiality is undoubtedly 


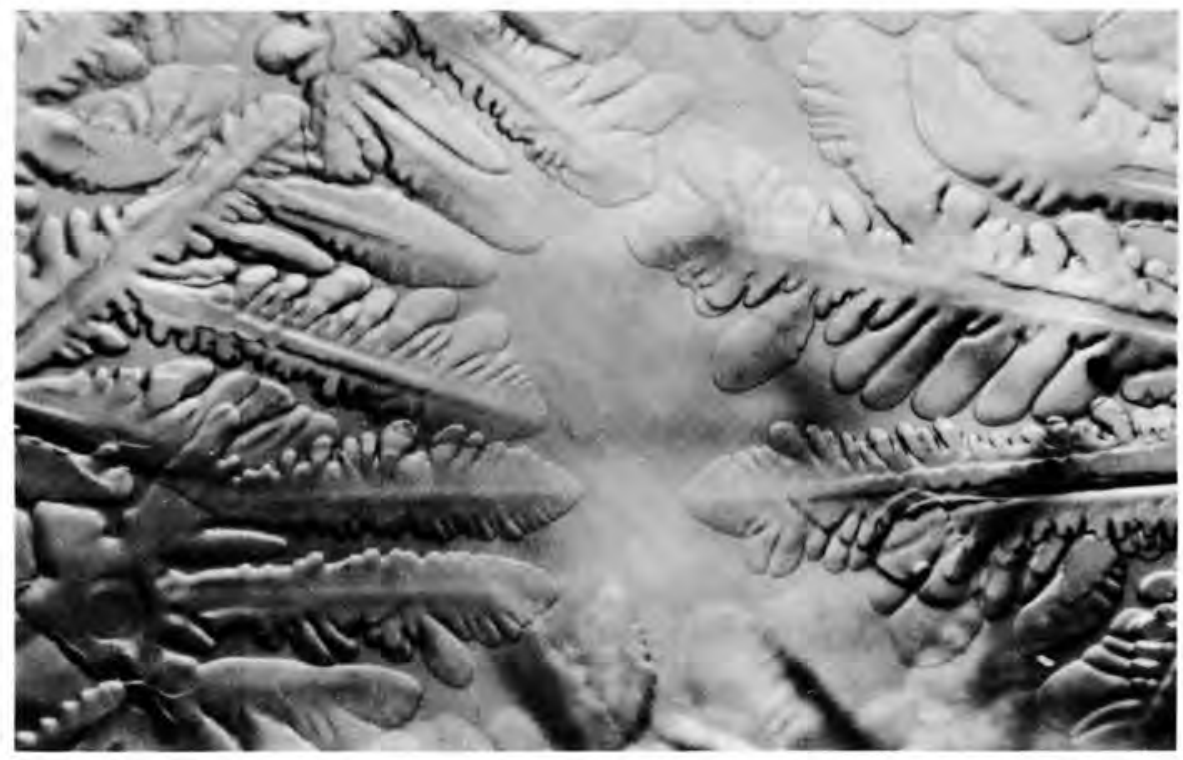

Figure 10. Stellar ice crystals growing in seawater.

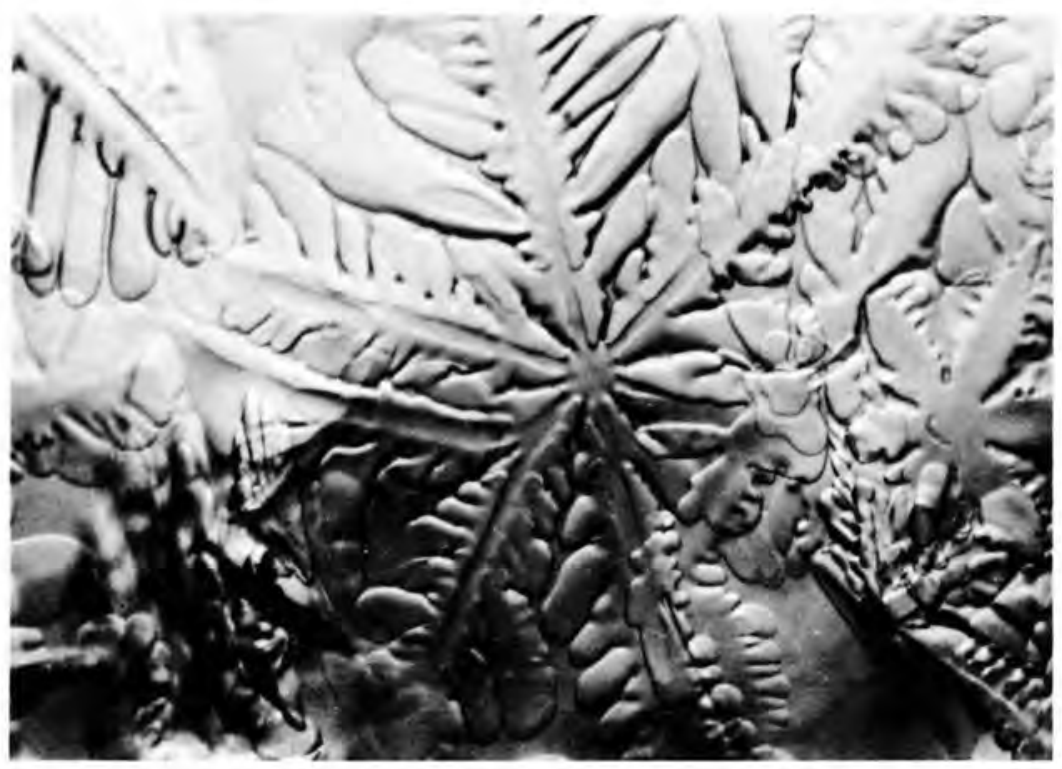

Figure 11. Stellar ice crystals grown from seawater.

produced by strains introduced in the crystals during their growth. Due to its low birefringence, ice is optically extremely stress-sensitive.

The star-1ike crystals grow rapidly across the surface of calm seawater until they overlap and freeze together, forming a continuous thin ice skim. Because of the tabular nature of both the initial ice discoids and stars, they float with their basal planes (0001) in the plane of the water surface. Ideally this would produce an ice skim with a completely c-axis-vertical orientation. However, since water conditions are rarely completely calm a number of discoids or stars are usually 


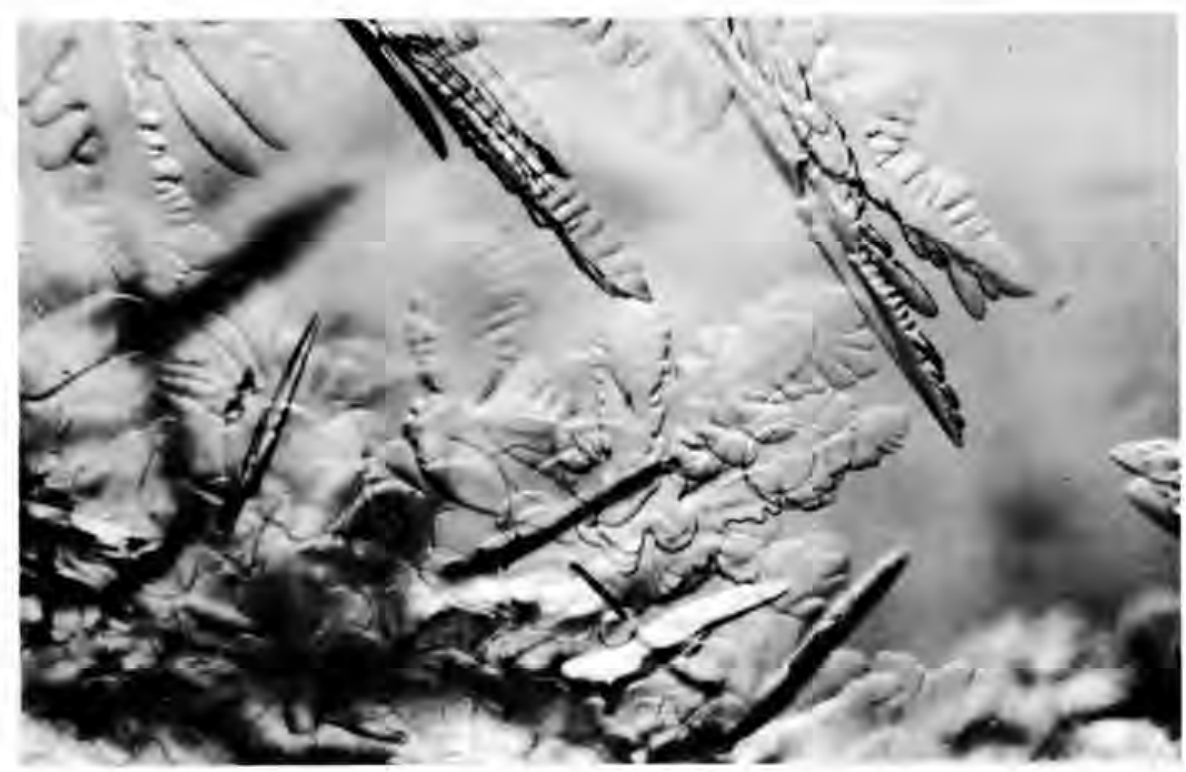

Figure 12. Initial ice crystal formation in calm seawater.

caught in an intermediate position, i.e. with their c-axes inclined at some angle to the vertical. This is well shown in Figures 9 and 12 which are photomicrographs of initial ice crystal formation in seawater of $32 \%$ salinity. A petrofabric diagram of such a skim will appear sinilar to the first fabric diagram in Figure 23, a strong caxis-vertical maximum and a few crystals in other orientations.

During the initial freezing of fresh water at low supercoolings, surface needles are extremely common (Fujino and Suzuki 1959, Hallett 1960). The needles form when a disc becomes inclined at an angle to the water surface. Subsequent growth then proceeds rapidly, in the form of long, thin, needle-like crystals, from the points where the disc intersects the surface. The needles appear to be confined strictly to the thin surface layer of water that is appreciably supercooled. If crystal growth were to continue downward along the basal plane, the crystal would immediately encounter water that is not supercooled and the growth would stop. If larger supercoolings are encountered more complex morphologies develop--simple double pyramids between -2.7 and $-5.5^{\circ} \mathrm{C}$ and, at yet lower temperatures, complex double pyramids showing secondary and higher order non-rational growth directions (photographs of such crystals can be found in Macklin and Ryan (1966) or in Hobbs (1974)).

The 1imited observations available on the freezing of sea- and salt-water indicate that although surface needles are occasionally encountered, they appear to be rarer than in fresh water (Fukutomi et al. 1949, Arakawa and Higuchi 1954, Suzuki 1955, Fujino and Suzuki 1959). This observation is readily explained by the fact that prior to the nucleation of the initial sea ice crystals, convective mixing has lowered an appreciable thickness of the water layer to the freezing point. This makes it possible for inclined discs to grow both downward as well as along the water surface. A significant downward growth component causes the disc to develop as a dendritic star instead of a needle, and also produces a moment due to buoyancy forces which tends to rotate the 


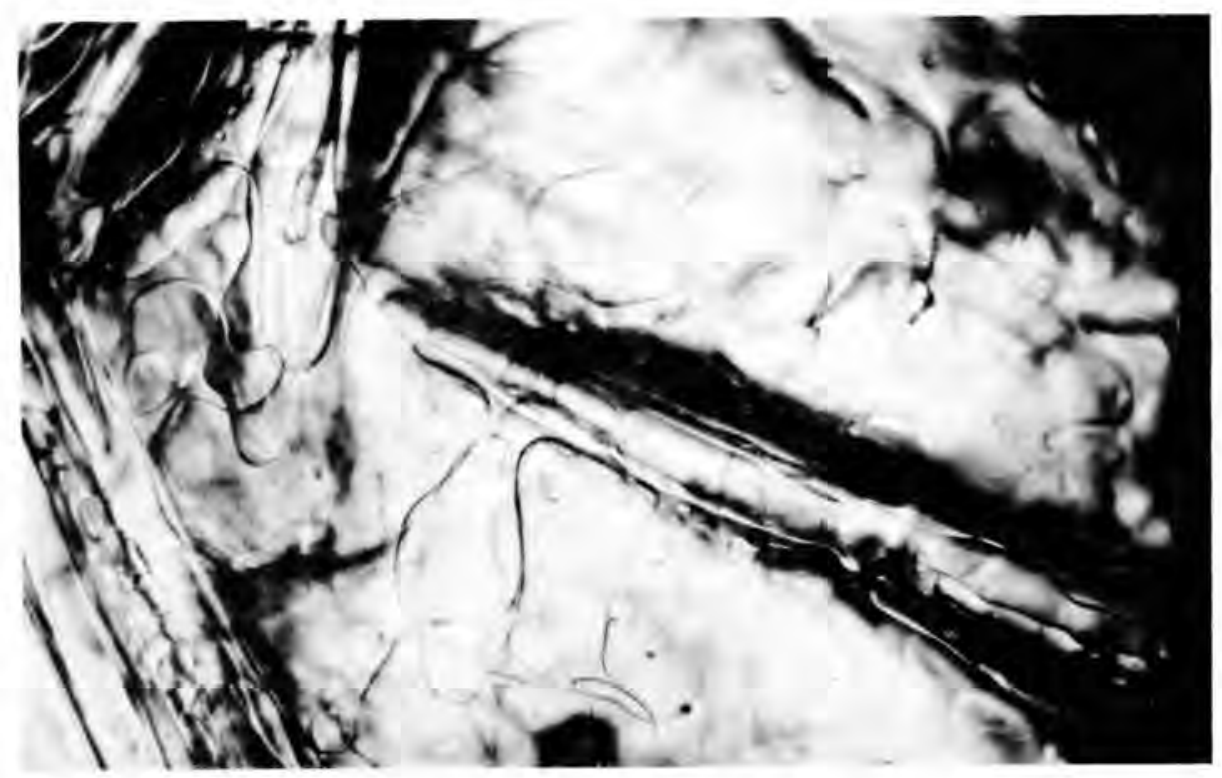

Figure 13. A needle surrounded by crystals with their c-axes vertical (normal to the plane of the photograph) (right $2 / 3$ of photograph).

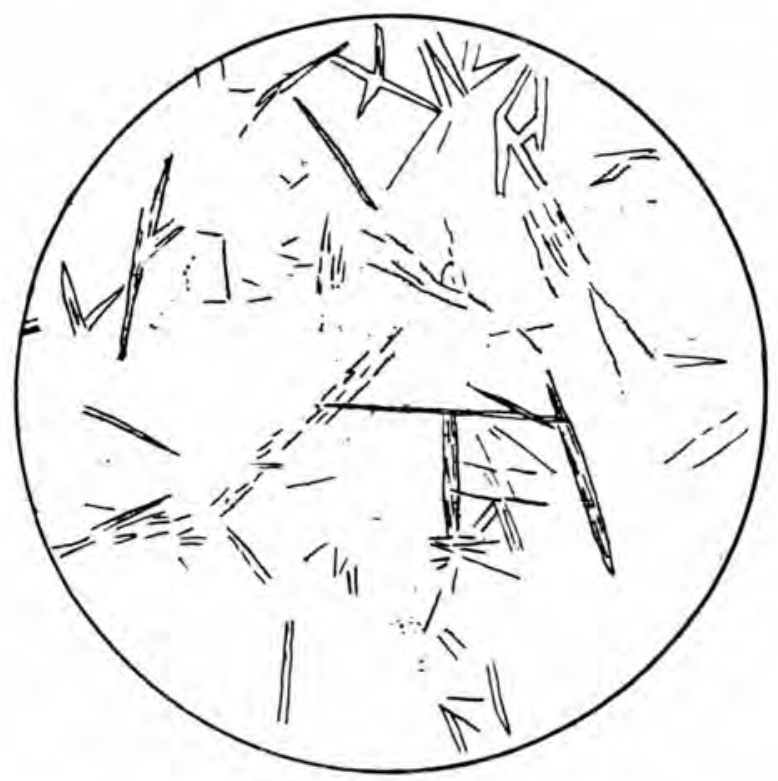

Figure 14. Inked copy of a surface rubbing of an ice skim.

stellar crystal until its (0001) plane is parallel to the water surface. Possibly needle-like growth in seawater occurs only when part of the needle has frozen to or is spatially restricted by other ice crystals, so that the needle is prevented from rotating when a downward growth component develops. Figure 13 is a photomicrograph of the upper surface of a thin ice skim showing the tip of such a needle (the surrounding ice is of an essentially c-axis-vertical orientation). Figure 14 is an inked copy of a rubbing of the upper surface of a similar ice 


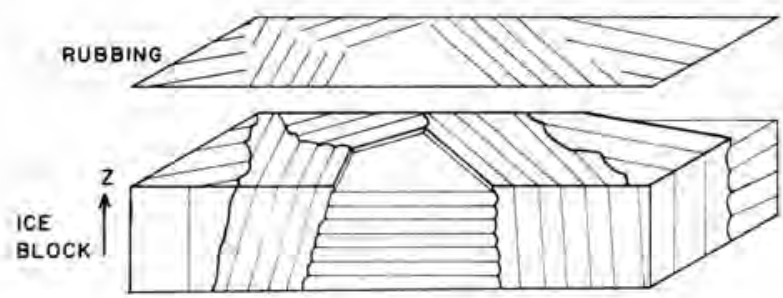

Figure 15. The relation between the ice surface topography produced by etching and the lines on a rubbing.

skim. This technique, which has been successfully applied to both glacier and lake 1 ce for grain size measurements and texture analysis (Seligman 1949, Ragle 1962), utilizes the fact that projections on the ice surface appear as lines or "ticks" on the rubbing, while "smooth" (0001) surfaces appear as white or unfformly shaded areas. Each group of parallel lines represents a single crystal of sea 1ce. Figure 15 shows schematically the relation between the ice surface topography and the lines that appear on the rubbings. The majority of the surface of the ice skim in Figure 14 is composed of crystals with their c-axes roughly perpendicular to the freezing surface, although several needles and crystals with their c-axes inclined are present. A study of a number of such rubbings from ice skims formed during calm conditions shows that commonly $>50 \%$ of the upper ice surface is composed of crystals with their c-axes approximately vertical. The curved dendritic growth patterns often noted on freshwater ponds do not appear to occur in sea ice. This is in keeping with the experimental results of Knight (1962a), which indicate that an increase in solute content tends to eliminate the curvature.

Avallable experiments suggest that the ice crystal morphologies developed during the freezing of pure water and of aqueous solutions are similar. Also, the presence of solutes appears to reduce the supercooling necessary for crystal growth to occur in non-rational crystallographic directions (Ryan and Macklin 1968, Ryan 1969). Therefore, one might expect to find reports of single and double pyramidal crystals forming during the freezing of seawater. We are not aware of such reported occurrences. We can, therefore, conclude that either natural supercoolings are not sufficient for pyramidal growth to develop or that no one has bothered to look. Both are probably true.

Crystal growth processes like those described above occur during calm, cold periods when there is no turbulence in the upper layer of the sea. The resulting ice cover "presents a smooth unbroken surface on which there are no highly evident horizontal changes in the structure of the ice layer" and has been termed "sheet ice" by Wilson et al. (1954). Commonly, however, in the open ocean there is some wave-induced turbulence during initial ice formation. This mixing introduces more nuclei into the area of active freezing and provides the energy to overcome the buoyancy forces so that the initial crystals may be "stirred" throughout a depth of up to several meters (Savel'ev 1958, Martin and Kauffman 1981). The effective supercooling is reduced, more crystals form per unit volume, and abrasive action between crystals is increased. As a result, extensive discoidal growth is favored. Even if stars were to form, their arms would commonly be broken off. It should be mentioned that in this freezing mode it has been found that is it not necessary for each individual crystal to nucleate separately. 


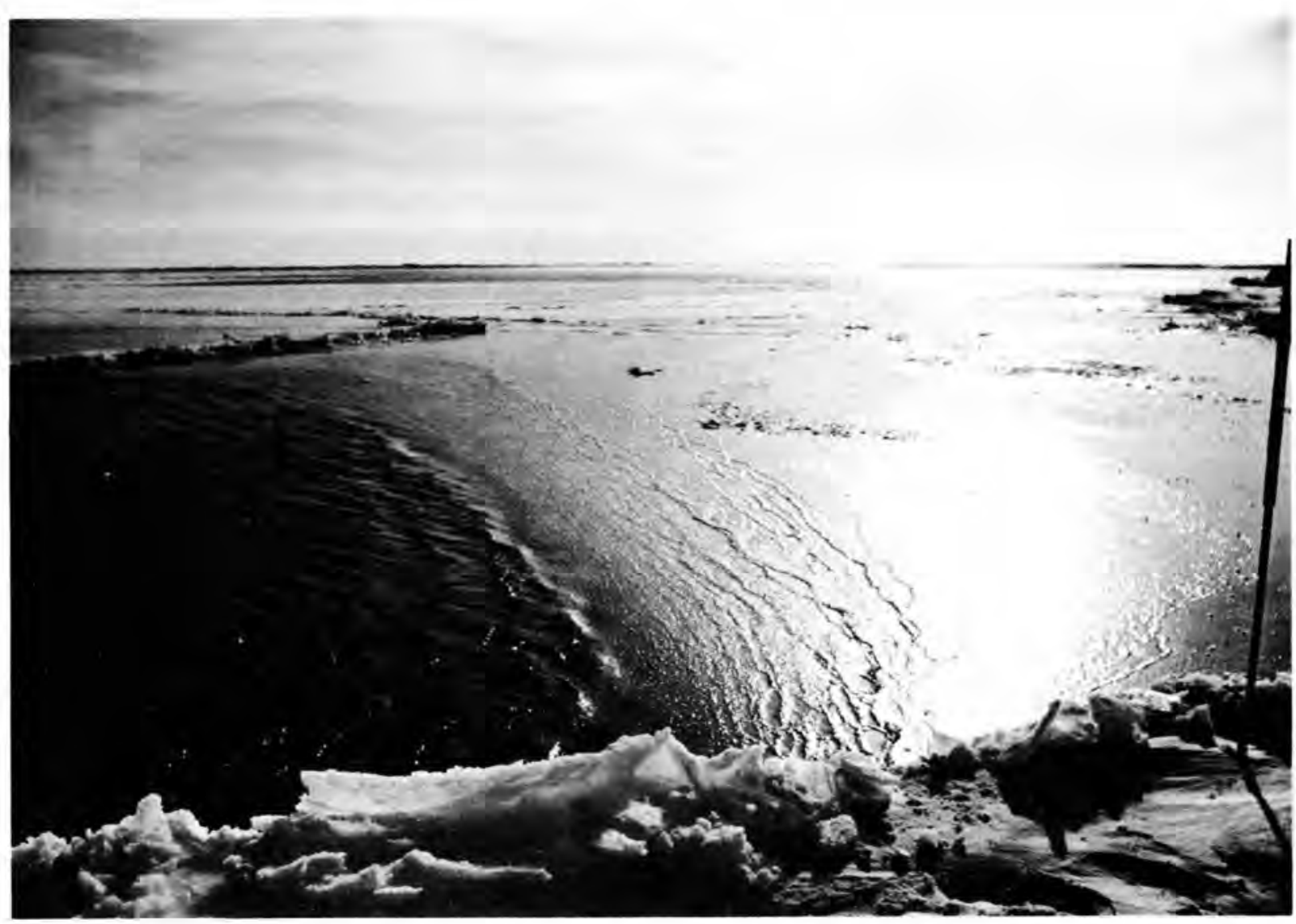

Figure 16. Grease ice forming on the surface of a lead and being driven by the wind into its downwind end (Martin and Kauffman 1981).

Wind action herds the resultant ice crystals, which are generally termed frazil, into agglomerations that take on various forms. For instance, grease ice is an agglomeration of frazil crystals into a soupy layer that can be distinguished as a result of the low reflectivity, matte-like appearance of its upper surface (Fig. 16). Its major distinction from thicker and/or more compact agglomerations of frazil is in its mechanical behavior where it exhibits viscous fluid-like properties as opposed to the rafting and bending behavior of thicker or more compact floes. Martin and Kauffman (1981) describe a wave-damping experiment indicating that a general concentration of about $40 \%$ by volume of frazil ice crystals is necessary for the mechanical properties to transition to more solid characteristics. These wind-driven frazil accumulations can reach thicknesses of $1 \mathrm{~m}$ as opposed to the $0.01-$ to $0.1-\mathrm{m}-$ thick frazil accumulations that occur before transitioning to columnar ice when quiescent conditions (no wind or waves) are present.

Pancake ice, rough1y circular pieces of new ice with upturned edges, also results from frazil accumulations (Fig. 17). During the initial stages of the development of pancakes from frazil ice the pancakes are only semi-consolidated slush. When touched by a probe this will break up into horizonally floating discoids that will not sustain their own weight when removed from the water. The areas between the pancakes are usually relatively free of crystals and act as source areas for the growth of new crystals. Wave action then causes oscillatory 


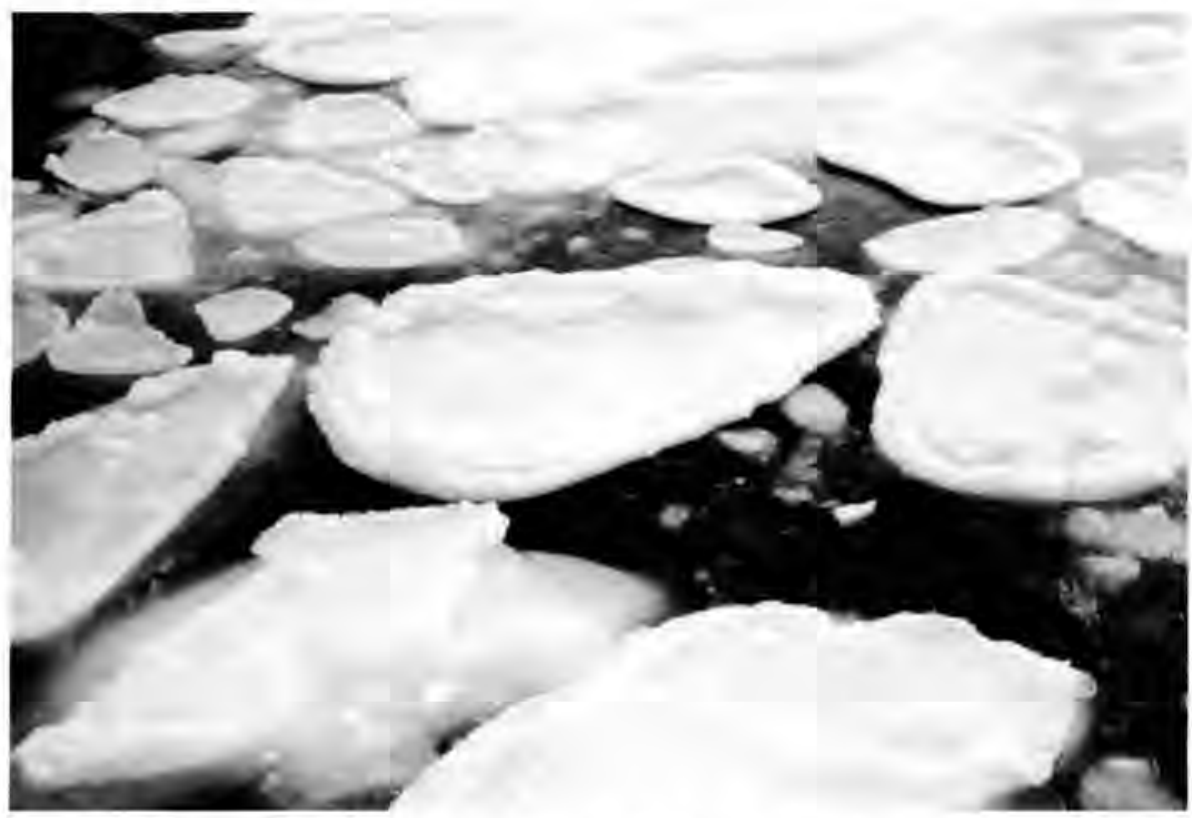

Figure 17. Pancake ice forming from frazil crystals (Dunbar and Weeks 1975).

motions that result in repeated contacts and separations between the floes, pushing the newly formed frazil crystals up to build the characteristic raised pancake rims. Bonding between frazil particles takes place when they are brought into contact, and is also a necessary process in forming these features. These intercrystal bonds develop by deformation and by surface energy forces (described in Hobbs (1974) and Colbeck (1979)). Two effects weld the particles. The first is regelation, where the force pressing the particles tends to locally depress the melting point, leading to heat flow away from and freezing at other contacts. As well, when the stress is removed, the unfrozen contact will change its freezing point and refreeze. The second mechanism is dependent on the radius of curvature and generally takes place in the unsaturated or above-sea-level portions of the pancake ice. Small particles in contact with the water and vapor that is present are thermodynamically unstable with respect to the equilibrium pressures between solid-1iquid, solid-vapor and liquid-vapor at the surfaces of larger particles. The imbalance in pressures tends to deform the ice particles, leading to a flattened solid interface between them and causing them to be welded together at a solid boundary. A distinction between grease ice and pancake ice in the formation process may be related to the ability of the pancake floes to drain somewhat and increase the likelihood of freezing contacts developing by the non-equilibrium pressures due to radius of curvature effects between particles. Generally, in the completely saturated case when the ice crystals are immersed in seawater, bond development is not as dramatic as in the unsaturated compacts. These processes are, however, invoked cautiously as speculative models since they have been developed primarily to explain wet snow properties. The specific application to seawater-ice crystal systems has not been made, and since the thermodynamics is affected by dissolved impurities a complete formulation of the problem is necessary with the seawater parameters specified. It seems clear, however, that the physical processes are qualitatively similar and that bonding between particles is necessary to build these ice forms. When such crystals are 


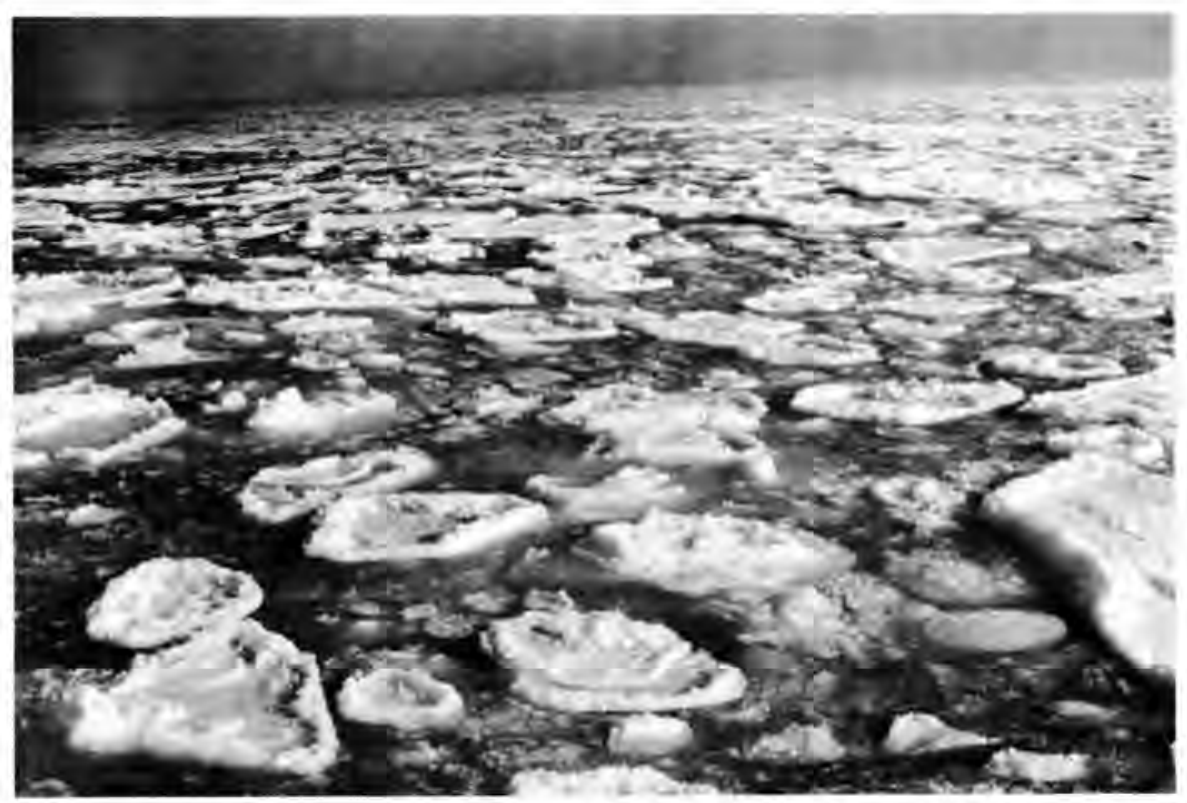

Figure 18. Composite ice sheet of pancakes and sheet ice, Gulf of St. Lawrence (Dunbar and Weeks 1975).

packed together into pancakes by wave motion and the movement of slush pancakes against one another, visual observations show that there is some tendency for the discoids to be stacked in a vertical position (caxis horizontal) so that a closer lateral packing of discoids is permitted. The degree of orientation produced by this packing process is, of course, far from perfect, and in many cases the overall orientation may be close to random. Unfortunately, fabric diagrams of this type of ice are apparently lacking. The initial ice cover that results when a slush layer congeals is usually fine-grained equigranular in texture. A series of excellent vertical and horizontal photomicrographs of such ice are shown in Tabata and Ono (1957, Fig. 10 and 11-1 to -6 ).

The general shape of the initial pancakes depends upon their position in relation to the wave motion and shore. In the open ocean, away from the edge effects of shore, the pancakes tend to be circular in outline due to constant abrasion by other pancakes, which removes sharp corners. Close to shore the pancakes are commonly unequidimenstonal, with their long axes parallel to the shoreline.

During periods of wave action, as the growing ice sheet moves out from shore there is commonly a definite sequence in its development. There is a change from open water containing frazil crystals to grease ice to agglomerating pancakes and grease 1ce to loosely joined pancakes and finally to a complete sheet of joined pancakes. If at any given time during this process turbulence subsides, grease 1 ce will form between the pancakes, producing a composite ice sheet (Fig. 18). Also, after the initial ice sheet has formed, sheet ice will develop beneath the pancakes and grease ice. Photographs 1llustrating the different aspects of the formation of both sheet and composite ice sheets can be found in Weeks and Lee $(1958,1962)$ and the illustrated ice glossaries (Armstrong et al. 1966, U.S. Navy Hydrographic office 1952, Rodhe 1959). 


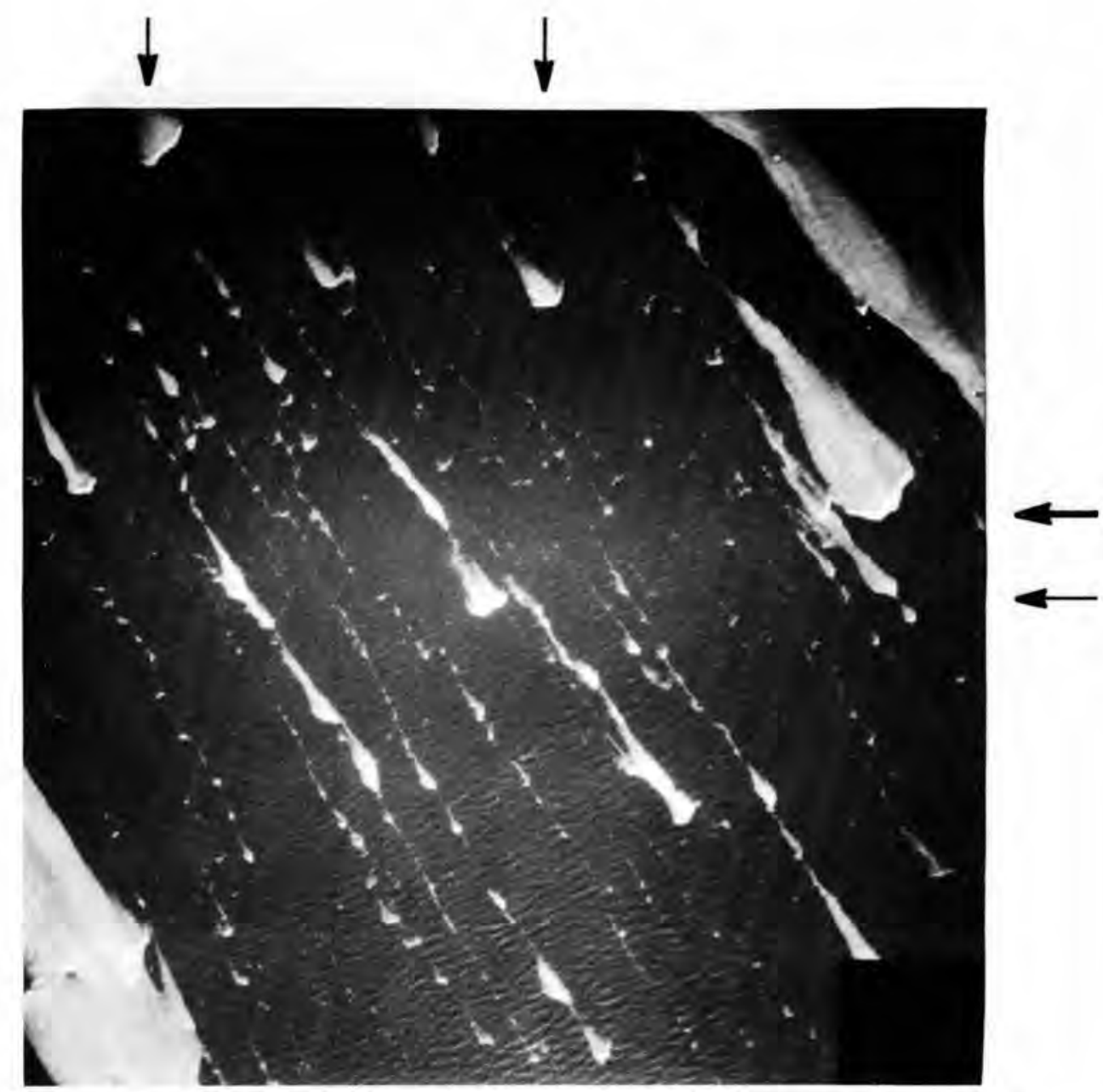

Figure 19. Aerial photograph from elevation of $147 \mathrm{~m}$ of grease ice showing tadpole shapes in a large polynya in the Bering Sea (Martin and Kauffman 1981).

In larger open-water regions, such as polynyas and open ocean-ice edge regions, cold, windy conditions cause grease ice and frazil crystals to stream out approximately parallel to the wind in long plumes. Figure 19 shows these plumes developing at surface temperatures of about $-20^{\circ} \mathrm{C}$ and wind speed of $15 \mathrm{~m} / \mathrm{s}$ in a polynya near Nome, Alaska. Dunbar [private communication; quoted in Martin and Kauffman (1981)] first suggested that a Langmuir circulation causes this organization of grease and pancake ice. Figure 20 schematically shows such a circulation. At the downwind head of such plumes a broadening occurs, usually consisting primarily of pancake ice. Such features have been dubbed "tadpoles" by Dunbar and Weeks (1975) because of their broad head - narrow tall shape. When formed by the offshore winds along shorelines or ice shelves these ice plumes eventually either disappear across regions of open ocean with warm conditions or form the relatively intact ice covers of larger fields of sea ice. Estimates of the ice production in such polynyas are large, with the possibility that an equivalent thickness of $2 \mathrm{~m}$ of ice can develop in as little as 20 hours, as opposed to an entire season's growth of 2 m of ice that would form under undisturbed conditions (Martin 1981). 


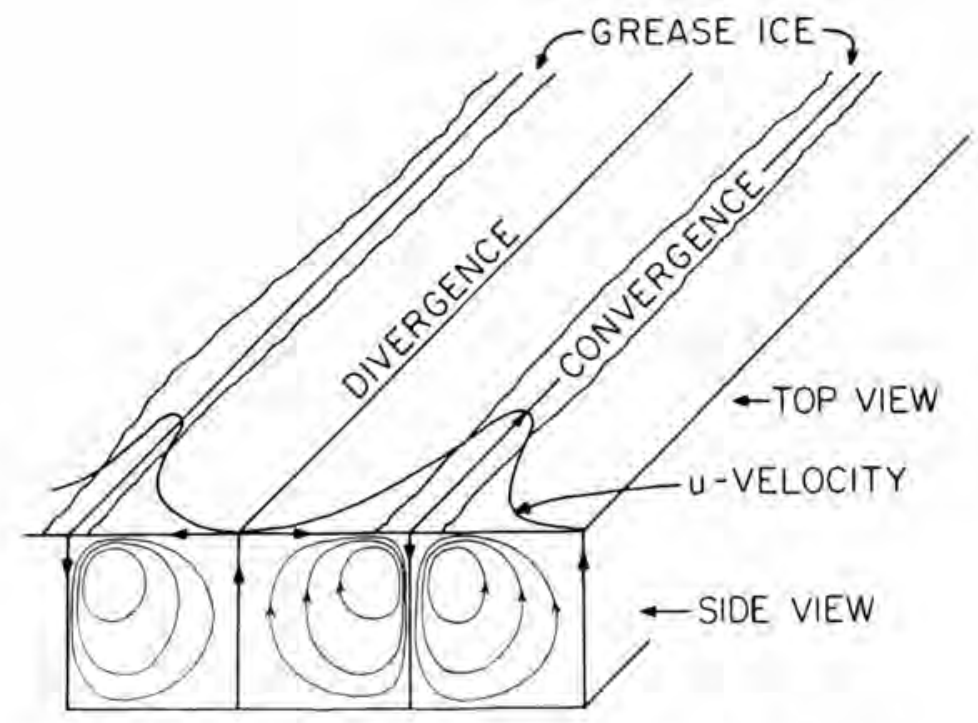

Figure 20. Schematic drawing of the general effect of Langmuir circulation on grease and pancake ice (Martin and Kauffman 1981).

As will be seen later, frazil ice formation can influence deep ocean circulation. It does this through salt fluxes caused by high ice production rates and through mechanical effects like the Langmuir circulations. Based on our most recent observations of Antarctic ice covers, frazil ice appears to be much more widespread than was previously thought. The mechanisms of ice-ocean interaction that contribute to frazil ice other than the initial forms we have just discussed are just being developed. We discuss the evidence for these other features and for possible mechanisms that could lead to increased occurrences of this ice type in a later section.

\section{THE TRANSITION ZONE}

Once a continuous skim of ice has formed across the sea surface, the possibilities for crystal growth due to purely "thermal" supercooling are greatly reduced. An lce skim now separates the melt (seawater) from the cold source ( $a 1 r)$. The latent heat is, therefore, extracted entirely through the ice sheet, and the growth rate is determined by the temperature gradient in the sheet and its effective conductivity. In addition, when a continuous ice layer has formed, the ice crystals lose a degree of growth freedom: only if the grain boundaries are exactly perpendicular to the freezing interface can crystal growth proceed without one grain interfering with the growth of another. Any tendency for anisotropic growth will produce geometric selection, with the crystals in the favored orientation eliminating the crystals in the unfavored orientation by cutting them off from the melt. Since "free-floating" 1ce crystals, forming both from fresh- and seawater, show pronounced anisotropic growth (ratios as high as 100:1; Hallett 1960), with the plane of maximum growth parallel to the (0001) crystallographic plane (Hobbs 1974), it is reasonable to suppose that geometric selection will occur. In fact, this phenomenon always does occur in natural ice sheets, and the ice layer in which the preferred orientation "wins out," 


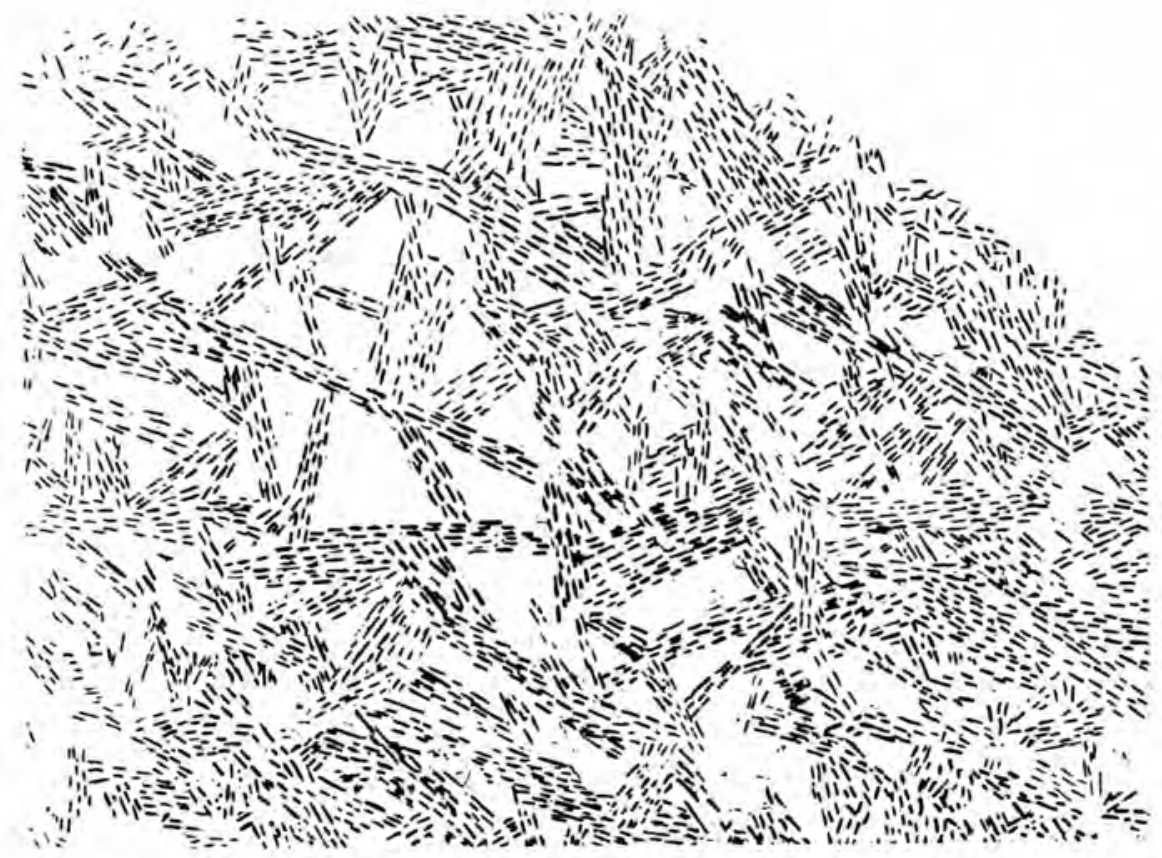

Figure 21. Rubbing of the bottom of a 2.5-cm-thick ice skim that is undergoing geometric selection (Hopedale, Labrador, 1955).

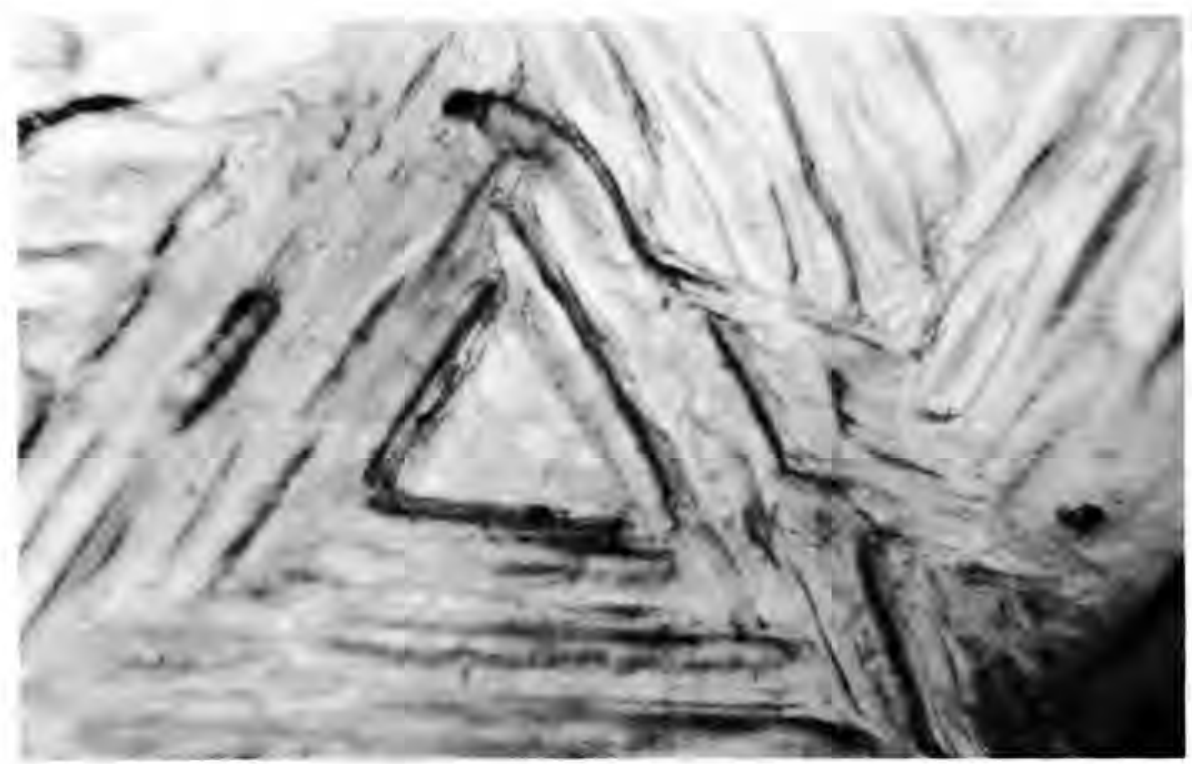

Figure 22. Photomicrograph of the lower surface of sea ice showing a triangular crystal being eliminated by geometric selection.

producing a characteristic growth fabric, has been termed the transition layer by Perey and Pounder (1958). In sea ice, the orientation change is usually essentially completed within a vertical distance of 5 to 10 $\mathrm{cm}$, although the base of the transition layer may be located at distances in excess of 1 meter below the upper lce surface if the initial ice sheet is composed of a thick layer of frazil (Pounder and Little 1959, Weeks and Gow 1980). 
A typical rubbing of the bottom surface of a $2.5-\mathrm{cm}$ ice skim in which the process of geometric selection is obviously occurring is shown in Figure 21. The blank plane-sided polygonal areas are where c-axes vertical or near-vertical crystals occur. These crystals grow appreciably slower than the surrounding c-axes horizontal crystals. They therefore form depressed $(\approx 2-$ to $5-\mathrm{mm})$ areas on the bottom surface of the ice skim and do not show in the rubbings. A photomicrograph of the bottom surface of an ice skim showing such a depressed area due to the presence of a c-axis vertical crystal is shown in Figure 22. If this ice were allowed to continue growing, the crystal in the center of the photomicrograph would be rapidly eliminated by the surrounding crystals as a result of selected growth parallel to the (0001) plane. Once the c-axes vertical crystals are eliminated, rubbings from the lower levels in the ice sheet are similar to Figure 27.

A more quantitative picture of this process can be obtained by making a series of c-axis orientation measurements at different levels in the ice sheet using a 4-axis universal stage. Figure 23 shows these results plotted on a Schmidt net from a layer of sheet ice that formed during a calm night. It is quite clear that the majority of c-axes vertical crystals are eliminated in the upper $1 \mathrm{~cm}$ of the ice sheet. By the 5-cm level, all the remaining crystals have their c-axes within a few degrees of the horizontal. Since the azimuthal distributions of caxes in Figure 23 and in other studied examples (Tabata and ono 1957) did not show any pronounced pattern, it was assumed that they are random and only the angle between the c-axis and the vertical need be considered. Figure 24 is a diagram prepared on the basis of this assumption. It clearly shows that in the initial skim, as well as in the top $1.5 \mathrm{~cm}$ of the ice sheet, tce crystals exist with all different orientations. Therefore, to form the characteristic c-axis orientation of the columnar zone (below the transition layer), it is not necessary to nucleate new grains with a c-axis horizontal orientation. The new orientation presumably forms by the survival of those grains with the favored orientation that are present in the initial ice skim. Similar conclusions have been reached from the study of the solidification of metal ingots (Walton and Chalmers 1959).

The process of geometric selection in ice can easily be rationa1ized in terms of crystal growth theory. The theory predicts that atoms from the melt arriving at a crystal surface will have a much higher probability of remaining if they arrive at a step in the surface than if they arrive at an atomistically smooth face. Therefore, growth normal to the closest packed plane [the (0001) plane in 1ce] requires either the existence of step-producing defects or the nucleation of an embryo that will then grow laterally to form a new plane of atoms. The activation energy for this latter process is quite high, necessitating a larger supercooling, $\delta \mathrm{T}$. These conclusions have been verified for $1 \mathrm{ce}$ by Hillig (1958, 1959), who found that the kinetics of ice growth parallel to the c-axis was consistent with the classical two-dimensional nucleation and growth model, while the growth kinetics parallel to the (0001) plane could be explained by a screw dislocation model (Hillig and Turnbu11 1956).

When the inftial downward growth starts in the ice sheet, the crystals in the most favorable orientations rapidly grow ahead of crystals 

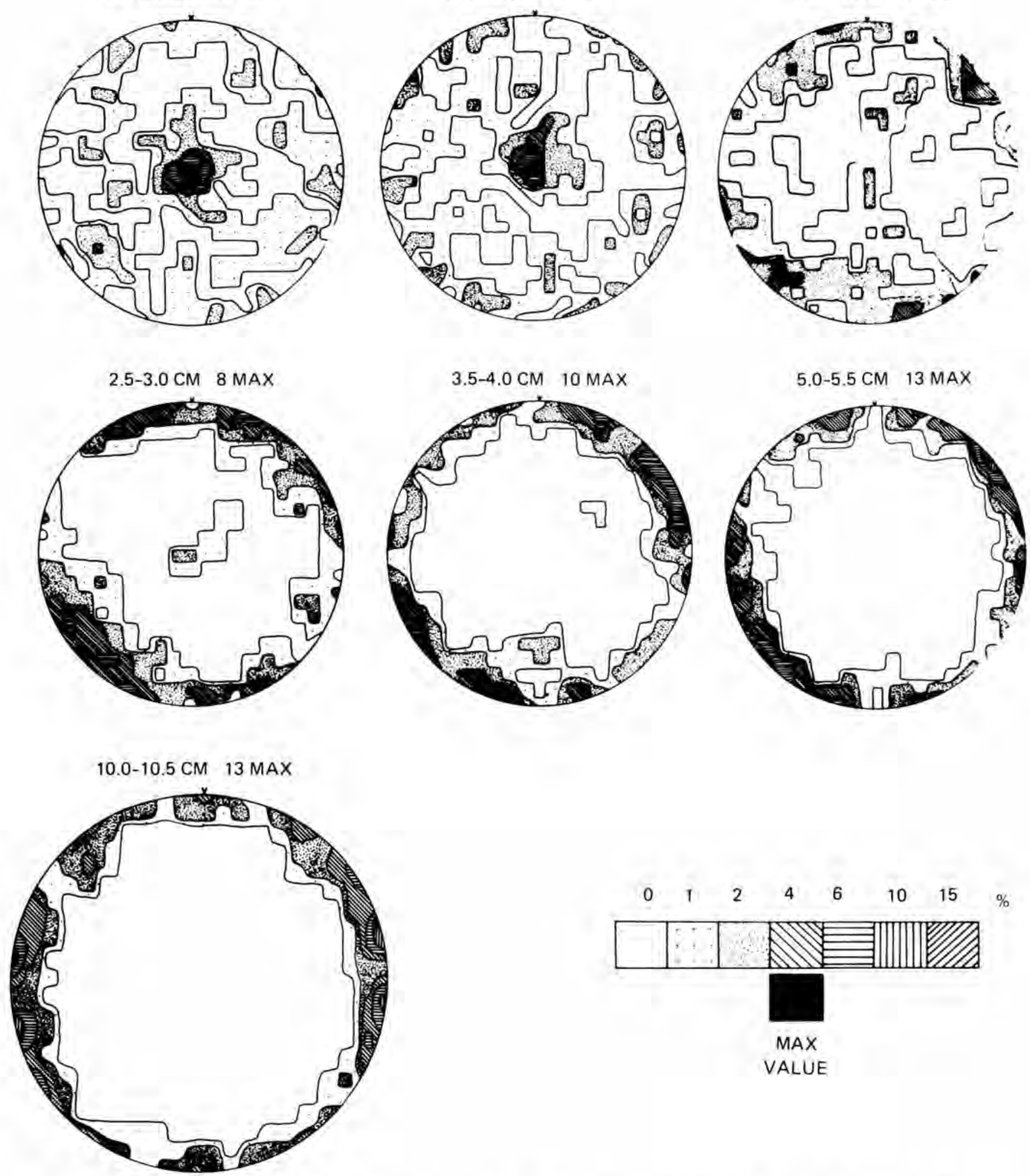

Figure 23. Orientation of the c-axes of sea ice crystals from different depths below the upper surface of an ice sheet (Thule, Greenland, 1957) plotted and contoured on the upper hemisphere of a Schmidt net. The diagrams are in the horizontal plane. Contour intervals (per $1 \%$ circle) as indicated. 

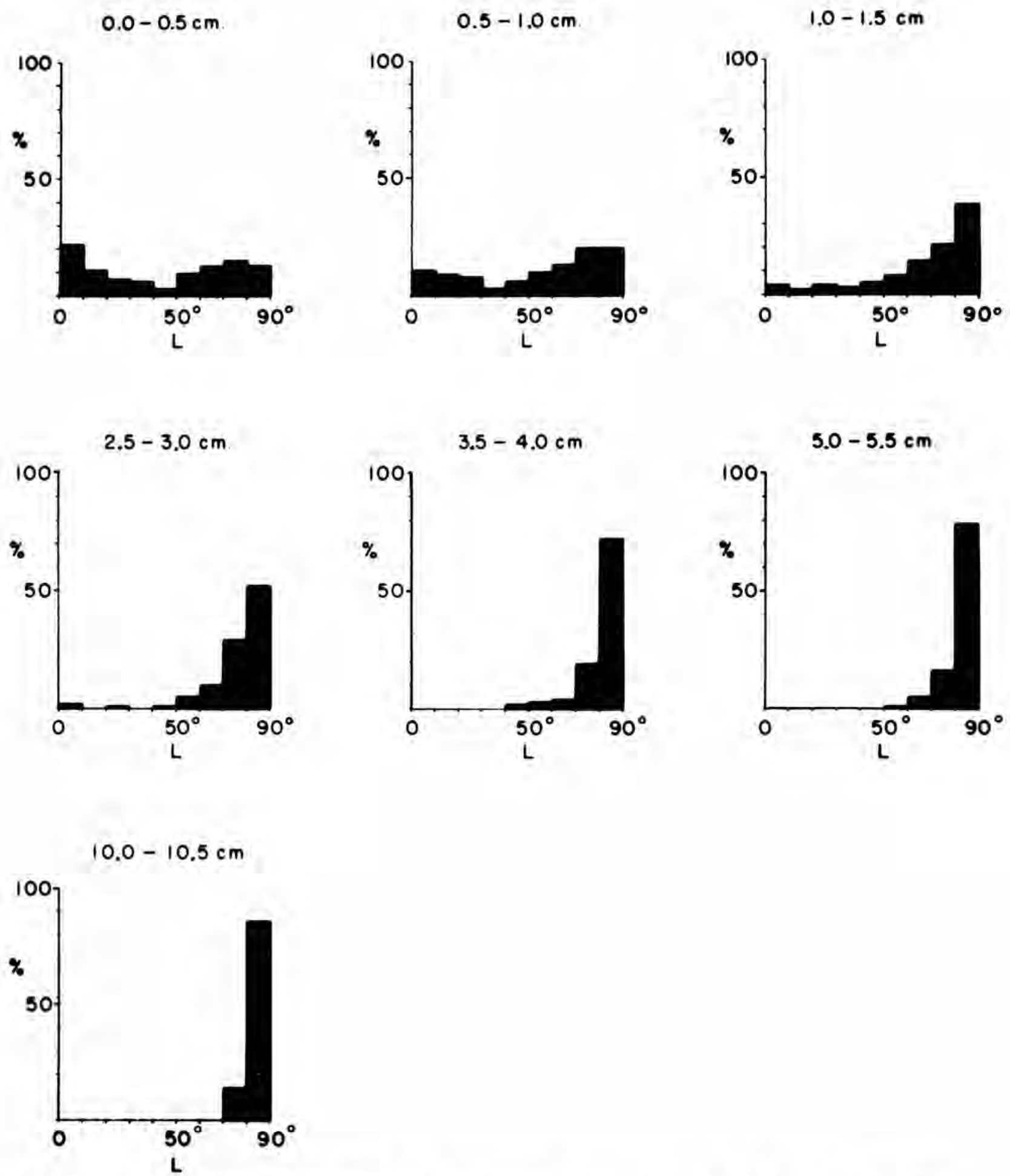

Figure 24. Histograms showing the relative percentage of different c-axis orientations $\left(0^{\circ}=\right.$ vertical, $90^{\circ}=$ horizontal $)$ in the ice studied in Figure 23. 

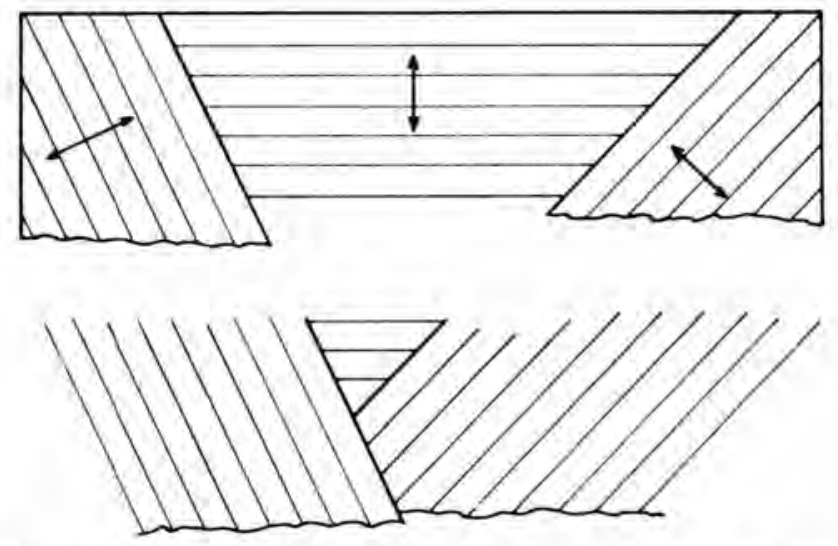

Figure 25. Schematic diagram showing the process of geometric selection according to Perey and Pounder (1958). The arrows indicate the direction of the c-axes.

with less favored orientations since they 1) can grow more rapidly at any given supercooling - at the same growth velocity, growth in a high index direction generally occurs at a much smaller $\delta \mathrm{T}$ than growth in a low index direction - and they 2) have to grow a smaller linear distance to advance the same distance parallel to the axis of heat flow. In addition, the latent heat evolved and the solute rejected by the more rapidly growing crystals reduces the effective interface supercooling of their slower neighbors. This selective growth process is shown diagrammatically in Figure 25 (Perey and Pounder 1958).

In the final growth orientation, all the (0001) planes are aligned approximately parallel to the thermal gradient (Fig. 23, diagrams from depths of greater than $5 \mathrm{~cm}$ ). This orientation has been found repeatedly in studies of both sea and NaCl 1ce (Shumskii 1955, Tabata and Ono 1957, Perey and Pounder 1958, Weeks and Lee 1958, Weeks and Assur 1963, Langhorne 1980, Weeks and Gow 1980). In sea ice, because the heat loss into the atmosphere is unidirectional there is no obvious reason why the (0001) planes should have any particular orientation in the horizontal plane of the 1ce sheet. Early field observations appeared to verify this, at least for relatively thin ice (Tabata and Ono 1957, Weeks 1958).

However, if the heat loss were two-directional, as it is during the refreezing of small vertical cracks in sea ice, then heat would be lost both to the air and to the cold ice that composes the sides of the crack. The ice crystals that form would therefore be expected to have their c-axes horizontal and parallel to the axis of the crack. Figure 26 is a diagram showing the c-axis orientations observed in healed sea ice cracks at Hopedale, Labrador. The orientations are exactly as expected. Similar observations from lake ice have been reported by Taylor and Lyons (1959, p. 13). In fact this pronounced orientation in the refrozen crack explains why once a crack heals it commonly does not refracture in tension but new cracks develop parallel to it (the crack has a crystal orientation that gives the highest possible tensile strength in the direction normal to the crack). 


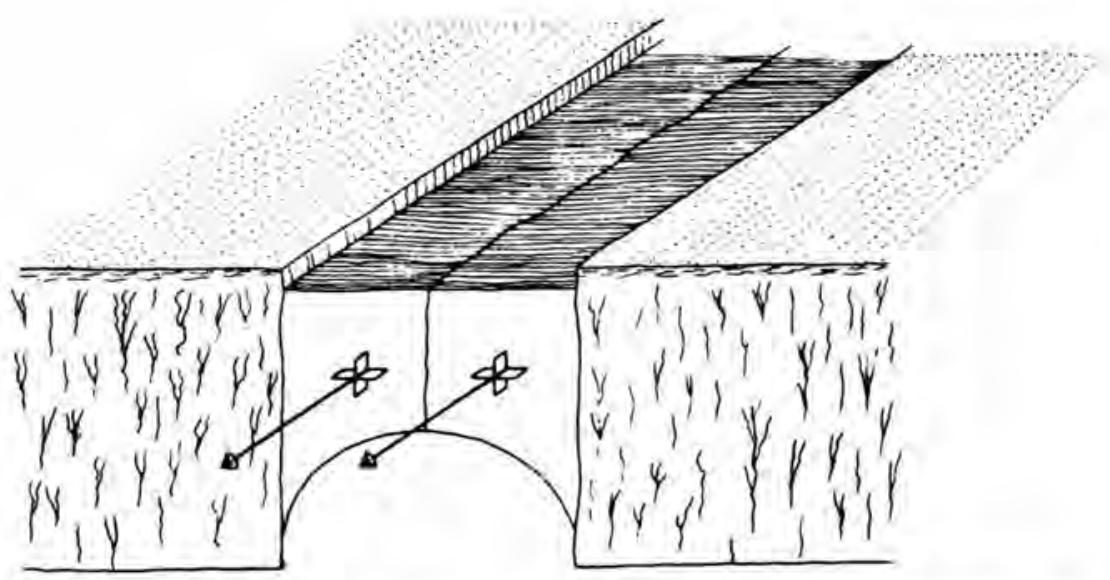

Figure 26. c-axis orientation in a healed crack at Hopedale, Labrador.

The percentage of a winter's ice sheet composed of transition zone ice is sma1l. But the importance of this zone exceeds its size. By studying the transition one can examine the processes that control the structure of the underlying columnar zone, the zone which contains the majority of the sea ice.

THE COLUMNAR ZONE

Below the transition layer in sea ice, the ice has all the characteristics associated with the so-called "columnar" zone in metal ingots [1.e. a strong crystal elongation parallel to the direction of heat flow, a pronounced crystal orientation, and an increase in crystal size over crystals closer to the cold source (Walton and Chalmers 1959)]. Therefore, it is useful to apply this term to sea 1 ce. Because the transition layer is thin and occurs at or near the 1ce/air interface, it commonly sublimates away or recrystallizes into the snow cover as the ice sheet grows. Therefore, the complete thickness of a one-winter sheet of ice can, to a good approximation, be considered as being in the columnar zone. Compared with the pronounced changes occurring in the transition layer, the changes in the columnar zone are considerably more subtle.

Fabric diagrams from the columnar zone are extremely monotonous, as shown by Figure 23 (diagrams below $5 \mathrm{~cm}$ ). A1l c-axes are oriented within a few degrees of the horizontal plane. An inked rubbing of columnar zone lce showing the grain boundaries and the trace of the (0001) plane for each crystal is presented in Figure 27. This rubbing was made just below the transition layer on the lower surface of a $5-\mathrm{cm} 1 \mathrm{ce} s \mathrm{sim}$ formed at Thule, Greenland. The grain boundaries are highly sutured, the details of the boundaries corresponding to the locations of individual platelets. Even with this suturing, it is usually quite easy to distinguish the boundaries of individual crystals. Suturing is usually clearly evident both in horizontal rubbings (Fig. 27) and thin sections (Fig. 35) and appears to be a common characteristic of Ice grown with a dendritic solid/1iquid interface (see Knight, 1962d, p. 323). A histogram showing the angles between the c-axes of neighboring crystals from the rubbing in Figure 27 is presented in Figure 28. If the diagram were 


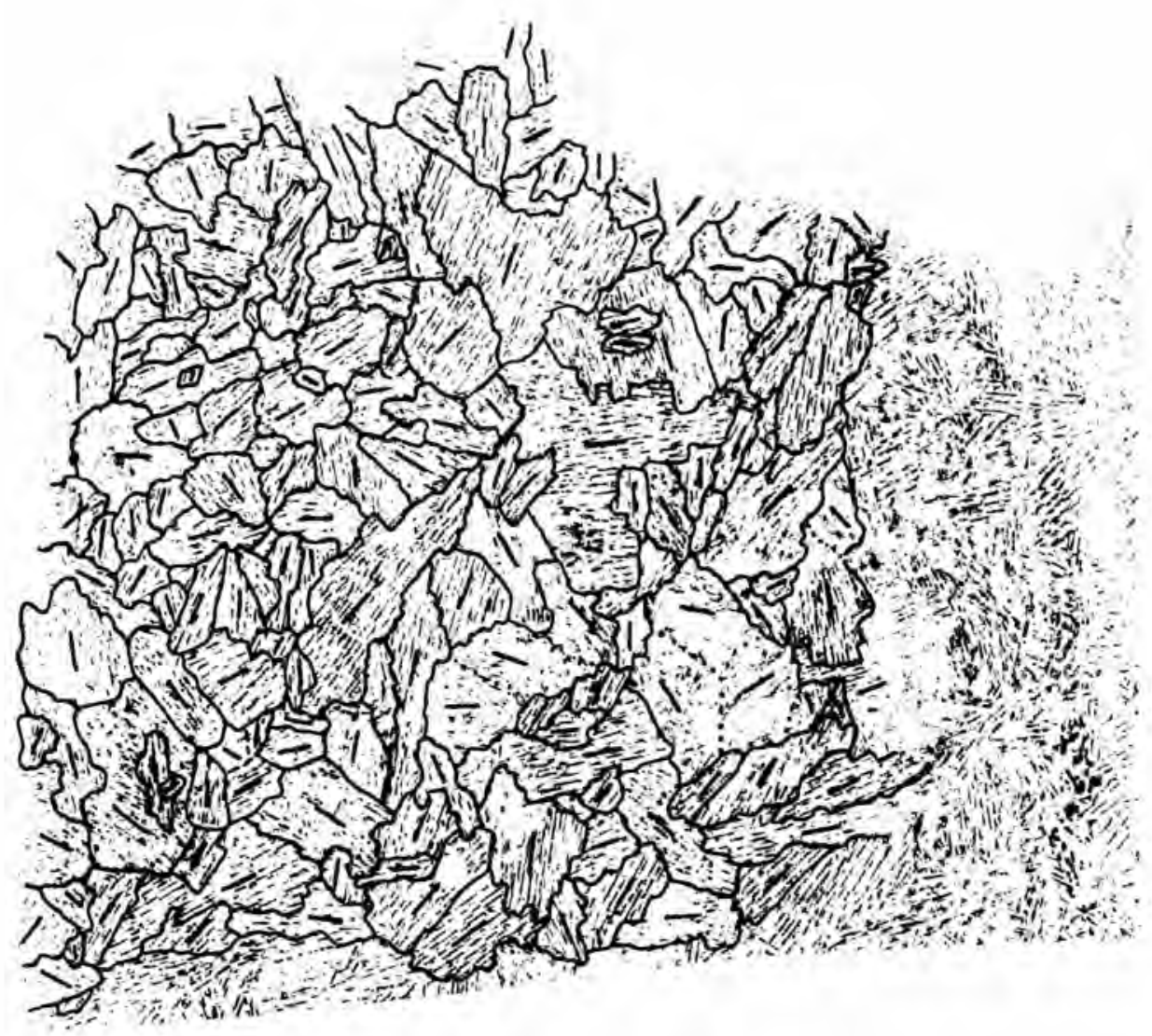

Figure 27. Rubbing from just below the transition layer on a 5-cm-thick ice sheet at Thule, Greenland. The inked "tick" marks indicate the trace of the (0001) plane.

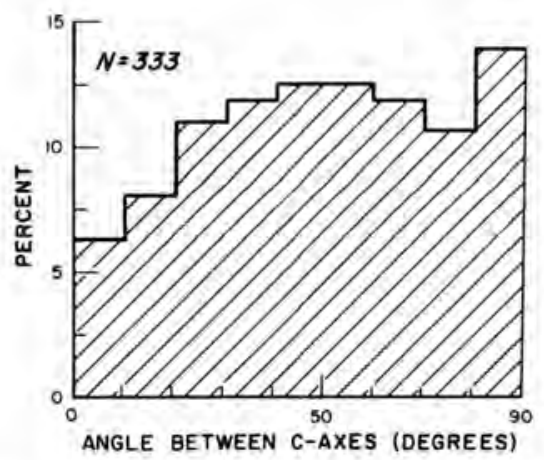

Figure 28. Histogram giving the angles between the c-axes of neighboring ice crystals shown in Figure 27 .

Isotropic, the theoretical frequency in each class would be 37 (11.1\%). A chi-squared test shows that there is no reason to doubt that this fabric is isotropic at the 0.05 significance level. Similar results have been obtained by Tabata and 0 no on thin sheets $(<33 \mathrm{~cm})$ from Hokkaido, Japan.

As compared with horizontal rubbings, vertical rubbings in the columnar zone are relatively uninformative. A typical example is shown in Figure 29. The lines reflect the vertical orientation of the platelike sea ice structure. The change in horizontal spacing of the lines is produced by changes in both the plate spacing at different positions in the ice sheet and the angle at which the plates intersect the plane of the rubbing. 


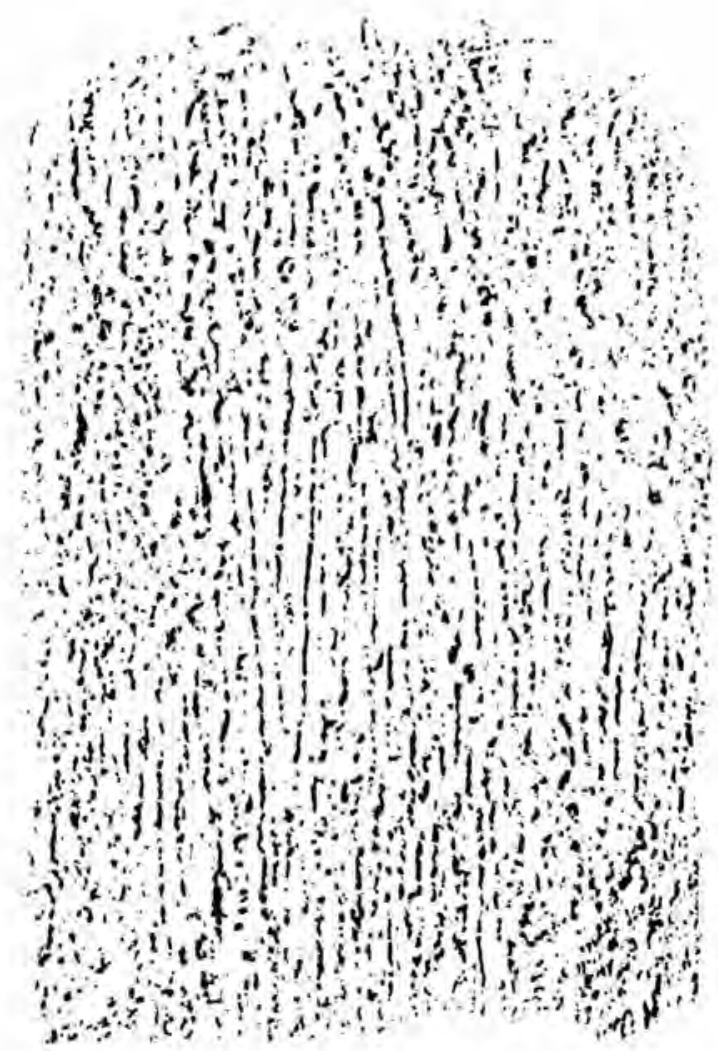

Figure 29. Vertical rubbing of columnar zone ice.

Although the c-axis orfentations of sea ice have received considerable attention, the orientations of the a-axes have not been examined, as they are harder to measure. The one exception to this is a recent study by Kawamura and Ono (1980), who studied both c- and a-axis orientations in sheets of thin $(4.0$ to $8.5 \mathrm{~cm})$, newly formed sea 1ce at Barrow, Alaska. Measurements were made at two different levels in the ice. Although formally both these samples would probably be considered to be from the transition zone, the samples from near the bottom of the ice sheets showed strong c-axis-horizontal orientations ( $88 \%)$. The relative frequency of the a-axis orlentations of the different grains from the bottom centimeter of the sheets is shown in Figure 30 . The vertical angle between the horizontal and the a-axis nearest the ice surface is indicated by the symbol $\theta$. As can be seen, the most frequent a-axis orientations are either horizontal to near-horizontal (38\%) or at 30 degrees $(17 \%)$. Th1s suggests that the favored a-axis growth direction is close or equal to either $\langle 11 \overline{2} 0\rangle$ or $\langle 10 \overline{1} 0\rangle$.

We would like to suggest that once the columnar zone has developed and all the remaining crystals are oriented with their c-axes essentially horizontal, it is the crystal with the most favorable a-axis orientation that has the growth advantage and will ultimately dominate at the interface. We would guess that the favored growth direction would be $\langle 11 \overline{2} 0\rangle$, that is parallel to the a-axis as opposed to normal to the first-order hexagonal prism $\langle 10 \overline{1} 0\rangle$. We would also guess that the growth advantage of $\langle 1120\rangle$ would be small, and that a strong $\langle 11 \overline{2} 0\rangle$ orientation 

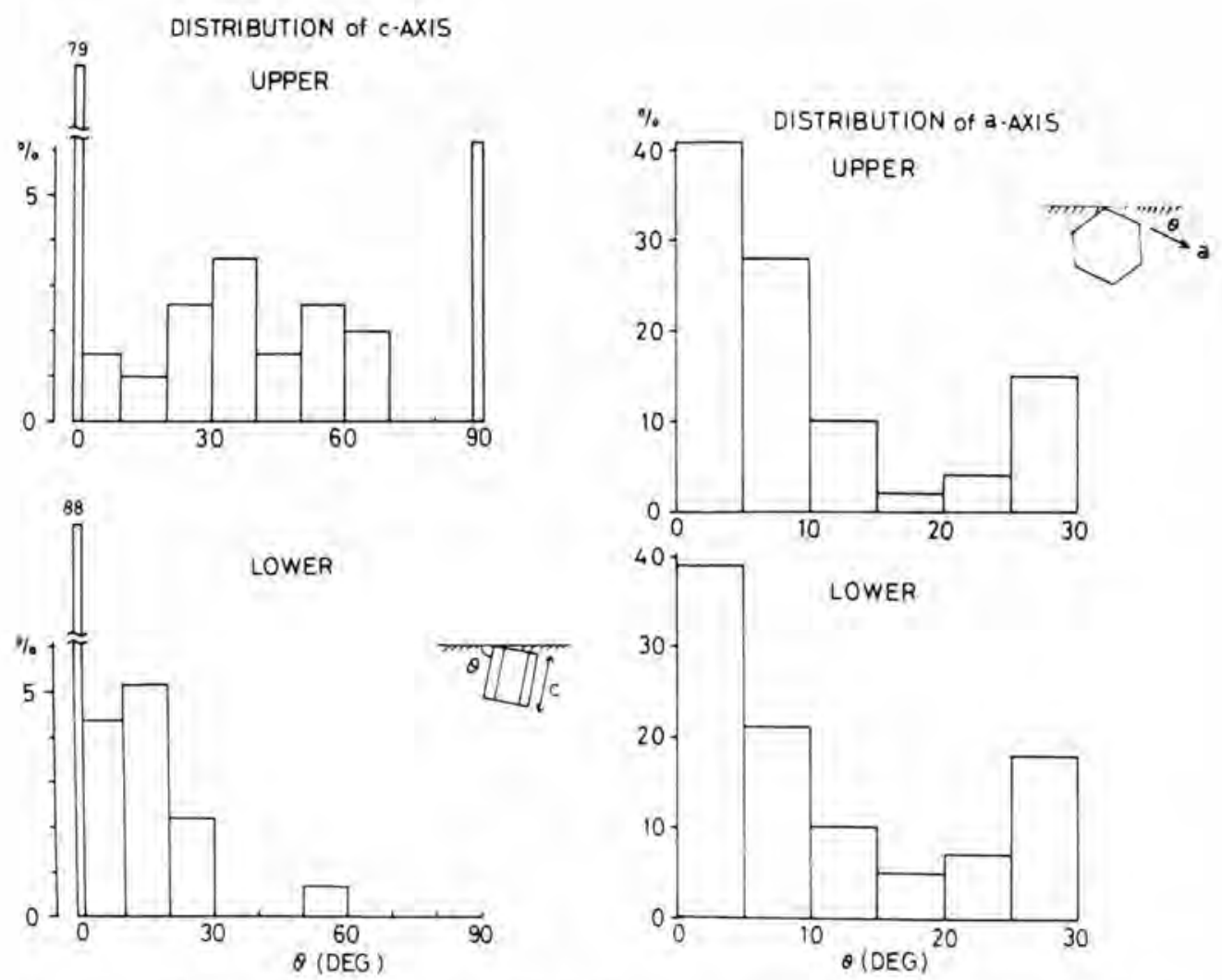

Figure 30. The distribution of $\mathrm{c}-$ and a-axis orientations in the upper $(4 \cdot 0-7 \cdot 7 \mathrm{~cm})$ and lower $(17-22 \mathrm{~cm})$ portions of thin ice sheets examined at Barrow, Alaska (Kawamura and Ono 1980).

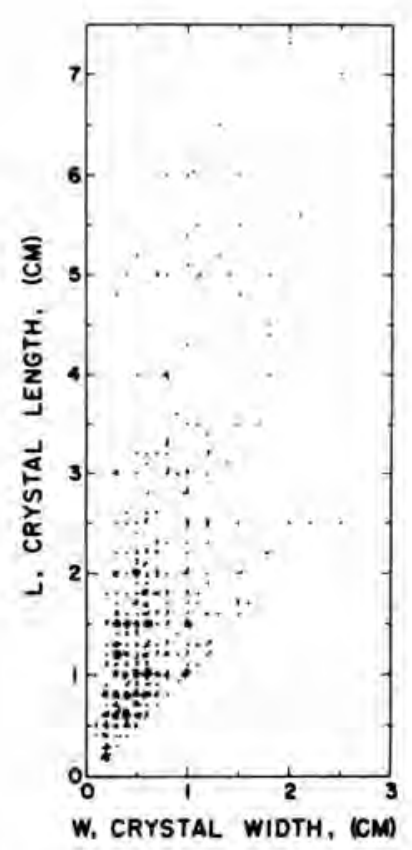

Figure 31. Lengths and widths (in the horizontal plane) of ice crystals at different levels in a sea ice sheet at Thule, Greenland.

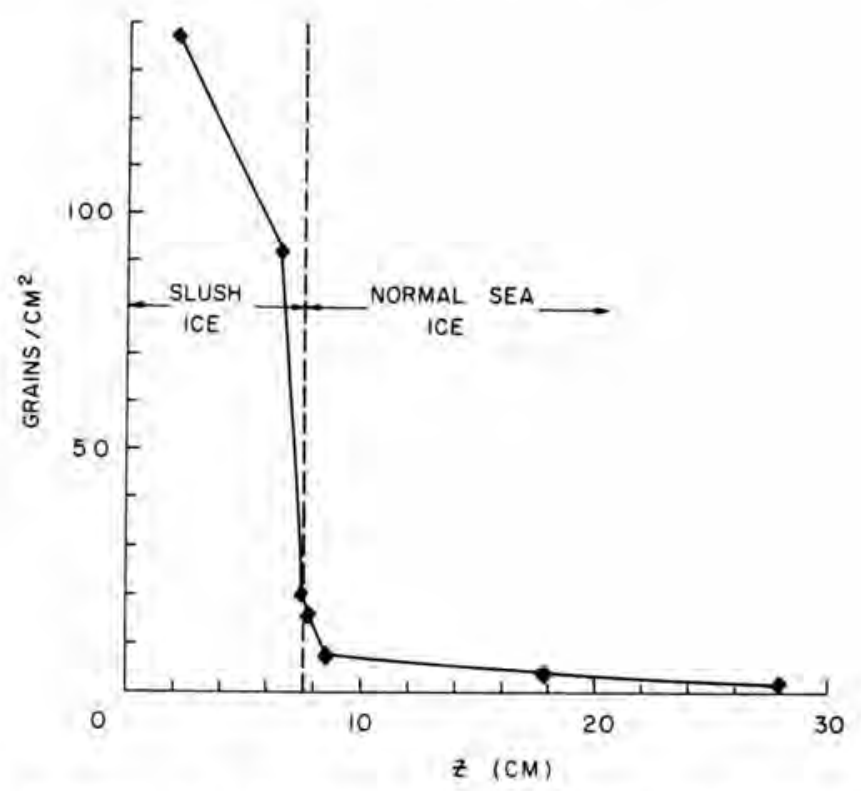

Figure 32. Increase in crystal size with distance below the surface of an ice sheet at Barrow, Alaska (Weeks and Hamilton 1962). 
in the vertical direction would take a prolonged period of ice growth before it would dominate. It should not be difficult to check these contentions by using etch techniques on samples collected from thick undeformed first-year and multiyear sea ice.

Another interesting aspect of the columnar zone is the variation in crystal size. The general relation between the maximum length $\mathrm{L}$ and the maximum width $\mathrm{W}$ of a number of crystals measured in horizontal thin sections has been studied by Weeks and Hamilton (1962) using relatively thin $(31.4 \mathrm{~cm})$ ice from Point Barrow, Alaska. Length measurements were always taken parallel to the (0001) plane and width measurements parallel to the c-axis. The data are reasonably well fitted by a linear regression line giving approximately a 2:1 length-to-width ratio. This indicates that the ratios of sidewise to edgewise growth of the individual crystals do not differ nearly as much as might be expected from the studies of growth anisotropy in free-floating ice crystals. Figure 31 shows a plot of the length-width values of a number of crystals measured from horizontal thin sections made at 5 -cm intervals through the upper $60 \mathrm{~cm}$ of the fast ice at Thule, Greenland. Here L refers to the maximum dimensions of the crystal and $W$ the value measured at right angles to $\underline{L}$ (i.e. the crystallographic orientation was not considered). Therefore, by definition, the $\mathrm{L}: \mathrm{W}$ ratio can never be less than 1 .

Keeping this difference in mind, the Thule results are quite comparable to those from Point Barrow.

The most noticeable change in the upper part of the columnar zone is the marked increase in grain size with increase in depth in the ice sheet. This change is clearly shown in Figure 32 (Weeks and Hamilton 1962), which plots the number of crystals per square centimeter at different depths in the ice sheet. Once the rapid grain size change at the base of the slush layer is completed, there is a slow but regular increase with depth. The grain size curve in this ice sheet is quite comparable to grain-coarsening effects observed in the columnar zones of both pure and impure metals (Walton and Chalmers 1959, Fig. 11-12, p. 451). The change in the grain size characteristics has been studied in some detall from the upper $60 \mathrm{~cm}$ of a $125-\mathrm{cm}-\mathrm{thick}$ ice sheet at Thule, Greenland. The measurements were stopped at the $60-\mathrm{cm}$ level because a large number of crystals were not completely contained in a given thin section. Fortunately, as a result of the fact that all grains in sea ice are columnar, the investigator is not faced with the problem of the thin section not cutting the "centers" of the crystals. The crystal "diameter" $d(d \equiv \sqrt{\mathrm{LW}})$ was measured and the average value $d$ computed for several levels in the ice sheet. There is a pronounced linear increase in $d$ with increasing depth in the ice. Also plotted in this figure are d values from Point Barrow (Weeks and Hamilton 1962) and Hokkaido (Tabata and Ono 1962). The slopes of all three curves are similar. This suggests that if a transformation is made correcting for the initial grain size at $(z=0)$, all these curves can be considered as identical. Figure 33 shows a plot of $[d-d(z=0)]$ versus $z$. The leastsquares line through the origin has a slope of 0.033 . The $[d(z=0)]$ value for Hokkaido $(0.87)$ was obtained by least squares extrapolation and the value for Point Barrow $(0.22)$ by setting $(Z=0)$ at the slush normal sea ice boundary. This preliminary examination suggests that grain size may prove to be an interesting and useful parameter. If further measurements support the hypothesis of "equal slopes," once the 


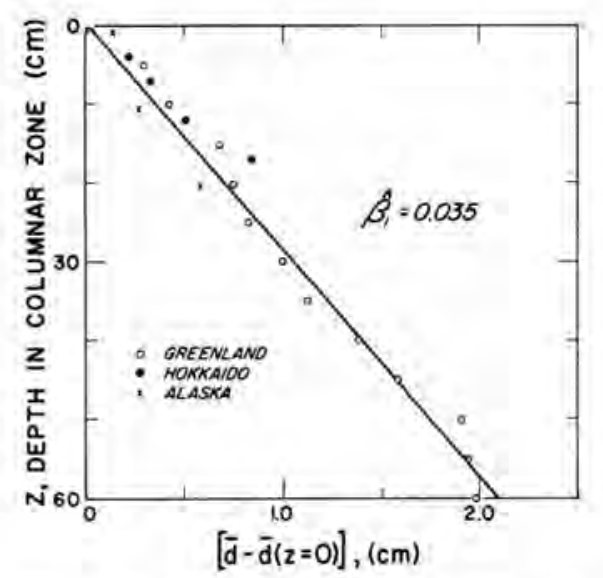

Figure 33. Plot of change in grain size with distance below the upper ice surface. The grain size curves are shifted to zero at the ice surface.

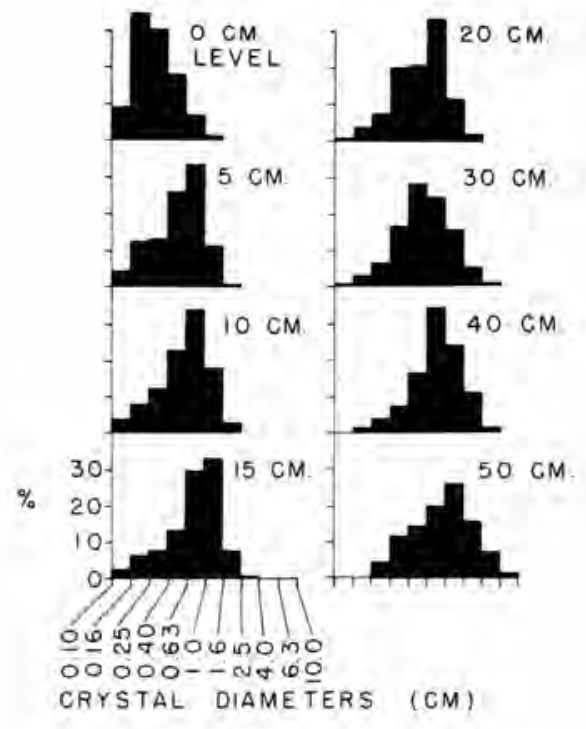

Figure 34 . Histograms of crystal diameters at different levels in an ice sheet at Thule, Greenland.

average grain size is determined at one level in an ice sheet it would specify the grain size for the complete sheet. This presumably could only be the case for continuously grown one-winter ice sheets since nucleation of new crystals would cause a discontinuity in the grain diameter curves. We would anticipate that the simple "equal slopes" hypothesis will not be verified and that the rate of increase in the mean grain diameter will be a function of the growth rate of the 1 ce, with the largest values of the slope occurring at the lowest ice growth rates. More will be sald later in this paper about grain size variations in sea 1ce with strong c-axis alignments.

There are, in fact, data already avallable in the 1iterature that tend to cast doubt on a simple relation between $d$ and the vertical position in the ice sheet. For instance, Koerner (1963) observed that sea ice cores from Jones Sound off Devon Island in the Canadian Arctic showed a smaller initial grain size and a more rapid increase in crystal size with depth than ice collected closer to shore. He also suggested that this difference might be the result of changes in growth rates. Also, in old sea ice incorporated into the ice island Arlis II, Smith (1964) observed areas as large as $10 \mathrm{~m}$ on a side with almost perfect caxis alignment. Using a slope of 0.033 it would require an ice thickness of approximately $300 \mathrm{~m}$ to give such an average grain size. Ice thicknesses of this magnitude appear quite unreasonable at the present.

Figure 34 shows a series of histograms of the distribution of crystal diameters for different levels in the 1 ce sheet from Thule, Greenland. The abscissa is scaled to permit ready comparison with similar data on lake ice presented by Marshall (Wilson et a1. 1954). The sea ice crystal diameter distributions in sea 1ce, with the exception of the 
upper surface which would be in the transition layer, are negatively skewed, while the lake 1ce distributions have a tendency to appear normal or even rectangular. Whether these differences are generally true between lake and sea ice is impossible to ascertain with the presently available data.

The preceding intracrystalline petrographic parameters are best measured in horizontal thin sections. There are also several petrographic features that are only clearly seen in vertical thin sections. In contrast to the preceding parameters, which are either constant or change gradually with position in the ice sheet, these commonly appear as sharp bands that extend for large lateral distances. Small scale horizontal banding in sea ice has been noted at widely separated regions (Shumskii 1955, Tabata and Ono 1957, plate XVI, Langleben 1959, Fig. 3, Bennington 1963a, Fig. 1, Paige 1966). For example, Shumskil observed a total of 58 secondary layers in a $291-\mathrm{cm}$ section of old pack ice, giving an average layer thickness of $5 \mathrm{~cm}$. The layers are produced by changes in the amount of impurities (brine and air) trapped in the ice. Similar effects are well known in studies of metals. As far as is known, this type of layering is not accompanied by the nucleation of new crystals. Air bubble layering in lake ice is also well known (Taylor and Lyons 1959, p. 16-19, Swinzow 1966, Gow and Langston 1977). These differences in impurity content are produced by changes in the growth rate of the 1 ce and can make convenient horizontal markers in the ice sheet throughout any region where the weather is latera11y homogeneous. Langleben (1959) has, quite effectively, used this layering as a reference mark in studying the location of the transition layer throughout the growth season. A similar technique should also be useful in studying the relative amounts of ablation from the lower and upper surfaces of pack ice during the melt season. This has been done for lake ice by Gow and Langston (1977). A theoretical analysis of the effect of changing the freezing velocity on the amount of impurity incorporated into the solid phase, assuming that solute transfer in the melt takes place by diffusion only, has been published by Tiller et al. (1953) and Smith et al. (1955). Up to the present time, there have been two attempts to apply this theory to bubbles in freshwater ice grown in the laboratory (Carte 1961, Bari and Hallett 1974) and one example using field observations (Gow and Langston 1977). Apparently, no work has been done on sea ice, although we would expect similar relations to hold.

There are several other important aspects of the structure of the columnar zone (e.g. variations in the width of the substructure in the ice crystals, brine drainage channels, annual layering in multiyear ice, directional c-axis alignments in the horizontal plane). These subjects will be treated in detafl later in the paper.

\section{SUBSTRUCTURE}

One invariably identifies sea ice by the presence of a characteristic cellular substructure consisting of reasonably evenly spaced ice platelets or cells separated by small angle grain boundaries. It is along these boundaries that the salt in sea ice is present in the form of liquid and solid inclusions. This cellular substructure is clearly shown in Figures 35 and 36. It has been known for some time that the spacings of this substructure change with vertical location in the ice 


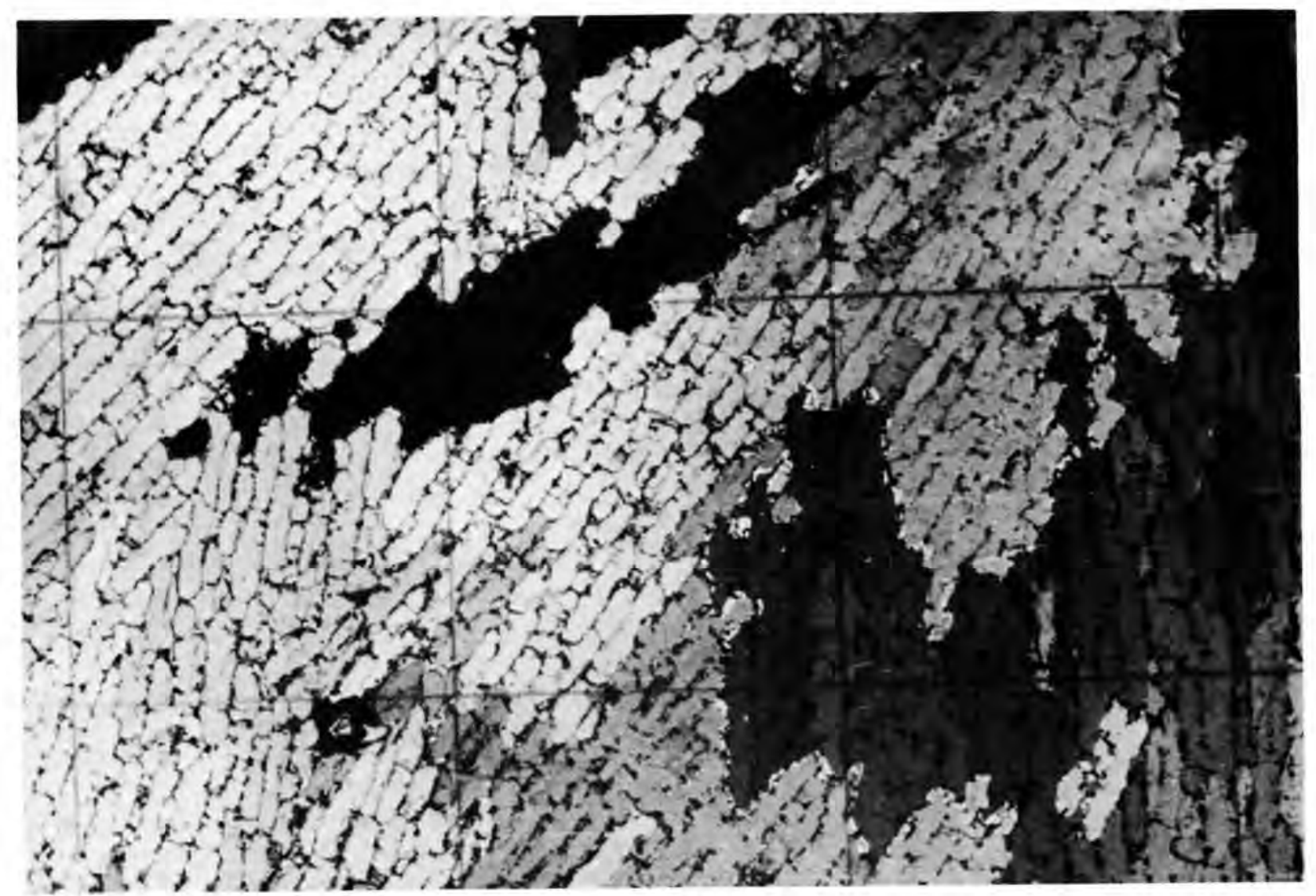

Figure 35. Horizontal thin section of sea ice from $27.9 \mathrm{~cm}$ below the upper ice surface, Point Barrow, Alaska (Weeks and Hamilton 1962). Grid is $1 \mathrm{~cm}$ on a side.

sheet (Fukutomi et al. 1953). In an attempt to understand these variations, observations have been carried out on natural sea ice (Tabata and Ono 1962, Weeks and Hamilton 1962, Paige 1966, Gow and Weeks 1977, Nakawo and Sinha, in press) and experiments have been undertaken on a variety of salt ices (Weeks and Assur 1963, Rohatgi and Adams 1967 a,b, Lofgren and Weeks 1969). The most important parameter in characterizing the substructure is the brine layer spacing $a_{0}$ (also referred to as the plate width), which is the distance between adjacent layers of brine pockets measured parallel to the c-axis (see Fig. 36; double-headed arrow indicates the c-axis direction).

Laboratory experiments have shown that in $\mathrm{NaCl}$ ice formed under conditions of unidirectional freezing, there is a gradual increase in the value of $a_{0}$ with increasing distance from the upper ice surface or from the constant temperature cold plate. An analysis of the factors controlling the variation in $a_{0}$ has been published by Bolling and Tiller (1960) for the case where the solute transfer in the liquid ahead of the advancing interface is by diffusion only. Although the final form of the analysis is approximate, the physical reasoning behind the analysis is clear. The exact solution to the steady-state solute distribution in the liquid ahead of an advancing plate tip consists of both plane and non-plane wave terms. These latter terms cause lateral diffusion and can be considered to extend some effective distance y into 

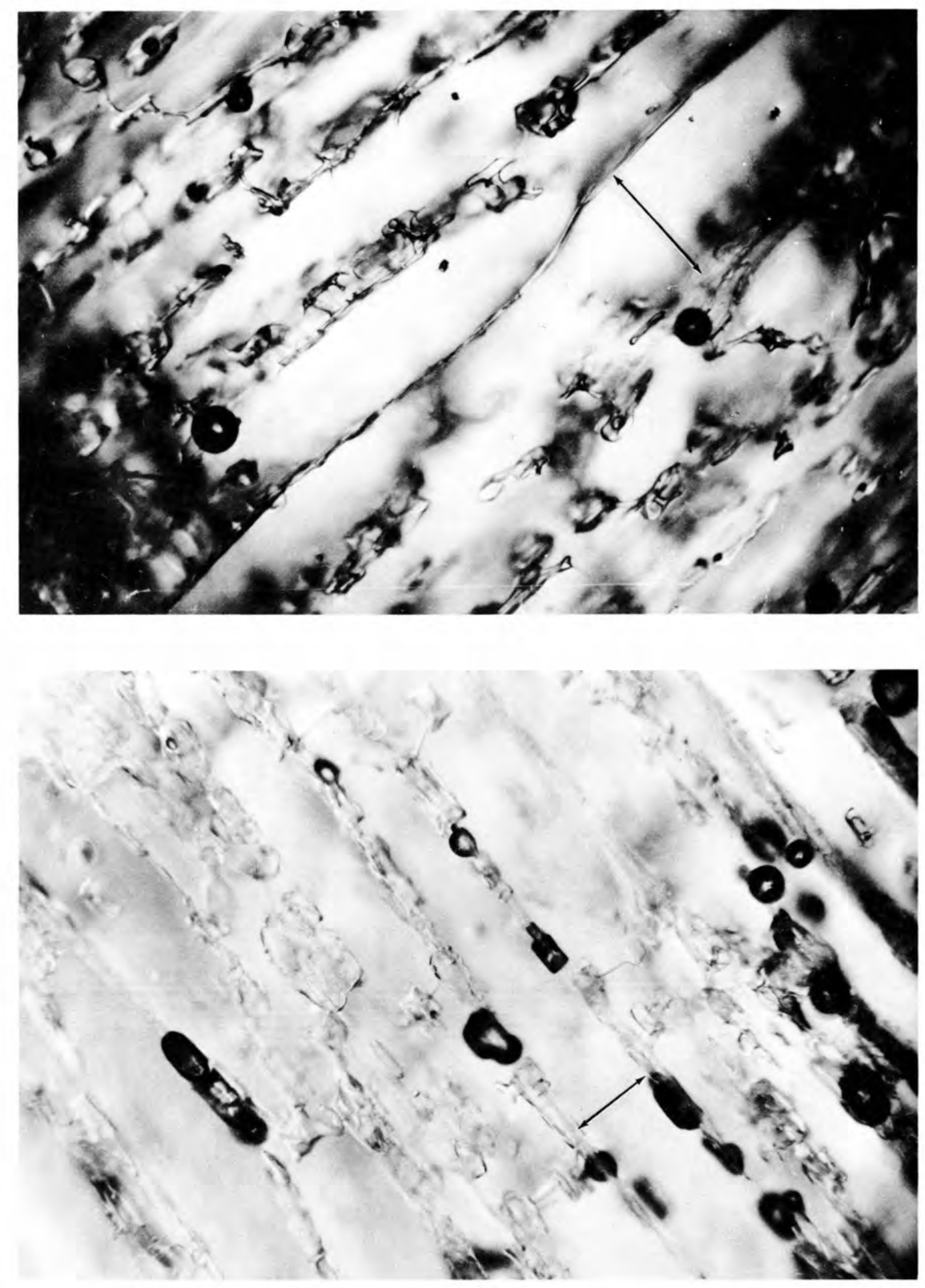

Figure 36. Photographs of two thin sections showing cellular substructure in sea ice. The c-axis direction is in the plane of the section and normal to the platy structure. The spacing between brine layers is approximately $0.6 \mathrm{~mm}$. 
the 11quid. Once lateral diffusion starts it continues until it is terminated by the advancing interface. The time allowed for diffusion is $t$ $=\left(y+y^{+}\right) / v$ where $y^{+}$is a function of interface shape and $v$ is the interface velocity. The distance that the solute can diffuse in this time is $x \approx \sqrt{D t}$. Assuming that $x=a_{0} / 2$ results in

$$
a_{0}=\frac{D}{2 \pi v}\left\{1+\left[1+\frac{16 \pi^{2} v}{D}\left(\frac{0.6 \gamma}{\Delta S G_{0}^{1}}\right)^{1 / 2}\right]^{1 / 2}\right\}
$$

Here $Y$ is the solid/1iquid interfacial energy, $\Delta S$ is the entropy of fusion per unit volume, and $\mathrm{G}^{\prime}{ }_{0}$ is the effective temperature gradient at the tip of the cell. This equation indicates that $a_{0}$ increases with an increase in $\mathrm{C}_{0}$, the bulk composition of the freezing solution ( $G^{\prime}$ o decreases as $C_{0}$ increases), and that the functional form of the relation between $a_{0}$ and $v$ is $a_{0} v=A$ for small values of $v$ and $a_{0} \sqrt{v}=A$ for large values of $v$ (here $A$ is a constant).

The experimental studies (Rohatgi and Adams 1967 a,b) corresponding to this theory are in reasonable agreement (Lofgren and Weeks 1969), indicating that $a_{0}$ increases as a linear function of $C_{0}$ and that $a_{0} v$ $\approx$ A. Lofgren and Weeks also found Bolling and Tiller's predictions to be compatible with their data for experiments where convection was not occurring at the freezing interface. When convection was predominant $a_{0} v v \approx A$ at high values of $v$ while at low values of $v, a_{0}$ became roughly constant. Figure 37 shows the test data; the fitted relation is of the form

$$
\log \left(\bar{a}_{0} v\right)=\log A+n_{1}\left(\log \frac{1}{v}\right)^{2}
$$

where $A$ and $n_{1}$ are constants.

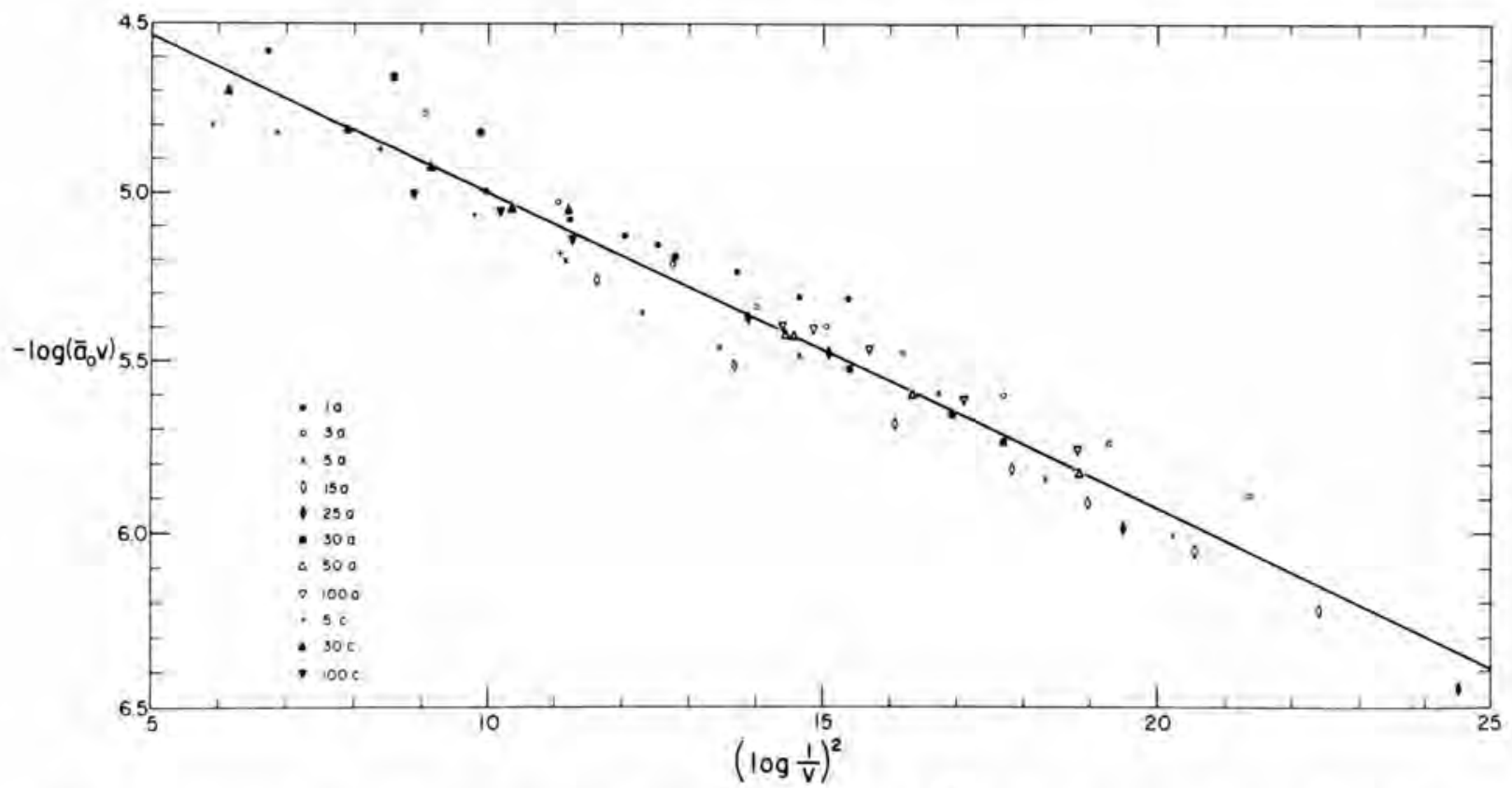

Figure 37. Plot of $-\log \left(a_{0} v\right)$ versus $(\log 1 / v)^{2}$ (Lofgren and Weeks 1969). 
The field observations have in general shown an increase in $a_{0}$ with increasing depth $\mathrm{Z}$ in the ice sheet (Tabata and Ono 1962, Weeks and Hamilton 1962, Paige 1966). However, at Narwhal Island, Alaska, a decrease in $a_{0}$ with increasing $Z$ was noted by Gow and Weeks (1977), and at Eclipse Sound, Baffin Land, a rather complex variation was observed by Nakawo and Sinha (in press). Typical a variations would range from $0.4 \mathrm{~mm}$ near the upper ice surface to $1.0 \mathrm{~mm}$ at $Z=2.0 \mathrm{~m}$ in firstyear sea ice. At a given level in the ice sheet the distribution of $a_{0}$ values is approximately normal about the mean (Weeks and Hamilton 1962), as might be expected from the Central Limit Theorem.

The best available study of the relation between $a_{0}$ and growth velocity in a natural ice cover was undertaken at Eclipse Sound, N.W.T., by Nakawo and Sinha (in press). Curve (a) in Figure 38 shows the calculated growth rate plotted as a function of $\mathrm{Z}$, the vertical position (depth) in the ice sheet. Curve (b) is the mean of the growth rate for an interval of $\pm 50 \mathrm{~mm}$ centered on the $25-\mathrm{mm}$ segment for which it is plotted. There is a pronounced variation in growth rate with $\mathrm{Z}$, with the maxima at about $0.2,0.5$, and $1.0 \mathrm{~m}$ corresponding to the observed cold periods in November, December, and January. Curve (c) presents the salinity profile obtained from an adjacent core. There is clearly a positive correlation between growth rate and salinity. More will be sald about this later. The curve on the right shows the corresponding values of $a_{o}$ and indicates an inverse proportionality with growth rate in agreement with the work of other investigators. Figure 39 shows the same data presented as an $a_{0}$ versus $v$ plot. The dashed line is a least-squares fit of the Bolling and Tiller equation. The agreement is quite reasonable if the two $a_{0}$ values from near the bottom of the ice sheet are disregarded. The ice studied here showed a pronounced c-axis alignment, not only in the horizontal plane but specifically in the

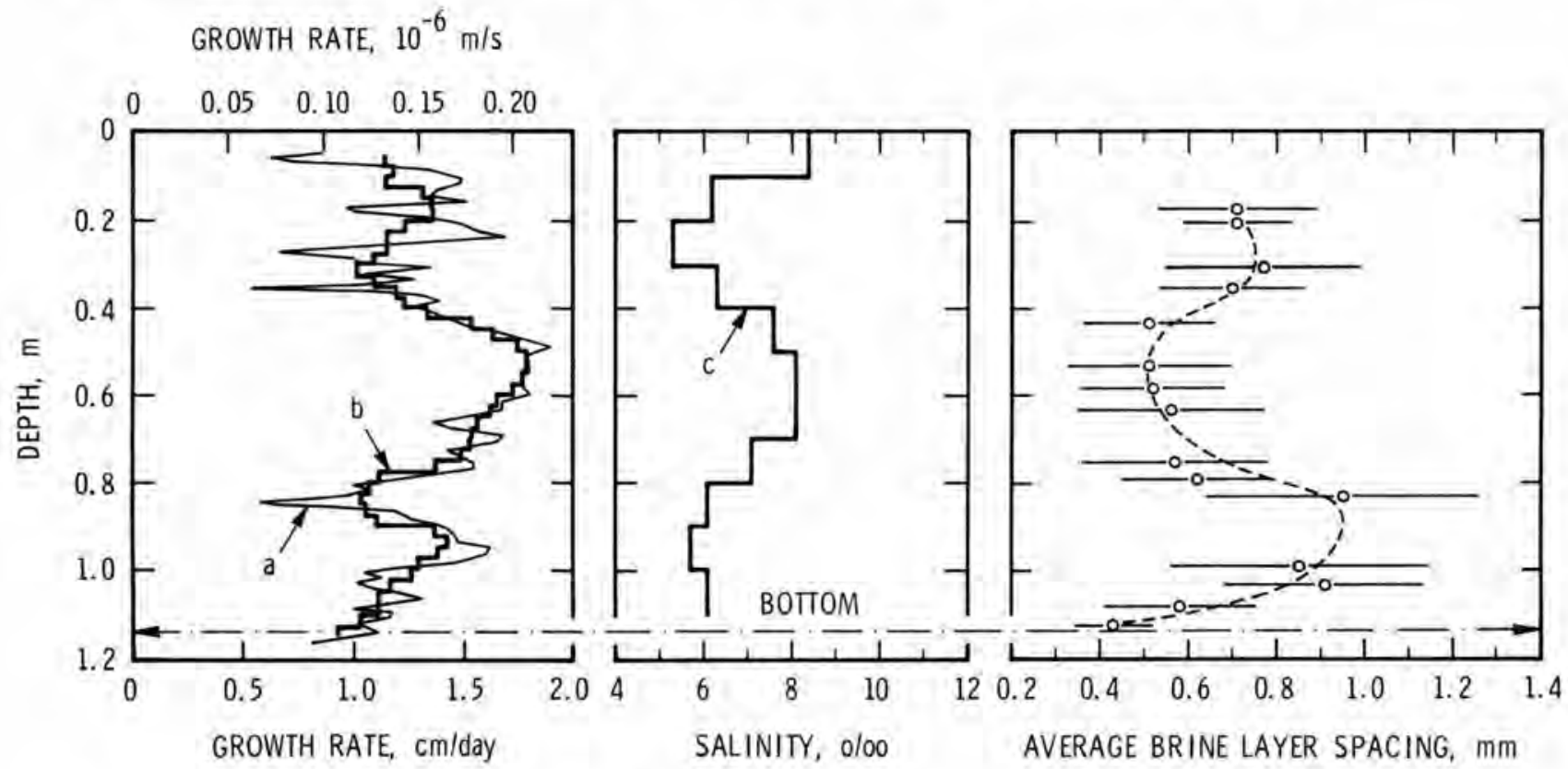

Figure 38. Profiles of growth rate, salinity and brine layer spacing. Curve b represents the mean of calculated growth rate, curve a, for an interval of $\pm 50 \mathrm{~mm}$ for every $25 \mathrm{~mm}$ (Nakawo and Sinha, in press). 
GROWTH RATE, $10^{-6} \mathrm{~m} / \mathrm{s}$

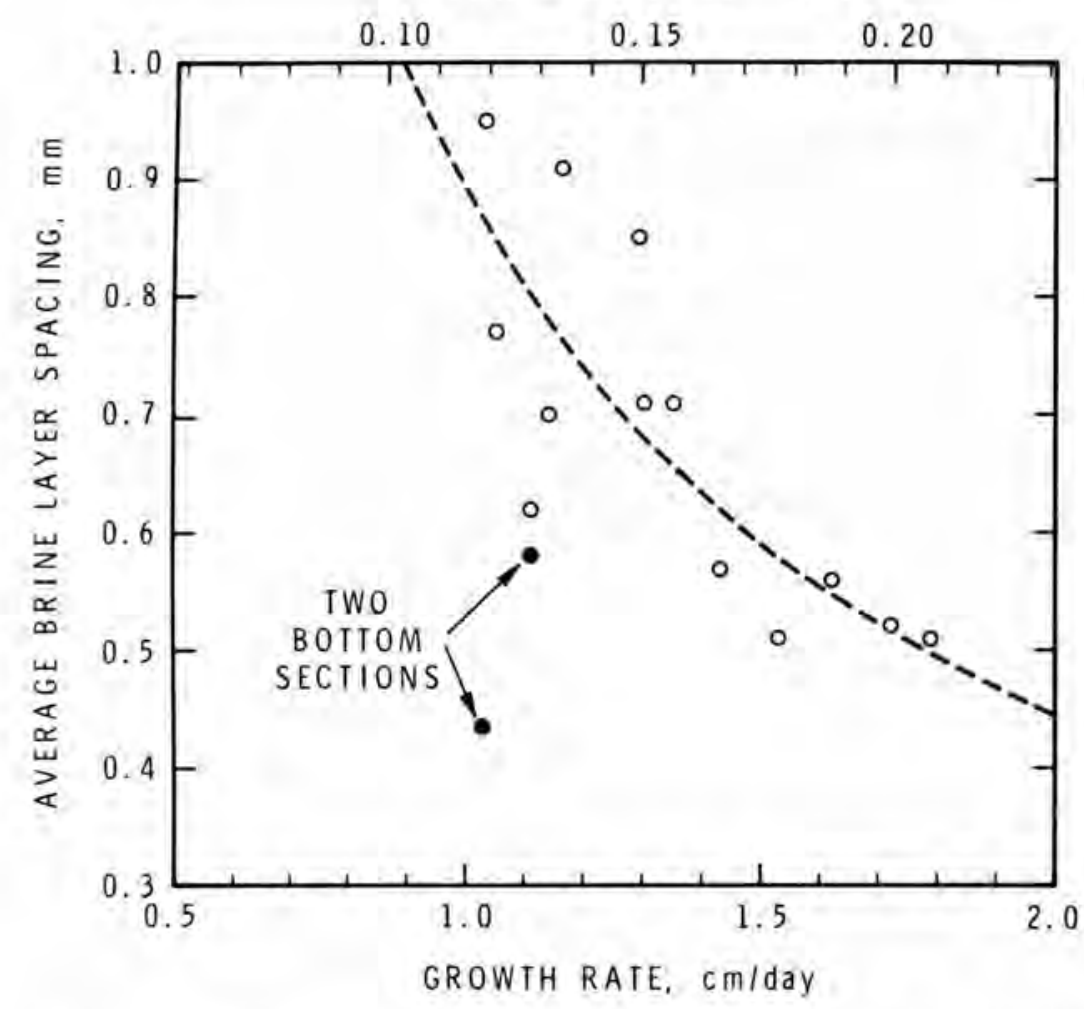

Figure 39. Plot of average brine layer spacing versus corresponding rate of growth from curve b (Fig. 38). Broken line shows a least squares $f i t$, assuming that the spacing is inversely proportional to the growth rate (Nakawo and Sinha, in press).

NE-SW direction in that plane. At a given level in the lce sheet (i.e. at a constant growth velocity) limited data suggest that $a_{o}$ is a maximum value when the c-axis is parallel to the favored direction, and that it systematically decreases when the angle to this direction increases. If this can be verified it both complicates the picture and makes studies of $a_{0}$ variations very interesting indeed.

The hypothesis that slower growth corresponds to larger $a_{o}$ values is quite strongly supported by field observations on very thick sea ice - ice that in all probability grew extremely slowly. Cherepanov (1964) obtained $a_{0}$ values of $1.5 \mathrm{~mm}$ on old sea ice 10 to $12 \mathrm{~m}$ thick observed on drifting station NP-6; Gow (personal communication) obtained $a_{0}$ values of 1 to $1.5 \mathrm{~mm}$ on thick sea 1ce that formed as part of the Koettlitz Ice Tongue, McMurdo Sound, Antarctica; and finally Zotikov et a1. (1980) obtained $a_{0}$ values of $5 \mathrm{~mm}$ from sea ice formed on the base of the 416-m-thick Ross Ice Shelf. Figure 40 shows a vertical thin section from the bottom of this core. The core was oriented so that the plane of the thin section was in general normal to the (0001) planes contalning the brine pockets. The growth velocity at the sample site (Camp J9) was estimated to be $2 \mathrm{~cm} /$ year, far slower than could readily be obtained in the laboratory. 


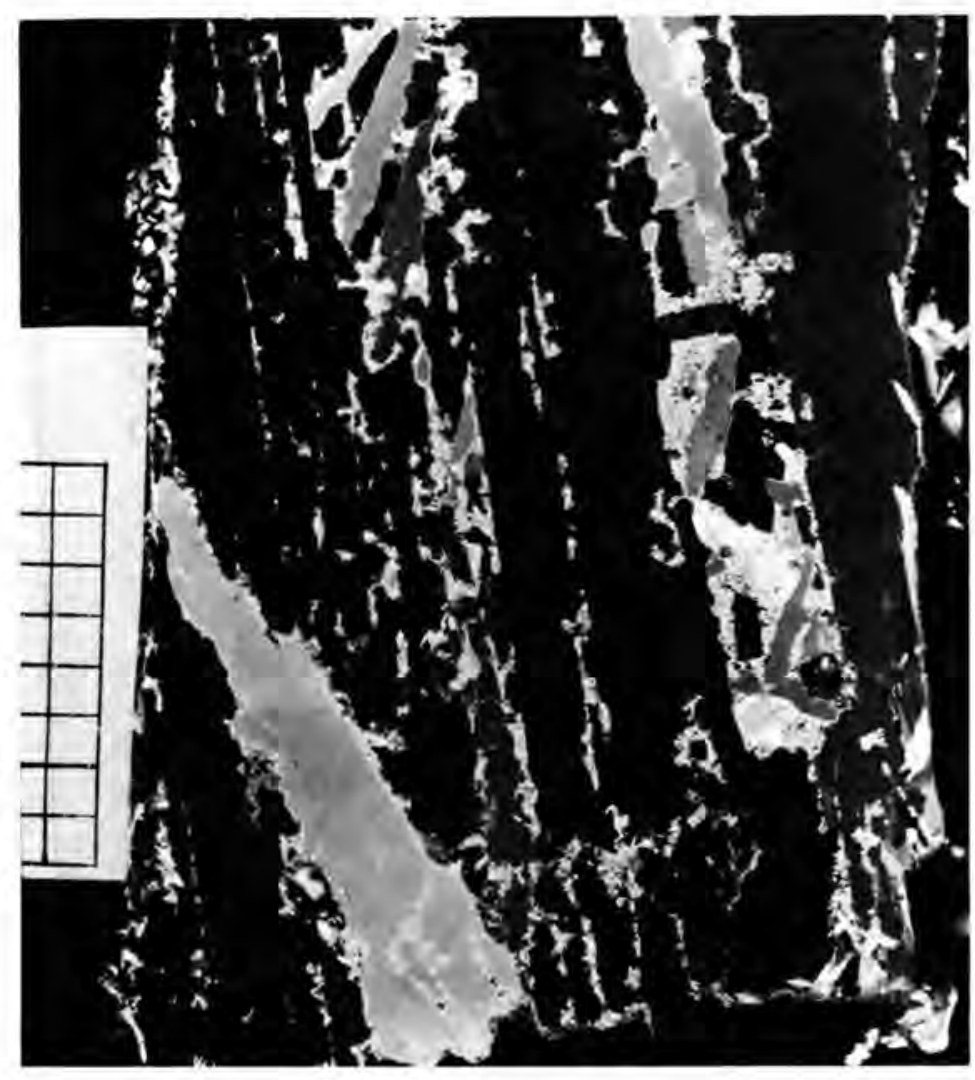

Figure 40. Vertical thin section of sea ice from the lower portion of the core from site $\mathrm{J}-9$, Ross Ice Shelf, Antarctica. The scale is marked in units of $5 \mathrm{~mm}$ (thin section prepared by A.J. Gow). The ice shelf at site J-9 is $416 \mathrm{~m}$ thick.

\section{CONSTITUTIONAL SUPERCOOLING}

Up to the present time we have demonstrated that the ice phase that forms from seawater should be pure ice. If this were strictly true it would be simple to desalinate seawater simply by freezing it. The reason this is not done is that salt becomes entrapped in the ice phase, largely in the form of 11quid inclusions located along the boundaries between the ice plates. To understand why this salt entrapment occurs one must first understand why sea ice grows with a platelet-like structure in the first place. In short, why does sea ice form with a nonplanar, dendritic interface, resulting in brine entrapment, while lake ice forms with a planar interface, resulting in almost complete impurity rejection back into the melt. Both result from the freezing of impure melts; it is only a matter of degree (35\% as compared with $(0.1 \%$ oo). The answer is that sea ice is a classic example of a material that invariably shows pronounced constitutional supercooling.

What is constitutional supercooling (C.S.) and how does it work? Briefly stated, the answer is as follows (Rutter and Chalmers 1953, Tiller et al. 1953, Elbaum 1959). Consider a salt solution freezing as 
the result of one-dimensional cooling. For such a system the distribution coefficient $k_{0}$ (defined as the ratio of the solute content of the solid to the solute content of the liquid when the two phases are at equilibrium) has a value of $10^{-4}$ or less (Harrison and Tiller 1963). Next assume that:

(a) Diffusion in the solid is negligible.

(b) Convection and mixing in the 11quid, due to causes other than diffusion, are negligible (for salt solutions this is a good assumption only if we freeze from the bottom up).

(c) $\mathrm{k}_{\mathrm{o}}$ is constant.

If the origin of the coordinate system is taken to be at the freezing interface, then freezing can be viewed as moving this liquid toward the interface at a velocity $v$ producing a net flow out of a unit volume of $v$ $(\mathrm{dC} / \mathrm{dx}$ ) where $\mathrm{C}$ is the concentration and $\mathrm{x}$ is the distance normal to the interface. At the same time there is a diffusive flow of impurity into the volume element of $D\left(d^{2} \mathrm{C} / \mathrm{dx}^{2}\right)$, where $\mathrm{D}$ is the diffusion coefficient. If a steady state is achieved these two terms must be equal, leading to the differential equation

$$
D \frac{d^{2} C}{d x^{2}}+v \frac{d C}{d x}=0
$$

The boundary conditions are

$$
\begin{aligned}
& C_{L}=C_{0} \text { at } x=\infty \\
& C_{L}=C_{0} / k \text { at } x=0 .
\end{aligned}
$$

Here $C_{L}$ is the concentration in the liquid and $C_{O}$ is the initial concentration in the liquid (the composition far removed from the interface). The steady-state solution is then

$$
\mathrm{C}_{\mathrm{L}}=\mathrm{C}_{\mathrm{a}} \exp (-(\mathrm{vx}) / \mathrm{D})+\mathrm{C}_{\mathrm{o}}
$$

where $C_{a} \equiv C_{i}-C_{o}$ and $C_{i}$ is the composition of the liquid at the interface. This ultimately leads to

$$
C_{L}=C_{0}\left[1+\left(\frac{1-k}{k}\right) \exp \left(-\frac{v}{D} x\right)\right]
$$

indicating that there should be a thin layer of liquid at the interface that shows an exponential decrease in $\mathrm{C}_{\mathrm{L}}$ as one moves away from the interface. This is shown schematically in Figure 41. Because of these compositional variations there are associated changes in the equilibrium freezing temperature of the liquid (Fig. 41) inasmuch as

$$
T_{E}=T_{0}-m C_{L}
$$

where $\mathrm{T}_{\mathrm{E}}$ is the equilibrium freezing temperature, $\mathrm{T}_{0}$ is the melting point of the pure solvent (ice), and $\mathrm{m}$ is the slope of the liquidus line from the phase diagram. This results in

$$
\mathrm{T}_{\mathrm{E}}=\mathrm{T}_{\mathrm{O}}-\mathrm{m} \mathrm{C}_{\mathrm{o}}\left[1+\frac{1-\mathrm{k}}{\mathrm{k}} \exp \left(-\frac{\mathrm{v}}{\mathrm{D}} \mathrm{x}\right)\right] \text {. }
$$

Next, take the actual temperature distribution in the liquid to be given by 


$$
\mathrm{T}=\mathrm{T}_{\mathrm{o}}-\mathrm{m}\left(\frac{\mathrm{C}}{\mathrm{k}}\right)+\mathrm{G}_{\mathrm{L}} \mathrm{X}
$$

where $G_{T}$ is the temperature gradient in the liquid. The first two terms on the right side of this equation give the temperature at the interface. For some compositional profiles and temperature profiles the composition is such that the liquid ahead of the interface become supercooled (see Fig. 42). Hence the term "compositional supercooling."

When the slope of the actual temperature profile is less than the slope of the $\mathrm{T}_{\mathrm{F}}$ curve at the interface, constitutional supercooling occurs. The criterion for this condition is

$$
\frac{\mathrm{G}}{\mathrm{v}}<\frac{\mathrm{mC}}{\mathrm{D}}\left(\frac{1-\mathrm{k}}{\mathrm{k}}\right)
$$

a relation obtained by differentiating eq 10 and 11 with respect to $x$ and evaluating them at $x=0$. This relation has been found to be in good agreement with experimental observations in metal systems (Walton et a1. 1955). When eq 12 is applied to the freezing of both salt solutions and seawater, it is found that even when optimum conditions for the maintenance of a planar interface occur $\left(v \approx 10^{-6} \mathrm{~cm} / \mathrm{s}, G \approx 1.0\right.$ $\mathrm{C} / \mathrm{cm}$, and $\mathrm{k}_{0}=10^{-4}$ ), the ratio $\mathrm{G} / \mathrm{v}=10^{6}$. For this ratio C.S. should exist (Fig. 43) even for salinities representative of typical lake water $(\approx 100 \mathrm{ppm}$ or $0.1 \%$ oo), not to mention the salt contents studied in this paper $(24.7 \%$ oo and greater).

Although the existence of a C.S. layer ahead of the advancing solid/1iquid interface is necessary for cell formation, it is not necessarily sufficient. In addition, there is considerable uncertainty in the preceding calculation as the result of possible variations in $\mathrm{G}$. This difficulty can be avoided by calculating if the growth conditions are such that the steep-walled cell boundary grooves associated with the

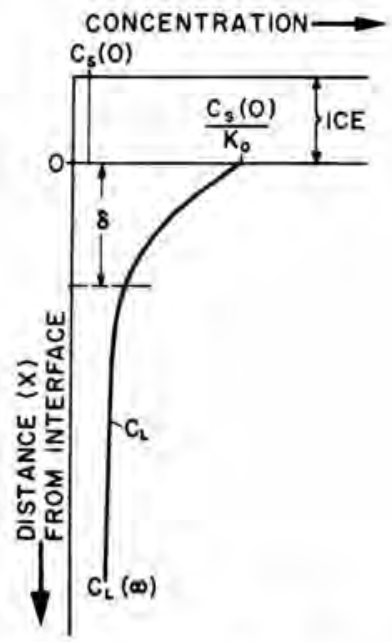

Figure 41. Steady-state distribution of solute in the liquid ahead of an advancing solid/ liquid interface.

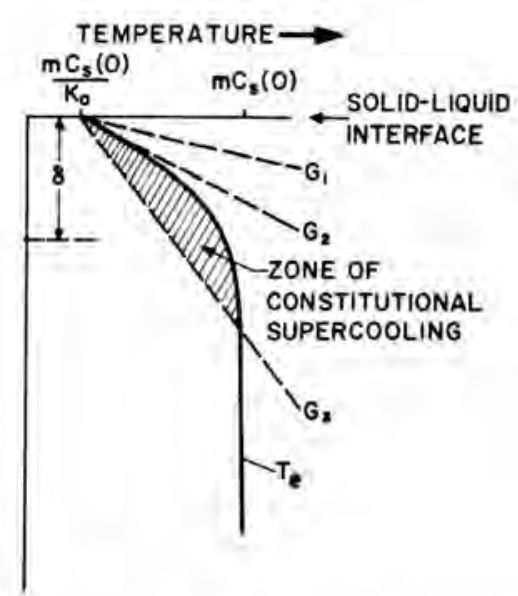

Figure 42, Constitutionally supercooled zone of liquid ahead of an advancing interface. 


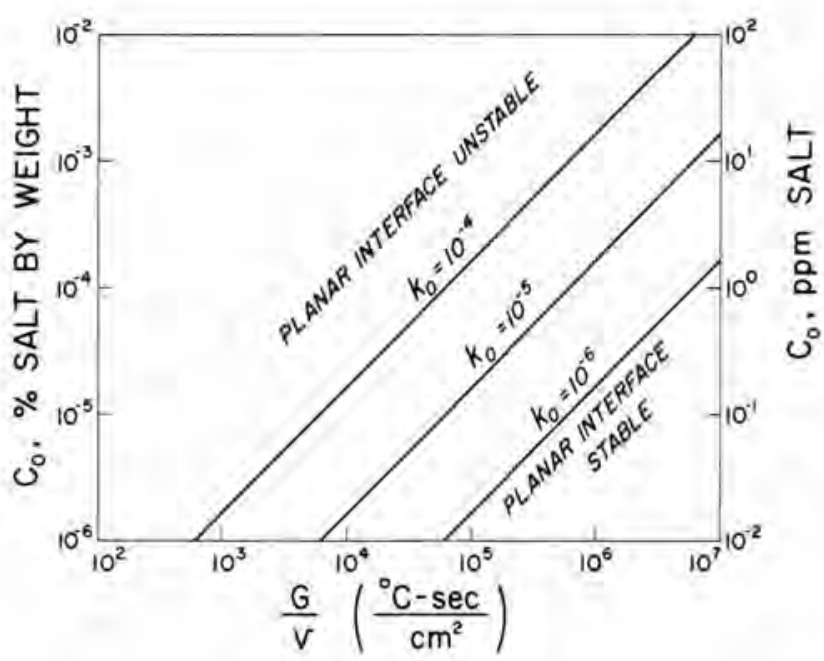

Figure 43. A plot of the boundaries that for different $k_{0}$ values separate growth conditions where a planar interface is stable and where it is unstable. Solute transfer in the liquid is assumed to be by diffusion only.

entrapment of brine along plate boundaries are stable. The stability criterion for the formation of these grooves (Tiller 1962) is

$$
\frac{G_{s}}{v}<\frac{-m C_{i}(1-k)}{D}
$$

where $G_{S}$ is the temperature gradient in the solid and $C_{i}$ is the composition of the liquid at the interface. If transfer in the liquid is by diffusion on $1 y, C_{i}=C_{o} / k$ and eq 13 becomes similar to eq 12 with $G_{S}$ substituted for $G_{L}$. Equation 13 is a more stringent criterion than eq 12 because for ice-solute systems $G_{S} \gg G_{L}$. Now, if

$$
t=\frac{\rho L h^{2}}{2 \kappa \Delta T_{0}}
$$

(Carslaw and Jaeger 1959), where $t=$ time, $\rho=$ density of the solid, $L=$ latent heat of fusion, $\Delta \mathrm{T}=$ difference between the upper surface (i.e. cold plate/ice) temperature of the ice and the freezing temperature of the seawater, $h=$ thickness of the $1 \mathrm{ce}$, and $k=$ thermal conductivity of the ice, then

$$
\mathrm{v}=\frac{\mathrm{dh}}{\mathrm{dt}}=\frac{k \Delta \mathrm{T}_{\mathrm{o}}}{\rho \mathrm{Lh}}
$$

and

$$
G_{s}=\frac{\Delta T_{0}}{h}
$$

Therefore, eq 13 becomes

$$
\frac{\rho L}{k}<\frac{-m C_{o}(1-k)}{D k}
$$

in which $\mathrm{C}_{o}$ is the only parameter under the control of the experimenter. Substitution of numerical values in eq 17 shows that for all seawater and brackish water salinities cell boundary grooves are stable if solute transfer in the liquid is by diffusion only. In actuality, because natural sea ice freezes from the top down, the primary mechanism of solute transfer is free convection (Farhadieh and Tankin 1972, Wakatsuchi 1977), which causes $C_{i}$ to approach $C_{0}$. This explains the 


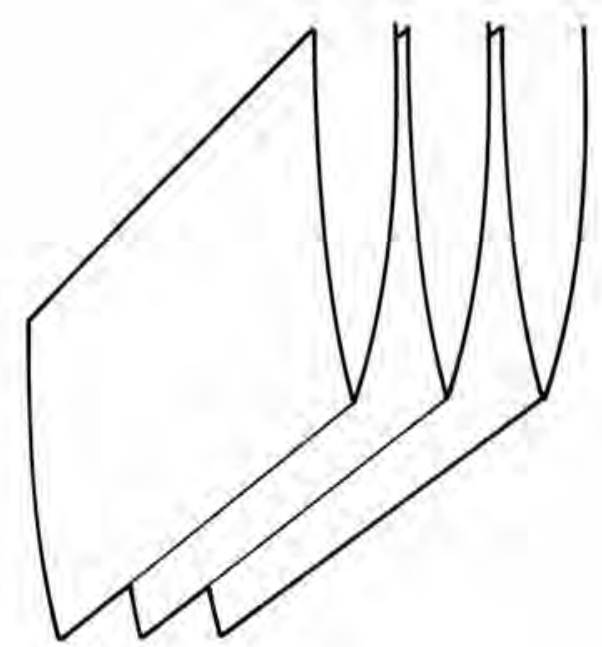

Figure 44. Schematic of knife-edged cells (Harrison and Tiller 1963).

observations of Weeks and Lofgren (1967), who recorded transitions from a non-planar to a planar interface during the freezing of $1 \%$ oo (unstirred) and $3 \%$ oo (stirred) NaCl solutions.

Once C.S. is established and a cel1-boundary groove is stable, the planar ice/water interface breaks down into parallel rows of cellular projections within each grain (Harrison and Tiller 1963). Concentrated brine is accumulated in the grooves that develop between the rows of cells (Fig. 44) and is eventually trapped when adjacent cells develop lateral connections. The entrapped brine leaves a permanent record of the positions of the intercellular grooves. It is the distance between the midpoints of these intercellular grooves that was termed the brine layer spacing $a_{0}$ earlier in this paper.

The relations we have just presented are useful in understanding the general phenomenon of C.S. However, a treatment of C.S. that is truly adequate for sea ice does not as yet exist. It will have to deal explicitly with the fact that the liquid is mixed by free convection and that the appropriate boundary layer is not a diffusive one, but a convective one.

It should also be mentioned that considerable work is currently underway to further develop and apply a more sophisticated interface stability theory, one that is based on the dynamics of the whole system rather than just the thermodynamics of the liquid and is capable of describing the time evolution of a perturbed interface and the accompanying temperature and concentration fields. A review of these developments has been published by Sekerka (1968). The diffusion equations are solved for a planar interface with a sinusoldal perturbation of a small amplitude $\delta$ superimposed upon 1t. The growth velocity of the perturbation $\delta$ is then calculated, a velocity which is a function of the wavelength of the perturbation $\lambda$ and several thermal parameters. If $\delta$ is greater than zero, the instability grows and develops into cells. The stability criterion involves the function $S(\omega)$, which for $k \ll 1$ is 


$$
S(\omega)=-T \Gamma \omega^{2}-G_{\ell}+m_{c}+\left(\frac{k_{s}-k_{\ell}}{k_{s}+k_{\ell}}\right) G_{\ell}-\frac{L v}{k_{s}+k_{\ell}} .
$$

Here $T$ is the melting temperature of a flat interface; $\Gamma=\gamma / \mathrm{L}$ where $\gamma$ is the specific 1iquid/solid interfacial free energy, and $L$ is the latent heat of the solvent per unit volume; $\omega=2 \pi \lambda ; \mathrm{k}_{\mathrm{s}}$ and $\mathrm{k}_{\ell}$ are the thermal conductivities of the solid and liquid; and $G_{S}, G_{\ell}$, and $G_{C}$ are respectively the temperature gradient in the solid at the interface, the temperature gradient in the liquid at the interface, and the concentration gradient in the liquid at the interface. When $s(\omega)<0$ the interface is stable. The principal stabilizing terms are $G_{\ell}$ as the temperature gradient is positive and the first and last terms, which are usually small. Because for ice $k_{s}>k_{\ell}$, the conductivity weighted term in $G_{\ell}$ offsets the stabilizing effect of $G_{\ell}$ alone. The principal term leading to instability is $\mathrm{mG}_{\mathrm{C}}$.

This relation is only strictly applicable to the study of perturbations about the steady-state solution. When expressed as a stability criterion it is usually stated as

$$
|\mathrm{m}| \frac{\mathrm{vC}}{\mathrm{D}}<\frac{2 \mathrm{k}_{\ell} \mathrm{G}_{\ell}}{\mathrm{k}_{\mathrm{s}}+\mathrm{k}_{\ell}}+\frac{\mathrm{Lv}}{\mathrm{k}_{\mathrm{s}}+\mathrm{k}_{\ell}}
$$

where $C_{i}$ is the concentration in the liquid at the interface. Sekerka et al. (1967) have also expressed this relation as

$$
\left[\frac{1}{k}-\left(\frac{1}{k}-1\right) e^{-t / t} \text { rise }\right]|m| \frac{v C o}{D}<\frac{2 k_{\ell} G}{k_{s}+k_{\ell}}+\frac{L V}{k_{s}+k_{\ell}}
$$

where $C_{o}$ is the bulk composition of the freezing solution, $t$ is time and $\mathrm{t}_{\mathrm{rise}}=\mathrm{D} /\left(\mathrm{kv}^{2}\right)$ is a characteristic time of solute buildup at the growing interface. In eq 20 the term in brackets increases monotonically from a value of 1 at $t=0$ to a value of nearly $1 / \mathrm{k} \approx 10^{4}$ for $t=$

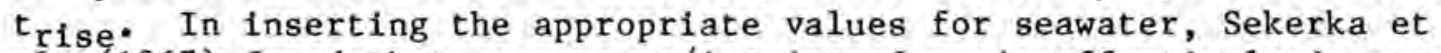
a1. (1967) found that a seawater/ice interface is effectively instantaneously unstable with respect to the time $t_{\text {rise }}$ associated with the buildup of salt at an advancing ice interface.

Modifications of this theory incorporating coupled convective and constitutional interface instabilities are under development. The equations are quite complicated (Coriell et al. 1980) and have not, as yet, been applied to the freezing of seawater.

It should also be mentioned that this theory can be used to estimate $\lambda_{\max }$, which is presumably equivalent to the brine layer spacing $a_{0}$. The resulting equations suggest that

$$
\lambda_{\max } \propto \mathrm{v}^{-1 / 2}
$$

and that for seawater freezing with a velocity of $10^{-5} \mathrm{~cm} / \mathrm{s}, a_{0}$ should have a value of $\approx 0.2 \mathrm{~mm}$. In fact, $a_{0}$ values from $0.5 \mathrm{~mm}$ to $0.95 \mathrm{~mm}$ are encountered, in reasonable agreement. 


\section{VARIATIONS}

\section{Directional C-Axis Alignments}

In the earlier portions of th1s paper we have pointed out that the crystals in the columnar zone have their c-axes oriented in the horizontal plane. We have also shown some early fabric diagrams (Fig. 23) in which the c-axis alignments within the horizontal plane were either random or near-random. It was reasonable to expect that this might be the case as the heat flow was apparently one-dimensional. Also, such random radial c-axis alignments were common in the solidification of metals.

However, in the early 1960's Peyton (1963, 1966, 1968), while examining a $3 \times 3-m$ block of $1.6-m-t h i c k$ sea ice from Barrow, found that the bottom meter exhibited a near-constant c-axis orientation over the entire $9-\mathrm{m}^{2}$ cross section. In his studies of mechanical properties, Peyton utilized this ice to investigate the effect of changes in the orientation of the uniaxial stress to the c-axis direction on the failure strength. At roughly the same time Cherepanov (1964) and Smith (1964) observed that old sea 1ce incorporated in the 1ce islands SP-6 and Arlis II showed near-perfect c-axis alignment over large areas (on SP-6 the entire $80-\mathrm{km}^{2}$ area of the "1sland" showed a similar c-axis alignment). Clearly such alignments were not statistical fluctuations, and specific efforts to study this phenomenon (or these phenomena) were in order.

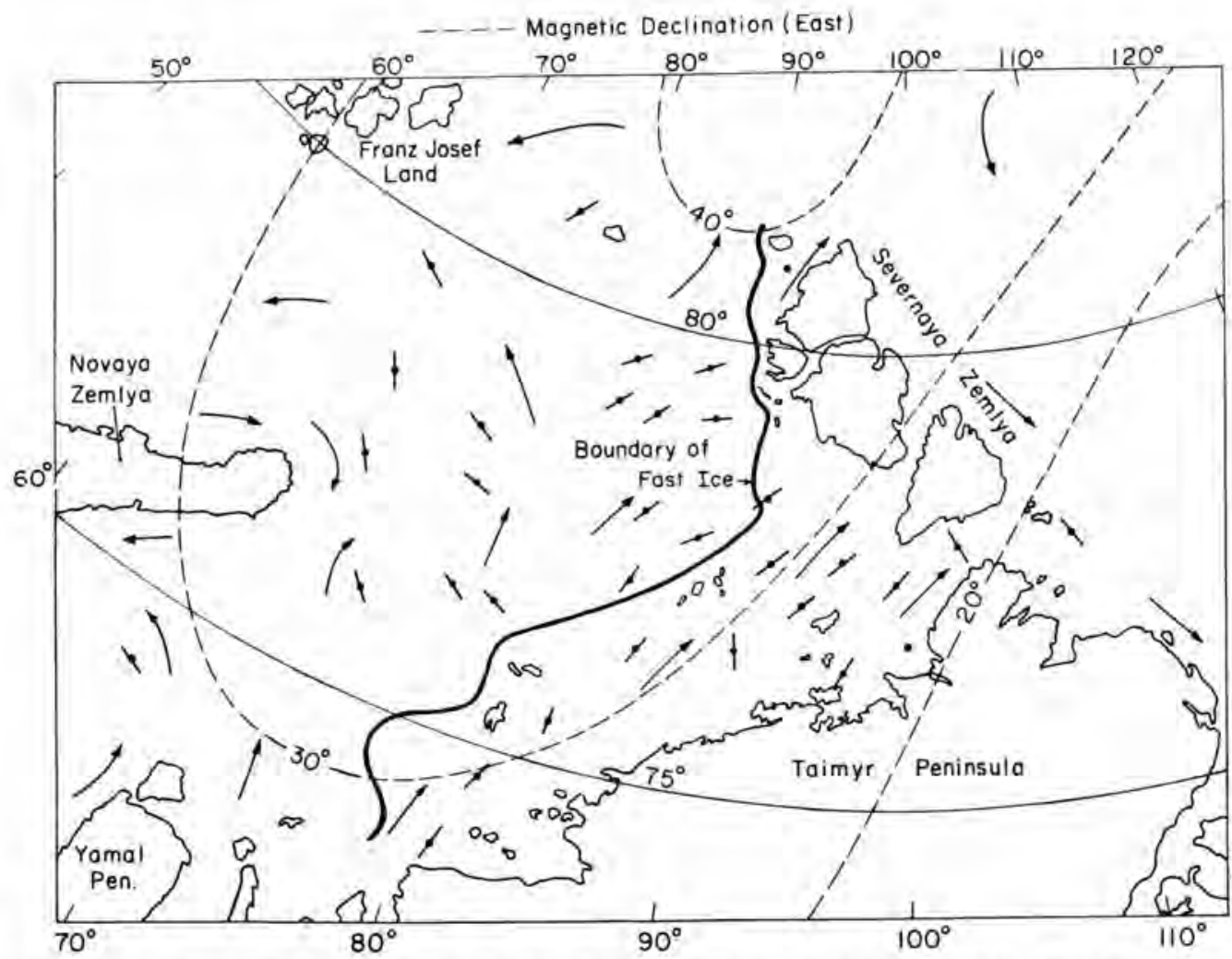

Figure 45. The c-axis orientations as determined by Cherepanov (1971) in the Kara Sea. The arrows indicate the estimated directions of the surface currents obtained from U.S. Navy sources (Weeks and Gow 1978). 
In 1971 a quite remarkable set of c-axis observations (Fig. 45) were published by Cherepanov, who observed nearly constant c-axis alignments over thousands of square kilometers in the Kara Sea. This was followed by studies of the directional dependence of the electrical properties of sea ice from widely separated sites in the Canadian Arctic that also supported the contention that c-axis alignments might well extend over lateral distances of the order of tens of kilometers (Campbell and orange 1974, Kohnen 1976). This work was followed by a series of three papers that provided a detailed look (Fig. 46) at crystal alignments along the coast of arctic Alaska (Gow and Weeks 1977, Weeks and Gow 1978, 1980). Similar studies are now available for the Mackenzie Delta portion of the Beaufort Sea (Langhorne 1980), for the ice surrounding artificial gravel islands that are used for drilling platforms (V1ttoratos 1979), for channels in the Canadian Arctic Islands (Nakawo and Sinha, in press), and for the Antarctic (Serikov 1963, Gow et al. 1981).

The results of these observations indicate the following:

1. In all sea ice formed by unidirectional freezing, c-axis-horizontal orientations develop rapidly after an initial ice skim forms, and they dominate the rest of the ice growth.

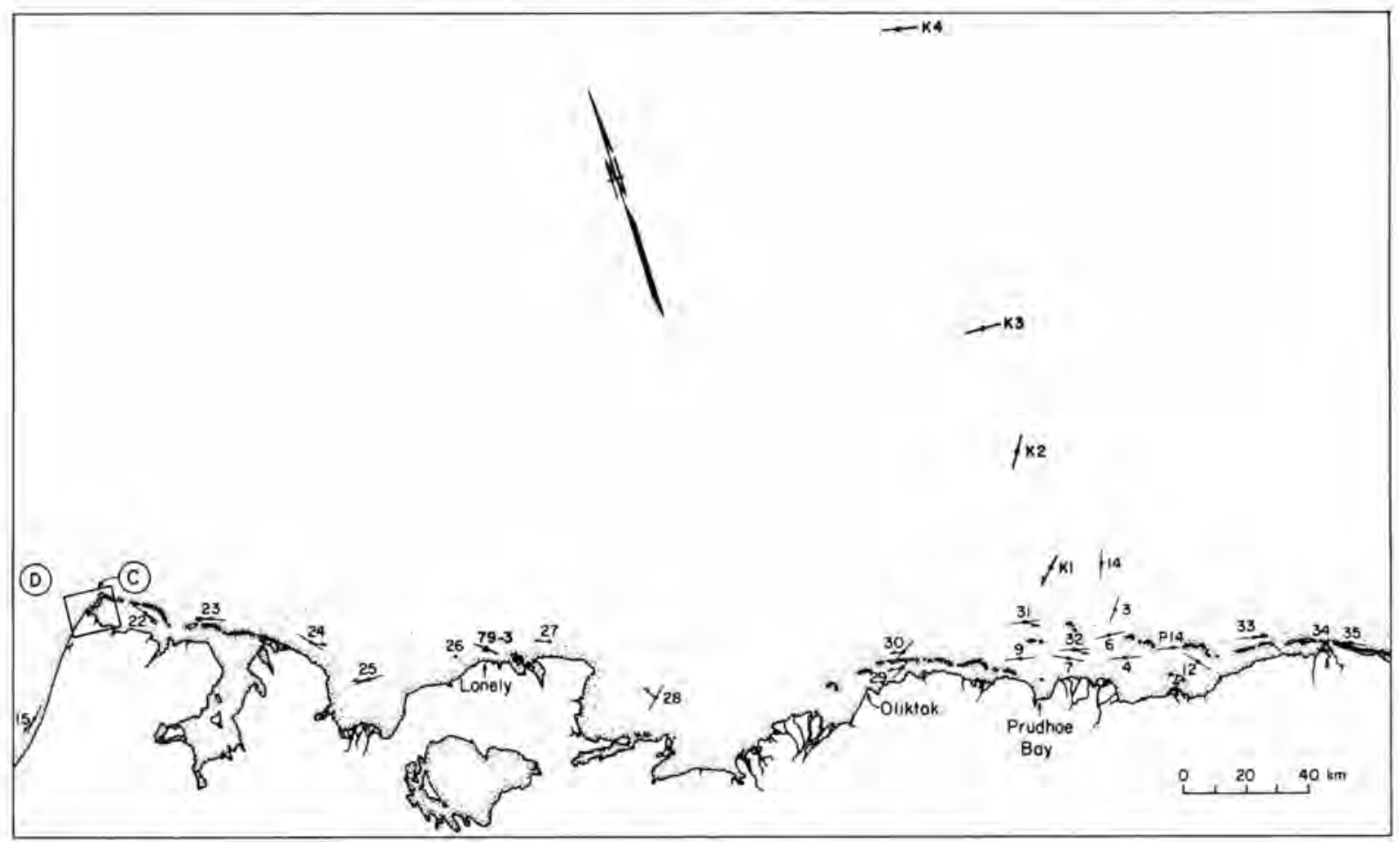

Figure 46. Sample site locations (dots), mean c-axis alignments (bars), and instantaneous current directions (arrows) determined along the coast of the Beaufort Sea, All the samples were collected during 1978 except site 79-3 north of Lonely and the low "out-of-sequence" sites $(3,4,6,7,9,12,14$ and P14) north of Prudhoe Bay, which were collected during 1977 (Weeks and Gow 1978) and are included for comparative purposes. Also shown are four orientations determined by radar (sites K1-K4) by Kovacs and Morey (1980). 
2. In much of the ice examined (95\% of the sample sites along the Alaskan coast; Weeks and Gow 1980) strong c-axis alignments also develop within the horizontal plane. Figure 47 shows a sampling of published fabric diagrams. Standard deviations around the mean are usually $<10^{\circ}$ for ice collected from near the bottom of ice sheets in excess of $1.5 \mathrm{~m}$ thick.

3. Alignments may occasionally be present in ice $20 \mathrm{~cm}$ thick and they invariably become stronger (show less scatter around the mean) with increasing depth in the ice (Fig. 48).

4. Although the mean c-axis direction is not constant at different levels in the 1 ce sheet, the variations are comronly $<20^{\circ}$.

5. Mean c-axis directions at the same site commonly appear to be similar from year to year; however, the "strength" of the alignment may vary.

6. In the nearshore regime the c-axes generally parallel the coast, swing around both natural and artificial islands in a streamlike pattern, and are aligned parallel to the axes (throats) of passes and inlets.

7. Limited information (Fig. 45 and 46) indicates that strong crystal alignments can also develop in areas of pack ice.

There have been several different suggestions concerning the cause of these allgnments. Cherepanov (1971) 1nitlally suggested that some

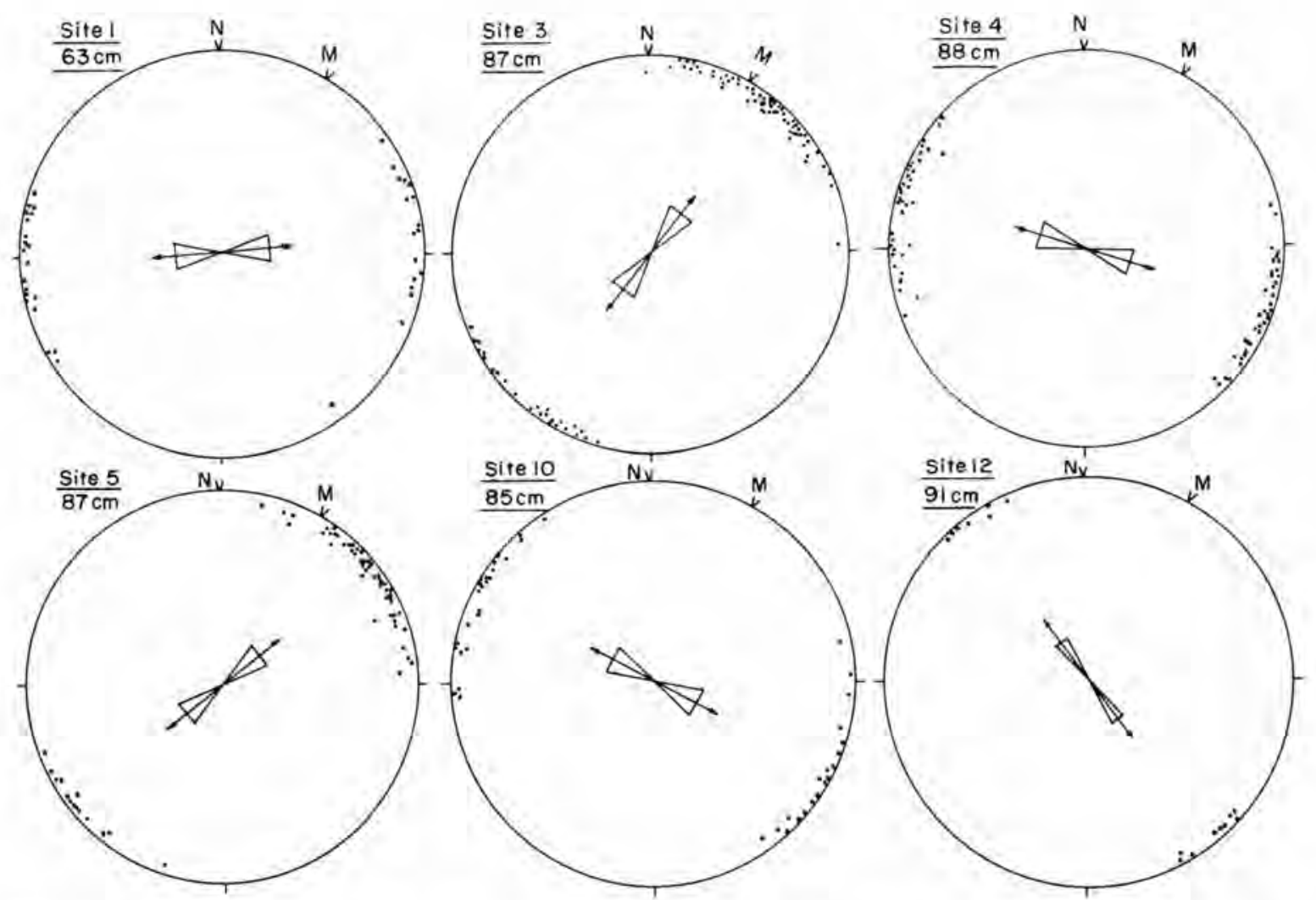

Figure 47. Schmidt net plots of Individual c-axis orientations for six different sampling sites along the coast of the Beaufort Sea (Weeks and Gow 1978). 


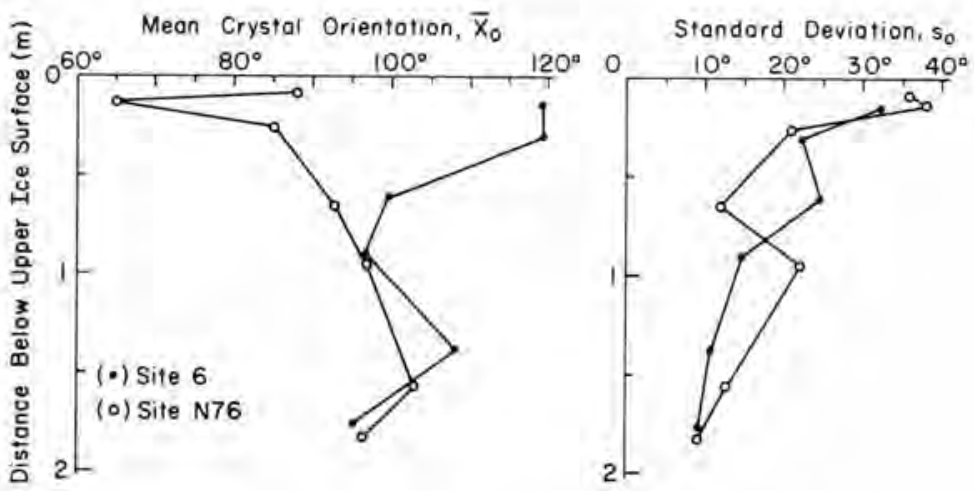

Figure 48 . Mean crystal orientation in the horizontal plane, $\overline{\mathrm{X}}_{\mathrm{O}}$, and the standard deviation, $s_{O}$, as a function of vertical location in the ice sheet. Sites along the coast of the Beaufort Sea (Weeks and Gow 1978).

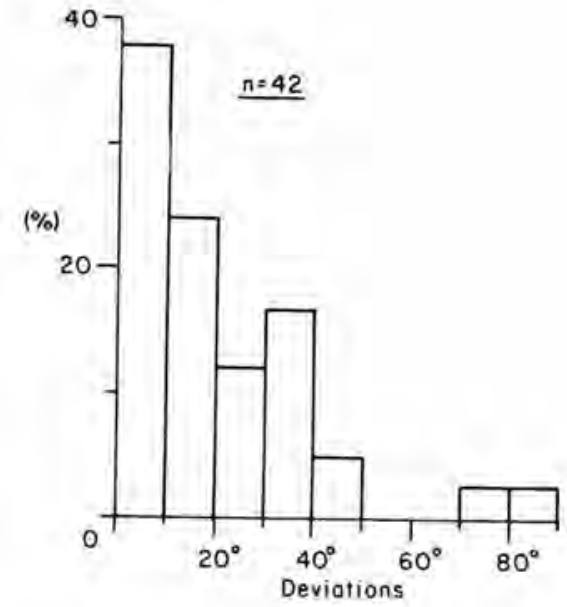

Figure 49. Histogram showing the relative frequency of different deviations between the observed instantaneous current direction and the mean c-axis direction (Weeks and Gow 1980).

interaction between the earth's magnetic field and the electric potential produced at the freezing interface caused them. No information was given concerning how such couplings might work. Weeks and Gow (1978) rejected this suggestion, pointing out that a) there does not appear to be a theoretical reason why the sea ice crystal orientation should be affected by the earth's magnetic field, b) similar alignments have not been observed in experiments on the unidirectional freezing of $\mathrm{NaCl}$ solutions in magnetic fields 80,000 times stronger than the earth's, and c) Cherepanov's own measurements show many examples of crystal alignment that are not in agreement with the direction of the geomagnetic field at the time the samples were collected.

Weeks and Gow then suggest, after examining a variety of alternatives, that the mechanism most 1 ikely to produce the aligned crystals works through the control that the current has on the composition of the 1iquid at the dendrite tips, and thus on the interface temperature. If the current is parallel to the basal ice plates, then a stable boundary layer can build up along a dendrite tip. If, however, the flow is perpendicular to the plates (1.e. parallel to the c-axis), then mixing will be enhanced at each plate tip, and the thickness of the diffusion-1imited solute boundary layer reduced. A reduced boundary layer thickness should give the crystals in this orientation a very slight growth advantage, permitting them to grow sideways at the expense of neighboring crystals. Although approximate calculations suggest that the Weeks and Gow hypothesis is plausible, its mechanisms are far from proved. It is, however, possible to test the suggested correlation between mean current direction and the direction of the c-axis alignment. These observations have been collected by Weeks and Gow $(1978,1980)$ and by Kovacs and Morey (1978). Figure 49 shows the relative frequency of different angular deviations between the observed "instantaneous" current direction determined just under the ice and the mean c-axis direction. The 


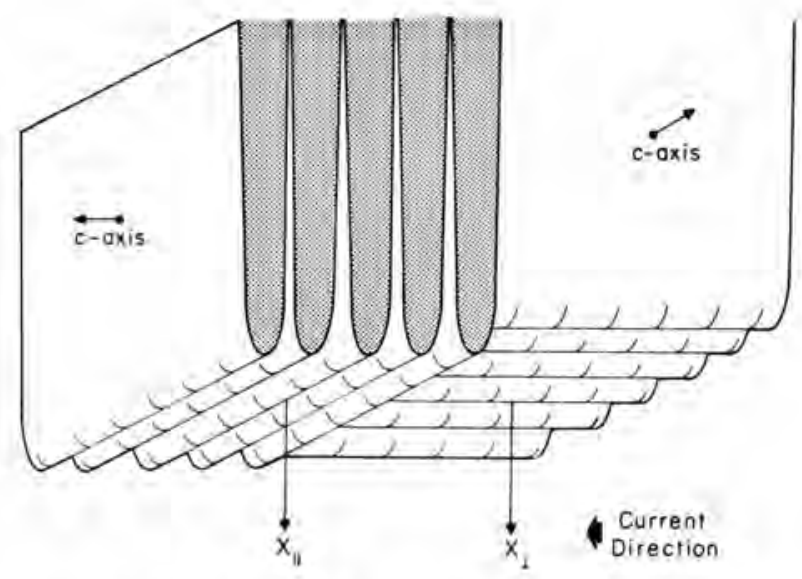

Figure 50. Sketch showing the interface geometry of two crystals of sea ice oriented so that the c-axis in one crystal (the left) is parallel to the current direction, while in the other crystal (the right) the c-axis is oriented norma1 to it (Weeks and Gow 1978).

agreement is quite good, considering that short-term current measurements are known to commonly show significant deviations from the longterm average current direction because of eddies. It should also be noted that Weeks and Gow measured a 7-hour average of the current vector at a site near Barrow and obtained an average value that differed from the mean c-axis alignment by only $4^{\circ}$.

Recently, Stander and Gidney (1980) have proposed a very different model to explain c-axis alignments: that the alignments are the result of stress-activated mechanisms such as grain boundary sliding and dislocation generation. Although details are not given, the authors state that their model is similar to that of Kamb (1959) [see review by Patterson (1973)], which discusses preferred fabrics in metamorphic rocks that are produced by recrystallization in an anisotropic stress field. We feel that it is quite clear that this theory is not applicable to c-axis alignments in sea ice. The fabrics in sea ice are the result of preferred directions of crystal growth from the melt. The orientation seen at each level in the ice is the orientation that was present when the ice layer initially formed. During this initial phase of crystal growth, each crystal is composed of a series of separated platelets that extend downward into the melt (Fig. 50). These platelets do not touch each other until approximately $2.5 \mathrm{~cm}$ above the gross solid/1iquid interface. It is a bit difficult to talk about stress transfer between crystals at a level in the ice where the crystals are not in direct contact. Finally, if the Stander and Gidney hypothesis were correct, there should be evidence that the sea 1ce has recrystallized. There is no indication that this has occurred, with the possible exception of the upper levels of multiyear ice where a completely different process is believed to be at work. Although we would agree that the sea ice substructure is not stable in a thermodynamic sense, it persists because the grain and sub-grain boundaries are locked in by the presence of innumerable brine and air pockets located along them. For 
recrystallization to occur, the grain and sub-grain boundaries would have to break away from these inclusions, a process that creates additional surfaces within each crystal, thereby raising the surface free energy and creating a barrier to recrystallization. For larger stresses this barrier would be overcome and recrystallization would occur. However, a simple petrographic examination clearly shows that in both aligned or unaligned sea ice this has not occurred, as the grain size and substructure remain unchanged.

It should be possible to resolve by experiments many of the questions about the mechanisms that lead to the c-axis alignments. Such work is now underway (Langhorne 1980). If the c-axis direction is a measure of the mean current direction it might at first glance be concluded that alignments would on1y be found in ice that was fast when the alignment developed. Two pieces of information suggest that this is not always true. Cherepanov (1971) found alignments in first-year ice in areas of the Kara Sea that were identified as pack (Fig. 45), and Kovacs and Morey (1980) obtained similar results for offshore areas of the Beaufort Sea (Fig. 46). This can be explained if the current velocity at the ice/water interface remains reasonably constant relative to the ice long enough for an alignment to develop. As both these sets of observations were made in the later winter when the ice pack in the Beaufort and Kara Seas was extremely tight, this would appear to be a plausible explanation.

Present observations suggest that very significant portions of the world's fast ice show strong c-axis alignments. The percentage of the pack that shows such alignments is unknown. We would guess that pack ice that forms at locations such as the Bering Sea, Baffin Bay, and much of the Antarctic, where the ice is highly mobile and the floes are free to rotate, would show random alignments in the horizontal plane. Where the pack ice becomes very tight during the ice growth season, restricting the possible rotation of floes, then aligned ice may be the dominant form. Systematic field observations should be made to resolve these questions.

\section{Frazil Ice}

Given an initial ice skim formed from individual discs or particles of ice, the ice cover was believed to usually take on the characteristic congelation or columnar ice structures so frequently observed. Frazil ice was thought to account for only the top $5 \%$ or so of the ice cover (e.g. Martin 1979), with congelation or columnar ice providing the vast majority ( $95 \%$ by volume) of most sea ice. This condition has been found in fast ice regimes in the Arctic Basin (Weeks and Gow 1978, 1980), in the Labrador Sea (Weeks and Lee 1958), and more recently in the fast ice region of Antarctica near McMurdo sound (Gow et a1. 1981).

In ice edge regions and in large polynyas where substantial open water can be maintained, Martin and others have described rapid frazil ice generation that could concelvably result in frazil ice thicknesses of up to a meter prior to the development of a columnar congelation structure.

Work in the Wedde11 Sea has, however, indicated even greater potential for frazil growth. A serious revision of ideas concerning the 


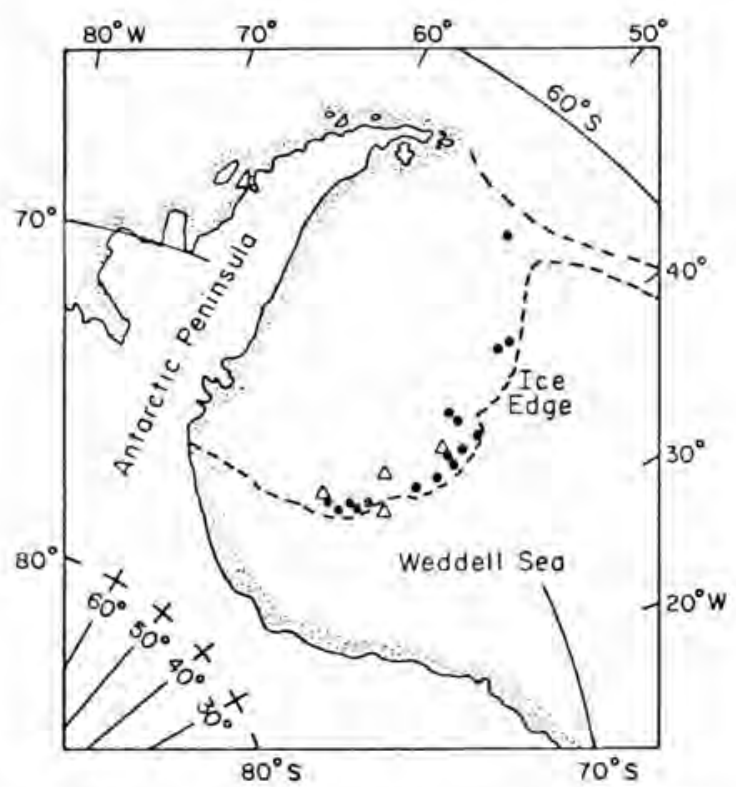

Figure 51. Site locations for sea ice core sampling from the USCGS Polar Sea in Feb-March 1980.

importance and distribution of frazil ice, at least for the Antarctic pack ice regions, appears to be in order. If frazil ice is more widespread than once believed, mechanisms for ice-ocean interaction must also be modifled. We first give the evidence for these new frazil structures and then discuss some preliminary 1deas for the 1ce-ocean mechanisms leading to the formation of the observed structures.

Figure 51 shows the location of sites in the Weddell Sea sampled during February-March 1980. Complete cores were obtalned from 66 individual floes ( 13 multiyear floes), with a total of $138 \mathrm{~m}$ of core being retrieved. Salinity and fluorescence measurements were also taken at $10-\mathrm{cm}$ intervals over the entire length of core. The crystal structure was defined in two ways. The first was by preparing two to six horizontal thin sections per core (depending on its length). This method gave only point samples of the structure, albelt at several locations along the core length. To verify the frazil percentages initially estimated from these point samples, vertical thick ( 2 to $3 \mathrm{~mm}$ ) sections were then prepared of the 1 ce. When these sections were viewed between crossed polaroids, the differences between relatively fine-grained equiaxed crystals (frazil) or coarse-gralned columnar crystals (congelation ice) could easily be distinguished. These changes were then sketched schematically (cartooned) as a function of the distance along the core.

We will now briefly describe the structure of several representative floes (afer Gow et al. 1981).

Floe 42-A-1 (see Fig. 52). This is an example of thick (4.8 m) multiyear ice with a maximum salinity of $9 \%$ and an average salinity of $3.5 \%$. The floe was composed of $4 \%$ snow ice (designated $S$ in the vertical structure profile), $61 \%$ frazil ice (designated $\mathrm{F}$ ) and $35 \%$ congelation 1 ce (designated $\mathrm{C}$ ). The congelation 1 ce component is characterized by a very strong alignment of the crysta1lographic c-axes as indicated by the arrows in the photographs of thin 


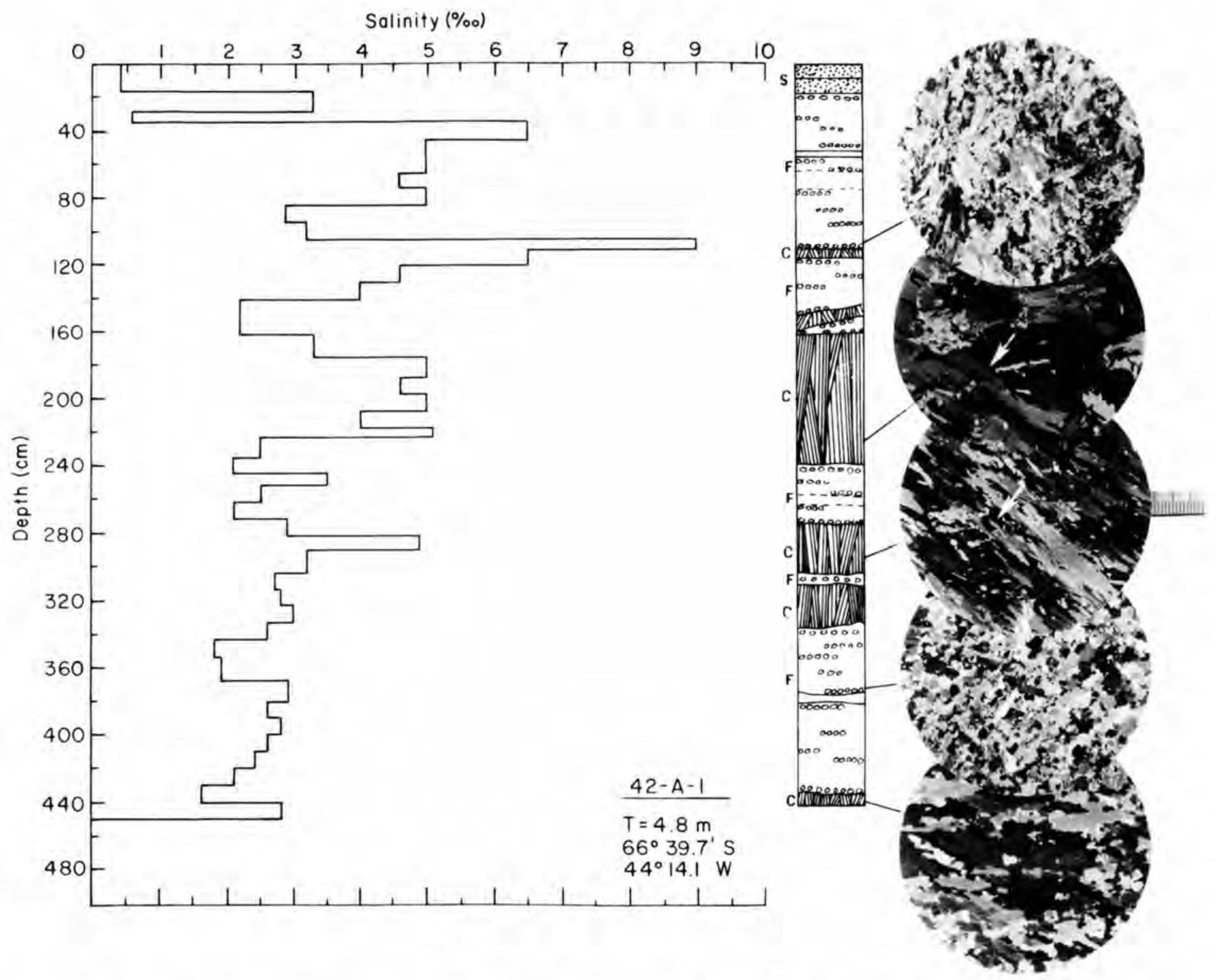

Figure 52. Salinity, structure and thin section photos from Floe 42-A-1. The key to the ice structure diagram is as follows: $\mathrm{S}=$ snow ice, $\mathrm{F}=$ frazil, $\mathrm{C}=$ congelation ice. 


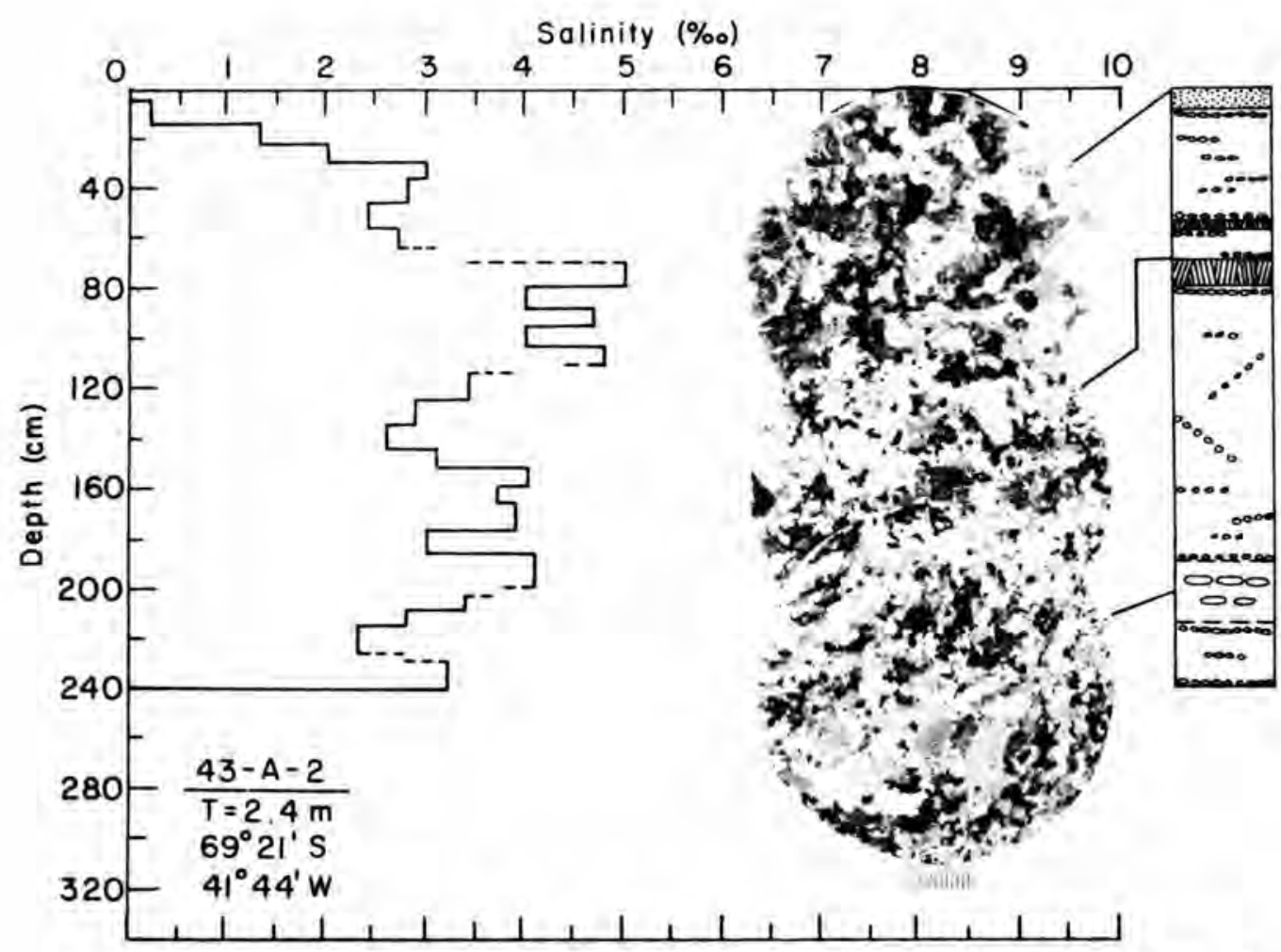

Figure 53. Salinity, structure and thin section photos from Floe 43-A-2. A key to the ice structure diagram is given in Figure 52 .

sections from $2.24 \mathrm{~m}$ and $2.93 \mathrm{~m}$. In this and other profiles presented here the much smaller crystals and the absence of brine lamellae-ice plate structure serve to distinguish frazil ice from the generally fibrous-textured congelation ice.

Floe 43-A-2 (see Fig. 53). The exact age and origin of this 2.4m-thick floe are difficult to assess. However, a maximum salinity of $5 \%$ and an average value of about $3 \%$ would indicate that this particular floe is multiyear. It is composed of $90 \%$ frazil ice of variable grain size with congelation ice composing 1ess than $6 \%$ of the floe thickness.

Floe 44-G-3 (see Fig. 54). This floe was located in a region of recently disintegrated sheet ice that produced floes measuring approximately $30 \mathrm{~m}$ in length. Identifled as first-year ice with an average salinity of $5 \%$ it is composed almost entirely of congelation ice ( $95 \%)$ with crystals showing well developed brine lamellae-ice plate structure and a very strong alingment of the crystallographic c-axes. The constancy of this alignment (indicated by arrows) would suggest either a fast ice origin or growth of ice in place in a relatively immobilized part of the winter pack.

Floe 49-G-2 (see Fig. 55). This first-year floe was composed mainly of congelation ice $(72 \%)$ but had some frazil ice (22\%) incorporated in a zone at $0.26-0.70 \mathrm{~m}$ depth. The thin section from $0.70 \mathrm{~m}$ exhibits a texture that is transitional between fine-grained frazil and coarser-grained congelation ice. The bottom section is composed of ran- 

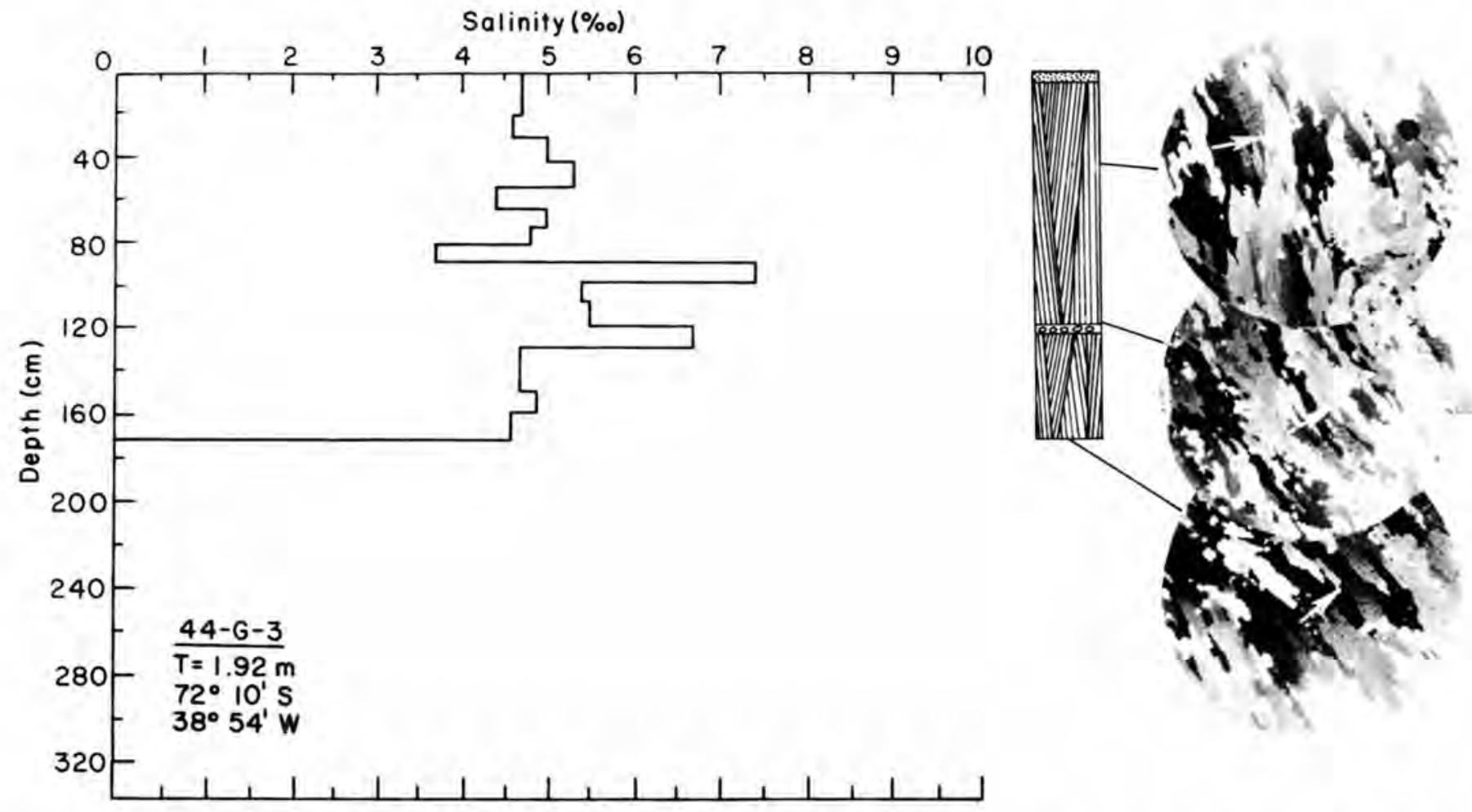

Figure 54. Salinity, structure and thin section photos from Floe 44-G-3. A key to the ice structure diagram is given in Figure 52 . 


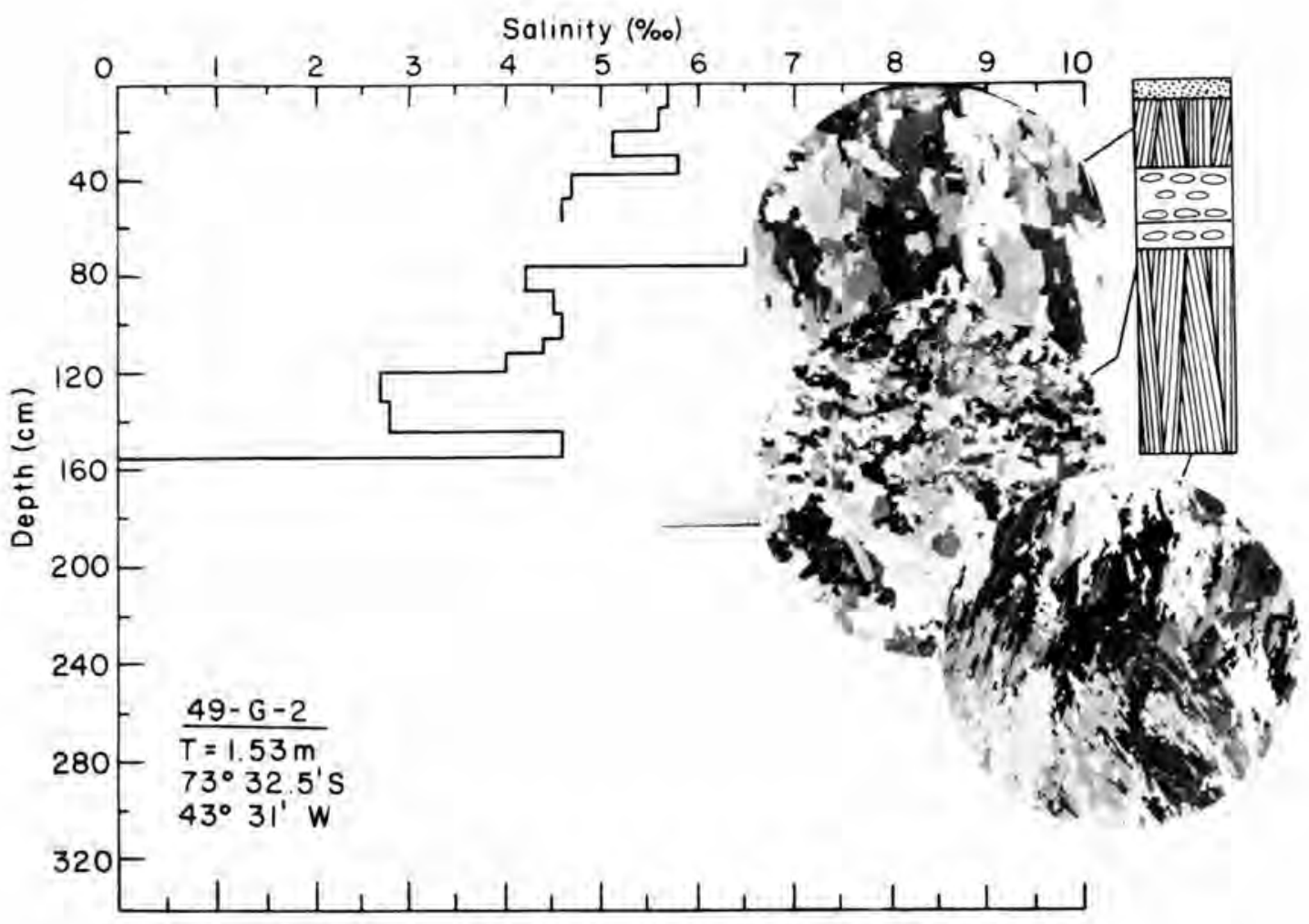

Figure 55. Salinity, structure and thin section photos from Floe 49-G-2. The key to the structure diagram is given in Figure 52 .

domly aligned fibrous-textured crystals. The average salinity of the floe is $4.7 \%$ oo.

Floe 61-G-2 (see Fig. 56). This is a multiyear floe with an average salinity of $3.5 \% \mathrm{oo}^{\circ}$ The upper meter of ice is mostly composed of congelation ice with moderately aligned crystals, underlain by $2.9 \mathrm{~m}$ of frazil ice of highly variable grain size. Crystals of frazil range in size from 0.4 to $4 \mathrm{~mm}$ and are usually arranged in layers that would suggest several separate episodes of frazil generation.

It was found that of the total length of multiyear core $(35.85 \mathrm{~m}$ samples), about $75 \%$ was fraz11 and only $19 \%$ was congelation, with the remainder $(6 \%)$ being fine-grained but of indeterminate origin. For the first-year ice $(85.7 \mathrm{~m})$ the frazil congelation percentages were $46 \%$ and $47 \%$ respectively, with $7 \%$ of indeterminate structure. These characteristics are shown in Figure 57, where congelation ice percentage is plotted as a function of ice thickness. The data indicate a slightly higher percentage of congelation ice for ice less than $1 \mathrm{~m}$ thick and roughly equal (but highly varied) percentages for 1 ce between 1 and $2 \mathrm{~m}$ thick. However, no floe exceeding $2 \mathrm{~m}$ in thickness is composed of more than $50 \%$ congelation ice. Therefore the thickest ice in the Weddell Sea $(>2 \mathrm{~m})$ is composed primarily of ice with frazil structure.

One's first reaction in looking at these statistics is that it is the almost complete reversal of what would be presumed based on the commonly held assumptions about the growth of sea ice. Instead of the 


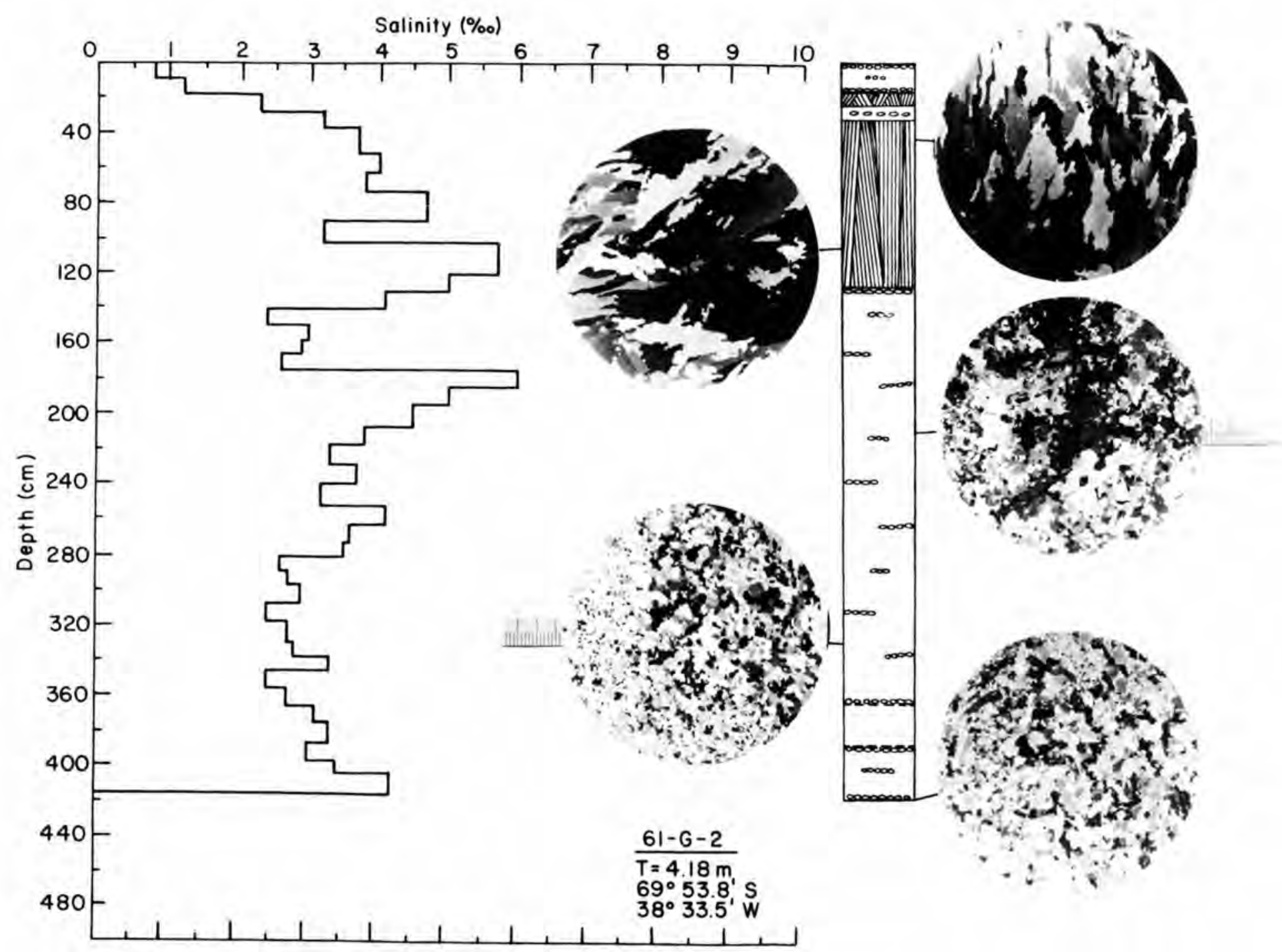

Figure 56. Salinity, structure and thin section photos from selected depths for Floe 61-G-2. A key to the ice structure diagram is given in Figure 52. 


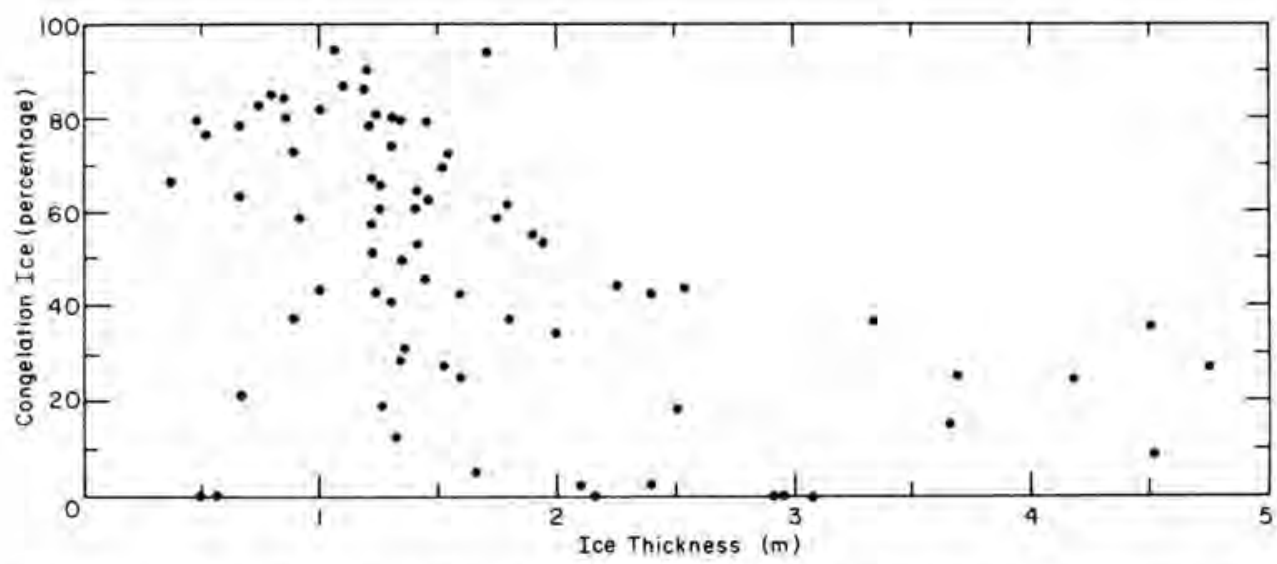

Figure 57. Congelation ice (percentage) vs ice thickness for all cores obtained in the Weddell Sea.

thinnest ice $(<1 \mathrm{~m})$ being primarily composed of frazil, it is the thickest ice that comonly contains the largest percentage of frazil.

Such frazil ice as occurs in the Weddell sea pack ice is particularly interesting in that its origin and properties are very different in most all respects from the congelation ice upon which most work has been concentrated. This will be seen quite clearly later in this paper when the effect of ice structure on ice properties is discussed. We will now discuss some possible mechanisms for the generation of oceanic frazil ice.

\section{Mechanisms of Frazil Generation in Oceans}

To generate fine-grained frazil ice during freezing from the melt, the observations from rivers, lakes and oceans suggest one necessary condition, namely turbulence. Frazil generation originates as a result of the large-scale ( $>\mathrm{cm}$ scale) mixing of waters and during its development has been likened to a blizzard (an upside-down one) in the water column. However, some basic differences exist in the momentum and heat flow characteristics of rivers and oceans. In rivers the turbulence is nearly always purely mechanically derived from accelerations in the flow by increasing discharge, varying bed geometry (falls and rapids) or the like. Although the literature is not clear on this point, it appears that a threshold velocity of $0.6 \mathrm{~m} / \mathrm{s}$ is necessary under freezing conditions to allow the onset of frazil formation (Ashton, pers. comm.). The constraint is primarily a mechanical one; while frazil generation requires efficient heat transfer between the cold atmosphere and the water, sufficient mechanical shear is necessary to mix the flow and carry the newly formed ice crystals rapidly away before a complete skim of ice can form. In the ocean, however, these mechanical influences are much less pronounced. Four possible sources of turbulence that can affect freezing conditions leading to frazil formation in the ocean are as follows.

(1) Wind- and wave-induced turbulence. As we previously described, this effect can only account for 11 mited frazil production in wide leads and polynyas and near ice edges due to the extreme damping of these effects when a significant percentage of the sea surface is covered by ice. 
(2) Water which is at a depressed freezing point due to pressure at depth and is suddenly adiabatically brought to the surface (Foldvik and Kvinge 1974). Water of this type typically exists under large ice shelves, and the ascent occurs near the front. If this were the only mechanism producing frazil one might expect the percentage of frazil in floes to increase as ice shelves are approached. Correlations of this type have not as yet been observed. As well, the amount of ice production available by this mechanism (since possible freezing point depressions are only a few tenths of a degree) does not seen compatible with the large amount of frazil ice observed ( $\approx 50 \%$ of the observed ice).

(3) Contact between two water masses of significantly different salinity but both at their freezing point. We will discuss this mechanism further in relation to multiyear ice structure since this type of ice formation occurs in under-ice melt ponds (of primarily fresh water) which drain into the ocean from melting surface ice and are stratified due to density differences. Freezing then occurs due to double diffusion (transfer of heat at a faster rate than salt) from the cold $\left(<-1^{\circ} \mathrm{C}\right)$ seawater to the fresh water on top of it (Martin 1974). This process could also occur associated with the drainage of river or glacier water into seawater that is colder than the fresh water freezing point. Again these effects are undoubtedly local in the regions they affect and it is difficult to see how they could account for the observed ice conditions in the Weddell Sea.

A process of sufficient generality that occurs over a broad enough region to account for much of the observed frazil production is:

(4) thermohaline convection initiated by surface cooling and freezing. Figure 58 indicates some differences between Arctic and Antarctic water column structure that indicate more potential for frazil ice generation in the Antarctic. In general, the mixed layer in the Antarctic is both considerably deeper than in the Arctic and is, also, totally at its local freezing point. Martin (1974), in a study of ice stalactites, indicated that the heat loss of a descending brine plume could be, when the water was at its freezing point, as much at $50 \%$ accounted for by frazil production. As the temperature of the brine plume is closer to the freezing point of the surrounding water, there is less tendency for stalactite forms to occur, implying all the heat loss could be taken out by frazil ice formation. We note, however, that in

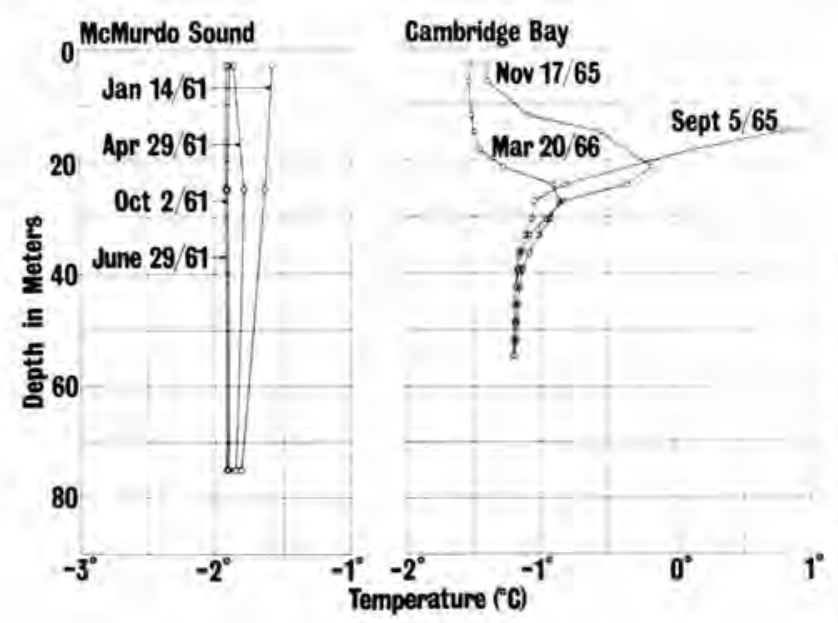

Figure 58. Profiles of seasonal changes of temperature with depth in the water column typical of the Antarctic (McMurdo Sound) and the Arctic (Cambridge Bay). The Antarctic near-surface waters remain closer to the freezing point at greater depths than do the Arctic waters (Lewis and Lake 1971). 
Martin's study the frazil crystals appeared to be entrained downward with the descending plume. More likely is that frazil crystals are generated in waters adjacent to the descending plume for two reasons. One effect is buoyancy. That is, the energy necessary to force an ice crystal downward with a density defect approaching $10 \%$ compared to surrounding waters is considerable and much larger than the relative density differences that can lead to water column overturning. Secondly, if the waters of a descending cold brine plume are entraining surrounding waters then the mixture will also be in equilibrium at its freezing point. That is, there should not be any ice production, merely a more saline mixture at a temperature intermediate between the cold brine plume and the surrounding water. A simpler mechanism that preserves the buoyant characteristic of the ice crystals and still allows ice production at depth is to maintain the integrity of the descending brine plume and allow it to gain heat at a different rate than salt. This is known as double diffusion and has been observed in several other contexts in the ocean (e.g. Turner 1973). In this mechanism, the descending brine plume gains heat but diffuses salt at a much lower rate, thereby cooling adjacent waters to temperatures below their freezing point (at their given salinity). An ice crystal is then nucleated and rises due to buoyancy, and the remalning water also descends at a new equilibrium freezing temperature and salinity. While the process appears to be diffusion-limited by the ability to extract heat from the brine plume, the convection is continuously strengthened by the ice formation so the effect is a convection cascade which should quite effectively use the heat sink of the brine plume and establish a circulation boosting the convective process. Based on the observed structures (Fig. 52-56), we also see that frazil forms under thicker 1ce. Advecting surface-generated frazil downward underneath this thicker ice is again a problem of overcoming strong upward buoyancy forces. A generation mechanism whereby 1ce crystals are formed at depth due to thermohaline convection is not constrained in this way. Descending brine plumes in leads and polynyas will set up a local circulation that could bring the ascending arm (containing some of the frazi1) underneath adjoining 1ce. As well, substantial shear usually exists between the ice and the water column due to wind action on the 1 ce, so motion of the ice cover would tend to bring a different plece (possibly thicker) into position over the ascending frazil crystals, if they are formed at depths greater than a few meters.

None of the above-mentioned mechanisms have, as yet, been detailed to any substantial degree. Whether they do indeed account for the observed frazil ice structures and whether frazil structures are more widespread than previously thought or are only an anomaly of the Weddell region remain subjects for future study.

\section{Suspended Material in Frazil Ice}

One very interesting aspect of frazil ice is that it may contain large amounts of fine-grained sediment and algae. Our observations in the Weddell Sea (Ackley 1982, Buck and Garrison 1982, Garrison and Buck 1982) Indicate that enough algae was incorporated into thin $(<20 \mathrm{~cm})$, young ( $\approx 1$ day old) ice to give the ice significant coloration. of primary importance is that our measurements indicated that the concentration of algae in this thin ice was several times the concentration in 
the water column in which the ice was growing. This observation is strongly in opposition to our past experience with growing ice sheets from the me1t, where water impurities, dissolved or suspended, are for the most part rejected and lesser concentrations are generally observed in the ice than in the water. Similar evidence from the Arctic has been gathered (T. Osterkamp and J. Gosink, personal communication) where, in coastal waters, bottom sediments that are stirred up and incorporated into the growing ice are at higher concentrations than observed in the water column itself.

The short time scales (a few hours) observed in the growth of the algae-loaded ice in the Antarctic mitigates against biological growth affecting the increase in the concentration in the ice relative to the water column. Two possible mechanisms, both relying on frazil ice formation processes, can be proposed to explain these increases in concentration of suspended material in the ice relative to the water column. The first is ice nucleation by foreign particles. Concentration by ice nucleation can occur if frazil ice crystals preferentially nucleate on suspended particles. Since the small observed supercoolings limit the volume of ice formed to a small fraction of the volume of water, the effect is to have the same number of foreign particles in a much smaller volume, that is, to increase the concentration of particles in the ice phase. We note, however, that this process still requires the ice to form in the water column (frazil ice) rather than on top of the water column (congelation ice).

The second mechanism, which we call concentration by lce scavenging, occurs by collision of the frazil ice crystal with particles as it travels through the water column to the upper water surface. Each crystal could collect several particles, depending upon how much the length of the path that the ice crystal travels exceeds the mean distance between particles in the water column.

We have microscopically examined thin sections of some of the Antarctic ice samples and have found evidence suggesting that for algae particles both nucleation and scavenging operate. This examination indicates that cells are found within individual ice crystals, suggesting that the cell nucleated the crystal, and also are found at grain boundaries between individual crystals, suggesting that the crystal scavenged the cell.

It appears, however, that scavenging is the dominant mechanism for incorporation of material. If nucleation were the only mechanism, a limit on the amount of material incorporated would be the number of crystals (one cell per crystal) per unit volume. Frazil ice crystal sizes observed are of the order of $\approx 1 \mathrm{~mm}$ diameter, implying an upper bound of $\approx 10^{6}$ cells/1iter if nucleation is the only mechanism. Measured concentrations of algae exceed this by one to two orders of magnitude $\left(* 10^{8}\right.$ cells/1iter), indicating scavenging may be the more effective mechanism for incorporating algae. Another observation is that most foreign materials allow water supercoolings of the order of a few degrees Celsius to exist before they become effective as ice nuclei (Hobbs 1974). Although supercoolings of a few tenths of a degree have been observed at the surfaces of Arctic leads (Katsaros 1973) these values are characteristically less than required for most suspended mineral matter 
to serve as a nucleating agent. Biological materials, especially living cells from cold waters, have not been well studied as to their effectiveness as nucleating agents, and this behavior should be investigated. In conclusion, in the few cases studied the total particle concentration relative to the ice crystal size as well as the wide range of organic and inorganic materials incorporated in the ice support the contention that scavenging is a more important incorporation mechanism than nucleation.

Multiyear Ice

Considering that vast areas of the polar seas are covered with multiyear ice, there is an amazing lack of information on its structure and properties. In the following discussion we will use the term "multiyear ice" to refer to ice that has survived at least one summer's melt season. This rather casual usage corresponds to the way that the word "multiyear" is commonly utilized by sea ice speciallsts. This differs from the recommended WMO usage in which second-year ice has survived one melt season, multiyear ice has survived two or more melt seasons, and the phrase old ice is used to characterize both of these ice types.

In the Arctic, multiyear ice is distinguished by two main characteristics: 1) its rolling, hummocky surface, which is the result of differential melt, and 2) its salinity profile, which indicates values near zero for the ice above sea level and shows a gradual increase to values of 3.0 to $3.5 \%$ o for the ice in the lower portion of the floe. As will be discussed later, this profile appears to be primarily produced by the flushing of nearly pure surface meltwater downward through the ice sheet.

What is the structure of this ice? The 11mited work that has been performed on multiyear ice has largely focused on the horizontal layers that are produced by the summer melt cycle. The reason for this interest is obvious: the annual layering allows one to establish a minimum age for thick floes of pack ice. Previous to these studies age estimates were based upon subjective criteria such as the amount of pressuring and the detailed morphology of the ice surface. Age estimates have also been made from the 1ce thickness and from the locations of the maxima and minima in the salinity profiles (Save1'ev 1958). As will be discussed later, although there is a general tendency to form a low salinity layer on the underside of the lce during the sumner melt period, this salinity distribution is rapidly modified by brine migration and is difficult to use in estimating ice age except in extremely simple cases.

The first study of a horizontal "translucent-longitudinal" section of a thick $(291 \mathrm{~cm})$ pack ice floe was by Shumskii (1955) when in July of 1954 he made a brief visit to the drifting station SP-3. As a result of the above-freezlng temperatures during the period of fleld work, very few detailed observations were made. The ice was divided into two main types, infiltered $(0-38 \mathrm{~cm})$ and normal sea 1 ce $(38-291 \mathrm{~cm})$. The $1 \mathrm{n}-$ filtered ice layer was described as resembling the firn of arctic glaciers and contalned four distinguishable layers whlch were interpreted as annual. The normal sea ice was also classifled into two 


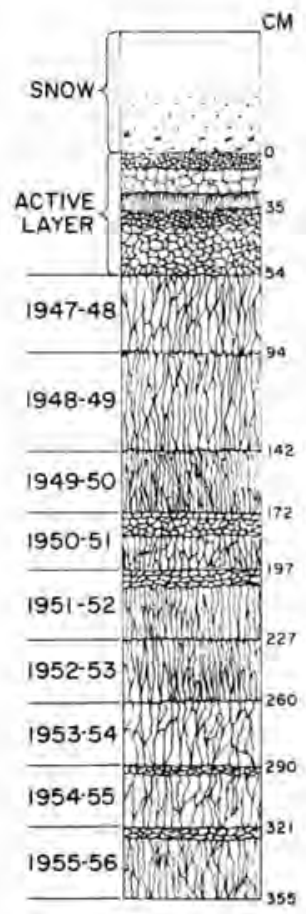

Figure 59. Cross section of a multi-year floe (Cherepanov 1957).

types. The upper part ( 38 to $150 \mathrm{~cm}$ ) contalned lens-like irregular strata that were believed to be the result of thaw cycles. These strata were absent in the lower portion $(150$ to $291 \mathrm{~cm})$ of the 1 ce. Therefore, Shumskif reasoned that the lower portion of the sea ice (141 cm thick) was formed after the end of the thaw period while the 4-year accumulation of infiltered ice was forming at the surface of the ice sheet. The upper $112 \mathrm{~cm}$ of the sea ice was belleved to be older. The total age of the floe was estimated at not less than 6 to 7 years. Shumskil also suggested that the presence of infiltered ice indicated that the snow line in the central Arctic is presently at sea level.

Following this preliminary study, detalled investigations of the horizontal layering in pack ice were made on SP-4 (Cherepanov 1957) and Station Alpha (Schwarzacher 1959). It was found that the annual layering is readily observable in the lower part of the ice sheet and less clearly defined nearer the upper surface where the effects of the summer melt are more pronounced. Cherepanov found ten recognizable annual layers in a $335-\mathrm{cm}-t h 1 \mathrm{ck}$ floe (Fig. 59), while Schwarzacher found either seven or eight layers in a $345-\mathrm{cm}-t$ hick floe. The boundaries between the annual layers were of two different types. The most common was a thin $(2-5 \mathrm{~mm})$ layer of milky white 1 ce with a sharp upper boundary and an irregular lower boundary. The details of the formation of this layer are not known but it apparently develops during the period when the ice growth has stopped. The milky color of the layer may, in some way, be connected with the biological activity beneath the ice during the summer months. The formation of the milky layer is apparently not associated with either recrystallization or the nucleation of new grains, since when ice growth starts in the fall the crystals of the previous winter commonly resume growth with the same crystallographic orientation (Schwarzacher 1959), 
The other type of summer layer is considerably thicker ( 1 to $10 \mathrm{~cm}$ ) and shows a sharp decrease in grain size relative to the overlying winter ice. The grain shapes in this layer have been described as slightly elongated in the vertical direction. The c-axis orientations are in general horizontal but they show deviations up to 30 degrees (Schwarzacher 1959). In the ice studied by Cherepanov the crystals were equi-axed and the orientation was randon. This ice does not show the platy substructure so characteristic of sea ice and has a much lower salinity ( 1 to $1.5 \%$ ) than the surrounding ice. The formation of annual layer is clearly the result of the formation during the summer of a stable layer of fresh meltwater between the lower surface of the ice and the underlying dense seawater. This process has been known for some time (Ma1mgren 1927) and has been described in considerable detail on Station Alpha by Untersteiner and Badgley (1958). They found that many of the freshwater melt ponds that develop during the summer drain through core holes, forming an irregular layer of fresh water between the ice and the seawater. At the interface between the fresh $\left(0^{\circ} \mathrm{C}\right)$ and saltwater $\left(-1.6^{\circ} \mathrm{C}\right)$, ice crystals formed and floated upward until the fresh water was filled with a mesh of fragile crystals. When the crystals forming at the fresh/saltwater boundary could no longer rise, the formation of a solid layer of freshwater ice began. The formation of such a layer is to be expected under any floe occupied by a scientific station because the large number of core holes drilled in the floe for technical studies readily facilitate the rapid transfer of meltwater to the underside of the ice. On an unoccupied floe early in the melt period, meltwater will either be channeled into open leads where wave action will favor mixing with the seawater or it will form large melt pools toward the interior of the floe. Only later in the melt period when deterioration is far advanced do drainage holes form in all areas of the floe (Bennington 1959). Even during this period, the lower density of the fresh meltwater inhibits it from percolating completely through the floe. When a freshwater layer does form, it is usually localized under the thinner portions of the ice floe and is particularly prevalent near open leads. This layer, if preserved by freezing, is very useful as a marker; Cherepanov found that four out of the nine annual boundaries in the NP-4 floe were marked by "fresh" ice layers (Fig. 59). On the other hand, Schwarzacher (1959) has noted froin examination of a large number of cores in the vicinity of Station Alpha that the "fresh" ice layers do not contribute significantly to the total ice growth.

Schwarzacher (1959) observed that the top $50 \mathrm{~cm}$ of the floes he examined contained ice which formed at or near the surface of the floe. This ice was predominantly the result of the freezing of meltwater pools that form during the summer and was characterized by c-axes-vertical orientations. A fine-grained granular ice may also be formed by snow falling in the meltwater pools, producing a slush which subsequent $1 \mathrm{y}$ freezes. This melt and refreezing associated with the upper ice surface tends to obliterate the annual layering in the upper part of the ice sheet and makes the accurate estimation of the age of the ice in a floe difficult if only one cross section is examined. For example, of the 150 cores collected by Schwarzacher in the summer of 1958 from areas that did not show signs of old pressure ridges, only $25 \%$ consisted of undisturbed ice and only $2 \%$ were sufficiently unaltered to show an annual layering throughout the complete thickness of the floe (eight 


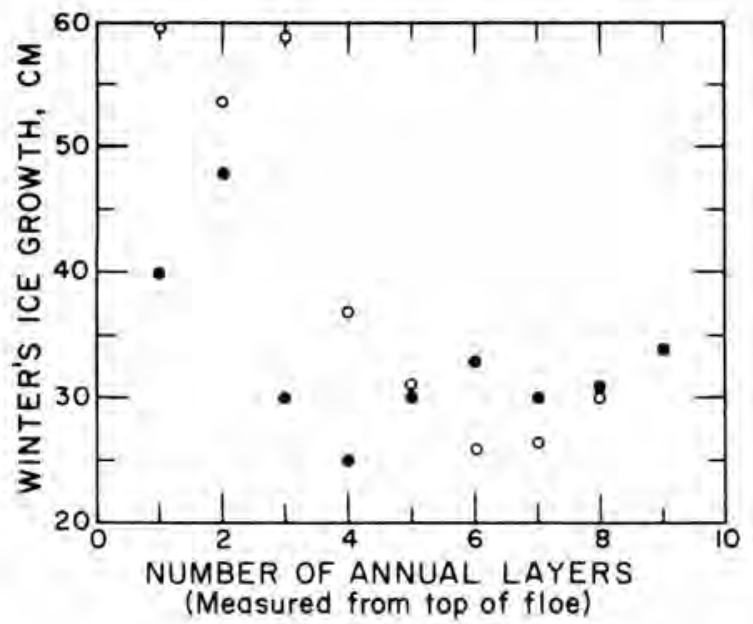

Figure 60. Winter's increment of ice growth plotted against the number of annual layers measured from the top of the floe. Data from Cherepanov (1957) and Schwarzacher (1959). The circles and dots represent observations on Stations A1pha and SP-4 respectively.

layers to 1950). Inasmuch as neither Schwarzacher, Cherepanov, or Bennington observed any annual stratification or superimposed firn, this casts considerable doubt on Shumskii's suggestion that the snow line in the central Arctic is currently at sea level. Both Cherepanov and Schwarzacher have noted that the formation of infiltered ice is strictly local and is highly dependent upon the details of the surface relief. If infiltered ice forms at all it will form in small depressed areas where old heavy snowdrifts are present. In most areas on both NP-4 and Alpha, both the snow cover and 20 to $30 \mathrm{~cm}$ of ice thawed during the summer (Untersteiner 196l). It therefore seems quite likely that the ice identified by Shumskii as superimposed firn was actually ice formed by melting and refreezing in the upper part of the ice sheet. If this is the case the SP-3 floe would be a minimum of 9 years old instead of 6 or 7 as suggested by Shumskii.

It is also of interest to point out that the thicknesses of the annual layers can be used to determine if the top annual layer is the layer representing the year when the ice sheet initially formed. Figure 60 shows the winter increments of 1 ce growth plotted against the number of the annual layer measured from the top of the floe. The data are from Cherepanov (1957) and Schwarzacher (1959). For the last 7 years $(\mathrm{SP}-4)$ and 5 years (Alpha) it is clear that the ice thickness has approximately reached a steady state, the ice growth in the winter being the same as the expected ablation during the summer. Even the thickest annual layer measured on Alpha indicates an existing ice thickness of 260 to $280 \mathrm{~cm}$ at the end of the summer prior to the accumulation of the layer if the empirical relations of Schwarzacher (1959, p. 2365) and Untersteiner $(1961, \mathrm{p} .165)$ are used. Inasmuch as $280 \mathrm{~cm}$ is the maximum one winter's fast sea ice accumulation known in the Canadian Arctic (Eureka, 1946-47; see Bilello 1961), this indicates that although the floe studied by Schwarzacher contained 8 years' accumulation of ice, the initial floe formed a minimum of 9 years prior to the time of measurement. Because the accumulation of winter ice in the Arctic Basin is usually considerably less than 260-280 cm [160 cm at NP-2 (Petrov 195455), $173 \mathrm{~cm}$ at NP-4 (Cherepanov 1957, Fig. 4, p. 183) and $180 \mathrm{~cm}$ at Alpha (Frankenstein, personal communication)] the estimate of 9 years for the age of the floe at Alpha is probably quite conservative, and the floe at NP-4 must be more than 11 years old. 


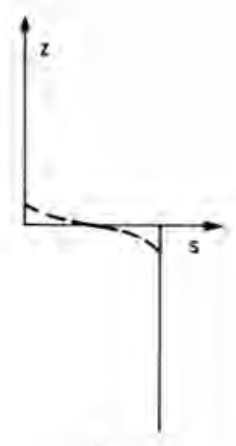

a.

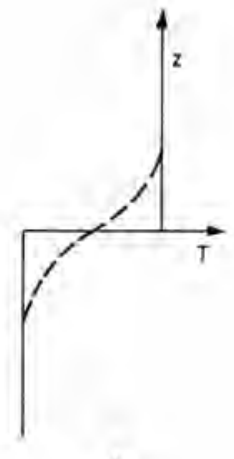

b.

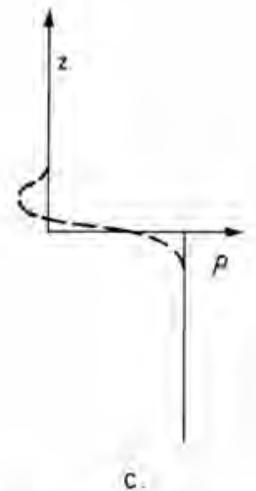

C.

Figure 61. The distribution of a) salinity, b) temperature and c) the resultant density caused by the diffusion of a freshwater layer over a saltwater layer, with both layers at their respective freezing points. The size of the density inversion is exaggerated. (Martin and Kauffman 1974.)

One interesting aspect of the freezing of the freshwater layers that can form beneath multiyear ice floes is that the heat transfer rates are 5 to 10 times those calculated assuming that all heat transfer is by thermal diffusion (Martin and Kauffman 1974). What appears to happen is as follows. When the surface meltwater flows off the pack into the ocean, and ultimately beneath the $1 \mathrm{ce}$, we have an ice layer at fts melting point $\left(\approx 0^{\circ} \mathrm{C}\right)$ underlain by a nearly freshwater layer at its freezing point $\left(\approx 0^{\circ} \mathrm{C}\right)$, in turn underlain by seawater at its freezing point $\left(-1.8^{\circ} \mathrm{C}\right)$. At the boundary between the fresh- and seawater a zone of water forms which, because of the rapid diffusion of heat relative to salt and the fact that the density of water with a salinity of $<24.7$ decreases on cooling, is both supercooled and less dense than the overlying water (Fig. 61). The resulting density distribution is unstable, with a Rayleigh number of $10^{3}$ to $10^{4}$, and free convection results. When this supercooled water rises, it is nucleated by the overlying ice layer and forms a mesh of thin vertical interlocking ice crystals that ultimately grow down to the fresh water/seawater interface. At this time the presence of ice crystals throughout the complete thickness of the freshwater layer eliminates supercooling, constrains both temperature and salinity to lie on the freezing curve, and permits them to diffuse in the vertical direction until both quantities become horizontally uniform. The combination of these processes results in the lateral growth of the ice crystals, which continues until a horizontal ice sheet forms. Excellent photographs showing the growth of 1ce crystals during a laboratory simulation of this process can be found in Martin and Kauffman (1974).

Just what is the structure of multiyear ice? The only thing that can be said at present is that we don't know. As was discussed, we used to think that we did, that multiyear ice was a layer-cake of annual growth layers with a layer thickness roughly equaling the amount of summer ablation. As has been shown, this type of ice clearly exists. However, based on the limited samples (150 cores) collected by Schwarzacher in the Arctic Ocean from multiyear ice that appeared to be unde- 
formed, only $25 \%$ of the ice actually was undeformed and only $2 \%$ showed annual layering throughout the complete thickness of the floe. These results should be coupled with the results obtained in the Weddell Sea by Gow et al. (1982) where $75 \%$ of the multiyear ice was frazil. It should also be noted (Meeks et a1. 1974) that recrystallized ice has tentatively been identified in the low salinity, above-water-level portions of thick multiyear floes studied in the Beaufort Sea during the 1972 AIDJEX pilot experiment. Perhaps the multimaximum fabric reported by Savel'ev (1958, Fig. 5) from a hummock on a multiyear flow is from this type of ice (similar fabrics are produced by recrystallization in glacier 1ce). If this interpretation is correct, we will not be surprised, as we have believed for a long time that sea ice would probably recrystallize if the brine inclusions, which presumably lock in the substructure, were drained from the ice. This drainage, in fact, does occur in the upper part of thick multiyear floes.

When all the above information is combined, we frankly must admit that we do not know what to think. However, we do know what is needed: a program that systematically obtains cores from different regions of the Arctic and Antarctic pack ice and studies their structure. Such a program is not hard to accomplish, but it requires good logistic support.

In concluding this section it should be pointed out that understanding why the structurally different types of sea ice form and being able to estimate how much of each ice type will exist at different locations at different times of the year is not only of academic interest. It is also a problem of considerable applied importance as each of these different ice types has different physical properties. At the present time we at least know what the problem is. This alone should stimulate further work in this area.

This is a convenient place to also mention that although undeformed multiyear ice commonly has a steady-state thickness of between 2.5 and 5 $m$ (Maykut and Untersteiner 1971) it appears to be possible to obtain undeformed multiyear sea $1 \mathrm{ce}$ with thicknesses of at least $12 \mathrm{~m}$ under present climatic conditions (Walker and Wadhams 1979). Examples of such thick ice would appear to be the floe upon which NP-6 was situated (10-12 m, Cherepanov 1964), a floe from Nansen Sound, Ellesmere Island, described by Serson (1972, $10 \mathrm{~m}$ thick), and the sea 1ce portions of the Koett1itz Glacier, McMurdo Sound, Antarctica (15 m, Gow and Epstein 1972) and the Ward Hunt Ice Shelf off Northern Ellesmere Island $(20 \mathrm{~m}$, Lyons et al. 1971). The formation of such thick ice requires rather special conditions in that the oceanic heat flux must be near zero and the annual snowfall must be sufficient to maintain a high surface albedo without allowing the accumulation of snow on the ice surface. Walker and Wadhams (1979) have calculated that under such conditions a thickness of $12 \mathrm{~m}$ would be reached in about 65 years, with a final equilibrium thickness of roughly $20 \mathrm{~m}$ requiring about 200 to 300 years. 


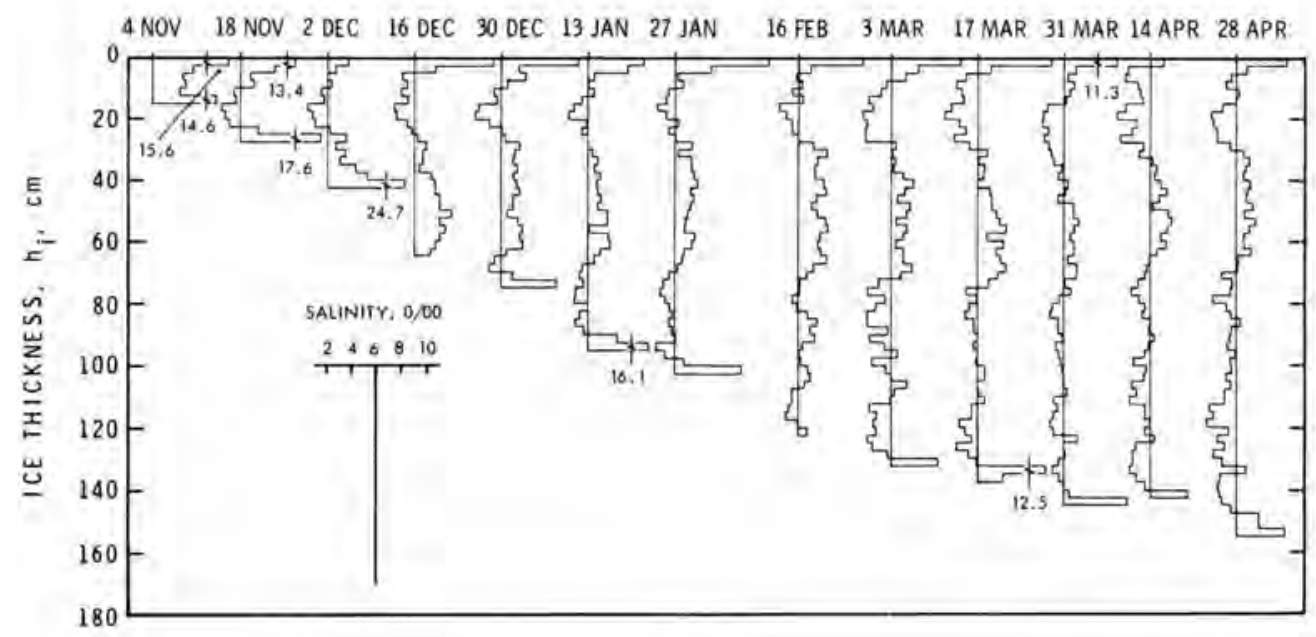

Figure 62. Salinity profiles of ice of Eclipse Sound at intervals of two weeks during the winter of 1977-78. Scale for salinity is shown in insert. Vertical solid lines represent a value of $6 \%$ and are given as reference (Nakawo and Sinha 1981).

\section{THE SALINITY PROFILE}

\section{Observations}

There are ice salinity data scattered through the sea ice literature. However, most of this information is very spotty - a profile here, a profile there. There are only a few exceptions where reasonably systematic salinity observations were made at a given site throughout the complete growth season. The best example of this type of study is by Nakawo and Sinha (1981), who obtained salinity profiles from a site in Eclipse Sound near Pond Inlet, Baffin Island, on a weekly basis from November 1977 to April 1978. The profiles are shown in Figure 62 (a two-week interva1 is used here for clarity). A plot of the variations in mean daily air temperature which can be consulted in the original reference shows values that were below $-10^{\circ} \mathrm{C}$ for all but a very few days just after freeze-up and comronly were below $-20^{\circ} \mathrm{C}$. These profiles show characteristics that are similar to those of innumerable other profiles obtained from ice in the high Arctic. Note that there is initially a rapid decrease in the salinity at a given level in newly formed ice [see also Malmgren (1927) and Weeks and Lee (1958, 1962)]. After this initial rapid decrease, which appears to occur within a week after the ice forms, the salinity values attain quasi-stable values which then decrease very slowly throughout the growth season. In many ice sheets the uppermost layer of ice shows a higher salinity, as does the lowermost layer. This results in the profiles having a $\mathrm{C}$-shaped appearance.

The other set of reasonably complete salinity measurements was obtained at Hopedale, Labrador, by Weeks and Lee (1958). The climate at Hopedale was very different than at Pond Inlet, with several thaw periods occurring when air temperatures went above $-10^{\circ} \mathrm{C}$ and at times above freezing. The continuous, relatively rapid desalination that was observed (Fig. 63) even in December and January is presumably caused by 


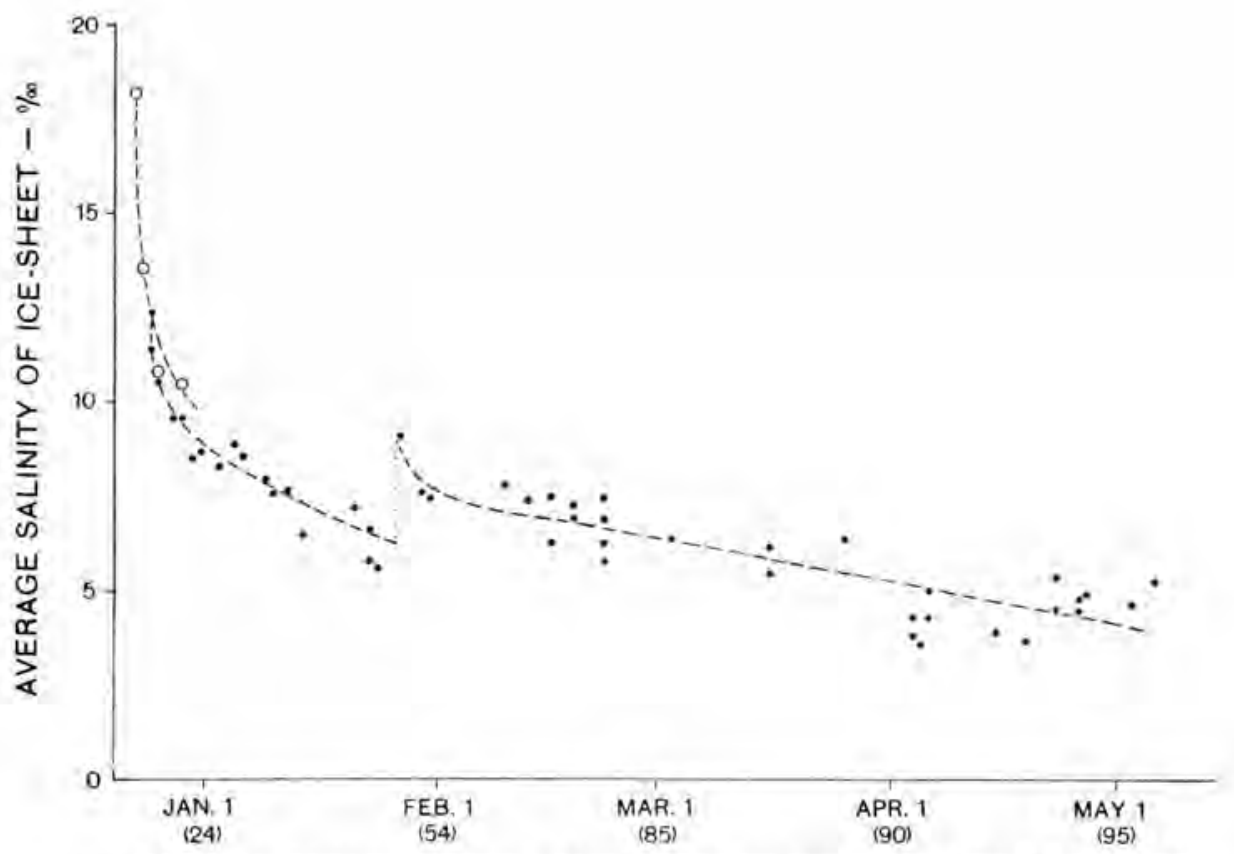

DATE OF DETERMINATION AND AVERAGE ICE-THICKNESS IN () - CM.

Figure 63. Average salinity of ice sheet at Hopedale, Labrador, plotted against ice thickness and date of measurement (Weeks and Lee 1958).

the higher air temperatures, which in turn produced higher ice temperatures, resulting in increased brine volumes and enhanced brine drainage. Nakawo and Sinha note that at Pond Inlet similar rapid desalination also occurred but not until May and June (data not shown in Fig. 62).

It should be remembered in examining salinity profiles that even in the most homogeneous-appearing ice there is a small-scale, apparently random variation in the salinity. In the on1y avallable study performed to date of such variations (Thule, Greenland), a standard deviation of $0.62 \%$ was obtained at a given depth level in ice that would seem to be completely uniform (Weeks and Lee, 1962).

Plots of the average ice salinity for the complete ice sheet versus ice sheet thickness have been prepared by Cox and Weeks (1974) for first-year sea ice using data from a wide variety of sources and locations. The results are rather surprising in that they are not only consistent but also show only a small amount of scatter (Fig. 64). Initially there is a rather rapid linear drop in the average salinity until an ice thickness of approximately $0.4 \mathrm{~m}$ is reached. At this and larger thicknesses the curve of average salinity versus ice thickness is also linear but with an appreciably decreased slope. Recent work by Gow et al. (1982) shows that the bulk salinity of Antarctic sea ice tends to be greater than that of sea ice of comparable age and thermal history in the Arctic.

When in the spring the upper surface of the ice starts to melt, there initially is a rapid decrease in the salinity of the above-sea- 


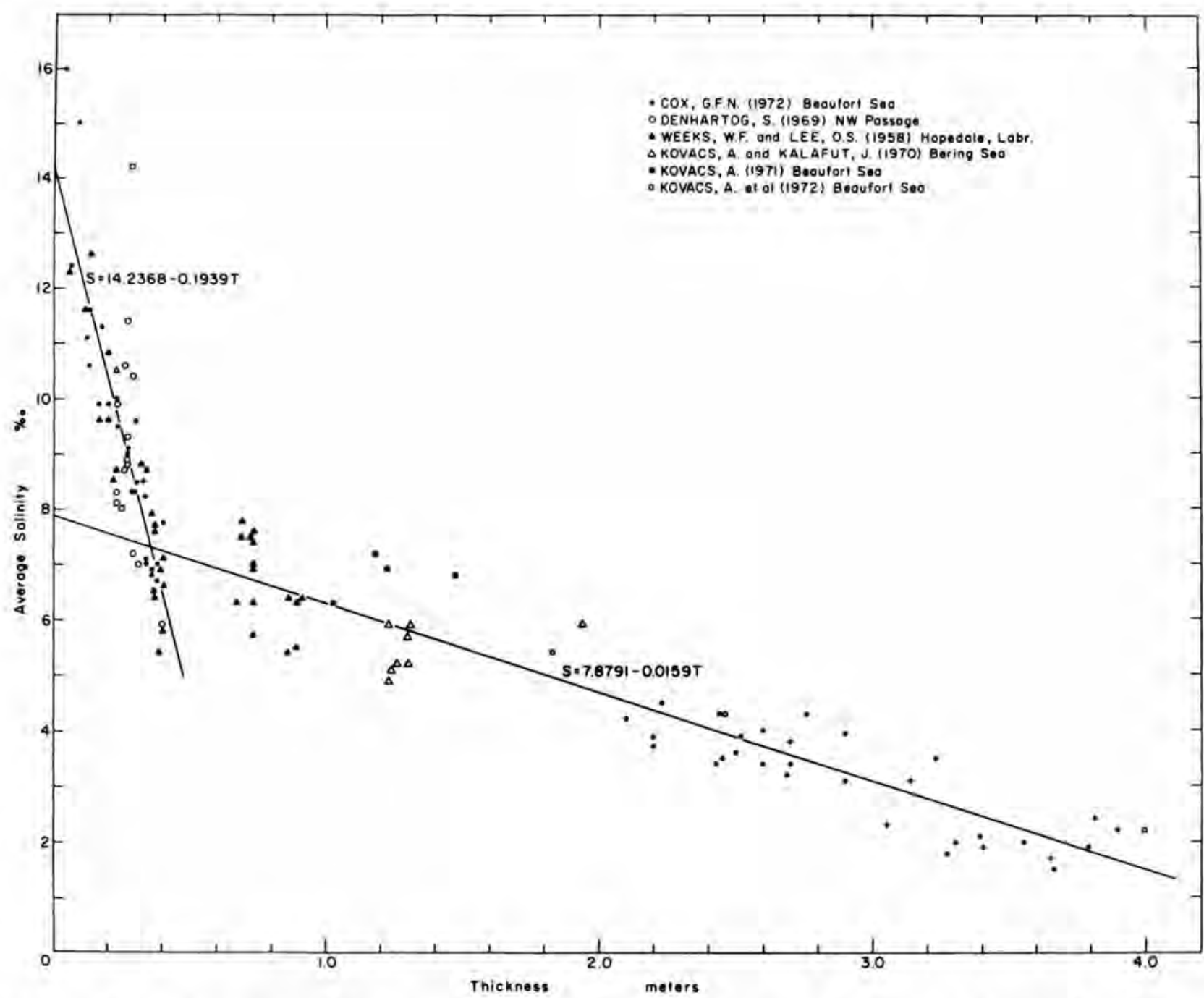

Figure 64. Average salinity of sea ice as a function of ice thickness for cold sea ice sampled during the growth season (Cox and Weeks 1974).

level portions of the ice. The best example of the final salinity profile for multiyear ice is by Schwarzacher (1959) based on 40 cores and 2060 salinity determinations (Fig. 65, curve C). In the more recent study by Cox and Weeks (1974) multiyear salinity data were separated Into two classes depending upon whether the core was selected from a hummock (Fig. 65, curve A) or from a depression (curve B). Based on these data Schwarzacher's curve appears representative of hummocky ice or at least ice with a high freeboard. Note the significant amount of scatter in the measurements. The same is presumably true of Schwarzacher's data, although he only presented average values. Note the extremely low salinity of the near-surface ice from the hummocky areas. In many of the thicker floes that have been studied this ice is sufficiently pure that it can be melted and utilized for drinking water. The near-surface ice from the depressed areas (curve B) is more saline by 3 to $4 \%$ oo. Some general feel for the lateral and vertical variations in ice salinity with changes in ice topography can be gained from Figure 66. Note the high salinities of the newly formed ice in the lower portion of the ice sheet and the great variability in the upper 


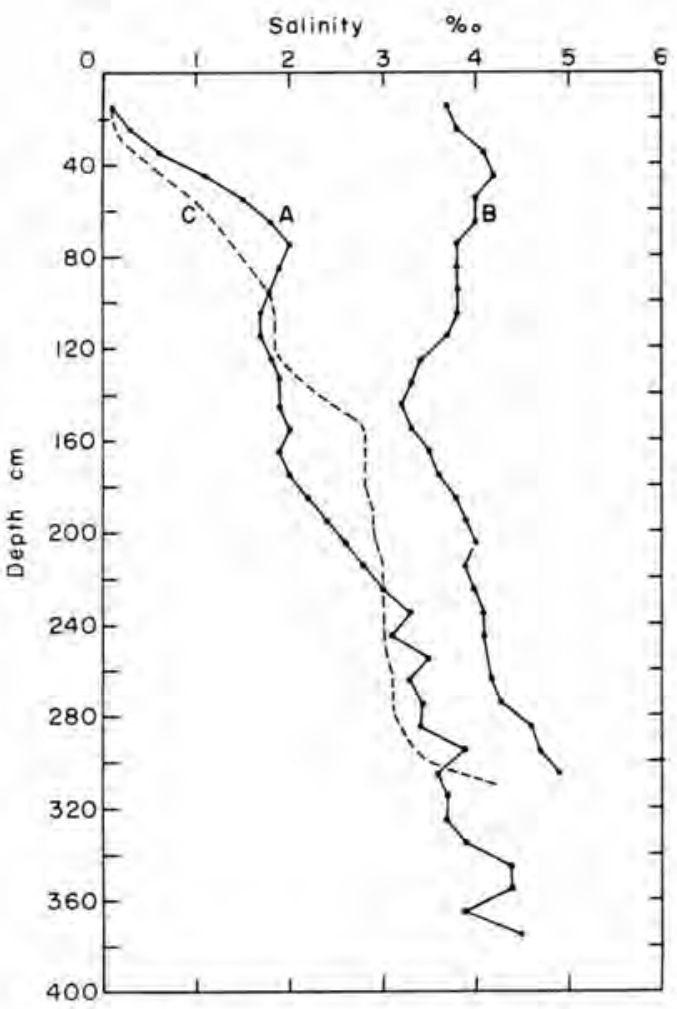

Figure 65. Average multiyear salinity profiles for hummocked (curve A) and depressed (curve B) areas. Curve $\mathrm{C}$ is the average multiyear salinity profile determined on Station Alpha by Schwarzacher (1959) (from Cox and Weeks 1975).

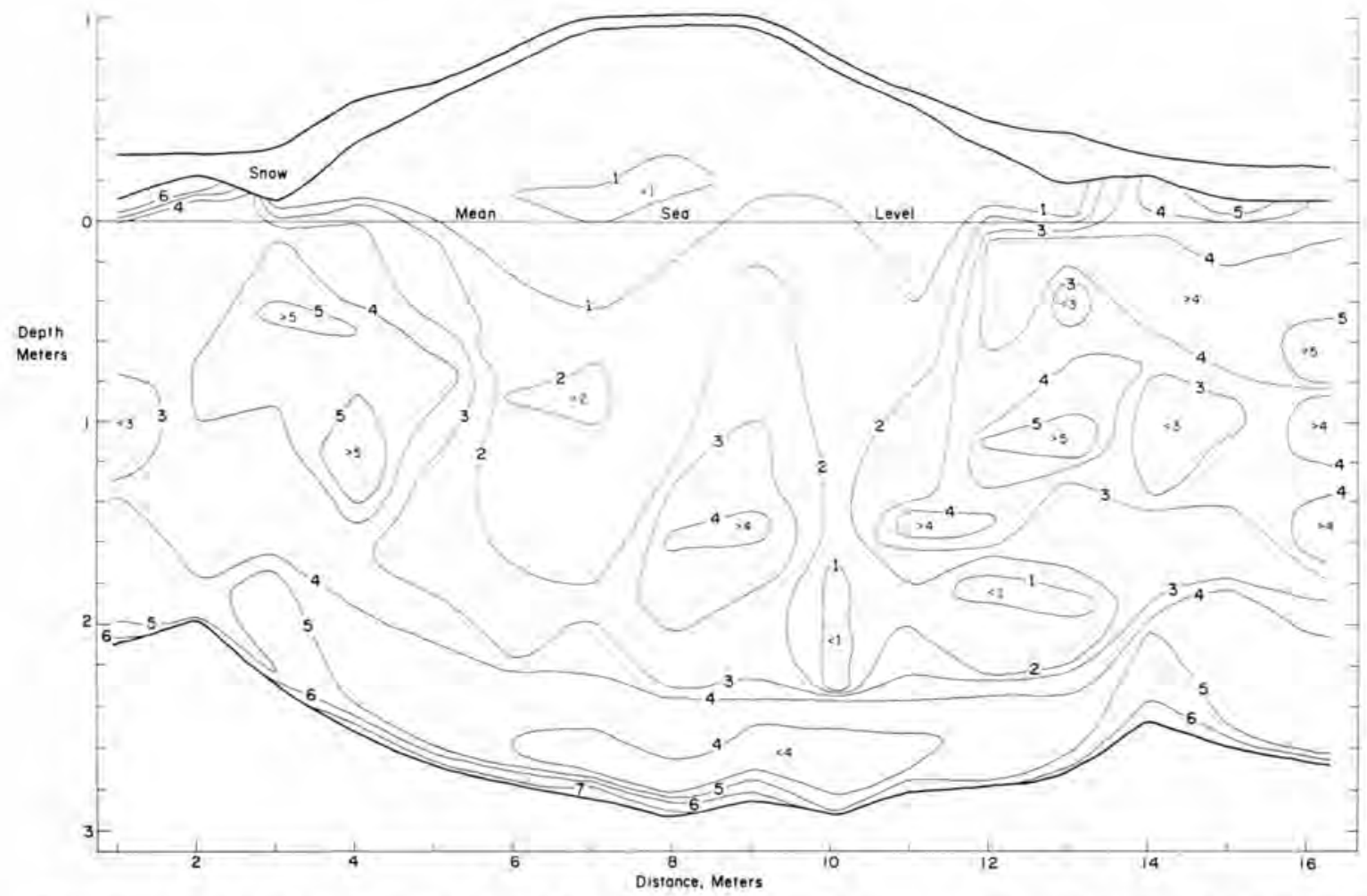

Figure 66. A cross section of an area of multiyear ice showing the variation of salinity with topography (Cox and Weeks 1975). 


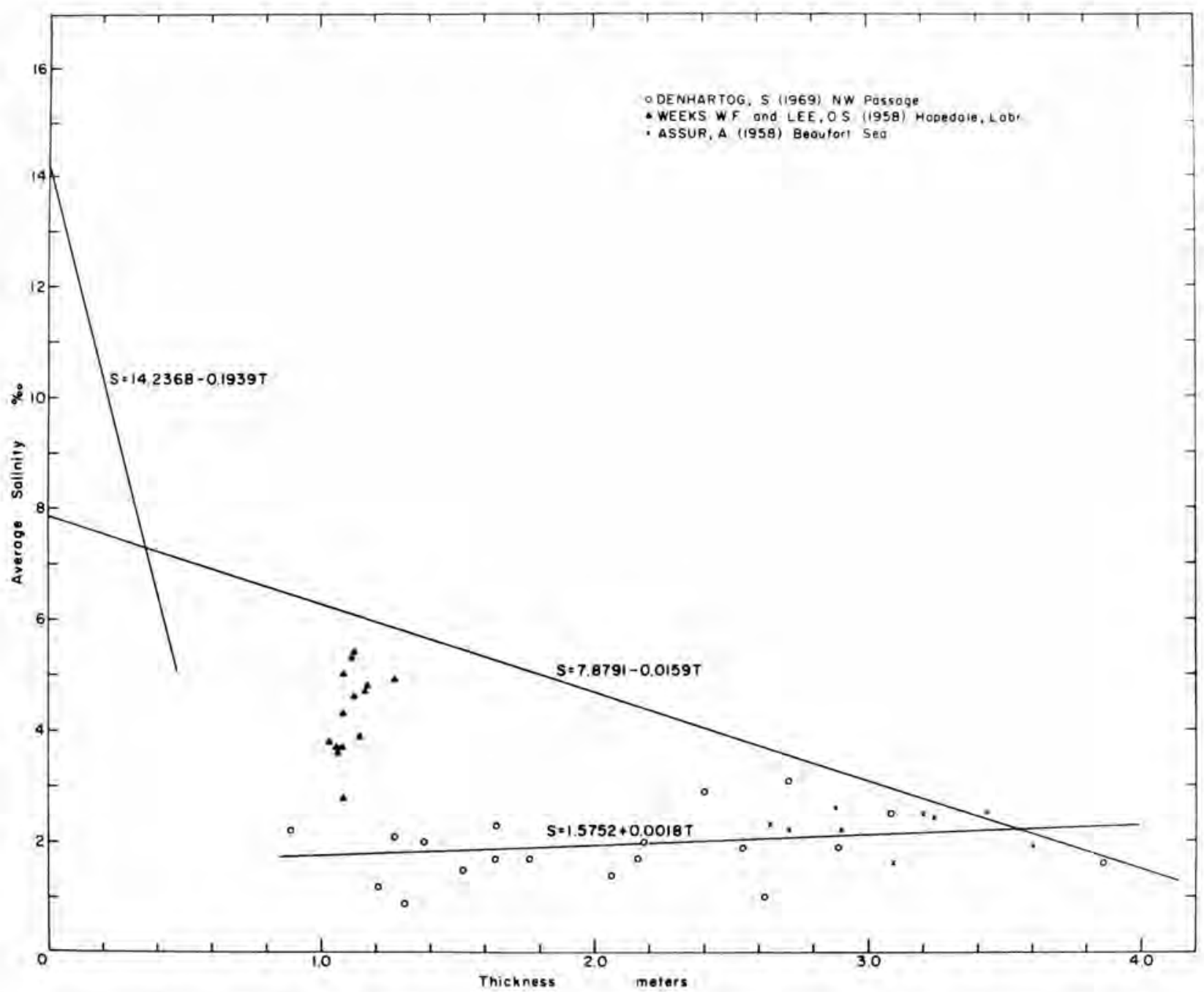

Figure 67. Average salinity of sea ice as a function of ice thickness for warm sea ice sampled during the end of the melt season (Cox and Weeks 1975).

portion of the profile. Figure 67 shows a plot of average salinity versus average ice thickness for multiyear ice. There is an appreclable amount of scatter and a very slight increase in mean salinity with increasing ice thickness.

There appear to be several factors that contribute in different degrees to determining the salinity profile that exists at any given time:

1. The infial amount of salt entrapped in the ice.

2. The migration of liquid inclusions through the ice crystals.

3. Brine expulsion or the squeezing of brine out of the ice as the result of differential volume changes in the different phases composing the sea ice.

4. Brine drainage.

5. Flushing.

We wi11 now discuss each of these factors in turn. 
Initial Salt Entrapment

The first step in unraveling the variations in the salinity profile of ice is to understand how much salt is initially entrapped in the ice as a function of growth conditions and structure. Surprisingly little work has been carried out on this subject. Fortunately, there has been considerable work on this general subject for other similar materials to serve as a guide to understanding the situation for sea ice.

Early studies focusing on the salt entrapment problem are those of Johnson (1943) and Adams et al. (1963). In some aspects these results were contradictory in that Johnson's results indicated that although there was a linear relation between the salinity of the ice $S_{i}$ and the salinity of water $S_{w}$, changes in the growth velocity of the ice $v$ did not appear to cause appreciable changes in the effective solute distribution coefficient $k \equiv S_{i} / S_{w}$. On the other hand, Adams and coworkers obtained experimental data indicating quite clearly that $S_{i}$ was an approximately linear function of $v$. In an attempt to resolve these differences, Weeks and Lofgren (1967) and Cox and Weeks (1975) performed a number of experiments using $\mathrm{NaC1}$ ice as a model for related behavior in sea ice. These two sets of experiments were similar in purpose but quite different in technique. In the Weeks and Lofgren study, ice sheets up to $25 \mathrm{~cm}$ thick were formed during freezing runs that lasted between 48 and 110 hours. At the end of the run the ice was removed and cut into $1-\mathrm{cm}$-thick slices, and the salinity of each slice measured. Because the freezing runs were very short, brine drainage was neglected, which is, of course, a rather questionable assumption because of the rapid drop in salinity that usually occurs during initial ice growth. Water salinities were also calculated for each stage of ice growth by considering the amount of salt rejected from the ice. The values of $k$ were then determined by combining the ice salinities with the water salinities that were appropriate for that ice level.

In the Cox and Weeks study the radioactive isotope ${ }^{22} \mathrm{Na}$ was used as a tracer and the salinity of both the ice and water was determined by sequentially measuring the gamma ray emission from different levels of the sample which, as in the previous experiment, was produced by unidirectional freezing. After considerable processing of the resulting data it was possible to obtain, via non-destructive observations, replicate salinity profiles that were in good agreement with more directly determined values. As these freezing runs took over 900 hours, it was no longer possible to neglect brine drainage. Therefore, only the salinities from the newly formed ice located just above the skeleton layer (that essentially no-strength layer at the bottom of a growing ice sheet where there are no lateral bonds between the ice platelets that compose each crystal) were used. It was assumed that the skeleton layer had a constant thickness of $3 \mathrm{~cm}$.

In analyzing these results Weeks, Cox and Lofgren used the theory of Burton et al. (1953) which has been quite effective in treating experimental results in the field of metallurgy. They assumed that because of mixing the concentration $C$ will approach a constant value of $C_{\ell}$ at some distance $\delta$ from the growing interface. For distances less than $\delta$ the velocity component normal to the interface approaches that due to crystal growth $v$. For a steady state at $x<\delta$, the continuity equation is 


$$
D \frac{d^{2} C}{d x^{2}}+v \frac{d C}{d x}=0
$$

with the boundary conditions

$$
\left(C_{i}-c_{s}\right) v+D \frac{d C}{d x}=0 \quad \text { at } x=0
$$

where $C_{i}$ and $C_{s}$ are the concentrations in the liquid at the interface $(x=0)$ and in the solid respectively and

$$
C=C_{\ell} \text { at } x \geq \delta .
$$

The solutions to eq 22 with these boundary conditions are given by

$$
\frac{c-C_{s}}{C_{l}-C_{s}}=\exp \left[\frac{v}{d}(\delta-x)\right]
$$

and the concentration $\mathrm{C}_{1}$ of the liquid at the interface is

$$
\frac{C_{i}-C_{s}}{C_{\ell}-C_{s}}=\exp \left[\frac{\delta v}{D}\right] \text {. }
$$

If $\delta$ is chosen properly this last equation can be forced to give the correct value of $C_{i}$. Because $c_{s} / C_{i}=k_{0}$, eq 25 can be rewritten as

$$
k=\frac{k_{0}}{k_{0}+\left(1-k_{0}\right) \exp \left[-\frac{\delta v}{D}\right]} .
$$

Here $k_{0}$ can be considered to be the value of $k$ at $v=0$ (provided that a cellular interface were to remain stable). Inasmuch as $k_{0}<1$ for salt-water systems eq 26 can be rearranged as

$$
\ln \left(\frac{1}{\mathrm{k}}-1\right)=\ln \left(\frac{1}{\mathrm{k}_{\mathrm{o}}}-1\right)-\frac{\delta \mathrm{v}}{\mathrm{D}}
$$

which is a straight line on a plot of $1 \mathrm{n}(1 / \mathrm{k}-1)$ vs $\mathrm{v}$ with a slope of $-\delta / D$ and a zero intercept of $\ln \left(1 / k_{0}-1\right)$. Figure 68 shows the resulting plot of Cox and Weeks' (1975) data. The data are quite linear with the exception of the values obtained at very low $v$ values. Based on Lofgren and Weeks' observations, the drift toward higher $(1 / k-1)$ values in the low $v$ range is undoubtedly related to changes in the morphology of the solid/1iquid interface as conditions are approached where a planar interface becomes stable. Ignoring the values at low $v$, least-squares gives $k_{0}=0.26$ and $\delta / D=7243 \mathrm{~s} / \mathrm{cm}$. The results obtained by Lofgren and Weeks were similar but the value obtained for $\delta / D$ was lower $(5090 \mathrm{~s} / \mathrm{cm})$. Flgure 69 shows the later data set presented as a plot of $\mathrm{k}$ versus $[\delta \mathrm{v} / \mathrm{D}]$. Note that at higher growth velocities essentially all the salt in the solution is trapped in the $1 \mathrm{ce}$.

How do these results compare with field observations? Figure 38 showed a plot of $\mathrm{v}$ as a function of depth in the ice against salinity $S_{i}$. There is clearly a positive correlation between $v$ and $S_{i}$ as predicted by the BPS theory. Replotting these results (Nakawo and Sinha 1981) as shown in Figure 70 clearly shows the linear relation suggested by the BPS theory. Presenting these results in a more direct manner by 


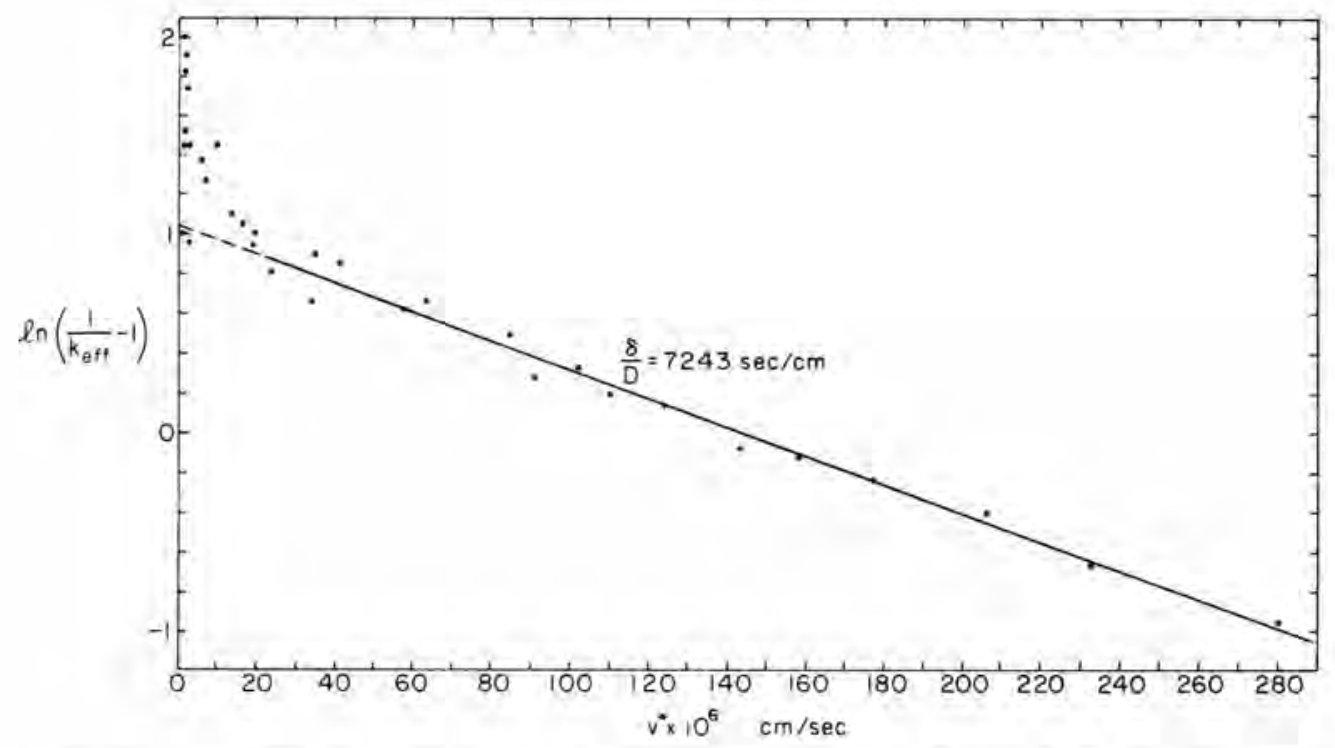

Figure 68. Plot of $1 \mathrm{n}(1 / \mathrm{k}-1)$ versus $\mathrm{v}$ using the salinity entrapment data of Cox and Weeks (1975).

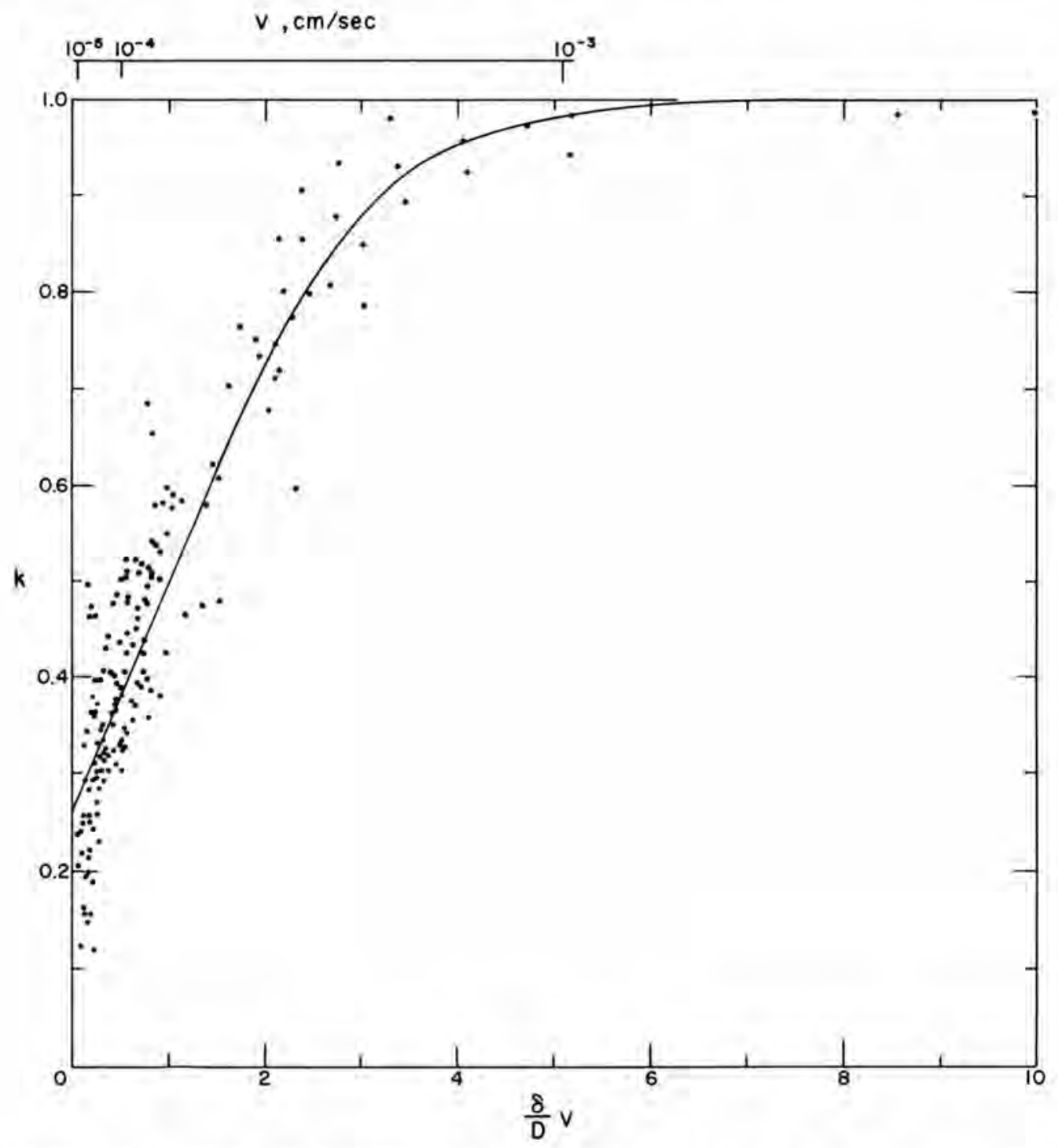

Figure 69. Plot of $k$ versus $\delta v / D$ for the salinity entrapment data of Weeks and Lofgren (1967). The curve is a least-squares fit of eq 26. 


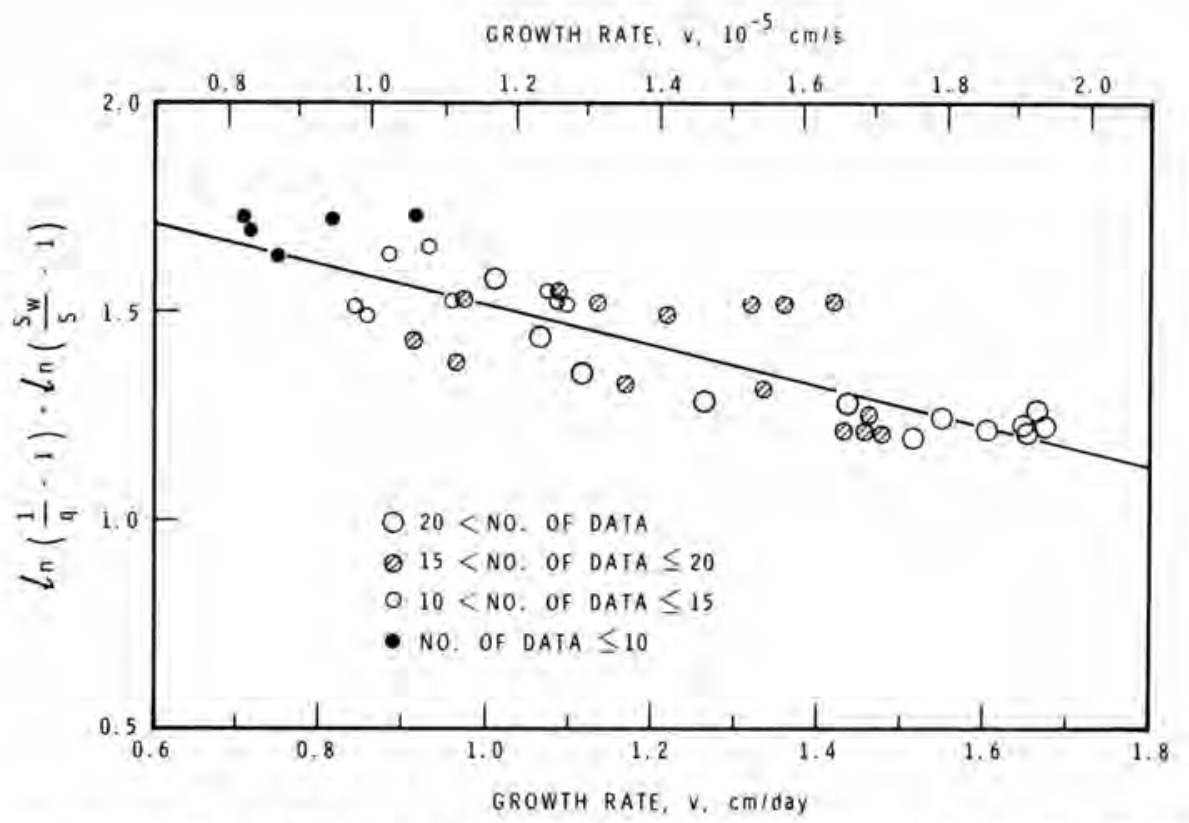

Figure 70. Plot of $1 \mathrm{n}(1 / \mathrm{k}-1)$ versus $\mathrm{v}$ for columnar-grained sea ice from depths between 25 and $125 \mathrm{~cm}$, Eclipse Sound, NWT. The solid line is a least-squares fit of eq 26 . After Nakawo and Sinha (1981).

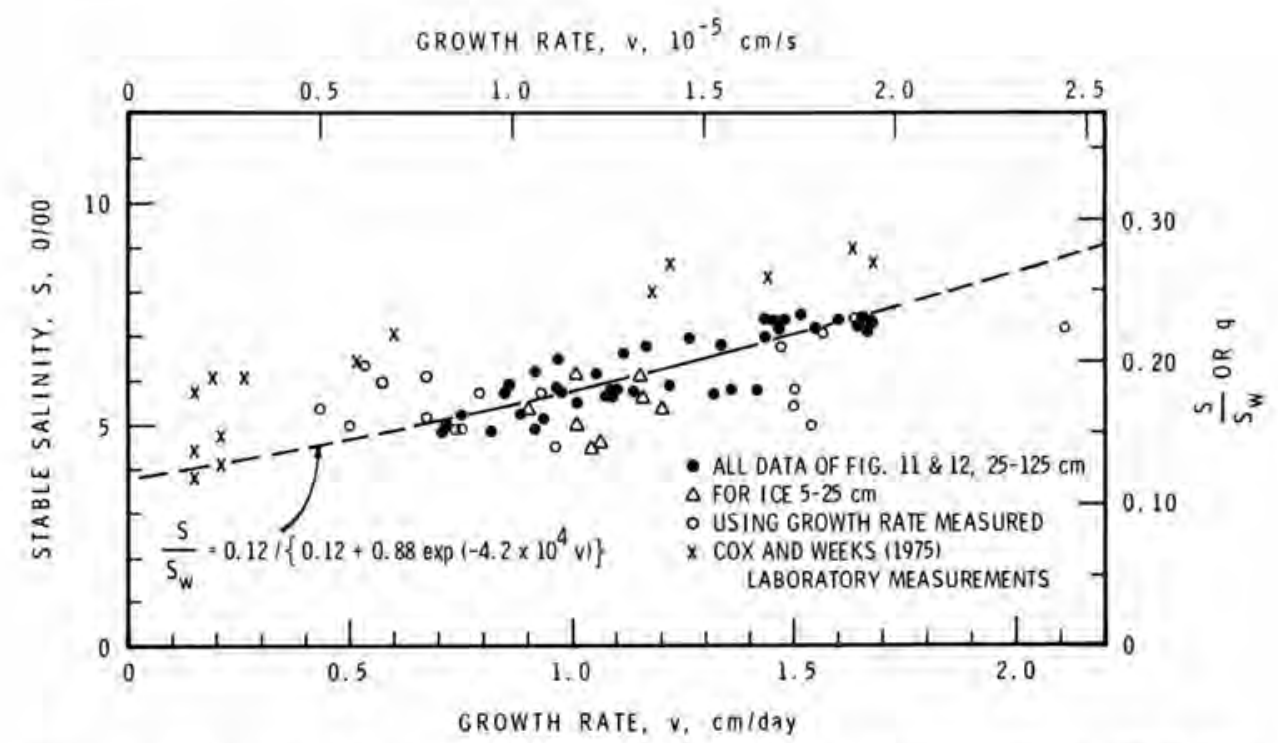

Figure 71. Stable salinity or $k$ versus growth rate (Nakawo and Sinha 1981). The figure numbers refer to figures in the original paper.

plotting $\mathrm{k}$ versus $\mathrm{v}$ gives Figure 71 . Here the 1 ce between 5 and $25 \mathrm{~cm}$ consists of discontinuous columnar grains, with the length of the columns less than $1 \mathrm{~cm}$. Below $25 \mathrm{~cm}$ the ice consists of long columnar grains. Note that there does not appear to be any appreciable difference between discontinuous columnar grains and continuous columnar grains. The BPS theory appears to work quite satisfactorily. Also shown in Fig. 71 are data points obtained by Cox and Weeks. These 
latter observations consistently show more salt present in the ice, a not unexpected result inasmuch as they were determined by nondestructive testing and did not experience the brine drainage that commonly occurs during normal sampling procedures. Therefore, at the present time the best way to estimate the amount of salt initially entrapped in sea ice is to use the relation

$$
S_{i}=S_{w}\left[\frac{k^{*}}{k^{*}+\left(1-k^{*}\right) \exp \left(-\frac{\delta v}{D}\right)}\right]
$$

with $k^{*}=0.12$ and $\delta / D=4.2 \times 10^{4} \mathrm{~s} / \mathrm{cm}$ (Nakawo and Sinha 1981). Here we have replaced $k_{0}$ with $k^{*}$ to distinguish it from the true equilibrium $k_{0}$ value.

Although it would appear that our knowledge of initial salt entrapment is in reasonable shape, there are some disturbing aspects. A1though the BPS theory appears to work it is based on a series of assumptions that strictly apply only to impurities that are incorporated in solid-solution in the solid phase. In the sea ice case we are clearly dealing with bulk entrapment of the melt at a dendritic interface. There have been some attempts to analyze this situation (Edie and Kirwan 1973, Myerson and Kirwan 1977a,b, Ozüm and Kirwan 1976). In the last reference this approach was applied to the freezing of stirred $\mathrm{NaC1}-\mathrm{H}_{2} \mathrm{O}$ solutions with considerable success. It would be interesting to modify these relations in order to treat free convection as the mixing process and then apply this analysis to the case of sea 1ce.

Brine Drainage Mechanisms

\section{Brine Pocket Migration}

In the first published discussion of a possible mechanism of removing salt from sea 1ce, Whitman (1926) pointed out that a temperature gradient in the 1 ce establishes a concentration gradient in a brine pocket if phase equilibrium is to be maintained. Th1s, in turn, during the winter causes the diffusion of solute from the cold, saline upper end of the brine pocket to the warmer, less saline lower end of the pocket. Associated with this diffusion, the ice at the warm end of the pocket dissolves while freezing occurs at the cold end, resulting in the migration of the brine pocket toward the warm side of the ice.

Since this early paper the phenomenon of liquid inclusions or liquid zones migrating through solid crystals has recelved considerable attention in the crystal growth and crystal purification literature (Wernick 1956, Pfann 1958, Tiller 1963) where it is referred to as temperature gradient zone melting (TGZM).

The theory is as follows. Because for salt-water systems the equilibrium value of $k$ is very small, for the migration of a small inclusion such as a brine pocket effectively all the salts can be considered to be excluded from the ice phase. Therefore $J$, the flux of solute at the freezing interface of a brine pocket, is

$$
\mathrm{J}=\mathrm{Cv}(1-\mathrm{k}) \approx \mathrm{Cv} \text {. }
$$


For the steady state, eq 28 can be written in terms of the concentration gradient $\mathrm{dC} / \mathrm{dx}$ as

$$
\mathrm{Cv}=-\mathrm{D} \frac{\mathrm{dC}}{\mathrm{dx}}
$$

where $D$ is the diffusion coefficient of the salt (or salts) in water. Then substituting

$$
\frac{\mathrm{dC}}{\mathrm{dx}}=\frac{\mathrm{dC}}{\mathrm{d} \theta} \cdot \frac{\mathrm{d} \theta}{\mathrm{dx}}
$$

where $\theta=$ temperature and $(\mathrm{dC} / \mathrm{d} \theta)$ is specified by the phase diagram, it follows that

$$
\mathrm{v}=-\frac{\mathrm{D}}{\mathrm{C}}\left[\frac{\mathrm{dC}}{\mathrm{d} \theta} \cdot \frac{\mathrm{d} \theta}{\mathrm{dx}}\right] \text {. }
$$

Here $\mathrm{D}, \mathrm{C}, \mathrm{dC} / \mathrm{d} \theta$ and $\mathrm{v}$ are all dependent on the temperature $\theta$. In eq 31 the appropriate temperature gradient is the gradient in the liquid $\mathrm{G}_{\ell}$.

For a spherical droplet a solution of Laplace's equation provides a relation between $G_{\ell}$ and the temperature gradient in the solid $G_{S}$ which is specified

$$
\frac{G_{\ell}}{G_{s}}=\frac{3 k_{s}}{\left(2 k_{s}+k_{\ell}\right)} \text {. }
$$

Here $k$ indicates the thermal conductivity. As $\kappa_{i c e}$ is approximately 4 times kbrine, the gradient ratio is falrly insensitive to small changes in kbrine caused by variations in the brine composition. Also, as the values of $k$ change slowly with temperature, the $G_{\ell} / G_{S}$ ratio is roughly constant. Substituting appropriate thermal conductivity values Seldensticker (1965) obtalned $G_{\ell}=1.34 G_{S}$. Making an additional correction caused by the density $(\rho)$ differences between the 1 ce and the brine Seidensticker finally obtained

$$
\mathrm{v}=\left(\frac{\mathrm{d}}{\mathrm{mC}}\right)\left(\frac{2 \kappa_{\mathrm{s}}}{\left(2 \kappa_{\mathrm{s}}+\kappa_{\ell}\right)}\right)\left(\frac{\rho_{\ell}}{\rho_{\mathrm{s}}}\right)=1.46 \frac{\mathrm{D}}{\mathrm{mC}}
$$

as the equation giving the velocity of migration in a unit thermal gradient. In eq $33 \mathrm{~m}=\mathrm{d} \theta / \mathrm{dC}$ and is the slope of the 1iquidus curve from the phase diagram (note that the units of $C$ do not matter as long as $m$ and $C$ are in compatible units).

How do the predictions of eq 33 agree with observed brine pocket migration rates? There have been a number of studies of the migration of brine inclusions through ice crystals (Kingery and Goodnow 1963, Hoekstra et al. 1965, Harrison 1965, Jones 1973, 1974). That the theory and observations are in reasonable agreement is shown by Figures 72 and 73. Figure 72 shows the relation between migration velocity and ice temperature at a constant temperature gradient of $1{ }^{\circ} \mathrm{C} / \mathrm{cm}$ in the $1 \mathrm{ce}$. The general shapes of the curves are in good agreement although the theory predicts velocities that are $\approx 20 \%$ higher than observed. That v is a linear function of $G_{S}$, the temperature gradient in the $1 \mathrm{ce}$, is clearly shown in Figure 73. Analysis of the experimental data shows that the rate of droplet migration is, indeed, almost completely con- 


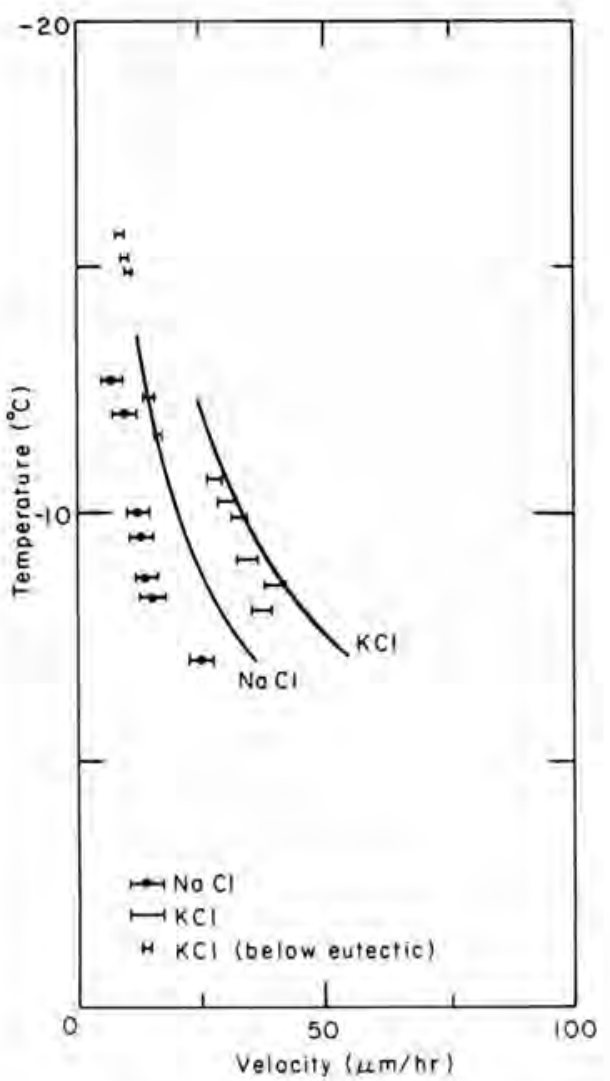

Figure 72. Relation between brine pocket migration velocity and ice temperature at a constant temperature gradient of $1^{\circ} \mathrm{C} / \mathrm{cm}$. The curves are calculated using eq 33 . (Hoekstra et a1. 1965, Seidensticker 1965.)

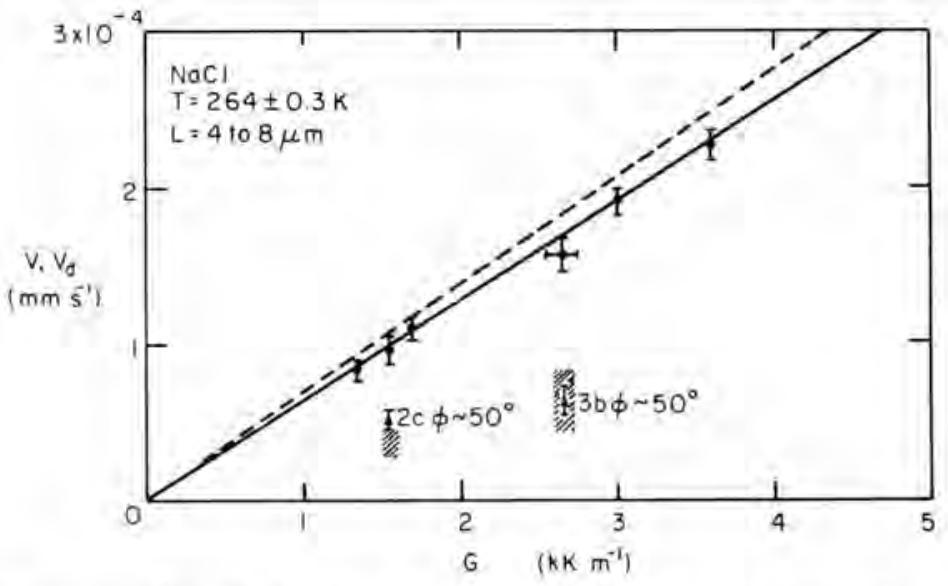

Figure 73. Relation between the temperature gradient in the ice and the brine pocket migration rate (Jones 1973). Each brace marked with a solid circle gives the mean and mean deviation of the velocities of about 10 separate droplets; the braces marked by solid triangles comprise rather smaller samples. The dashed line indicates, to an accuracy of $\pm 10 \%$, the maximum (diffusion-1imited) values of $\mathrm{V}$ determined from calculated values of $D$. The cross-hatched areas give values of $\operatorname{Vcos}^{2} \phi$ for those droplets migrating diagonally.

trolled by the rate of transport of solute through the liquid. At the present time the results suggest that in some, if not all, of the cases studied droplet migration depends on the presence of crystal defects (presumably screw dislocations) in the solid ahead of the high temperature 1nterface (Jones 1973).

The obvious problem with brine pocket migration as an effective contributor to desalination is the fact that brine pockets appear to migrate extremely slowly. In fact Untersteiner (1968) has calculated that, if representative values for the temperature distribution in multiyear ice are used, a brine pocket between 10 and $20 \mathrm{~cm}$ below the ice surface would migrate $2 \mathrm{~cm}$ downward between August and April and then between May and July experience an essentially equal migration upward for a net year's travel of near zero. As an example of an extreme case of brine pocket migration consider a $30^{\circ} \mathrm{C}$ temperature difference across a 1-m-thick piece of first-year ice giving a temperature gradient of $0.3^{\circ} \mathrm{C} / \mathrm{m}$. If the temperature at the brine pocket location is $-6^{\circ} \mathrm{C}$, eq 33 gives a migration velocity of $14.0 \mu \mathrm{m} / \mathrm{hr}$, which corresponds to almost exactly $1 \mathrm{~cm}$ migration per month. 
In closing this discussion, we note that the brine pockets that have been studied have all been very small ( 4 to $80 \mu \mathrm{m})$. In inclusions this small there is little chance for convective motions to occur in the brine. In much larger 1nclusions, with diameters on the order of $1 \mathrm{~mm}$, convection becomes possible, and the transfer of solute in the inclusion is much more efficient, with effective "diffusion" coefficients of $10^{-3}$ as opposed to $10^{-6}$ for pure diffusion. Migration rates should be accordingly enhanced. It should also be noted that the convection will only occur when the temperature increases downward (during the winter). During the summer, when the temperature gradient is reversed, the salt is produced at the bottom of the brine pocket, resulting in a stable density distribution in the liquid. It would be interesting to see this problem explored further.

Brine Expulsion

In his studies of sea ice Bennington (1963a) noted that when the ice was cooled, a pressure buildup occurred in the brine pockets where the liquid portion of the inclusion had separated from the vapor bubble. At times this pressure becomes sufficient to cause the surrounding ice to fail along the basal plane, allowing brine to escape and migrate toward the warm side of the ice sheet. This process is called brine expulsion, and its contribution to the overall removal of brine from sea ice has been explored by Untersteiner (1968) and by Cox and Weeks (1975). Untersteiner has used a simple model which gives $S$, the decrease in the bulk ice salinity, from its initial value of $S_{0}$ when the temperature drops from $\theta_{0}$ to $\theta$, as

$$
\mathrm{S}=\mathrm{S}_{0}\left(\theta_{0} / \theta\right)^{\Delta \rho / 1-\Delta \rho}
$$

where $\Delta \rho \approx 0.1$ is the difference in density between water and ice. This relation only holds while the temperature is continuously dropping from $\theta_{0}$ to $\theta$. Therefore the salinity of the ice at any time $t>0$ depends on the 1nitial salinity of the sample and on all subsequent periods of cooling that the ice has undergone in its history. Equation 33 is then applied to estimating the salinity profile of a multiyear floe. The resulting salinity values indicate that the near-surface 1ce should have a salinity of a few tenths of a part per thousand (as observed), and that below the near-surface ice the salinity profile in all but the lowest part of the ice is very slightly concave upwards (which is not observed).

Cox and Weeks develop a more complex model and utilize it via the application of a finite difference scheme to calculate the change in salinity that should occur in first-year ice. A portion of the results are shown in Figure 74 , where the solid curves give the intial and final experimental salinity profiles and the broken curves were calculated from the model. From this, combined with a number of other comparisons, it was concluded that brine expulsion plays only a small role in the desalination of first-year ice. However, the change in salinity is significant and cannot be neglected. This is especially true during periods of rapid ice growth when the rate of change of temperature at each level in the ice sheet is high. In a way it is unfortunate that brine expulsion is not the dominant desalination mechanism as it is independent of the ice permeability in that the volume changes rupture the 


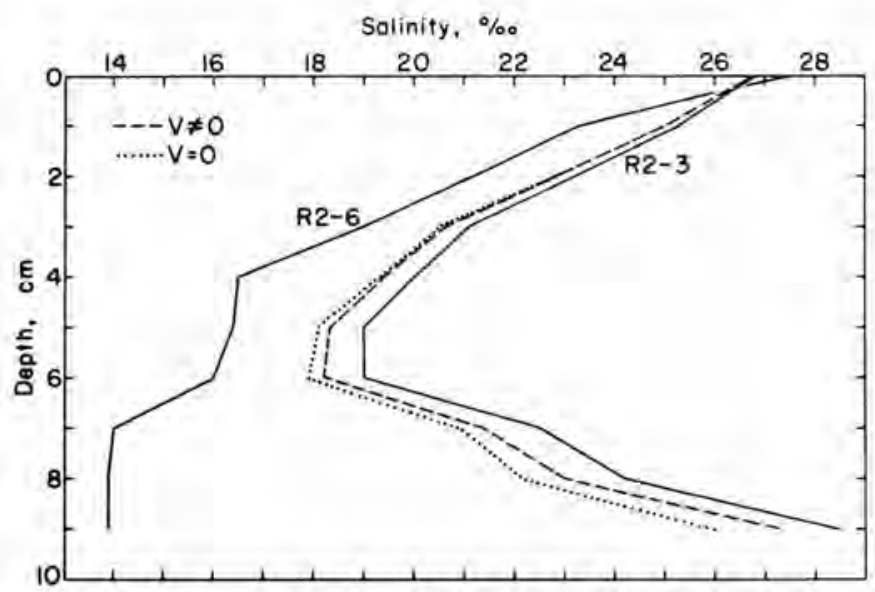

Figure 74. Comparison between experimental salinity curves and theoretical salinity curves determined from a brine expulsion model. $\mathrm{R} 2-3$ and $\mathrm{R} 2-6$ are the initial and final observed curves. The other curves were calculated. The dashed curve considers the effect of brine velocity; the dotted curve does not (Cox and Weeks 1975).

ice, allowing the brine to migrate (no permeability is required as the process makes its own). Therefore a detailed knowledge of the brine pocket and brine channel structure is not required. Photomicrographs showing the effects of brine expulsion in multiyear ice can be examined in Knight (1962c).

\section{Gravity Drainage}

If brine pocket migration and brine expulsion are not sufficiently vigorous processes to explain the observed changes in the salinity profiles of growing sea ice then gravity drainage must be the culprit (unless there is something "undiscovered" taking place). Here by gravity drainage we refer to all processes where brine, under the influence of gravity, drains out of the ice sheet into the underlying seawater. As an ice sheet grows, its surface gradually rises higher above sea level to maintain isostatic equilibrium. This in turn produces a pressure head in the interconnected brine system, driving the underlying brine out of the ice (Eide and Martin 1975). In addition, because the density of the brine in equilibrium with ice is determined by the temperature distribution, during the period of time when the temperature within the ice increases downward an unstable vertical density distribution exists within the brine channels in an ice sheet. This should produce a convective overturn of the brine within the ice as well as an exchange between the denser brine within the ice and the underlying seawater. In such a process the rate of brine drainage should be a function of the temperature gradient in the $1 \mathrm{ce}$, which determines the brine density gradient and the brine volume, which is presumably related to the permeab111ty. Whether or not this is true in an 1ce sheet was examined by Cox and Weeks (1975). Figures 75 and 76 indicate that as elther the brine volume or the temperature gradient in the ice sheet increases, the rate of change of salinity also increases. In fact gravity drainage 


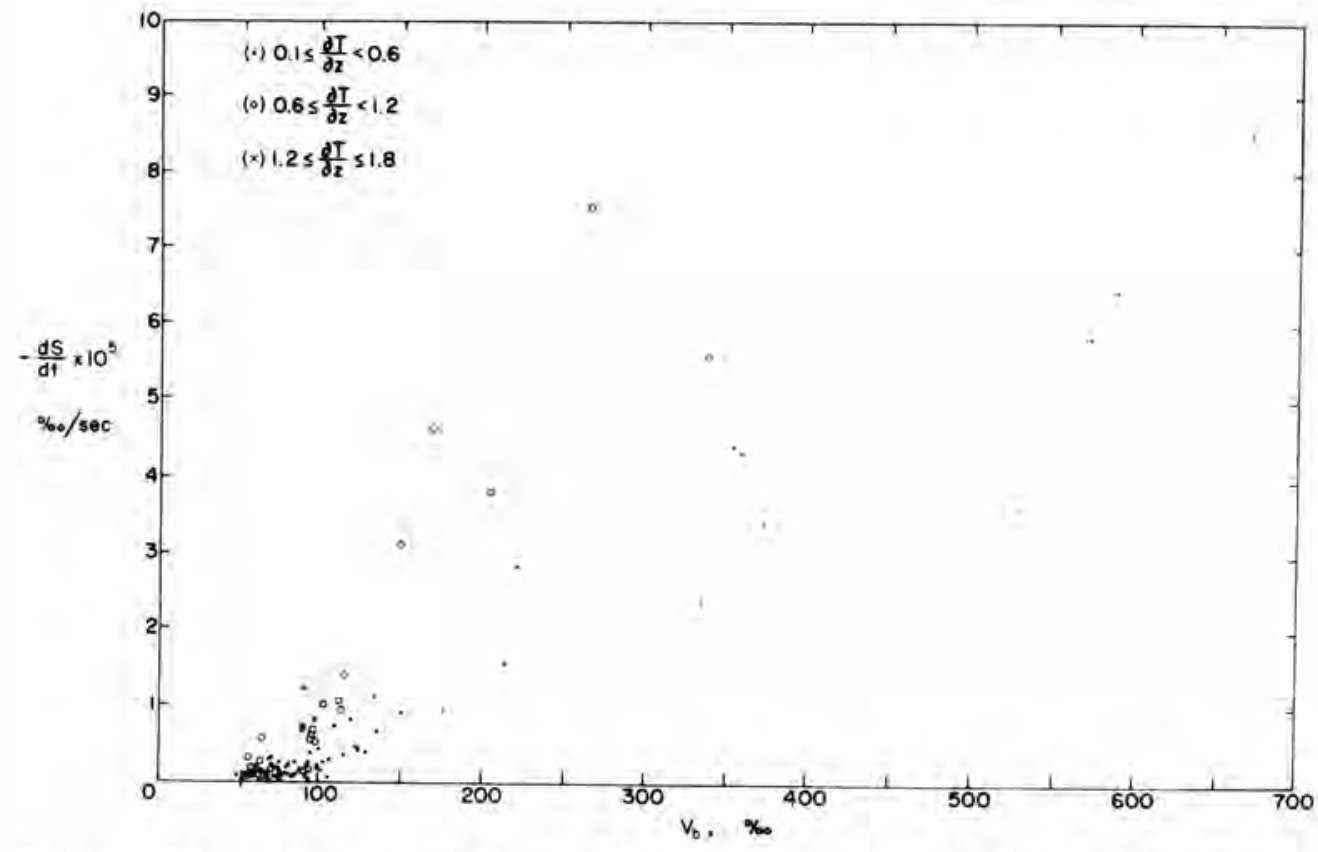

Figure 75. Plot of rate of change of salinity due to gravity drainage $\mathrm{ds} / \mathrm{dt}$ versus brine volume for different temperature gradients $\partial t / \partial z\left({ }^{\circ} \mathrm{C} / \mathrm{m}\right)$ (after Cox and Weeks 1975).

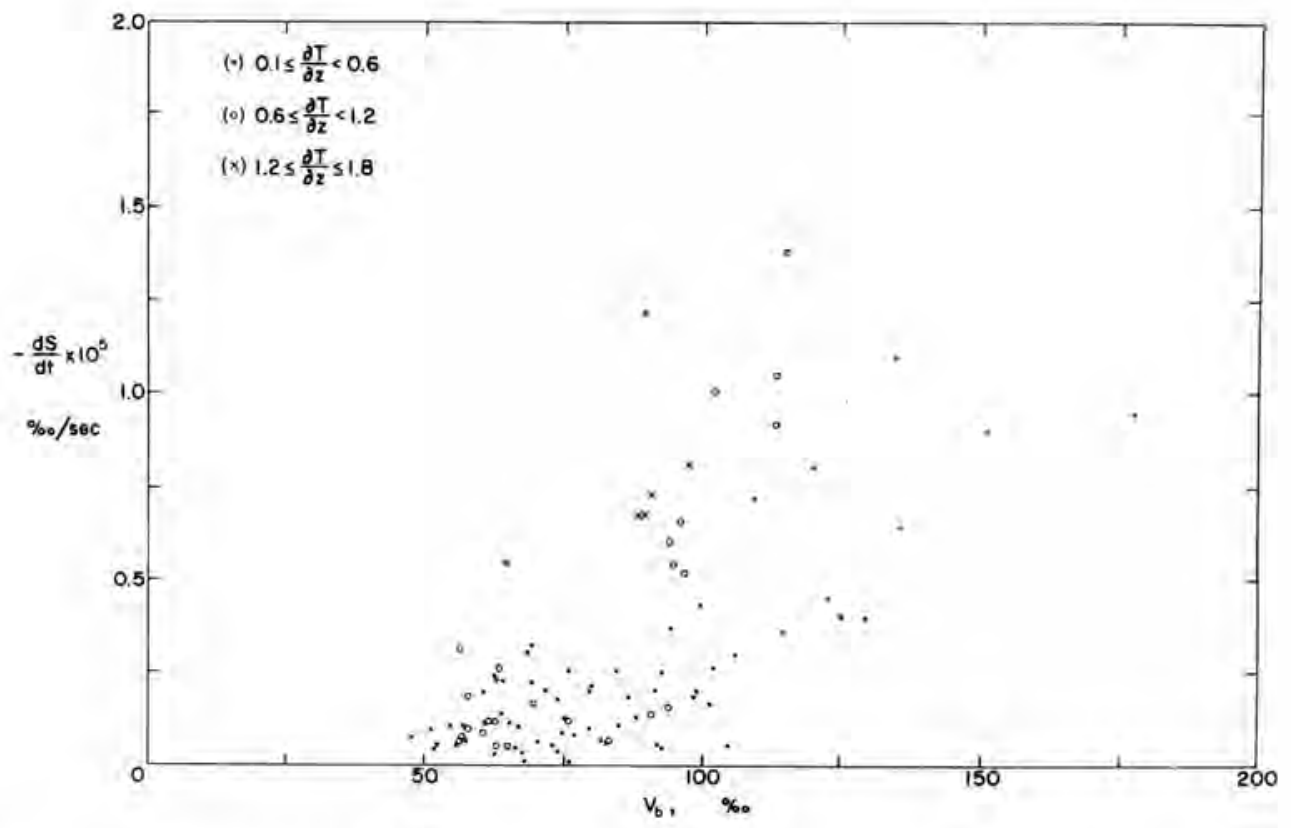

Figure 76. Plot of rate of change of salinity ds/dt due to gravity drainage against brine volume (at low brine volumes) for different temperature gradients $\partial t / \partial z\left({ }^{\circ} \mathrm{C} / \mathrm{m}\right)$ (after Cox and Weeks 1975). 


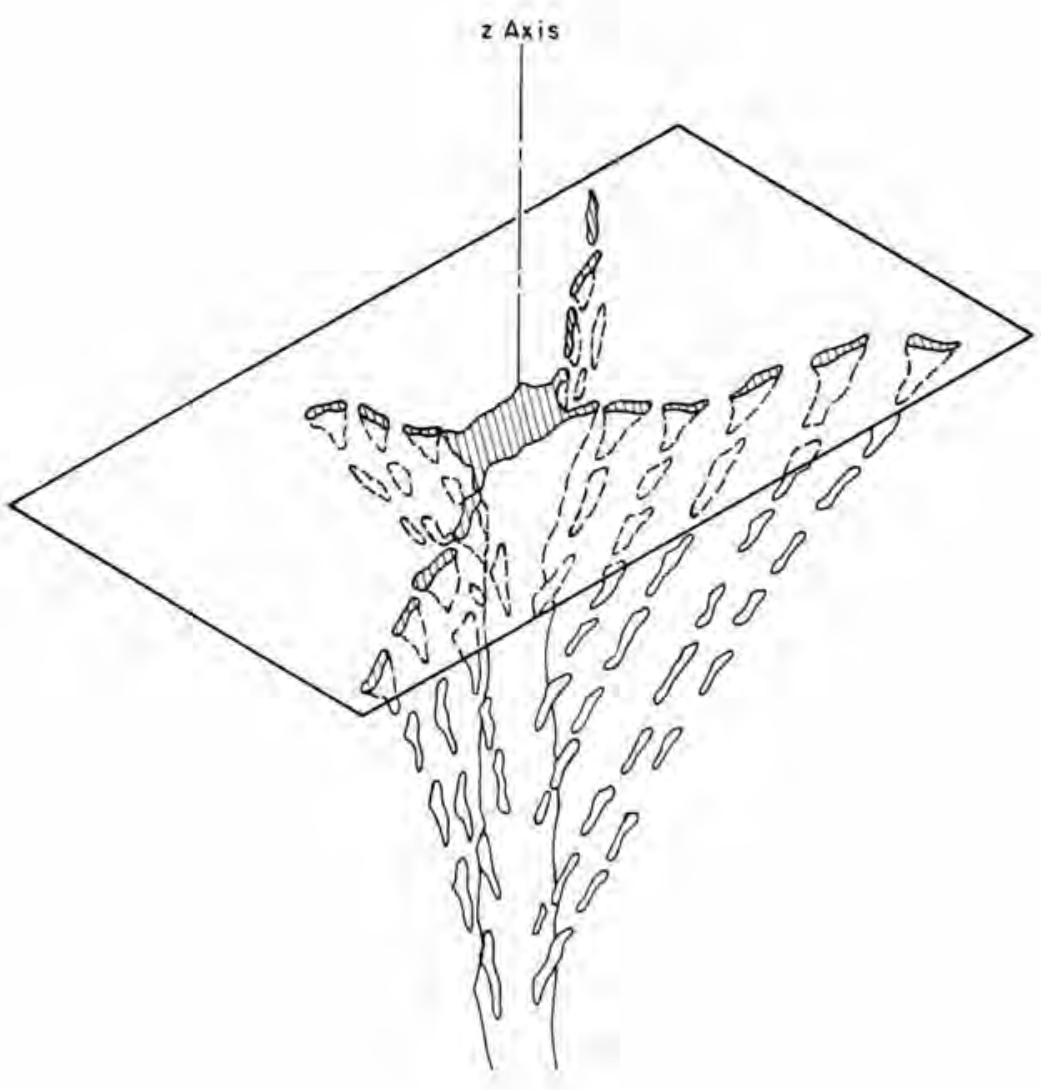

Figure 77. Schematic drawing of a cut through a brine drainage channel (Lake and Lewis 1970).

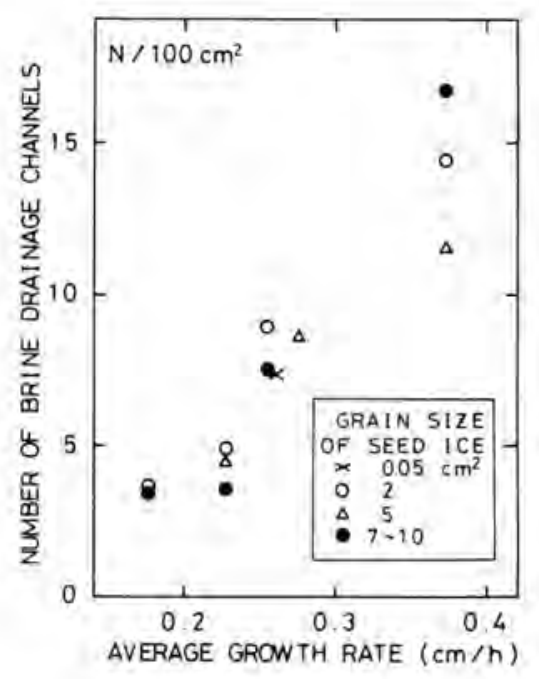

Figure 78. Number of brine drainage channels developed in thin ice sheets versus the average growth rate (Saito and Ono 1980).

does appear to be the dominant mechanism for removing salt from growing sea ice.

The fact that gravity drainage is the dominant mechanism is not surprising. That this is the case was suggested by Kingery and Goodnow in 1963, although in 1968 Untersteiner still remained skeptical that gravity drainage was important in ice thicker than a few tens of centimeters. What is surprising is how gravity drainage works. Although it might be reasonable to expect that gravity drainage would be a process that occurs in a uniform manner at any given level in the ice sheet, this clearly does not appear to be the case. Knight (1962b) and Lake and Lewis (1970) first noted that in natural sea ice large vertical tubular brine drainage structures are attended by smaller tributary tubes, much as in a vertically oriented, radially symmetric river system. Figure 77 shows a schematic drawing of such a brine drainage tube (Lake and Lewis 1970). Representative diameters of the tubes at the bottom of a $1.55-\mathrm{m}-\mathrm{thick}$ ice sheet were $0.4 \mathrm{~cm}$, and there was one large channel every $180 \mathrm{~cm}^{2}$. In a given horizontal plane the large channels show a starburst pattern, with the arms of the star generally following the crystal boundaries. In thick ice $(<10 \mathrm{~cm})$ it has been found (Saito and Ono 1980) that the number of brine drainage channels is related to the average growth rate (Fig. 78) but not to the average grain size. Even at the lowest growth velocities studied there were three channels per $100 \mathrm{~cm}^{2}$ or $33 \mathrm{~cm}^{2}$ per channel as compared to the $180 \mathrm{~cm}^{2}$ per channe 1 
noted in thicker ice by Lake and Lewis. Presumably, some of the channels in the thin ice merge in the same manner as river systems join as the 1ce thickens.

The nature of brine drainage channels has been investigated in a series of papers by Martin and his coworkers (Dayton and Martin 1971, Martin 1974, Eide and Martin 1975, Niedrauer and Martin 1979). The flow from the channels is oscillatory, with the duration of the downward flow being typically shorter than the duration of the upward flow. 0scillatory periods of approximately 1 hour have been described, with an 8- to 15-minute Inflow followed by a 45-minute outflow (Eide and Martin 1975). Dayton and Martin (1971) have described the drainage of brine from such channels at a rate of approximately $111 \mathrm{ter} / \mathrm{minute.} \mathrm{They} \mathrm{have}$ also noted channel dianeters of the order of $10 \mathrm{~cm}$ although most channels appear to have diameters ranging between 0.1 and $1.0 \mathrm{~cm}$.

When the cold, saline brine streamers leave the base of the ice sheet, hollow tubes of 1 ce form around them. These ice stalactites (Paige 1970) can be very large. Dayton and Martin (1971) present exce1lent photographs of such features and note stalactite lengths of 1.5 to $6.0 \mathrm{~m}$ (lengths of 20 to $50 \mathrm{~cm}$ are probably more representative). Once the ice tube is formed around the brine streamer, the horizontal transfer of heat between the brine and the surrounding seawater occurs through the ice wall. However, lateral transfer of salt cannot occur. Immediately after a tube forms, the "relatively" warm brine is in contact with the inner ice wall. For phase equilibriuin to be maintained, this brine must be both cooled and diluted back to the composition specified by the eutectic curve. This is accomplished by melting the inner tube wal1, with the heat of melting coraing from ice accretion on the outer wall. Therefore, the stalactite both accretes on the outside and ablates on the inside while at the same time lengthening.

A similar enlargement appears to take place in brine channels within the ice sheet. Let a flow of cold, dense brine occur through a brine channel from the upper (cold) part of the lce to the lower (warm) part. To warm the cold brine there is a lateral flow of heat (through the ice) to the brine channel. As in the stalactite the brine warms above its equilibrium temperature. To reestablish equilibrium the channel wall melts, cooling the ice and diluting the brine. Therefore, the results of pumping brine down through the ice are both the cooling of the adjacent ice and an increase in the diameter of the brine channel (Martin 1974).

Because the seawater beneath growing sea ice is at its freezing point, there is an inportant difference between brine drainage channels and river systems. A river system usually continuously widens as its mouth is approached. Brine channels, on the other hand, neck just above the ice/water interface (a similar neck also occurs at the tips of growing stalactites; Eide and Martin 1975). Two factors appear to determine this necking. Not only is the seawater below the ice sheet at its freezing point, but it is also less dense than the brine flowing from the ice. This density difference $\Delta \rho$ creates a buoyancy force $\Delta \rho g$ which acts upward and opposes the pressure gradient force $F_{p}$, which drives the brine out of the ice. The value of $F_{p}$ can be calculated (Martin 1974) by assuming that the volume flux $q$ in the neck is imposed on the 
neck by the nature of the upper portion of the drainage channel and that the flow through the neck is Poisseuille flow. Then

$$
F_{p}=\frac{8 \rho_{b} \quad \nu_{b} q}{\pi a^{4}}
$$

where $a$ is the radius of the neck. For a sufficiently small value of $a$, $\mathrm{F}_{\mathrm{p}}>\Delta \rho \mathrm{\rho}$, causing brine to flow out of the neck. For a larger neck

radius $F<\Delta \rho g$, and buoyant seawater intrudes into the neck. When this occurs, because the seawater is at the freezing point and the ice is colder than the water, ice forms on the side of the neck, reducing the value of a. The ratio of these two forces $E$, which is referred to as the "entrainment number," is given by

$$
E=\frac{\pi \Delta \rho g}{8 \rho_{b} \nu_{b}} \frac{a^{4}}{q}=\frac{\text { buoyancy force }}{\text { pressure gradient force }} .
$$

For stalactite tips the tip radius is nearly predicted by $E=1$ (Martin 1974). The sequence of adjustments in the tip radius is as follows. First, the brine flows uniformly out of the tip, causing the tip radius a to increase so that $E>1$. The flow then decreases and seawater intrudes into the neck, freezing to the walls and reducing the radius back to the subcritical value $(E<1)$, at which time the whole process starts anew.

For very slow $(q \rightarrow 0)$ flows salt diffusion is important and the above criterion is not valid. In this situation Lake and Lewis (1970) have argued that a Rayleigh number criterion

$$
\frac{g \frac{1}{\rho} \frac{\partial \rho}{\partial x} a^{4}}{D \mu} \approx 68
$$

(where $\partial \rho / \partial z$ is the density gradient inside the tube caused by the temperature field in the ice, $\mu$ is the viscosity, and $D$ is the salt diffusivity) determines the minimum tube radius. Substituting appropriate values into eq 37 we obtain $a=0.3 \mathrm{~mm}$, which is of the observed order, indicating that in the limit of $q=0$ the channels will remain open.

The reason that oscillations occur is that the brine level inside the ice oscillates between two positions of hydrostatic equilibrium. When cold, dense, saline brine from the upper levels of the ice fills the drainage channel the equilibrium brine level is lower than when warmer, less saline seawater fills the channel. When the tip radius has increased until E $>1$ then any small mass perturbation in the stalactite results in a large pressure imbalance in the brine drainage tube, which accelerates seawater up the tube until the second higher equilibrium level is reached. At the same time, ice growth associated with the influx of seawater is decreasing a, causing $E<1$. In addition, the seawater is being cooled to a brine and the process starts over again. The important factor in governing the oscillations would appear to be the geometry of the brine channels (Martin 1974).

In conclusion, although this has not been investigated, it would appear that the brine drainage channel - stalactite combinations, in addition to providing an efficient mechanism for removing brine that is within the channel, also facilitate desalination by three other mechanisms: 
1. The increase in the diameter of the brine channel both entrains brine pockets and reduces the viscous drag on the downward-flowing brine.

2. The pressure drop associated with the formation of the stalactites facilitates the drainage of brine into the channel.

3. The cooling of the lce surrounding the channel causes the expulsion of brine into the channel (Martin 1972).

There are many aspects of brine drainage that have not been explored at a11. In particular, we refer to the effects of the formation of ice in the brine drainage system and the effective permeability of such systems. We would expect that features similar to brine drainage tubes develop during the solidification of other materials.

\section{Flushing}

Although flushing is actually a particular type of gravity drainage, it is considered separately in that the pressure head necessary to overcome capillary retention is provided by the hydrostatic head resulting from surface meltwater. Therefore, flushing can only occur in the spring and summer when surface melt is possible. The other requirement for flushing is that the ice be permeable. The presence of significant amounts of surface meltwater also suggests that the 1 ce 1 s either at or near the pressure melting point. Such near-melting ice temperatures result in very high brine volumes for a given salinity, and high brine volumes generally correlate with large permeabilities.

It is generally believed that flushing is the most effective mechanism for desalination. The reason for this belief is the fact that the time when flushing starts corresponds to the time during the spring and early summer when major changes occur in the salinity of sea 1 ce. It is also reasonable to believe that the continual percolation of fresh water down and through sea ice should result in significant decreases in the salinity. Considering its probable importance as well as the fact that flushing is undoubtedly similar to (and probably simpler than) processes that have been extensively studied in soils and other permeable materials it is surprising that the only discussion of flushing is by Untersteiner (1968).

In this study, it is assumed that a steady-state salinity profile will be achieved when the downward flux of salt $F_{s}$ is balanced by the upward flux $\omega \cdot s$. Here $\omega$ is the velocity of upward ice displacement (in the Arctic Ocean $\omega \approx 30 \mathrm{~cm} / \mathrm{yr}$ ) and $\mathrm{s}$ is the 1 ce salinity in $\mathrm{g} / \mathrm{cm}^{3}$. To specify $F_{S}$ it is assumed that $\partial F_{s} / \partial z$ is a function $f$ of the largest brine volume $\nu_{\mathrm{m}}$ attained during the period when melt is occurring at the upper surface of the ice floe. Letting $+z$ be the vertical axis (positive downward) the steady-state case is given by

$$
\frac{\partial s}{\partial t}=-w\left(\frac{\partial s}{\partial z}\right)+f\left(\nu_{m}\right) \equiv 0 \text {. }
$$

Then, following Assur (1958), by letting $v_{m}=c\left(s / \theta_{m}\right)$ where $c \approx c o n-$ stant $\approx-55$ and $\theta_{\mathrm{m}}$ and $v_{\mathrm{m}}$ are the highest temperature and highest brine volume attained during the year, Untersteiner obtains

$$
w \frac{\partial s}{\partial z}=\mathbf{f}\left(c \frac{s}{\theta_{m}}\right) \text {. }
$$




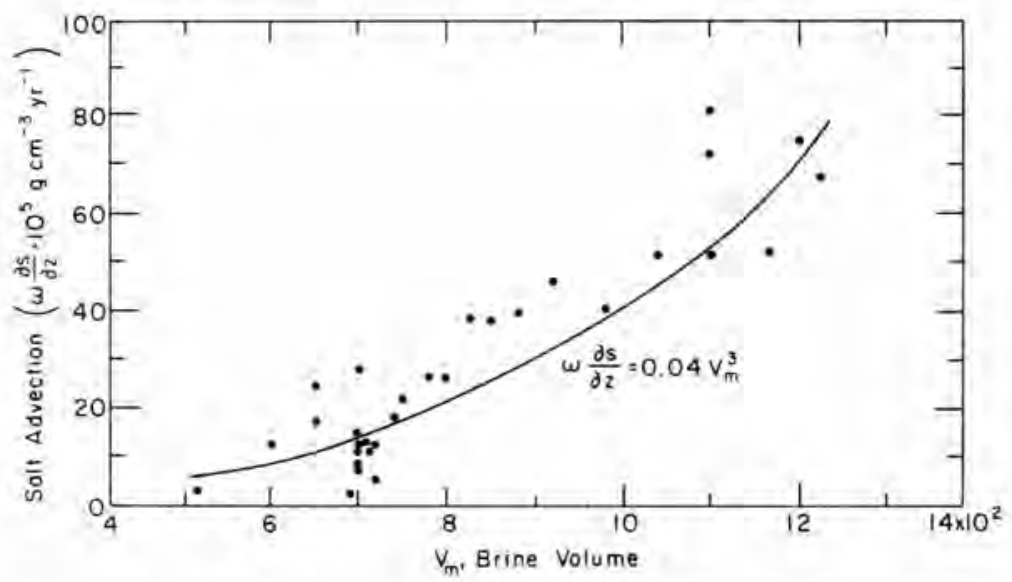

Figure 79. Relationship of maximum brine volume and salt advection required to maintain the steadystate salinity profile shown as curve $\mathrm{C}$ in Figure 65 (Untersteiner 1968).

Untersteiner then presents field data obtained on drifting station Alpha showing vertical profiles of $v_{m}$ and $(d s / d z)$. Both relations are similar, supporting the suggestion that the greatest salt loss occurs at the level where $v_{m}$ reaches its highest value. Based on the observed salinity profile, the values of salt advection necessary to maintain the profile are then calculated and plotted against $\nu_{n}$ (Fig. 79). Based on this plot, 1 t is assumed that $\mathrm{F}_{\mathrm{S}} \approx 0$ at $\mu_{\mathrm{n}} \approx 0.05(5 \%)$. The steady-state case then becomes

$$
\omega\left(\frac{\mathrm{ds}}{\mathrm{dz}}\right) \equiv \omega\left(\frac{\mathrm{ds}}{\mathrm{dz}}\right) \equiv \frac{\mathrm{ds}}{\mathrm{dt}}=0.04 \nu_{\mathrm{m}}^{3}
$$

a relation that can be used to recalculate the salinity profile. The resulting salinity profile shows a very reasonable agreement with the observed salinity profile for multiyear ice (see Untersteiner, 1968, Fig. 1). However, as was also pointed out by Untersteiner, this apparent agreement between "theory" and observation is probably misleading in that the reasoning is somewhat circular: first a salinity profile characteristic of multiyear sea ice was selected, then a relation was selected between ( $\partial \mathrm{s} / \partial t)$ and $\nu_{m}$ that would maintain the steady-state salinity profile. This relation (eq 40) then allowed the recalculation of the original salinity profile. Although encouraging, the agreement can hardly be considered proof that the multiyear salinity profile is the result of flushing. However, flushing certainly does appear to be the most $11 k e l y$ (and almost the only) candidate.

\section{Solid Salt Crystals}

There is only one paper that examines the nature of the solid salt crystals in sea 1ce (Sinha 1977). In this work a microtoming and replicating technique was used to examine the nature of the brine pockets and the precipitation pattern of the salt crystals at low temperatures $\left(-30^{\circ} \mathrm{C}\right.$, which is below the crystallization temperature of $\mathrm{CaCO}_{3} \cdot 6 \mathrm{H}_{2} \mathrm{O}$, $\mathrm{Na}_{2} \mathrm{SO}_{4} \cdot 10 \mathrm{H}_{2} \mathrm{O}, \mathrm{MgCl}_{2} \cdot 8 \mathrm{H}_{2} \mathrm{O}$ and $\mathrm{NaCl} \cdot 2 \mathrm{H}_{2} \mathrm{O}$ ). Figure 80 shows vertical scanning electron micrographs of a brine pocket. Although the individual crystals were not positively identified the majority of the crystals are undoubtedly $\mathrm{NaCl} \cdot 2 \mathrm{H}_{2} \mathrm{O}$. Note the random distribution of the 


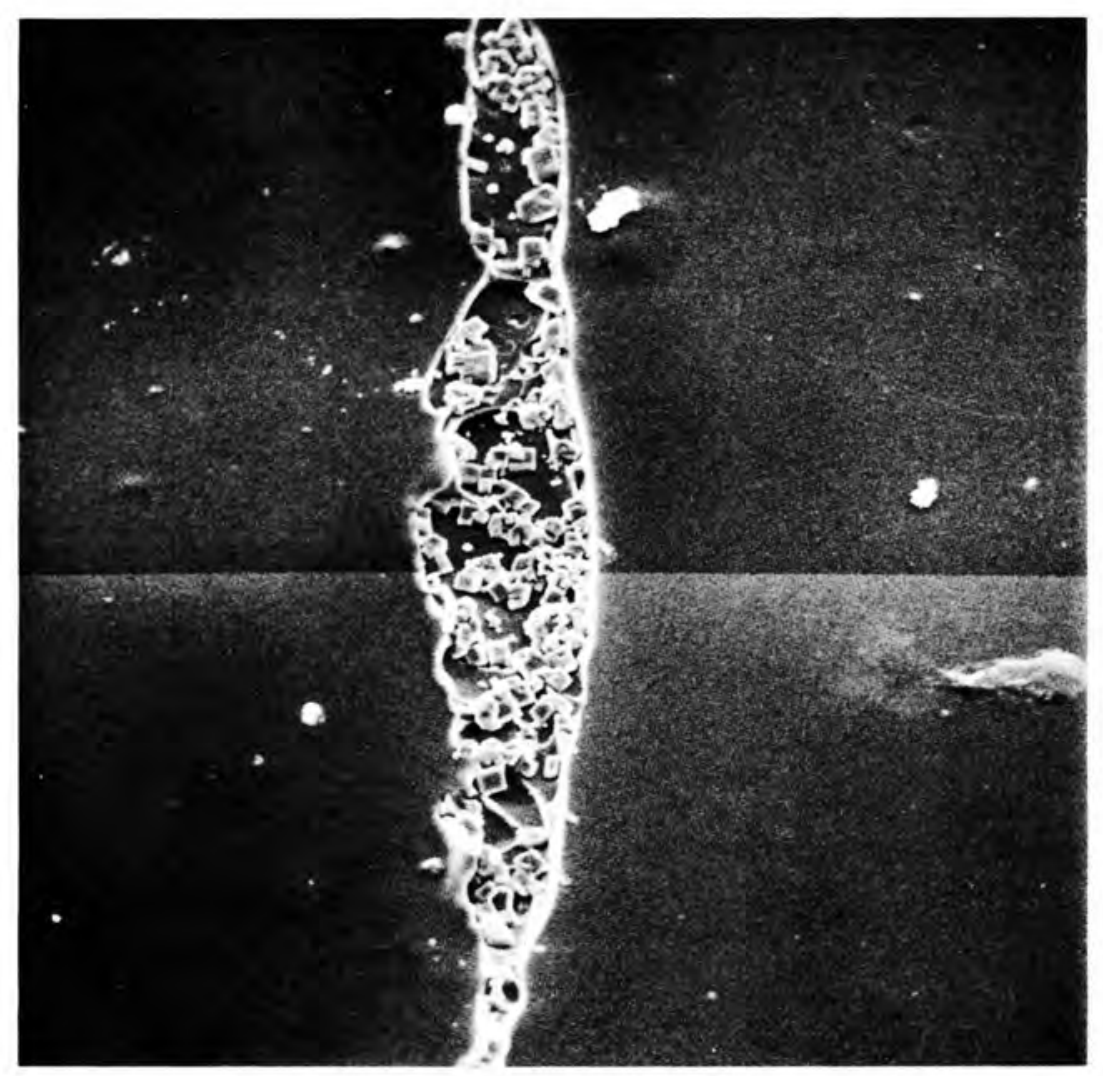

a. 140X magnification.

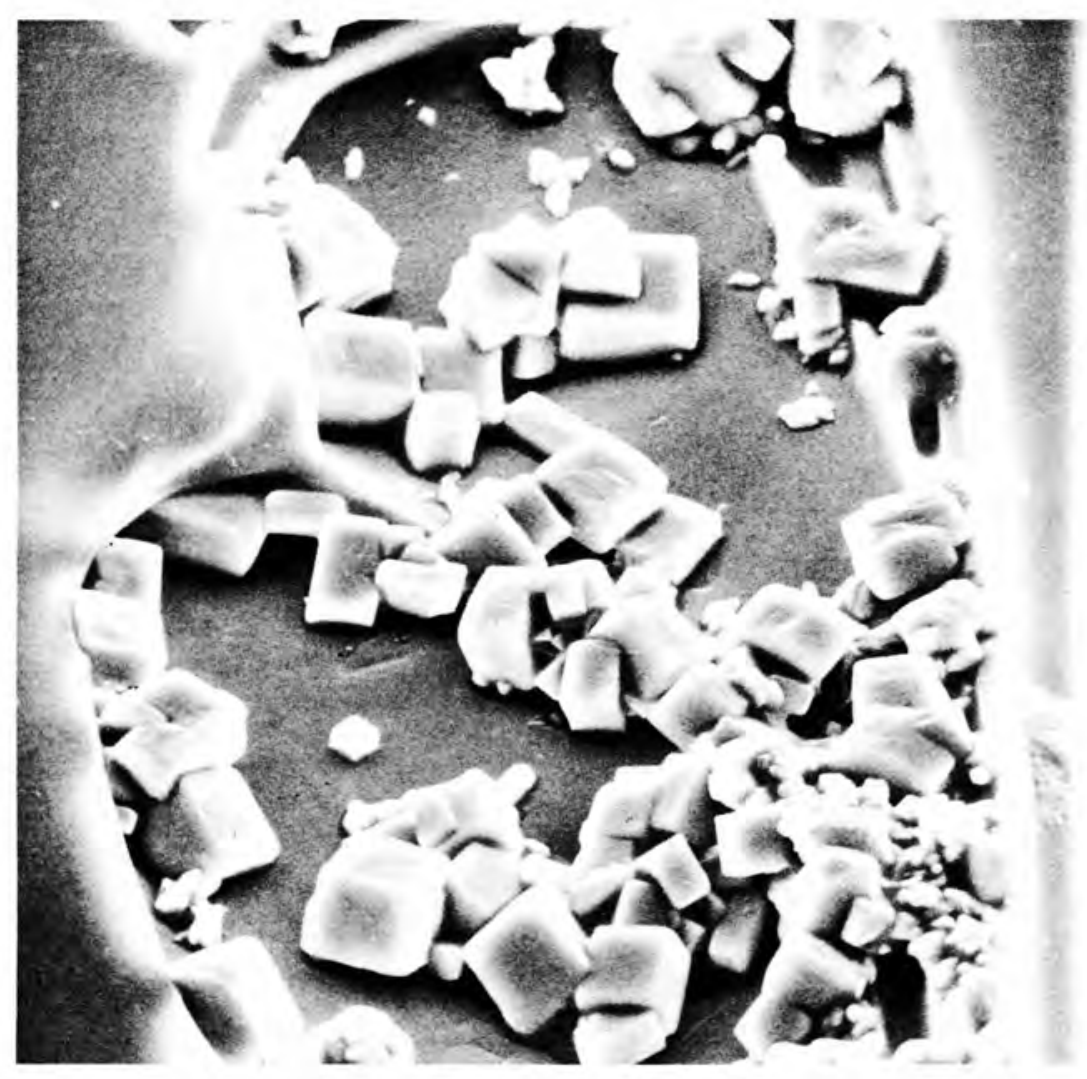

b. $800 \mathrm{X}$ magnification.

Figure 80. Scanning electron micrographs of a vertical section of brine pocket at $-30^{\circ} \mathrm{C}$, second replica (Sinha 1977). 
salt crystals. Most crystals appear to be loosely packed in the cavitles and can be removed either by preparing successive replicates or by washing the microtomed surface with kerosene before the replicates are prepared.

Some brine pocket replicates were also made at $-10^{\circ} \mathrm{C}$, a temperature at which only $\mathrm{Na}_{2} \mathrm{SO}_{4} \cdot 10 \mathrm{H}_{2} \mathrm{O}$ should be present in the ice in appreciable quantities. In this case the walls of the pockets were quite smooth and it appears that many of the salt crystals remained in the liquid brine. If this is the case it is difficult to see how the presence of $\mathrm{Na}_{2} \mathrm{SO}_{4} \cdot 10 \mathrm{H}_{2} \mathrm{O}$ could have a significant effect on the strength of sea ice as suggested by Peyton (1966).

Clearly more work using these or related techniques to exanine the solid salt crystals is needed. It certainly would also be useful to positively identify the different crystals that are observed.

RELATIONSHIPS BETWEEN SEA ICE STRUCTURE AND PROPERTIES

In the above we have discussed a number of aspects of our current understanding of the internal structure of sea ice. We will now review selected examples of how the physical properties of sea ice are affected by changes in its internal structure. Here we will start with the mechanical properties, then discuss the thermal properties, and finally treat our limited understanding of the electromagnetic properties of sea ice. In this last section we will stress electromagnetic properties in the microwave range in that these properties are important in developing and interpreting several different types of remote sensing observations that are currently used in sea ice research.

Models for the Variation in the Mechanical Properties of Sea Ice

Failure Strength

Early studies of the mechanical properties of sea ice revealed that the fracture surface was commonly controlled by the pronounced sea ice substructure. For example Figure 81 (Anderson and Weeks 1958) clearly shows the fracture surface in a sample subjected to tension to tend to run parallel to the (0001) planes of the ice crystals. Additional rubbings showing similar trends have been published by Tabata (1960) and by Paige and Kennedy (1967). Clearly the breaks are following the planes in which the brine pockets and air bubbles are concentrated. That these planes, if correctly oriented, should be planes of weakness is reasonable in that the gas and brine inclusions reduce the percentage of the fallure plane that is solid (ice), allowing failure to occur at lower bulk stress levels. Therefore it would be expected that sea ice samples with low porosities would, being essentially pure ice, have strengths similar to that of freshwater 1ce. Also that sea 1ce with higher porosities would have very low strengths. Experimental observations (Schwarz and Weeks 1977, Weeks and Assur 1967, 1969) support this reasoning.

What was needed was a model that could be used to extrapolate and interpolate strength values at intermediate values of porosity and that was based on a reasonable model of the pore geometry of real sea ice. 


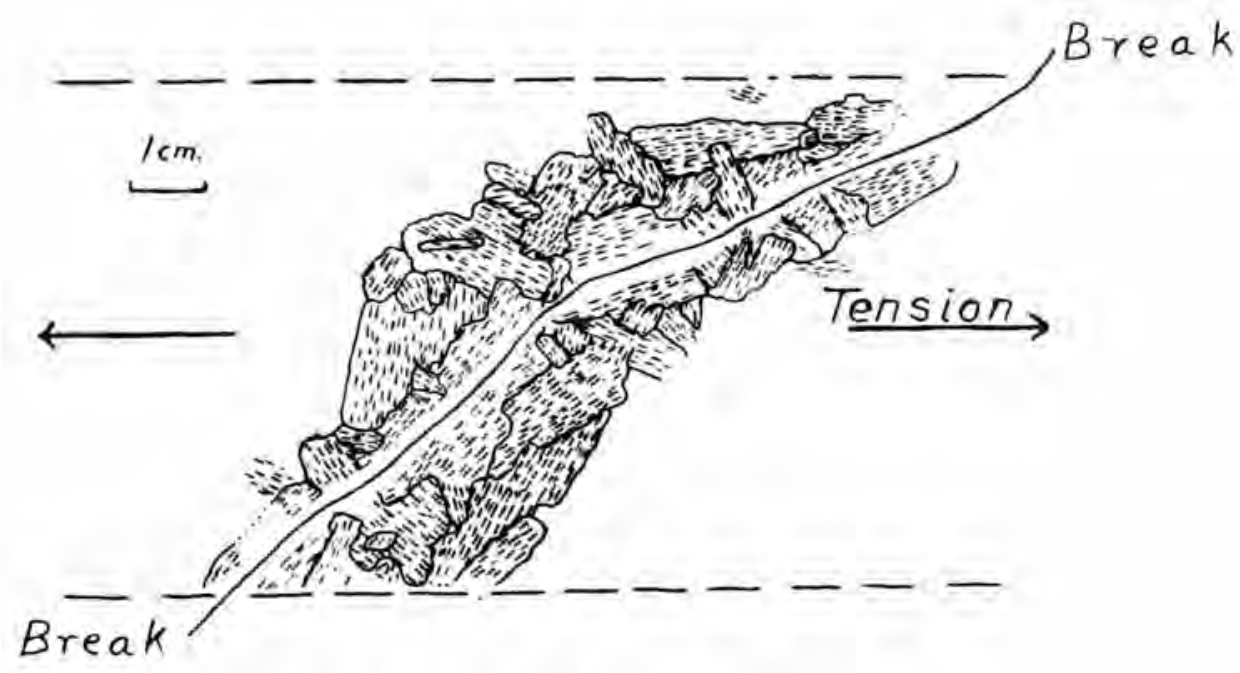

Figure 81. Rubbing of a broken segment of sea ice (Anderson and Weeks 1958).

Such a model was developed by Assur (1958), Anderson and Weeks (1958) and Anderson $(1958,1960)$. They assumed that it should be possible to express the variation in the fallure strength $\sigma_{F}$ for sea 1 ce produced by variations in 1 ts porosity in the general form

$$
\frac{\sigma_{\mathrm{f}}}{\sigma_{\mathrm{o}}}=1-\psi
$$

where $\sigma_{0}$ is the basic strength of sea ice (i.e. the strength of an imaginary material that contains no brine, but still possesses the sea ice substructure and fails as the result of the same mechanism(s) that cause fallure in natural sea ice) and $\psi$ is the "plane porosity" or relative reduction in the area of the fallure plane as the result of the presence of brine and air inclusions. The critical value of $\psi$ in the fallure plane is

$$
\psi=f(v)=f\left(v_{a}+v_{b}\right)
$$

where $\nu$ is the void volume or porosity and $\nu_{a}$ and $\nu_{b}$ are the volume of air and brine respectively in the sea 1ce. Usually it is considered that $v_{b} \gg v_{a}$ (that the volume of brine is sufficiently larger than the volume of air so that $v_{a}$ can be neglected).

It is now necessary to express $\psi$ in terms of $\nu_{b}$ through a simplified model of the brine geometry in real sea ice. Figure 82 shows such a model given by Assur (1958). Here the relative brine volume is

$$
v_{b}=\frac{F_{g}}{a_{0} b_{0} g_{0}}
$$

where $\mathrm{F}_{\mathrm{g}}$ is the average area of a brine inclusion in the BG plane and defining

$$
\beta_{0} \equiv \frac{b_{0}}{a_{0}}
$$




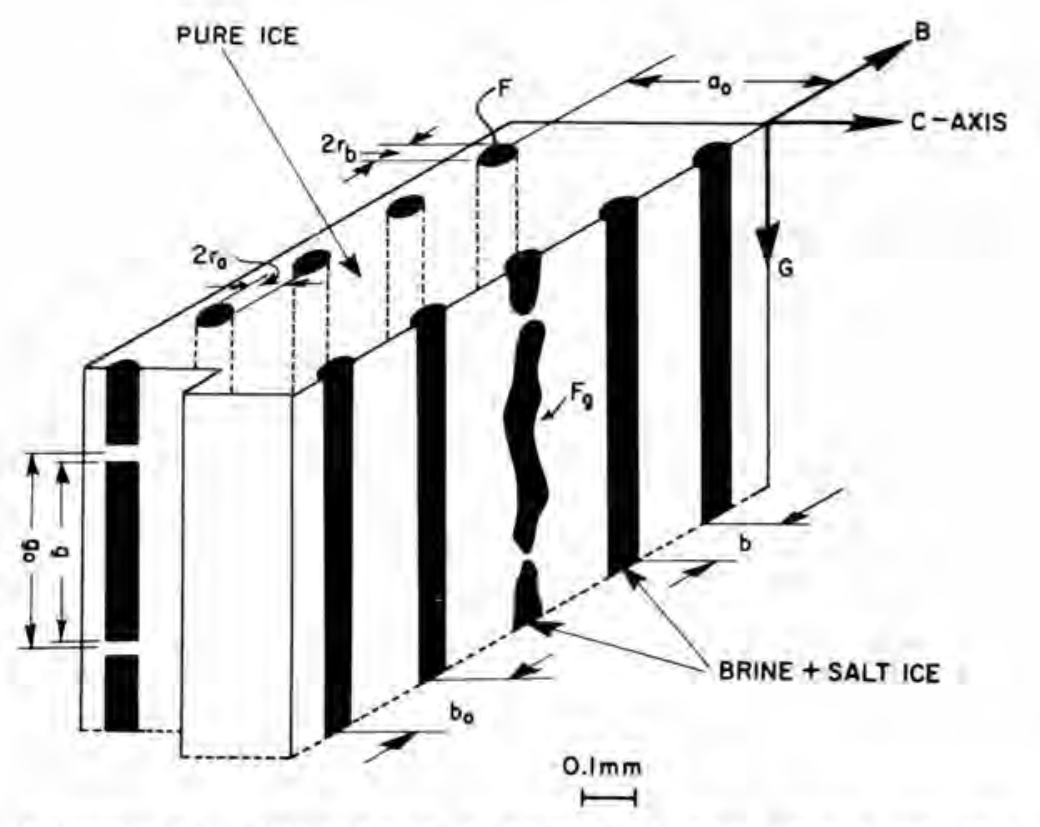

Figure 82. Idealized diagram of the shape of the brine inclusions in sea and $\mathrm{NaCl}$ ice (Assur 1958).

$$
\gamma=\frac{g}{g_{0}}
$$

the reduction in the cross-sectional area caused by the presence of the brine pockets is

$$
\psi=\frac{2 r_{b} g}{b_{0} g_{0}}=\frac{2 r_{b} r}{\beta_{o} a_{o}} .
$$

The question now is: How do the geometric parameters $r_{b}$ and $\psi$ vary with $\nu_{\mathrm{b}}$ ? A number of assumptions are possible; however, two are commonly used. The simplest is to assume that geometric similarity is maintained along the B-axis (see Fig. 82) and that the width as well as the relative length $(\gamma)$ of the brine pockets remain constant. In this instance $r_{b}$ changes proportionally to $\nu_{b}$ and an equation of the form

$$
\frac{\sigma_{f}}{\sigma_{o}}=1-c v_{b}
$$

is obtained. The other assumption commonly made is that the average length and spacing of the brine pockets remain constant and that changes in $v_{b}$ are reflected only in the $B C$ cross section. In this case the resulting equation is

$$
\frac{\sigma_{f}}{\sigma_{o}}=1-c \nu_{b}^{1 / 2} .
$$

These two models can be represented as straight lines in $\sigma_{f}, \nu^{k}$ coordinates where $k$ is 1 and $1 / 2$ respectively. The $\sigma$ axis intercept is $\sigma_{0}$ and

$$
c=\nu_{0}^{-k}
$$


where $\nu_{0}$ is the volume of brine required to cause the ice to have zero strength.

Two specific models that have been utilized in discussing strength results are the constant width and elliptical cylinder models. In the constant width model

$$
F=4 r_{a} r_{b}
$$

and

$$
v_{0}=\frac{2 r_{a}}{a_{0}}=\frac{d_{0}}{a_{0}} .
$$

Here $d_{0}$ is the minimum width of a parallel brine layer before it splits as the result of interfaclal tension to produce individual brine pockets. It is commonly assumed that $d_{0} \approx$ constant (values of $\approx 7 x$ $10^{-3} \mathrm{~cm}$ have been measured in natural sea $\left.1 \mathrm{ce}\right)$.

In the elliptical cylinder model

$$
\varepsilon=\frac{r_{b}}{r_{a}}
$$

and

$$
F=\pi r_{b} r_{a}=\frac{\pi r_{b}^{2}}{\varepsilon}
$$

and eq 48 becomes

$$
\frac{\sigma_{f}}{\sigma_{o}}=1-2 \sqrt{\frac{\varepsilon y}{\pi \beta_{o}}} \sqrt{v_{b}} .
$$

Additional detalls can be obtalned from Weeks and Assur (1967, 1969).

$$
\text { Plots of } \sigma_{f} \text { versus } \nu_{b}, \nu_{b}^{1 / 2} \text {, and } \nu_{b}^{2 / 3} \text { (this last case is where all }
$$

brine pockets remain of a similar shape during changes in $\nu_{b}$ ) have been made for a number of different sets of test data, and it has commonly been found that eq $48 \mathrm{glves}$ the best fit. Therefore, some authors have routinely plotted strength measurements of every type against $\sqrt{v}$. As is pointed out by Mellor (1982), such indiscriminate application of eq 48 is to be avolded, particularly in cases where the structure of the ice 1s unknown, when the orientation of the pore structure to the principal stresses and to the fallure stresses is uncertain, and when the fracture mechanisms are not fully understood.

For Instance, it would clearly be inappropriate to apply the details of such models to marine frazil 1ce (a material whose mechanical properties have not, as yet, been investigated), as its structure is very different from that of congelation sea ice (see F1g. 52-56). Structurally, marine frazil 1ce appears to be similar to compact snow, with the included brine and air distributed between the grains (as contrasted to within the grains as is the case for congelation ice). If, as a first approximation, the brine and air inclusions can be assumed to be 
randomly distributed throughout the ice in a fashion similar to that observed for dense snow then we would expect strength to decrease as a linear function of $\nu_{\mathrm{b}}$, since in such a case the relative plane porosity in any cross section is equal to $v_{b}$. Also the properties of the ice would not depend upon the orientation of the sample relative to the applied stresses.

In this section we have discussed the effect of brine and gas inclusions in the ice on the bulk properties of the 1 ce. Nothing has been said concerning the effect of the presence of solid salts. There have as of now been two attempts to develop a theory for the effect of solid salts. Assur (1958) postulated two different situations based on a model of the reinforcement of the brine pocket walls by a continuous layer of internixed ice and solid salt. In the first case the elastic modulus (E) of the salt-ice reinforcenent is similar to that of pure ice, and rupture occurs within the reinforcement. As a result a relatively thin layer of salt-ice should abruptly increase the ice strength, but little further increase would be observed with the thickening of the reinforcement. In the second case a substantial difference in $\mathrm{E}$ between the salt-ice mixture and the pure lce is assumed, with the strength of the mixture being sufficiently high so that the initial failure occurs in the ice as opposed to in the mixture. It was suggested that the first situation might apply to the precipitation of $\mathrm{Na}_{2} \mathrm{SO}_{4} \cdot 10 \mathrm{H}_{2} \mathrm{O}$, where only a small amount of salt forms, with the second case applying to the precipitation of $\mathrm{NaCl} \cdot 2 \mathrm{H}_{2} \mathrm{O}$, when much larger quantities of salt form. Further work on this problem was later undertaken by Peyton (1966), who utilized a similar salt reinforcement model.

There are two obvious problems here. First, the very limited direct observations on the nature of the distribution of solid salt crystals in brine pockets reported by Sinha (1977) show a random distribution of loosely packed crystals. This clearly does not support the geometric assumptions of Assur's mode1. However, more important there is still no adequate set of strength tests on real sea ice against which the predictions of any model can be tested. The closest to an adequate study of this problem was by Weeks (1962), who performed ring-tensile tests on $\mathrm{NaCl}$ ice. He found that the strength of $\mathrm{NaCl} \cdot 2 \mathrm{H}_{2} \mathrm{O}$ ice was a) essentially independent of temperature and the volume of $\mathrm{NaCl} \cdot 2 \mathrm{H}_{2} \mathrm{O}$, and b) comparable to the strength of freshwater ice. This plus Sinha's observations suggest that solid salts may well have little effect on the fallure strength of sea ice. What is clearly needed now is a set of high quality tests that are speciflcally focused on resolving this problem.

\section{Elastic Modulus}

It is only recently that a similar mode1 has been suggested to explain the variation in the elastic modulus (E) of sea ice with changes in the volume of brine included in the ice (Bergdah1 1977). First, stress in the vertical direction (G-direction, see Figure 83 ) is considered. Also, the value of $\nu_{a}$ is assumed to be negligible and the vertical interruptions in the brine cylinders are neglected. Then the deformation for the brine inclusions and for the ice matrix are set equal $(\nu=0)$ and the loading is considered to be dynamic. Then 


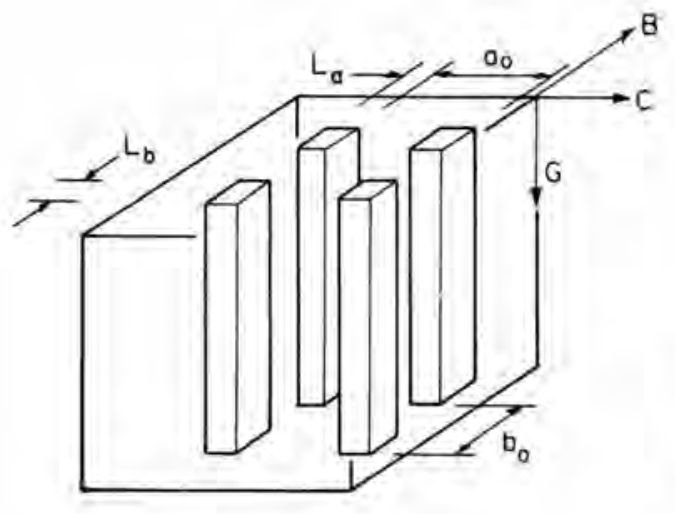

Figure 83. An idealization of the structure of sea ice used in calculating its elastic modulus (Bergdah1 1977). The rectangular areas represent brine inclusions.

$$
\varepsilon=\mathrm{pK}=\sigma_{l} / \mathrm{E}_{\mathrm{l}}=\sigma / \mathrm{E}
$$

where $\varepsilon=$ strain

$\mathrm{p}=$ pressure in the brine pockets

$\sigma_{1}=$ stress in the ice

$\sigma=$ stress averaged over the cross section $A, \sigma=P / A$

$\mathrm{E}=$ bulk elasticity of sea $1 \mathrm{ce}$.

From eq 55

$$
\sigma=E \varepsilon \quad \mathrm{p}=\varepsilon / \mathrm{K} \quad \sigma_{1}=\varepsilon \mathrm{E}_{1}
$$

and the average stress is

$$
\sigma=\sigma_{1}\left(1-A_{b}\right)+p A_{b}
$$

where $A_{b}$ is the relative cross-sectional area of brine. These equations give

$$
E=E_{1}+\left(1 / K-E_{l}\right) A_{b}
$$

or, if $\nu_{b}=A_{b}$,

$$
E=E_{1}+\left(1 / K-E_{1}\right) \nu_{b}
$$

suggesting that $\mathrm{E}$ should prove to be a linear function of the brine volume. This, of course, has been shown to be the case experimentally (see Mellor 1982, Weeks and Assur 1967, or Schwarz and Weeks 1977).

When horizontal deformations in the sea ice cover are considered, a more complex model must be utilized. In doing this Bergdahl approximates the brine pockets as rectangular tubes with a horlzontal crosssection area $\mathrm{L}_{a} \cdot \mathrm{L}_{\mathrm{b}}$ (see Fig. 83 ). Deformation along the c-axis is then given by

$$
a_{0} \varepsilon=a_{0} \sigma / E_{h}=L_{a} \sigma / E_{b}+\left(a_{0}-L_{a}\right) \sigma / E_{l}
$$

w1th

$$
\begin{aligned}
E & =\text { average strain along the c-axis } \\
a_{0} & =\text { brine layer spacing } \\
\sigma & =\text { average stress } \\
E_{h} & =b u 1 k \text { modulus of elasticity } \\
E_{b} & =\text { bulk modulus of the brine layer } \\
E_{1} & =\text { elasticity of pure lce. }
\end{aligned}
$$


The bulk elasticity can ultimately be simplified to

$$
E_{h}=E_{l} /\left(1-\left(1 / K-E_{l}\right) v_{b} / E_{b}\right)
$$

indicating that the elastic modulus in the horizontal direction would be expected to be a function of both the brine volume and the shape of the brine pockets. As in the equations for failure strength, to evaluate eq 61 a relation must be assumed between the ratio $\mathrm{L}_{\mathrm{b}} / \mathrm{L}_{\mathrm{a}}$ and $\nu_{\mathrm{b}}$.

There are many problems with the utilization of such models. $O b-$ viously they represent gross simplifications of the structure of real sea ice, which in actuality is very complex. One difficulty is that there is very little information on how brine pocket shapes actually change with changes in $v_{b}$. Also, usually the total void volume is assumed to equal $\nu_{b}$, the brine volume (i.e. $v_{a}$ is assumed to equal zero). Now this is not strictly true, even for young sea ice, while for low salinity multiyear ice $v_{a}$ may be much larger than $v_{b}$. There are, at present, no good observations to support the common assumption that air bubbles are localized along the same substructure as the brine pockets. This, of course, seems reasonable, and many tines the total void volume $v$ is taken to be the sum $v_{a}+v_{b}$. Finally, there are very few sets of measurements of the mechanical properties of sea ice available in which both $\nu_{a}$ and $v_{b}$ were determined. Even considering these weaknesses, the geometric models for the variations in the mechanical properties of sea lce have proven to be very useful and they undoubtedly will continue to be utilized in treating a variety of different problems.

\section{Applications}

We conclude this section with a discussion of one such application. As was discussed earlier it is known that some elements of the substructure of sea ice vary systematically with changes in the growth velocity. The growth velocity is in turn controlled by the meteorological conditions. If changes in the substructure affect the mechanical properties of the ice, it is then possible to formulate relations between the meteorology and the ensuing 1ce properties. For example, let us first assume that the relation between brine layer spacing $a_{0}$ and growth velocity $\mathrm{v}$ can be expressed as

$$
a_{0} \sqrt{v}=c
$$

where $c$ is a constant. Then if the 1ce growth equation can be approximated by

$$
t=\frac{\rho L h}{\Delta \theta}\left[\frac{1}{e}+\frac{h}{2 k}\right]
$$

where $t$ is time, $h$ is ice thickness, $p$ is the density of the ice, $L$ is the latent heat of fusion of the $1 \mathrm{ce}, \Delta \theta$ is the difference between the amblent air temperature and the freezing temperature of seawater, $k$ is the thermal conductivity of sea ice, and $e$ is the overall coefficient of surface heat transfer, by rearranging and differentiating we can obtain

$$
\mathrm{v}=\frac{\mathrm{dh}}{\mathrm{dt}}=\frac{\Delta \theta}{\rho \mathrm{L}\left[\frac{\mathrm{l}}{\mathrm{e}}+\frac{\mathrm{h}}{\mathrm{k}}\right]} .
$$


This relation, when combined with eq 62 , gives

$$
a_{0}=\sqrt{\frac{c^{2} \rho L}{\Delta \theta}\left[\frac{1}{e}+\frac{h}{k}\right]} .
$$

For thin ice $a_{0}$ is independent of ice thickness $\mathrm{h}$, as $1 / \mathrm{e} \gg \mathrm{h} / \mathrm{k}$. For thlck ice, on the other land, $h / k \gg 1 / e$, giving $a_{o}$ varying proportional to $\sqrt{h}$.

The structural paraneter $a_{0}$, however, appears in the ice strength equations. For instance, in the constant width model as

$$
\frac{\sigma_{f}}{\sigma_{0}}=1-\frac{\nu_{b}}{\nu_{0}}=1-\frac{a_{0} \nu_{b}}{d_{0}}
$$

and the elliptical cylinder model as

$$
\frac{\sigma_{f}}{\sigma_{0}}=1-2 \sqrt{\frac{\gamma \varepsilon a_{0}}{\pi b_{0}}} \sqrt{v_{b}} .
$$

Therefore, combining these relations with eq 65 we obtain, respectively,

$$
\sigma_{f}=\sigma_{o}\left[1-\frac{c \nu}{d_{o}} \sqrt{\frac{\rho L}{\Delta \theta}\left[\frac{1}{e}+\frac{z}{k}\right]}\right]
$$

and

$$
\sigma_{\mathrm{E}}=\sigma_{\mathrm{o}}\left[1-2 \sqrt{\frac{\nu_{\mathrm{b}} \gamma \varepsilon c}{\pi b_{0}} \sqrt{\frac{\rho L}{\Delta \theta}\left[\frac{1}{\mathrm{e}}+\frac{z}{k}\right]}}\right]
$$

where $z$ is the position of a given ice layer below the surface and $\Delta \theta$ is the temperature difference when that layer formed. Combining all the constants and considering only thin ice, the two different models give, respectively,

$$
\sigma_{f}=\sigma_{o}\left[1-\text { const } \frac{\nu_{b}}{\sqrt{\Delta \theta}}\right]
$$

and

$$
\sigma_{\mathrm{f}}=\sigma_{\mathrm{o}}\left[1-\operatorname{const} \sqrt{\frac{v_{\mathrm{b}}}{\sqrt{\Delta \theta}}}\right] .
$$

These equations support the intuitive conclusions of early Soviet investigators (see Sharp 1947), who claimed that the strength of young sea ice was in some way affected by its growth conditions. For thick ice we obtain

$$
\sigma_{f}=\sigma_{o}\left[1-\operatorname{const} v_{b} \sqrt{\frac{z}{\Delta \theta}}\right]
$$


and

$$
\sigma_{f}=\sigma_{o}\left[1-\text { const } \sqrt{v_{b} \sqrt{\frac{z}{\Delta \theta}}}\right] .
$$

More details and a consideration of the effect of a snow cover on the sea 1 ce can be found in Assur and Weeks (1964). The important point here is that similar studies can easily be made of the effect of vertical variations in a variety of structural characteristics of sea ice upon the profile properties of the sheet, provided that the relations between the characteristics and the ice growth conditions have been established. A related study that exanines the effect of growth conditions on the salinity and brine profiles of first-year sea ice has been pub11shed by Weeks and Lofgren (1967).

Models for the Variation in the Thermal Properties of Sea Ice

By the thermal properties of sea ice we specifically refer to the parameters that compose the thermal diffusivity term in the thermal diffusion equation, i.e. the specific heat, the density and the thermal conductivity. Of these three terms the first two depend only on the temperature and the composition of the 1ce. The geonetric distribution of the components is not a factor. Therefore they will not be discussed here. Good recent reviews and studies of these two properties can be found in Bergdahl (1977), Yen (1981) and Cox and Weeks (1982).

\section{Thermal Conductivity}

The thermal conductivity of sea ice and the thermal diffusivity which contains the thermal conductivity are dependent on the spatial arrangement of the different phases composing the sea ice: the pure ice, the brine, the entrapped gas and, if the ice is sufficiently cold, the solid salt hydrates. Figure 84 gives thermal conductivity $\left(\lambda_{i}\right)$ of pure polycrystalline ice determined by several investigators (see Yen 1981 for references). For practical purposes Yen suggests that the complete set be used, resulting in the relation

$$
\lambda_{i}=9.828 \exp (-0.0057 \mathrm{~T})
$$

where $\lambda_{1}$ is in $\mathrm{W} / \mathrm{m} \mathrm{K}$ and $\mathrm{T}$ is in kelvins. The effect of crystal orientation on $\lambda_{i}$ has been 1ittle studied (Landauer and Plumb (1956) suggest that $\lambda_{1}$ parallel to the c-axis is approximately $5 \%$ higher than values measured normal to the c-axis). Note that at $273 \mathrm{~K}, \lambda_{i}$ is roughly $2.2 \mathrm{~W} / \mathrm{m} \mathrm{K}$, which is about 4 times the thermal conductivity of water at that temperature. There are, as yet, no measurements on the conductivity of seawater brine in equilibrium with ice. However, data on other salts suggest that $\lambda_{b}$ is strongly dependent on concentration and less dependent on temperature. Based on $\lambda_{b}$ measurements for NaC1 and $\mathrm{Na}_{2} \mathrm{SO}_{4}$ solutions, Schwerdtfeger (1963) has suggested that the value for seawater brine can be approximated by

$$
\lambda_{b}=0.4184\left(1.25+0.030 \theta+0.00014 \theta^{2}\right)
$$

where $\lambda_{b}$ is in units of $W /(m K)$ and $\theta$ is in $K$. As Schwerdtfeger 


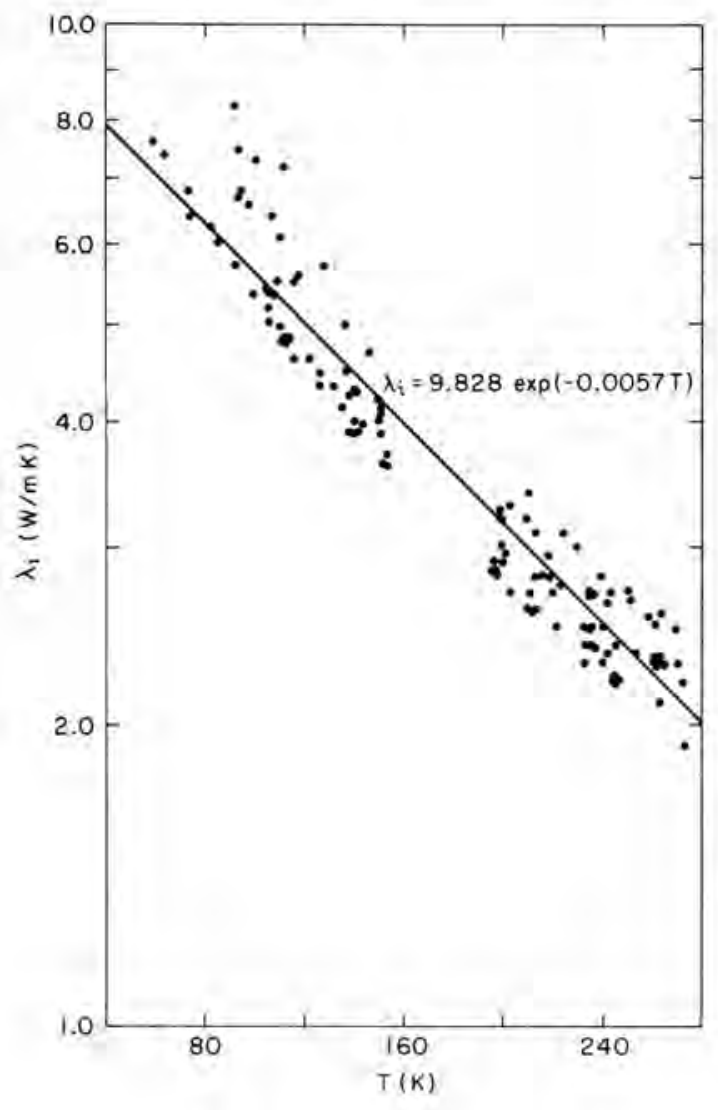

Figure 84 . Thermal conductivity of pure ice as a function of temperature. See Yen (1981) for the data sources.

polnts out, although eq 75 becomes less accurate at lower temperatures, the value of $\lambda_{b}$ is less Important under such conditions because the relative volume of brine becomes negligible. The thermal conductivity of a1 $\mathrm{r}\left(\lambda_{\mathrm{a}}\right)$ is approximately $0.03 \mathrm{~W} /(\mathrm{m} \mathrm{K})$ at temperatures between $-30^{\circ} \mathrm{C}$ and $0^{\circ} \mathrm{C}$, or roughly $1 \%$ of the conductivity of the ice. Therefore, for most purposes $\lambda_{a}$ is taken as nil. The conductivities of the solid hydrates at temperatures below $-8.7^{\circ} \mathrm{C}$ are not well known and they are usually neglected inasmuch as they would be expected to have only a very small effect on the bulk conductivity of sea ice.

Next it is necessary to consider the effect of the geometry of the brine and gas inclusions on the bulk conductivity of the sea 1ce. This was first done by Anderson $(1958,1960)$, who considered the presence of brine in several different spatial configurations. Among these were the cases with the brine distributed

a) in isolated spherical bubbles

b) In parallel cylinders or layers between ice platelets with the conductivity measured in the direction of the brine layers (analogous to electrical conduction in parallel), and

c) in parallel layers with the conductivity measured perpendicular to the layers (analogous to electrical conduction in series).

These results are shown in Figure 85. Note that the conductivity measured parallel to the c-axis (perpendicular to the brine layers) is appreciably lower than the equivalent value measured perpendicular to the c-axis. This difference in thermal conductivity with crystal orienta- 


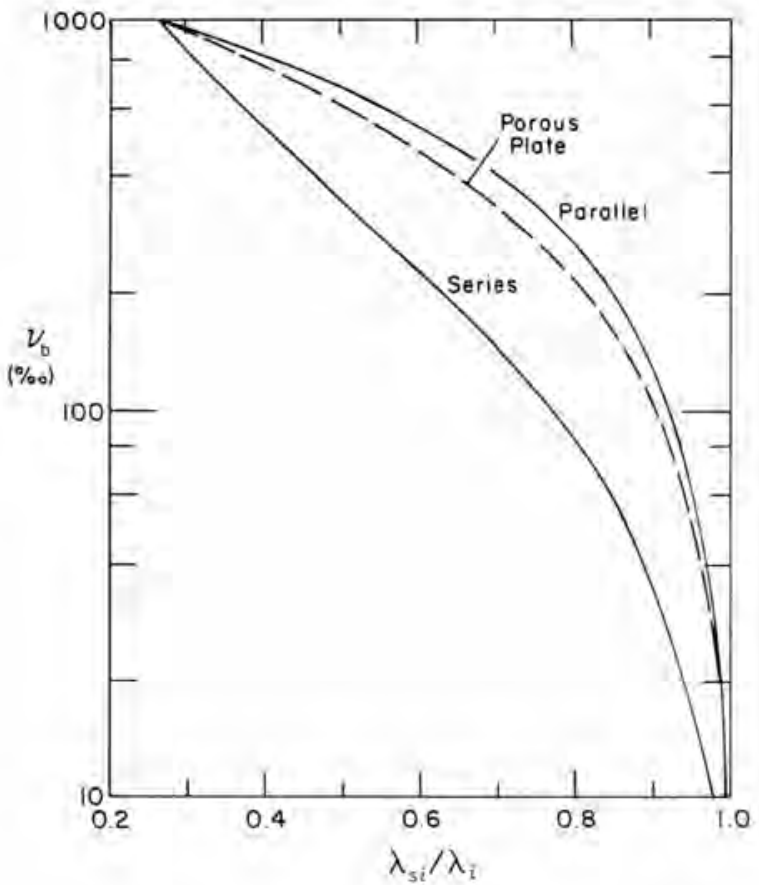

Figure 85 . Thermal conductivity of sea ice (Anderson 1958). The different curves represent different arrangements of the brine inclusions.

tion is undoubtedly an important contributing cause of the fact that in the transition layer in the upper part of newly formed sea ice the crystals with their c-axes horizontal are observed to grow ahead of crystals in other orientations (the c-axis-horizontal crystals have their direction of maximum thermal conductivity aligned in the vertical, parallel to the direction of heat flow (Weeks 1958)).

Inasmuch as the heat flow in sheets of undeformed sea 1ce is essentially one-dimensional (in the vertical) and the great majority of congelation ice is oriented with its c-axes horizontal, this is clearly the case that should be considered in most practical problems. Schwerdtfeger (1963) expanded upon Anderson's treatment by considering the presence of air in the sea ice. This was done by assuming that the air in sea ice consists of a serles of unfform, randomly distributed spherical air bubbles. Then, using a relation developed by Maxwell (1891), which incidentally is the same relation Anderson used in calculating the "porous plate" conductivity given in Figure 85 ,

$$
\lambda_{b i}=\frac{2 \lambda_{1}+\lambda_{a}-2 v_{a}\left(\lambda_{i}-\lambda_{a}\right)}{2 \lambda_{1}+\lambda_{a}+v_{a}\left(\lambda_{i}-\lambda_{a}\right)} \lambda_{i}
$$

where $\lambda_{b i}$ is the thermal conductivity of pure ice containing randomly distributed bubbles as stated and $V_{a}$ is the volume of air per unit volume of sea ice. Figure 86 gives the resulting values of $\lambda_{b i}$ (and of the density of bubbly ice $\rho_{\mathrm{bi}}$ ) for temperatures in the 0 to $-20^{\circ} \mathrm{C}$ range. Here $\lambda_{1}$ and $\lambda_{a}$ were respectively taken to be 2.09 and $2.51 \mathrm{x}$ $10^{-2} \mathrm{~W} / \mathrm{m} \mathrm{K}$. Schwerdtfeger then considered sea 1ce as the composite material composed of layers of brine and layers of pure ice containing air bubbles, with a resulting thermal conductivity $\lambda_{s i}$ given by

$$
\lambda_{s i}=\lambda_{b i}-\left(\lambda_{b i}-\lambda_{b}\right)\left(\frac{\sigma \rho_{s i}}{\alpha \rho_{w} \theta}\right) \text {. }
$$




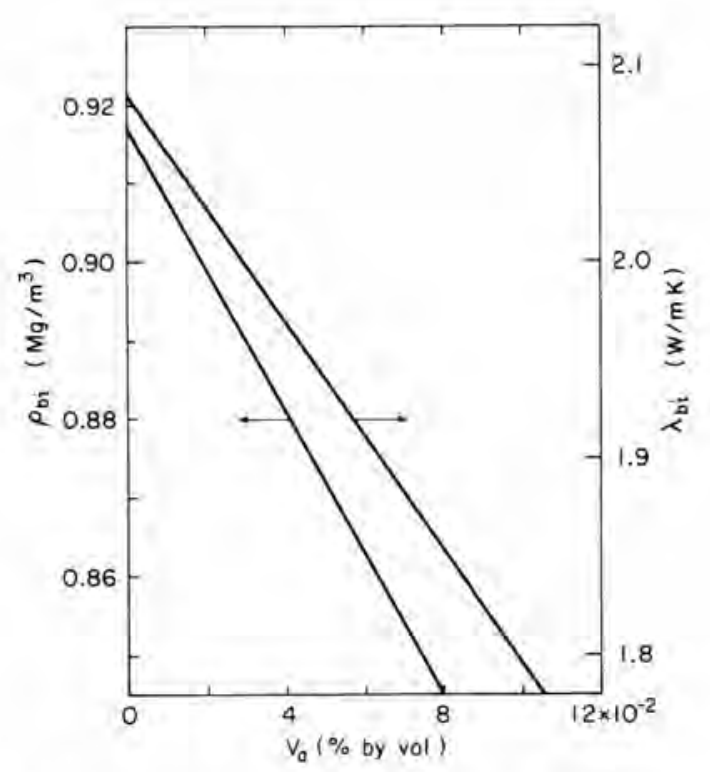

Figure 86. Density and thermal conductivity of bubbly ice as a function of the fractional air content (Schwerdtfeger 1963).

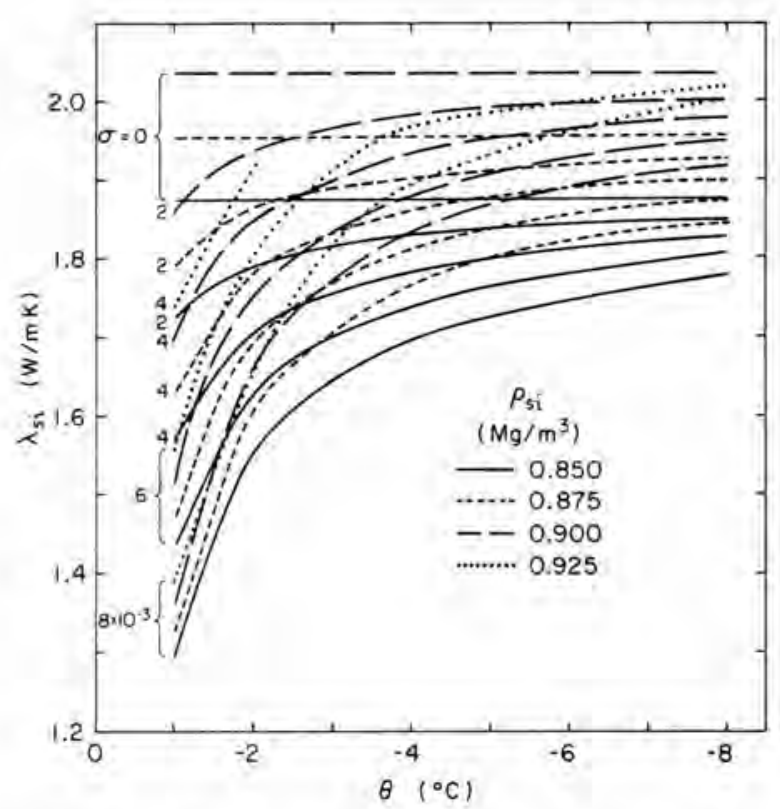

Figure 87. Effective thermal conductivity of sea ice as a function of temperature for various salinities and densities (Schwerdtfeger 1963).

Here $\lambda_{b}$ is the thermal conductivity of the brine, $\sigma$ is the salinity of the ice, $\alpha$ is the constant in the relation $s=\alpha \theta$ where $s$ is the fractional salt content and $\theta$ is temperature, and $\rho_{w}$ and $\rho_{s i}$ are the densities of pure water and of bulk sea ice respectively. The results of Schwerdtfeger's calculations are shown in Figure 87 , redrawn by Yen (1981). As is apparent in this figure and has been noted by Schwerdtfeger, even at temperatures of $-8^{\circ} \mathrm{C}$ the curves in Figure 87 exhibit asymptotic behavior, with the conductivity of sea ice approaching the value for pure lce at low temperatures. Therefore at low temperatures It is the air content of the sea ice that controls its thermal conductivity, while at temperatures near the melting point it ts the brine volume in the ice that is important and which in turn at a given temperature is controlled by the salinity.

The most recent work on the conductivity of sea ice is by ono (1968) who realized through his studies of its internal structure that it was probably not realistic to assume that air bubbles are only trapped in the ice matrix. He therefore developed a model in which the air bubbles are spherical and are uniformly dispersed through both the ice and the brine, with identical concentrations in both phases. However, as in the previous models the layers of bubbly ice and bubbly brine are assumed to be arranged in parallel. The results of Ono's calculations are shown in Figure 88. The conductivity curves are for air-free sea ice. The effect of the presence of air is included by first using the figure to determine the point specified by the ice temperature and salinity and moving vertically downward paralle1 to the conductivity $(y)$ axis an amount specified by the $v_{a}$ inset scale.

The requisite petrographic data necessary to quantitatively determine which model, Schwerdtfeger's or Ono's, is the most appropriate to 


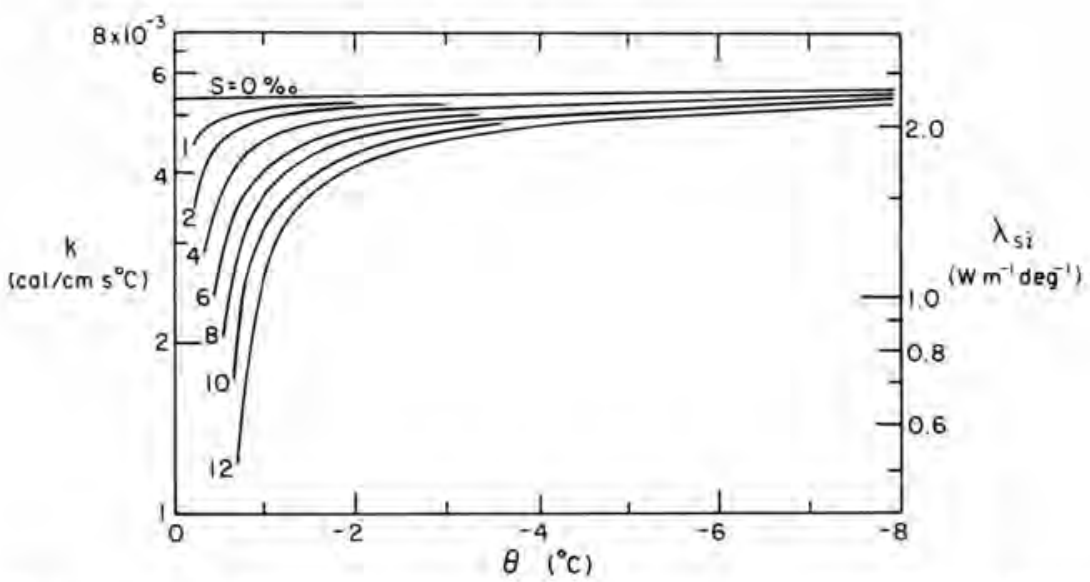

Figure 88. Thermal conductivity of sea ice calculated using Ono's model (Ono 1968).

different types of congelation ice are not available. It is our impression, however, that 0no's model is the most realistic. A further improvement would probably be to consider the case where the amounts of air bubbles in the brine and in the ice are different. However, we doubt that there is much profit in the fine-tuning of these models unless it is required by some speciftc problem. It should also be noted that present models do not suitably describe marine frazil ice. An adequate model of this material could undoubtedly be obtained by combining models that independently consider randomly distributed brine and air inclusions.

Thermal Diffusivity

The thermal diffusivity $\sigma_{s i}=\lambda_{s i} /\left(\rho_{s i} c_{s i}\right)$ of sea ice as calculated by 0 no (1968) is given in Figure 89 . As can be seen $\sigma_{\mathrm{s} i}$ is

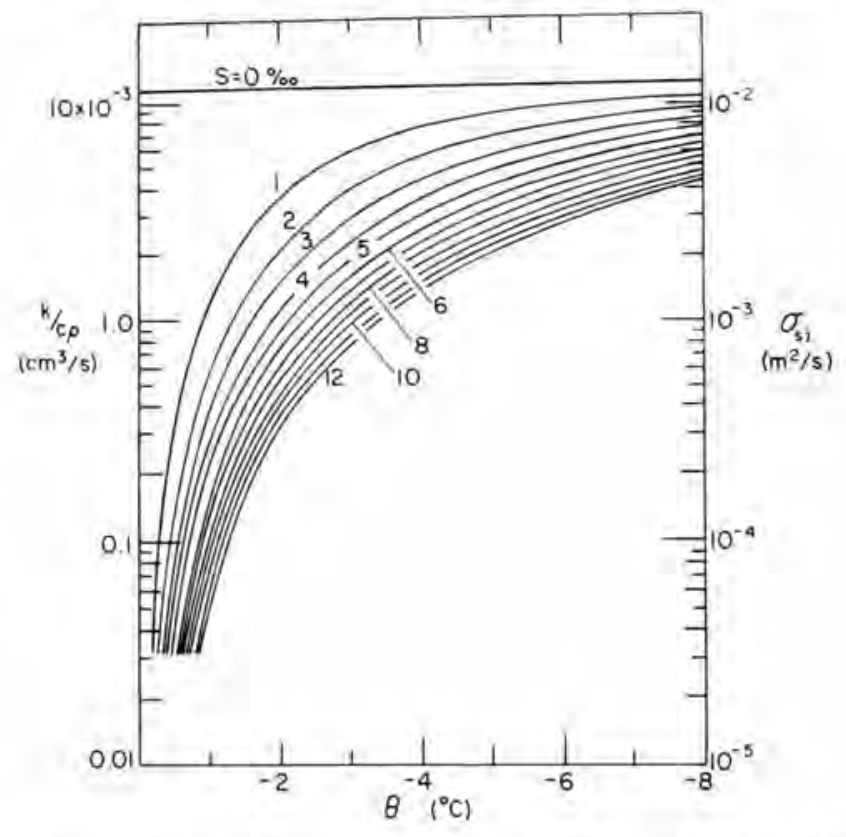

Figure 89. Thermal diffusivity of sea ice (Ono 1968). 
strongly dependent on the temperature of the ice. This is not surprisIng in that, as noted by Schwerdtfeger, all three terms composing $\sigma_{\mathrm{s} i}$ are monotonic functions of temperature. As temperature rises $\lambda_{s i}$ decreases while the two terms in the denominator $\left(\rho_{s i}\right.$ and $\left.c_{s i}\right)$ both increase. Therefore the thermal diffusivity $\sigma_{\mathrm{si}}$ shows a decrease that is more temperature-dependent than any of its constituent parameters. However, it should be noted that the values of $\sigma_{\mathrm{si}}$ are not appreciably affected by changes in the air content of the ice. This insensitivity can clearly be seen by examining Table VI In Schwerdtfeger (1963). The same insensitivity to changes in air content occurs in the thermal diffusivity of freshwater ice (Bergdahl 1977, p. 70-71).

The particular importance of $\sigma_{s 1}$ is that it is the most directly observable thermal property, as it can be directly calculated from the rate of change of the temperature profile in an ice sheet. For a convenient method of determining $\sigma_{s 1}$ the reader is referred to 0no ( 1965 , 1968 ) and to Yen (1981). Determinations of $\sigma_{\mathrm{s} 1}$ from observed temperature profiles of natural sea ice have been made by Lewis (1967), Weller (1968) and Ono (1965, 1968). In all cases the observed and calculated $\sigma_{s 1}$ and $\lambda_{s i}$ values proved to be in reasonable agreement. In fact we are rather surprised with the agreement in that, at least in warm first-year sea ice with large brine volumes, we would expect convective processes, that are not considered at all in current thermal conductivity models, to be very important. For instance, it is hard for us to believe that the processes occurring in brine drainage tubes that alternatively expell cold brine and take in "warm" seawater would not have an effect on the observed $\sigma_{s 1}$ values. These matters should clearly be explored further.

\section{Electrical Properties of Sea Ice in the 0.1 to $40 \mathrm{GHz}$ Range}

Active radar and passive microwave emission measurements over sea ice (generally in the frequency range between 0.1 and $40 \mathrm{GHz}$ ) have been used extensively over the past decade to obtaln information on ice thickness, ice age, and ice concentration on vertical scales (for thickness) of the order of one to a few meters and on horizontal scales (for ice age and concentration) of the size of the Arctic Basin and the area covered by the maximum extent of Antarctic sea ice $\left(\approx 20 \mathrm{mililion} \mathrm{km}^{2}\right)$. Universal to an interpretation of this information, whether emission characteristics (passive methods) or reflection characteristics (active methods), is some model for the dielectric characteristics of the various ice types that we have discussed previous1y. These characteristics are manifested in the physical-structural nature of the ice cover, for example its salinity, temperature, and density (air content) profiles, and to some extent crystal structure in that it controls the configuration of the other phases (air, brine and solid salt) within the ice structure. Since these properties control the dielectric properties, variations in measured dielectric properties as observed by satellite, aircraft, or ground-based systems hold the promise of providing useful information for geophysical and engineering purposes on the variability of these physical parameters.

For sea ice, different formulations of the dielectric properties are necessary, depending on 1) the frequency range of the remote sensing device and, in combination with this, 2) the description of the ice as 
"high loss" (generally correlated with first-year and younger ice types) or "low-loss" (which is almost exclusively associated with multiyear ice). The distinction arises relative to the level of electromagnetic theory needed to model the various phenomena observed. Since sea ice consists of a mixture of constituents with variable dielectric properties, in some cases (primarily at low frequencies or longer wavelengths) the sizes of the individual dielectric inhomogeneities (brine pockets, air bubbles, and solid salt particles) only influence the reflection/ emission characteristics as they contribute to the average properties of the medium. This constraint, that the individual particle sizes can be neglected, and only the total volume be consldered, applies as long as the particle sizes are less than $\approx 0.1$ wavelength of the incident (or outgoing) radiation.

If, on the other hand, the particle sizes are commensurate with the wavelength, then scattering by individual particles becomes a factor. More complex theories that account for the geometry and interaction of the particles, as well as the average dielectric properties of the medium, are then necessary. The description of these materials is by Rayleigh scattering methods, and a body of theory pertaining to aerosols and atmospheric scattering problems is available. The necessity to apply scattering theory only applies to "low loss" materials (in our case multiyear ice) since "high 1oss" materials (first-year and younger 1ce) efther attenuate active signals or confine thermal microwave emissions to such a thin layer that the scattering is relatively low. As we11, in the younger ice types, the dielectric inhomogeneities are primarily brine pockets with size scales of a millimeter or less, while in old ice the air bubbles (with sizes approaching several millimeters) are the inhomogeneities. The air bubbles therefore affect properties at more frequencies of interest between 0.1 and $40 \mathrm{GHz}$ than do brine pockets. The cutoff where scattering from air bubbles is relatively important is for frequencies above $2-3 \mathrm{GHz}$, while for brine pockets scattering may be important only above about $20-30 \mathrm{GHz}$.

We first discuss the basic translation of physical properties into electrical parameters, 1.e. the dielectric constants of sea ice as functions of its constituents (and their configurations), then the effects of structural and physical properties on active radar sounding, and fina1ly on the passive microwave emission characteristics of sea ice.

\section{Dielectric Properties of Sea Ice}

Since sea ice consists, to a greater or lesser degree, of four phases, ice, brine, air and solid salts, each with different dielectric properties, we therefore need a formulation of the dielectric properties as functions of the relative proportions of these constituents. In reality, however, the dielectric properties are dominated efther by the relative amounts of 1 ce and brine or, when the amount of brine is sma11, the amounts of ice and air. Solid salts do not have a strong effect since their dielectric properties (between 0.1 and $40 \mathrm{GHz}$ ) are generally close to those of ice so the presence of a small amount of solid salts is generally indistinguishable at these frequencies. In formulating the dielectric properties, therefore, two-phase formulations accounting for 1 ce and brine or 1 ce and air have generally been adopted. The dielectric propertles of both brine and air present sufficient contrast with 
those of ice to give a distinct contribution to the dielectric properties relative to that of pure ice.

Dielectric properties of ice and air. The complex dielectric constant of most materials is defined ( $i n$ the pure phase) as

$$
\varepsilon=\varepsilon^{\prime}-j \varepsilon^{\prime \prime}
$$

where $\varepsilon^{\prime}$ is the real part (sometimes also called the dielectric constant), $\varepsilon^{\prime \prime}$ is the dielectric loss or imaginary part (and can also be related to the conductivity of the media) and $j=\sqrt{-1}$.

As noted earlier, the ability of ice to reject salts is large, that is the solubility of salts in the pure ice phase is invariably down by several orders of magnitude relative to the liquid phase. The ice phase in sea ice is, therefore, relatively pure, and its dielectric properties correspond closely to those observed for pure ice as reviewed, for example, in Evans (1965). The dielectric loss is of the order $10^{-2}$ to $10^{-4}$ which, in the sea ice context, is relatively insignificant as we w111 show later. The real part of the dielectric constant $\left(\varepsilon_{1}=3.2\right)$ is constant over the frequency range from 0.1 to $40 \mathrm{GHz}$. Similarly, the air component is relatively loss-less and has the value $\varepsilon_{a}=1$ in its rea1 part.

Dielectric properties of brine. Of the four components in sea ice, brine shows the greatest variability in dielectric properties over the Erequency range of our interest $(0.1$ to $40 \mathrm{GHz})$. An equation of the Debye form is necessary to describe its behavior due to the relaxation brine undergoes in this frequency range. After Stogryn (1971), this is

$$
\varepsilon_{2}=\varepsilon_{\infty}+\frac{\Sigma_{0}-\varepsilon_{\infty}}{1-j 2 \pi \tau f}+j \frac{\sigma}{2 \pi f \varepsilon_{0}}
$$

where $\Sigma_{0}, \varepsilon_{\infty}, \varepsilon_{0}, f, \tau, \sigma$ are the static and high frequency dielectric constants of the brine, the free space permittivity, the frequency, the relaxation time and the fonic conductivity of the dissolved salts. As frequency increases, the contribution to dielectric loss from Ionic conductivity (third term in eq 79) drops off but the second term on the right-hand side contains the water dipole relaxation at $\approx f=1-25$ $\mathrm{GHz}$ so the dielectric loss which is related to attenuation also increases for frequencies between 1 and $25 \mathrm{GHz}$. If we reformulate eq 79 so that $\varepsilon_{b}=\varepsilon_{b}^{\prime}-j \varepsilon^{\prime \prime} b$ as in eq 78 , then Figure 90 compares the real and imaginary parts of the dielectric constant (here labeled $K^{\prime}$ and $\left.\mathrm{K}^{\prime \prime}\right)$ for pure water and brine at the same temperature $\left(-10^{\circ} \mathrm{C}\right)$. Unlike air and pure ice, the dielectric properties of brine undergo substantial changes between 0.1 and $40 \mathrm{GHz}$. As also implied in this figure, the values of the dielectric constants at any given frequency are dependent on the concentration of salts in the brine. To compute dielectric properties of the brine in sea ice, it is therefore necessary to know the temperature and salinity of the mixture and then compute the brine concentration based on the phase diagram for sea ice.

From Figure 90, we note that compared to ice, the dielectric loss of either brine or pure water is several orders of magnitude higher than that of pure ice (e.g. 10 to 100 at $1 \mathrm{GHz}$ compared to $10^{-4}$ for $1 \mathrm{ce}$ ). 


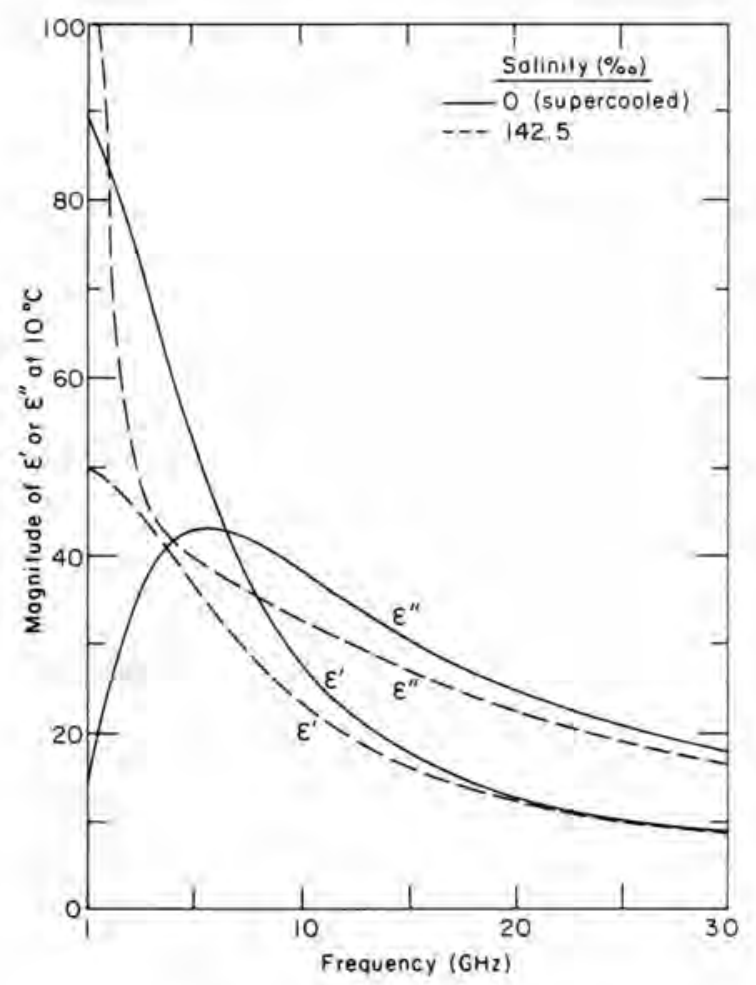

Figure 90. Rea1 $\left(\varepsilon^{\prime}\right)$ and imaginary $\left(\varepsilon^{\prime \prime}\right)$ parts of the dielectric constant for brine and pure water (Poe et al. 1972).

The change in the dielectric constant is also substantial but, relative to ice, only increases by about a factor of 10 to 30 (one order of magnitude). Therefore, since the amounts of brine in sea ice are small, the contribution of brine to the real part of the dielectric constant is sma11, but the electromagnetic loss (1maginary part of the dielectric constant) is almost completely accounted for by the brine. Ice, therefore, controls the behavior of the real part while brine dominates the loss behavior.

Averaged or composite dielectric properties of sea ice. As mentioned earlier, both the low frequency and the high frequency dielectric behavior require at least a formulation of the composite dielectric behavior of $1 \mathrm{ce}$. Poe et al. (1972) reviewed several formulations of the avallable evidence to establish a bulk dielectric constant using several empirical formulations. More recently, however. Vant et al. (1975) showed that a more analytical formulation of the mixture constant after Tinga et al. (1973) gave a theoretically justifiable dielectric constant based on analytic solutions from electrostatics. Golden and Ackley (1981) have also used Tinga et al.'s formulation in explaining some active radar properties of sea ice so we will pursue that formulation here as we11. Some differences in formulation are noted between Vant et al. and Golden and Ackley, however, since the possibility of dielectric horizontal anisotropy of sea ice was not allowed for in Vant et al.'s formulation. The overall sea ice structure taken is that discussed by Anderson and Weeks (1958) and here earlier. Essentially, brine layers (Fig. 9la) formed at the dendritic growth interface neck with decreasing temperature (Fig. 91b) further up in the ice sheet and freeze out into cylinders (Fig. 91C) and eventually into elliptical cylinders (Fig. 91d). An idealized model of a brine inclusion is a non-degenerate e1sipsold $(a>c>b$, where $a, b$ are in the $x, y$ plane and $c$ in the $z$ plane or in the depth direction) with surface defined by: 


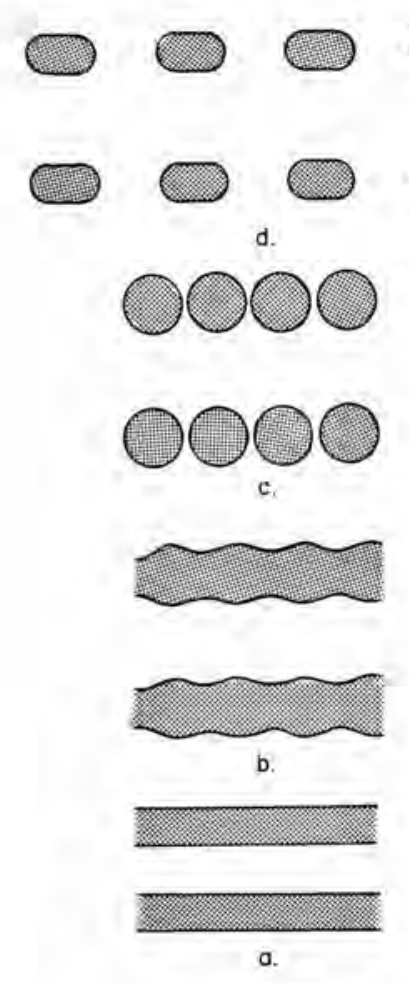

Figure 91. Brine layers at the bottom (a) of the ice sheet showing necking off as the temperature is lowered (Anderson and Weeks in Golden and Ackley 1981).

$$
\frac{x^{2}}{a^{2}}+\frac{y^{2}}{b^{2}}+\frac{z^{2}}{c^{2}}=1
$$

Tinga et al. (1973) derived an expression for the complex dielectric constant $\varepsilon_{k}$ of a mixture consisting of ellipsoids (brine) of complex dielectric constant $\varepsilon_{2}$, relative volume $V_{b}$ and uniform axial alignment, dispersed in a homogeneous medium (ice) of complex dielectric constant $\varepsilon_{1}$, when the mixture is subjected to an initially uniform electric field directed along one of the principal axes of the ellipsoid:

$$
\varepsilon_{k}=\varepsilon_{1}+\left[\frac{v_{b} \varepsilon_{1}\left(\varepsilon_{2}-\varepsilon_{1}\right)}{n_{k}\left(1-v_{b}\right)\left(\varepsilon_{2}-\varepsilon_{1}\right)+\varepsilon_{1}}\right]
$$

where $\mathrm{n}_{\mathrm{k}}$ is the depolarization factor of the ellipsoid:

$$
n_{k}=\frac{a b c}{2} \int_{0}^{\infty} \frac{d s}{\left(k^{2}+s\right) \sqrt{\left(a^{2}+s\right)\left(b^{2}+s\right)\left(c^{2}+s\right)}} .
$$

This solution allows an accounting for cases when the field is allgned with one of the ellipsold axes as sometimes occurs in active sounding. If the field is not aligned with one of the axes or if the axes are randomly aligned with respect to any direction of the fleld, then in the case of random alignments, Ackley and Keliher (1979) show the dielectric constant is

$$
\varepsilon \equiv \frac{1}{3} \varepsilon_{\mathrm{a}}+\frac{2}{3} \varepsilon_{\mathrm{b}}
$$

(when the E-field is in the $a-b$ plane).

The brine volume can be obtained either directly from the phase diagram or by using one of the equations of Frankenstein and Garner 
(1967) or Cox and Weeks (1982) for the appropriate temperature range. Salinity and temperature also control the concentration in the brine and, therefore, the real and imaginary values of $\varepsilon_{2}$, the dielectric constant of the brine. Since the dielectric constant of the brine is a complex number, the composite dielectric constant $\varepsilon_{\mathrm{k}}$ is also complex.

For ice covers where air is the primary second component, the effects of geometry on the mixture dielectric constants are not usually included. Normally the primary electromagnetic effects are confined to the top portion of the ice cover down to the freeboard level where salinity usually increases, leading to a dominance of 1 ce-brine dielectric mixtures below these depths. In the top portions of the ice cover, especially in multiyear ice where the air content is most significant, several factors appear to discount other geometries of the air bubbles besides spherical as being very important for dielectric modeling purposes. The ice above freeboard typical1y arises from several sources: a) Brine-drained ice of usually frazil structure from the previous year or years of growth. The inclusions are probably at least random if not spherical, leading to little difference than treating them as spherical. b) Recrystallized ice. Here again the tendency is for the air bubbles to trend toward more spherical shapes because of the annealing at the melting point that has taken place. c) Snow-ice or snow infiltrated by meltwater and refrozen. Again, spherical air inclusions would dominate. Even if the inclusions are non-spherical, the dielectric contrast between ice and air is small ( 3.2 to 1) so the ice component dominates the real part of the dielectric constant at the 1 ow percentages of air $(<20 \%)$ typically found in sea ice covers. This behavior is in contrast to the imaginary part of ice-brine mixtures where the brine dominates. Since the pure ice dielectric properties are homogeneous and isotropic (at these frequencies) the alr-ice dielectric properties are also mostly isotropic, even if some anisotropy exists in the inclusions. The changes in dielectric constant can be related to the density of the ice and, after Gudmandsen (1971), this is:

$$
\varepsilon=\left(1+0.85 \rho_{1}\right)^{2} \text {. }
$$

As the radar sounding of sea ice via the use of active methods depends directly on the dielectric properties as shown in the mixture constants we w111 discuss these next.

\section{Active Radar Sounding of Sea Ice}

To emphasize this point again, the mixture dielectric constants given in eq 81 have an apparent dependence on the inclusion geometry. However, this geometric dependence appears only in the depolarization factor $n_{k}$ which can be solved for in terms of axial ratios of the major and minor dimensions of the inclusions. Therefore the same dielectric effect would be attributed to large inclusions as to small inclusions if 1) the total volume occupled was similar and 2) the axial ratios were the same. The geometry is, therefore, decoupled from the wavelength as long as a, b, c, « $\lambda$. The apparent effect arises from the boundary conditions on Maxwell's equation at the surface of the inclusions, In that much more surface area of the included medium is present to particular views of the electric field if the inclusions are anisotrop1c. 
In active sounding, an electromagnetic wave polarized in one direction travels into the sea ice and is reflected by any dielectric discontinuities it encounters. The major discontinuities are the top (air/ice) and bottom (ice/water) interfaces of the 1 ce sheet. Recently radar measurements in the frequency range from 0.1 to $0.5 \mathrm{GHz}$ (100 to $500 \mathrm{MHz}$ ) have been used to obtain thickness information on sea ice (when dielectric properties are either known or assumed), primarily from ground-based transceivers but also by instruments mounted in helicopters. We have formulated the dielectric constant of sea ice in a form that includes anisotropy because one of the effects seen recently (Campbel1 and Orange 1974, Kovacs and Morey 1978) is anisotropy in the strength of the return from impulse radar soundings in these thickness soundings of sea ice.

The effect seen is marked dependence of returned radar signal strength, depending on the orientation of the linearly polarizing antenna of the radar system on the surface. The strongest return also coincided with the azimuthal orientation of the c-axes in the ice cover, while the weakest return was found to be at $90^{\circ}$ from the direction of the c-axis. This implied a structural control on the radar signal return primarlly through the major elements affecting radar attenuation in sea ice, the brine inclusions. We have previously shown how brine platelet spacing aligns well with c-axis direction within any given crystal and also that large areas of sea ice have pronounced azimuthal alignments of the c-axes in response to currents under the ice cover. These alignments also control the brine inclusion geometry and affect the strength of the radar returns. To examine the observed radar anisotropy, Golden and Ackley (1981) used the mixture dielectric constants with some assumptions regarding brine pocket geometry to model the radar behavior of sea ice. Figure 92 shows a typical salinity temperature profile from the Alaskan Arctic and the computed brine volume profile. To depict the radar behavior, the profile was divided into $10-\mathrm{cm}$ lengths with the dielectric constant at each level computed by eq 81 from the computed brine volume at that level. Direct information on the brine inclusion geometry was not available for this data set (nor are such observations generally available), so an assumed profile was taken to compute the depolarization factor as a function of depth. Since the depolarization factor is dependent only on the axial ratio, these were varied from the top to the bottom of the 1ce. At the bottom, previous measurements (Anderson and Weeks 1958, Kovacs and Morey 1978, Weeks and Assur 1967) indicated reasonable ratios of the ellipsoldal axes were of the order of $\mathrm{a}: \mathrm{b}: \mathrm{c}=30: 1: 5$ (here the a-axis direction is in the vertical plane and normal to the direction of the crystallographic c-axis). Near the top of the ice sheet a frazil-1ike initial layer probably formed, with more isotropic characteristics of the brine inclusions. These were assumed to be in the rat10 $a: b: c=1: 1: 0.5$. The brine inclusion geometries ( $a$ and $c$ dimensions) were then taken to vary linearly between these values. Later data (Langhorne et al. 1980) on brine inclusion geometry in oriented ice showed the variation in axial ratios to follow stmilar patterns to the brine volumes so the most extreme excursions were concentrated in the bottom few centimeters.

As we show later, this can only enhance the behavior derivable from the assumed linear changes. The dielectric constant profiles for the two directions are shown as a function of depth in Figure 93. The 

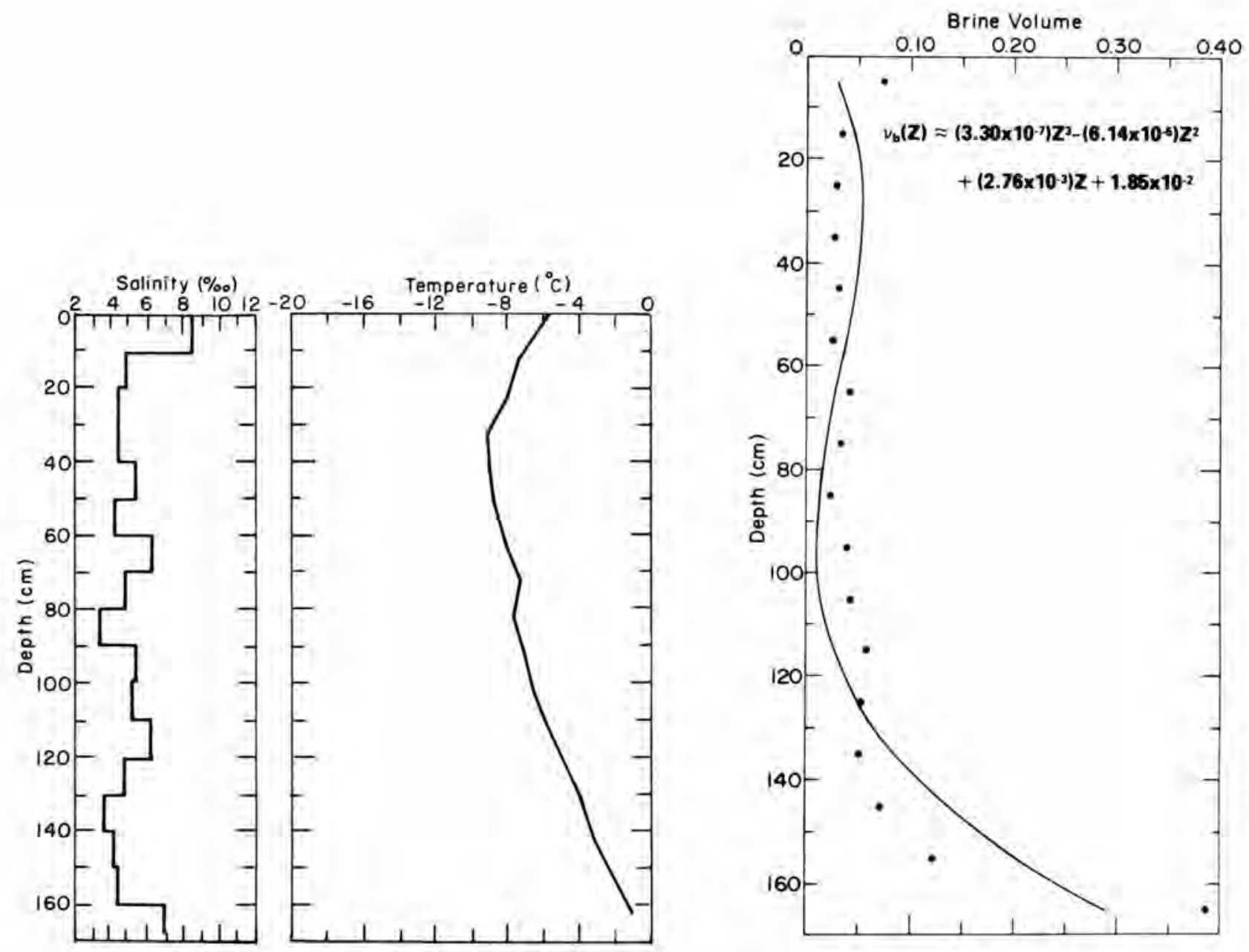

Figure 92. Ice salinity-temperature and brine volume profile from the Alaskan Arctic (Harrison Bay) (Golden and Ackley 1981).

normal polarization Indicates the E-field parallel to the preferred caxis (normal to the long axes of the ellipsolds) while the tangential polarization refers to the direction perpendicular to the c-axis. We see the strong anisotropy in the dielectric constants (particularly in $\left.\varepsilon^{\prime \prime} n, t\right)$, especially near the bottom of the ice where the brine volume and axial ratios dramatically increase. It is easy to imagine that if the inclusion geometry were allowed to vary directly with the brine volume then this behavior would be even more pronounced.

Figure 94 shows the power returned as a function of depth when a multilevel reflection, attenuation, and bean spreading model is used to calculate the returned power. The returned power for the two polarizations is down by more than one order of magnitude ( $6 \%$ compared to $0.3 \%)$, compatible with the radar attenuation observations. Large electric field penetration into the brine layers for the highly attenuated direction allows conduction effects to attenuate the wave. This in turn reduces the power returned from the ice/water interface relative to the other direction.

The radar properties of sea ice, therefore, exhibit a response to the structural controls given by the ice sheet and are dependent 

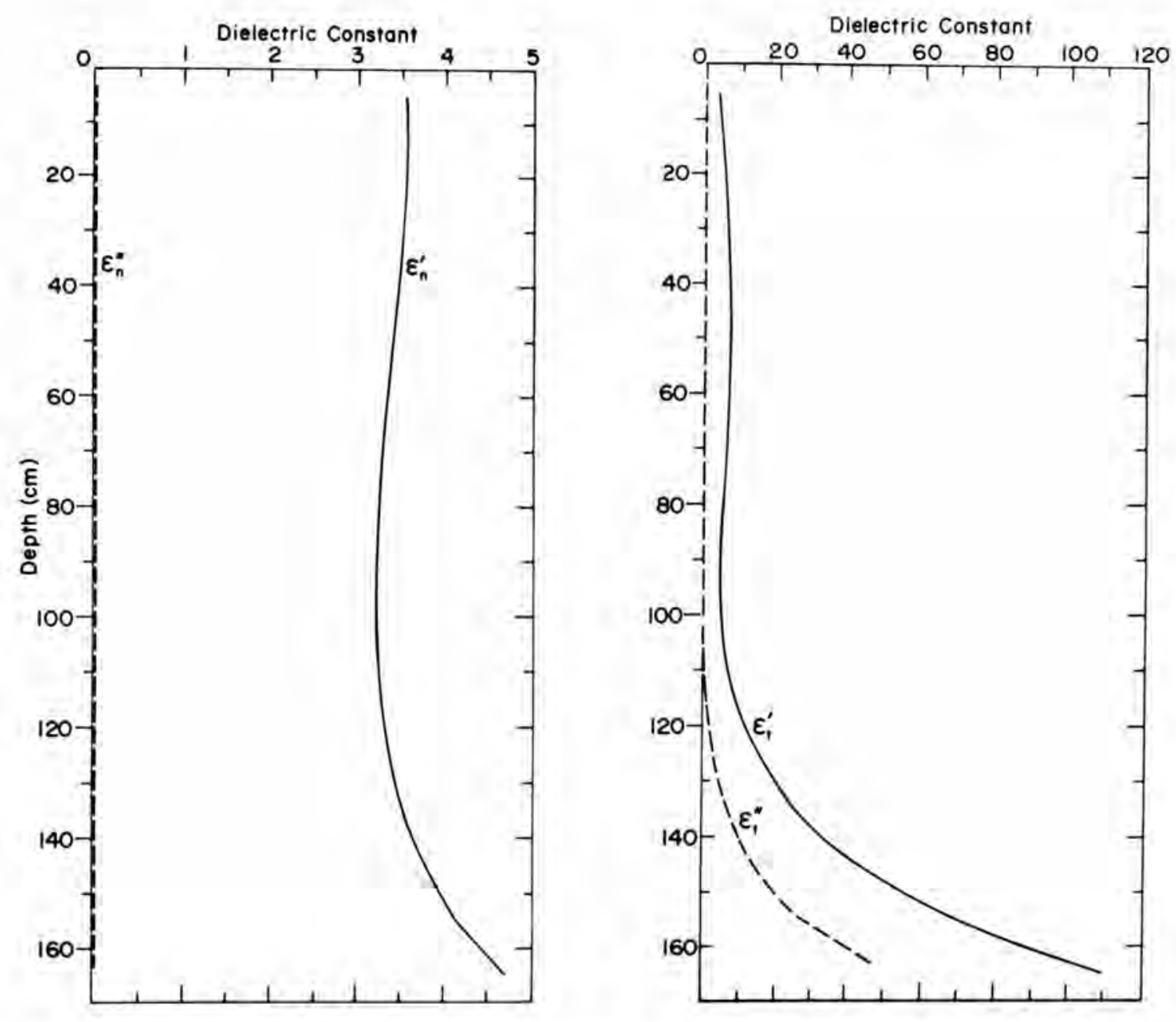

Figure 93. Computed depth-dielectric constant profiles using the brine volume profile from Figure 92 and assumed axial ratios of the inclusions at the top $a: b: c=1: 1: 0.5$ and at the bottom $a: b: c=$ 30:1:5 (Go1den and Ackley 1981).

specifically on the salinity-temperature profile (determining the brine volume) and, where strong anisotropy is observed, on the macroscopic manifestations of the brine inclusion geometries as given by the depth variation of the axial ratios of the inclusions.

In the future by suitable radar modeling and sounding of sea ice, active radar measurements could provide a nondestructive means of determining sea ice structure by inverting the return radar signals and calculating the brine volume and brine inclusion geometry profiles that lead to the observed power levels.

\section{Passive Microwave Emission Characteristics of Sea Ice}

As we noted in the last section, active radar returns reflect the physical properties of the medium. Similarly, passive emissions are another technique used to acquire information on the intrinsic dielectric properties and also upon factors such as surface roughness, layering, and internal or volume scattering of the ice. Passive microwave emission is the thermal emission at microwave frequencies due to black 


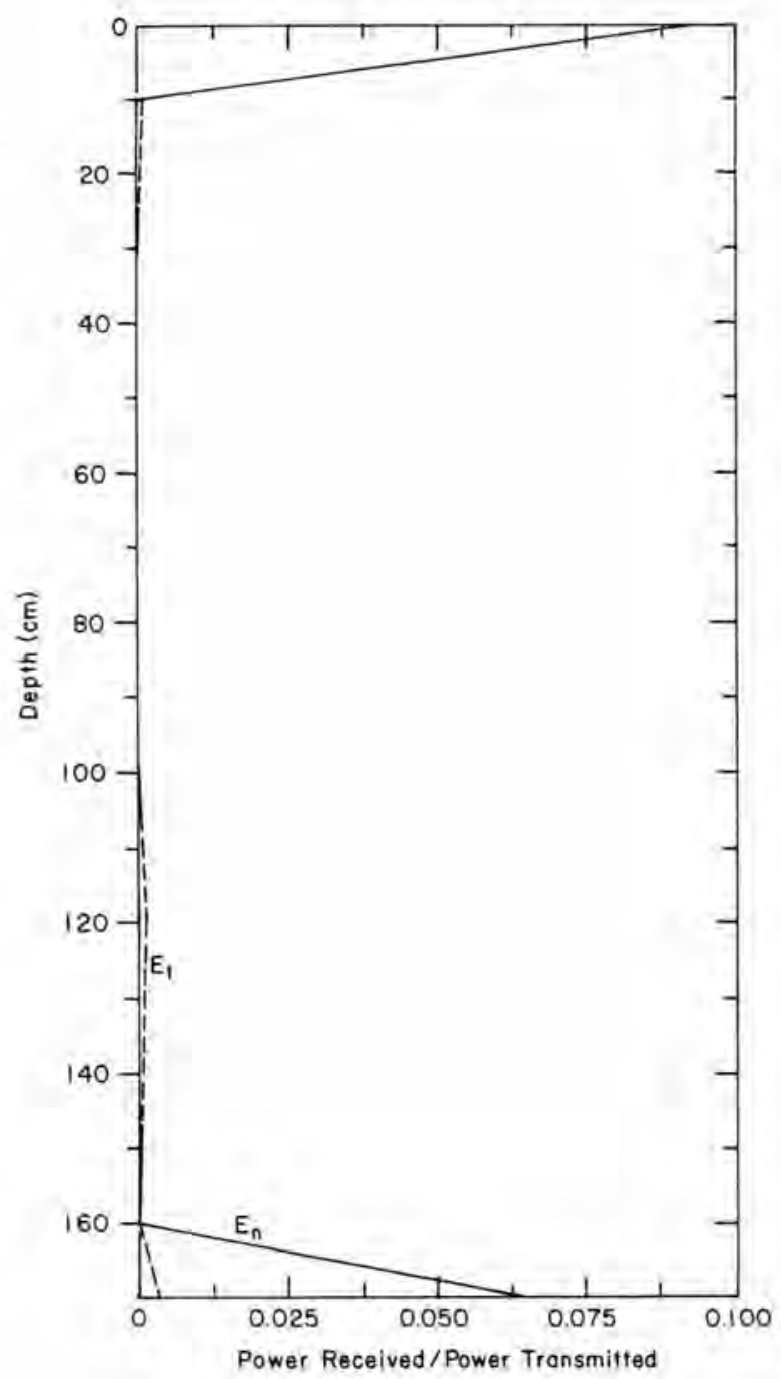

Figure 94. Simulated returned power/ incident power vs depth for profiles shown in Figures 92 and 93 (Golden and Ackley 1981).

body radiation by the material. It therefore has the additional characteristics of dependence on the thermal temperature as well as the dielectric properties of the material.

Stogryn (1970) developed the theory for a vertically structured medium that is smooth, flat, and semi-infinitely extended and shows continuous variations in dielectric properties and temperature with depth. If the dielectric properties and thermal temperature are known with depth, and if the brightness temperature of the radiation incident upon the surface is known, then the brightness temperature (horizontally polarized) at polar angle $\theta$ and frequency $\nu$ is

$$
\begin{aligned}
T(\theta, \nu)= & \left|R_{h}(\theta, \nu)\right|^{2} T_{\text {sky }}(\theta, \nu)+4\left(\frac{2 \pi \nu}{c}\right)^{3} \cos \theta \int_{-\infty}^{0} \\
& T\left(z^{\prime}\right)\left|A\left(z^{\prime}\right)^{2}\right| \operatorname{Im}\left[\varepsilon\left(z^{\prime}, \nu\right)\right] d z^{\prime}
\end{aligned}
$$

where $T_{s k y}$, the incident radiation, is due to atmospheric attenuation and reradiation of cosmic notse, and $R_{h}, c, T\left(z^{\prime}\right), \varepsilon\left(z^{\prime}, f\right)$ are the horizontal reflection coefficient, the speed of light, the temperature at depth $z^{\prime}$, and the complex dielectric constant respectively $\left(\operatorname{Im}\left[\varepsilon\left(z^{\prime}, v\right)\right]\right.$ is the Imaginary part of the dielectric constant). 
For application to sea ice we note the clear dependence of the parameters mentioned, first the temperature with depth and second the dielectric constant. The dependence of the brightness temperature on the imaginary part of the dielectric constant is also of note, since for first-year sea lce this is controlled almost exclusively by the brine volume profile. As with the radar model previously mentioned, the only dependence here is on the aggregate or mixture propertles of the material and not on the individual geometries of the other components of the other materials in the ice matrix (air, brine, and solid salts). However, a comparison of such a theory with observations of brightness temperature of sea lce did not give good agreement (Poe et al. 1972). Similarly, theoretical results from a surface roughness theory using Kirchoff approximations also did not provide good agreement, although parameterization of the surface backscatter coefficients appears to be a necessary component in any of these models.

A discussion of surface backscatter is both beyond our scope and somewhat independent of our theme, which is to understand some of the relationships between internal sea ice properties and observed emission characteristics. We therefore only mention it as one of the necessities in the complete description of the emission characteristics. England (1975) notes that surface roughness, while not easily treated theoret $1-$ ca11y, is visually apparent, so cautlous interpretations of its effect can be made.

For the case of sea ice at microwave frequencies, a more important effect which must be included to improve the agreement between theory and observation is a consideration of volume scatterers within the ice. The field intensity calculations from scattering phenomena are somewhat burdened with notation, so the more interested reader is advised to consult the references for details. Scattering can be conveniently divided into three tasks (England 1975). These are 1) the derivation of the direct field intensity resulting from self emission of the medium and from sky radiance, as we discussed earlier based on the work of Stogryn $(1970), 2)$ the derivation of the diffuse field resulting from radiation singly or multiply scattered from the direct field (this calculation involves the third task), and 3 ) the derivation of the relative scattering strength or scattering albedo in terms of wavelength, scatterer size and concentration, and dielectric properties. The derivation of the diffuse field is the notation-ridden exercise, whlle task 3 , the scattering albedo, gives conditions more directly comparable to our purpose since It related most directly to the physical properties under discussion. A brief derivation of the scattering albedo, therefore, follows after England (1975). Simplifying assumptions are that the embedded particles are spherical and effectively separated so that interaction effects between scatterers are not considered. The Rayleigh scattering cross section $\sigma$ is related to the size parameter (the ratio of scatterer diameter to free space wavelength) and to the dielectric constant (the ratio of the dielectric constant of the scatterer (brine or air) to that of the layer (ice)). Spheres of diameter $d$ and dielectric constants $\varepsilon_{2}$ embedded in a medium whose dielectric constant is $\varepsilon_{1}$ have an average dipole moment (Stratton 1941)

$$
\overline{\mathrm{P}}=4 \pi \varepsilon_{1} \quad \varepsilon_{0}\left[\frac{\varepsilon_{2} / \varepsilon_{1}-1}{\varepsilon_{2} / \varepsilon_{1}+2}\right] \frac{\overline{\mathrm{d}}^{3}}{8} \mathrm{E}_{\mathrm{o}}
$$


where $\varepsilon_{0}$ is the free space permittivity, $E_{0}$ is the inctdent electric fleld strength (or emitted radiation strength from below), and $\bar{d}$ is the mean diameter of the scatterers. The average outward energy flow $P$ from the scatterer is

$$
\overline{\mathrm{p}}=\left(\frac{\mu}{\varepsilon_{1} \varepsilon_{0}}\right)^{I / 2} \frac{\omega^{4} \overline{\mathrm{p}}^{2}}{12 \pi}\left(\frac{\varepsilon_{1}}{\mathrm{c}^{2}}\right)
$$

where $\mu$ is the permeability $\left(\mu=\mu_{0}\right.$ for the dielectrics of interest), $\omega(=2 \pi f)$ is the angular frequency of the incident wave, and $c$ is the free space velocity of light. Poynting's relation yields the energy flow per unit area of the source wave (the energy flow prior to scattering encounter),

$$
\bar{S}=\frac{1}{2}\left(E_{0}\right)^{2}\left(e_{1} \varepsilon_{0} / \mu_{0}\right)^{1 / 2}
$$

so that the average scattering cross section $\sigma=\overline{\mathrm{P}} / \overline{\mathrm{S}}$ is

$$
\vec{\sigma}=\frac{2}{3} \pi^{5}\left(\frac{\bar{d}}{\lambda_{0}}\right)^{3} \frac{\varepsilon_{1}^{2}}{\lambda_{0}} \bar{d}^{3}\left[\frac{\varepsilon_{0} / \varepsilon_{1}-1}{\varepsilon_{2} / 31+2}\right]^{2}
$$

where $\lambda_{0}=\frac{2 \pi c}{\omega}$ and $\mu_{0}=\frac{1}{c^{2} \varepsilon_{0}}$ are used.

If $\mathrm{f}^{*}$ is the volume fraction of scatterers in the layer (related to the ice density for alr inclusions) then

$$
\mathrm{f}^{*}=\overline{\mathrm{N}} \frac{4}{3} \pi\left(\frac{\mathrm{d}}{2}\right)^{3}=\overline{\mathrm{N}} \pi \frac{\mathrm{d}^{3}}{6} .
$$

The scattering loss is the number of scatterers times the scattering cross section per scatterer or

$$
\overline{\mathrm{N}} \bar{\sigma}=\frac{2 \pi\left(\varepsilon_{1}\right)^{1 / 2} \tan \delta_{1}}{\lambda_{0}} \mathrm{~S}_{\mathrm{c}} \mathrm{f} \text { * }
$$

where $\tan \delta_{1}=\varepsilon^{\prime \prime}{ }_{1} / \varepsilon^{\prime}{ }_{1}$ is the loss tangent and

$$
\mathrm{s}_{c}=(2 \pi)^{3}\left(\frac{\overline{\mathrm{d}}}{\lambda_{0}}\right)\left[\frac{\varepsilon_{1}}{\tan \delta_{1}}\right]^{3 / 2}\left[\frac{\varepsilon_{2} / \varepsilon_{1}-1}{\varepsilon_{2} / \varepsilon_{1}+2}\right]^{2} .
$$

The total loss $\alpha_{1}$ in the layer is the sum of the scattering loss $\mathrm{N}$ $\sigma$ and the dielectric loss $2 \beta_{1}$ where

$$
\alpha_{1}=\overline{\mathrm{N}} \bar{\sigma}+2 \beta_{1}
$$

and

$$
2 \beta_{1}=\left[2 \pi\left(\varepsilon_{1}\right)^{1 / 2} / \lambda_{0}\right] \tan \delta_{1} \text {. }
$$


(Here the appropriate values for $\varepsilon_{1}, \tan \delta_{1}$ could be the mixture dielectric constant and loss tangent instead of the ice constants if scattering is sma11, in analogy to the active radar parameterization shown earlier.)

A useful parameter to estimate the influence of scattering is the scattering albedo $\omega_{0}$ which is defined as the ratio of scattering loss to total loss in the layer or

$$
\omega_{0}=\frac{\bar{N} \bar{\sigma}}{\bar{N} \bar{\sigma}+2 B_{1}} .
$$

Naturally, if $\omega_{0}$ is small then the contribution to total loss from scattering is small so we can define combinations of frequency ranges, concentrations of scatterers and dielectric properties where scattering has to be taken 1nto account. We will now show a few simulations of these parameters of interest.

Figure 95 shows the scattering albedo versus $d / \lambda_{0}$ (ratio of scatterer size to wave length) with the volume fraction as a parameter for ice overlying fresh water. We note the middle three curves $f=(.05$, $.1, .2$ ) are typical air content values seen in multiyear sea 1ce (Meeks et al. 1974). These curves indicate that "significant" contributions to the total loss from scattering occur at a minimum fractional diameter to wavelength ratio of about 0.1 . From the 1imited data on multiyear sea ice, air bubble sizes varying from $0.5 \mathrm{~mm}$ to several millimeters (Poe et al. 1974) are observed, indicating a wavelength cutoff of about 0.5 to 1 $\mathrm{cm}$ where scattering losses become important and indeed dominate the emission character of multiyear ice. This corresponds to frequencies greater than $1-3 \mathrm{GHz}$.

The effects of brightness temperature as would be sensed by an above-surface radiometer are shown in Figure 96 where the scatter-1nduced brightness temperature change is plotted versus scattering albedo as a function of the layer thickness to wavelength rat1o. Generally for thin layers (low $\mathrm{D} / \lambda_{0}$ ) the brightness temperature induced by scattering increases, while for thick layers (high $\mathrm{D} / \lambda_{0}$ ) the brightness temperature drops for almost all values of scattering albedo. The conclusion is that where we have "significant" values of scattering albedo $(>0.5)$ the major effect seen will be for thicker layers of scattering material and that change will be a drop in brightness temperature. This behavior is what is typically observed for multiyear ice in the Arctic, with lower brightness temperatures implying significantly more scattering and layer thickness at the higher frequencies than for first-year ice. As the dielectric loss (non-scattering part, $2 \beta_{1}$ ) increases, the effect of layer thickness drops of $f$. This behavior also is indicated in the equation for scattering albedo $\omega_{0}$, where increasing numbers of scatterers would be required for the scattering to dominate the ordinary dielectric loss, $2 \beta_{1}$. For first-year ice, which is both lossy and of lower alr content, the influence of scatter-induced changes on brightness temperature are commensurately less than for multiyear ice. In first-year 1ce, the scatterers are primarily the brine pockets, which have a dimension of about $0.1 \mathrm{~mm}$ and are effective as scatterers only at high frequencies $(20-40 \mathrm{GHz})$. However, this point is still inconclusive 


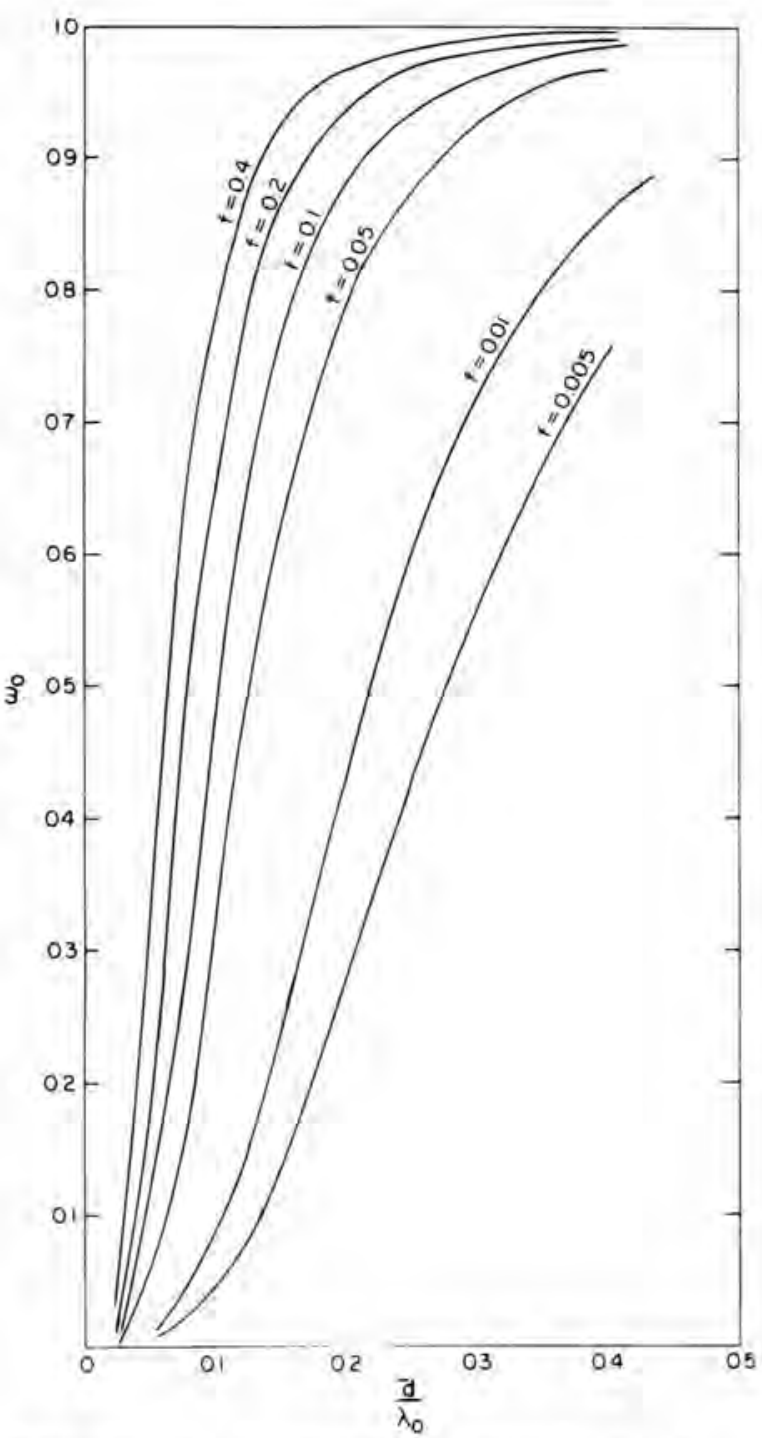

Figure 95. Scattering albedo $\left(\omega_{0}\right)$ vs scatterer size to wavelength ratio $\left(d / \lambda_{0}\right)$ for ice overlying fresh water. The volume fraction of scatterers ( $f$ ) is the parameter on the curves (England 1975).

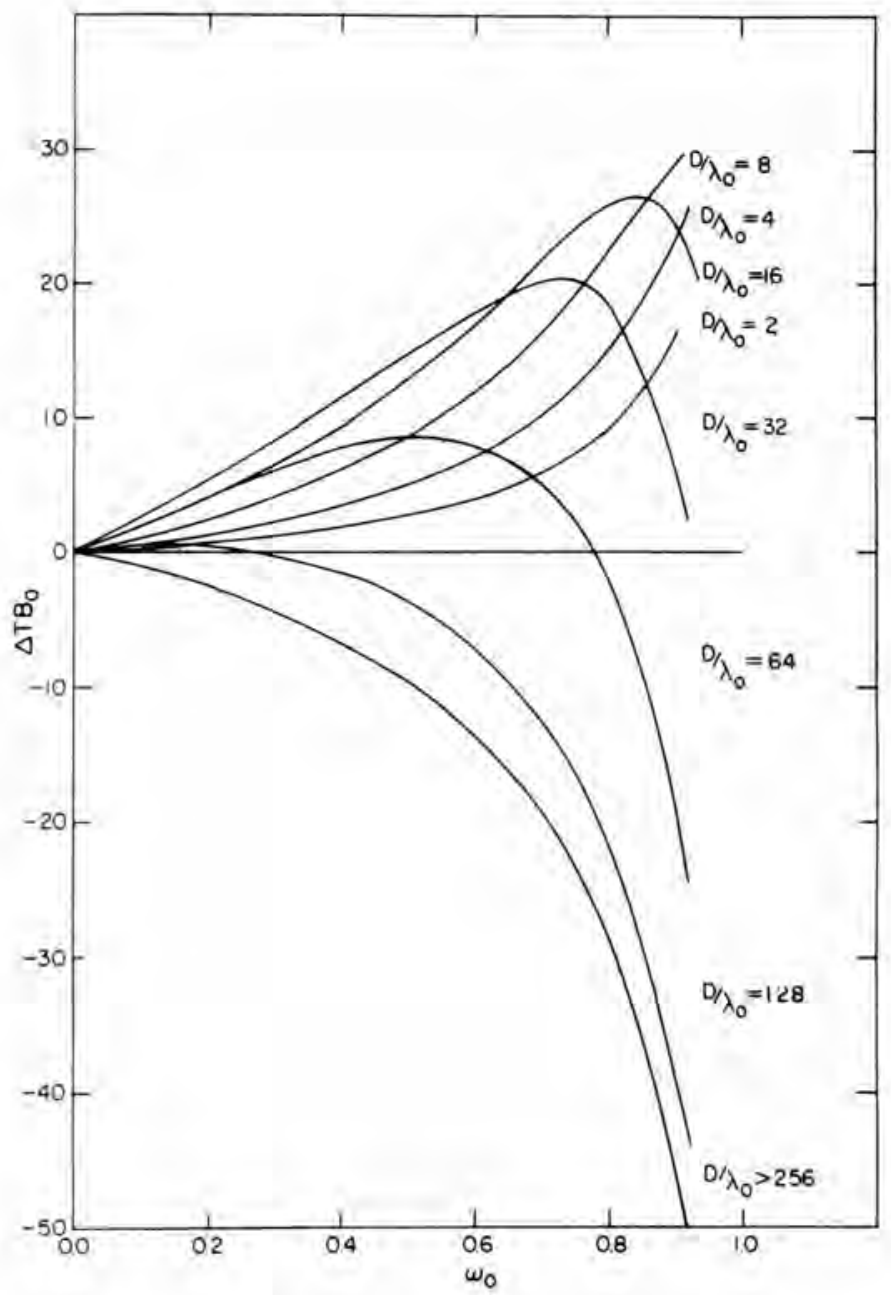

Figure 96. Changes in brightness temperature $\left(\Delta \mathrm{TB}_{\mathrm{O}}\right)$ plotted against scattering albedo $\left(\omega_{0}\right)$ with the layer thickness to wavelength ratio $\left(D / \lambda_{0}\right)$ as a parameter (England 1975).

without detailed information on the brine pocket geometries or a solid theoretical base which would permit calculations of scattering from strong fluctuations (Poe et al. 1974). While the general behavior can be seen from this type of calculation, other authors (Poe et al. 1972, Fung 1981) note that correlation function techniques (small perturbation method), the distorted Born approximation, and generally more sophisticated solutions to the wave equation are probably necessary in order for a complete specification of the sea ice scattering problem. These calculations are, however, significantly limited by the current lack of data on the physical properties of sea ice, specifically a detalled knowledge of the brine pocket and air bubble geometries, and the variation in the mean values of the dielectric constants as function of depth. 
In this paper we have attempted to give the reader a general knowledge of the current state of understanding of the structure of sea ice, how and why it develops and varies, and a few examples of how these variations can affect the bulk properties of the 1ce. Progress in this fleld has been slow, largely as the result of a lack of support for such work. This is unfortunate in that, as we hope was shown in the paper, an understanding of the ice structure is essential as the foundation upon which the sclence of the property varlations of sea 1 ce must be built.

\section{LITERATURE CITED}

Ackley, S.F. (1982) Ice scavenging and nucleation: Two mechanisms for incorporation of algae into newly forming sea ice. AGU-ASLO Ocean Sciences Meeting, San Antonio (abstract to be published in EOS).

Ackley, S.F. and T.E. Keliher (1979) Ice sheet internal radio-echo reflections and associated physical property changes with depth. J. Geophys. Res., vo1. 84 , no. 80.

Adams, C.M., D.M. French and W.D. Kingery (1963) Field solidification and desalination of sea ice. In Ice and Snow: Properties, Processes and Applications (W.D. Kingery, Ed.), Cambridge, Mass.: MIT Press, p. 277-288.

Addison, J.R. (1977) Impurity concentrations in sea ice. J. Glaciol., vo1. 18 , no. 78 , p. 117-127.

Anderson, D.L. (1958) A model for determining sea ice properties. In Arctic Sea Ice. U.S. National Academy of Sciences - National Research Counci1, Pub. 598, p. 148-152.

Anderson, D.L. (1960) The physical constants of sea ice. Research, vol. 13 , no. 8 , p. 310-318.

Anderson, D.M. and W.F. Weeks (1958) A theoret1cal analysis of sea 1ce strength. Trans. Am. Geophys. U., vol. 39, no. 4, p. 632-640.

Arakawa, K. (1954) Studies on the freezing of water, II. J. Faculty Sci. Hokkaido Univ., Ser II, vo1. 4, p. 311-339.

Arakawa, K. and K. Higuchi (1954) On the freezing process of aqueous solutions. Low Temp. Sci., A 12, p. 73-86 (in Japanese),

Armstrong, T., B. Roberts and C. Swithinbank (1966) Illustrated glossary of snow and ice. Scott Polar Research Institute, Special Pub. No. 4,60 p.

Assur, A. (1958) Composition of sea ice and its tensile strength. In Arctic Sea Ice. U.S. National Academy of Sciences - National Research Counc11, Pub. 598, p. 106-138. 
Assur, A. and W.F. Weeks (1964) Growth, structure, and strength of sea ice. USA Cold Regions Research and Engineering Laboratory, Research Report 135, 19 p.

Bari, S.A. and J. Hallett (1974) Nucleation and growth of bubbles at an ice-water interface. J. Glaciol., vol. 13, no. 69, p. 489-520.

Barrett, C.S. (1952) Structure of Metals. New York: McGraw-Hill.

Bennington, K.0. (1959) Preliminary report on sea ice crystal fabrics on Station Charlie. In Semi-Annual Report, 1 December 1959, Drifting Station Charlie, Project Husky Nonr. 477(24) T.0. 307-252.

Bennington, K.0. (1963a) Some crystal growth features of sea ice. J. Glacio1., vo1. 4 , no. 36, p. 669-688.

Bennington, K.0. (1963b) Some chemical composition studies on arctic sea ice. In Ice and Snow - Processes, Properties, and Applications (W.D. Kingery, Ed.), Cambridge, Mass.: MIT Press, p. 248-257.

Bergdah1, L. (1977) Physics of Ice and Snow as Affects Thermal Pressure. Göteborg, Sweden: Chalmers University of Technology, $\mathrm{De}-$ partment of Hydraulics, Rept. Series A:1, 158 p.

Bilello, M.A. (1961) Ice thickness observations in the North American Arctic and Subarctic for 1958-59, 1959-60. USA Cold Regions Research and Engineering Laboratory, Special Report 43, 43 p.

Blinov, L.K. (1965) The salt content of sea water and sea ice. Trudy Gos. Okeanograf. Inst., no. 81, p. 5-55.

Bolling, G.F. and W.A. Tiller (1960) Growth from the melt. I: Influence of surface intersections in pure metals. J. App1. Phys., vol. 31 , p. 1345-1350.

Bragg, W.H. (1922) The crystal structure of 1ce. Proc. Phys. Soc., vo1. 34 , p. $98-103$.

Buck, K.R. and D. Garrison (1982) Sea ice algal communities in the Wedde1l Sea. II: Population comparisons between the water column and sea ice. AGU-ASLO Ocean Sciences Meeting, San Antonio (abstract to be published in EOS).

Burton, J.A., R.C. Prim and W.P. S11chter (1953) The distribution of solute in crystals grown from the melt. Part I: Theoretical. J. Chem. Phys., vol. 21,p. 1987-1991.

Campbe11, K.J. and A.S. Orange (1974) The electrical anisotropy of sea ice in the horizontal plane. J. Geophys. Res., vol. 79, no. 33, p. 5059-5063.

Carslaw, H.S. and J.C. Jaeger (1959) Conduction of Heat in Solids. Oxford Univesity Press, 510 p.

Carte, A.E. (1961) Air bubbles in ice. Proc. Phys. Soc. (London), vol. 77, no. 495 , p. 757-768. 
Cherepanov, N.V. (1957) Using the methods of crystal optics for determining the age of drift ice. Problemy Arktiki, vol. 2, p. 179-184 (in Russian).

Cherepanov, N.V. (1964) Structure of sea 1ce of great thickness. Trudy Arkt. 1 Antarkt. N.I. Institut, vol. 367 , p. 13-18.

Cherepanov, N.V. (1971) Spatial arrangement of sea 1ce crystal structure. Prob. Arkt. 1 Antarkt., vol. 38 , p. 176-181.

Colbeck, S. (1979) Grain clusters in wet snow. J. Coll. Inter. Sci., vol. 72 , no. 3 .

Corle11, S.R., M.R. Cordes, W.J. Boettinger and R.F. Sekerka (1980) Convective and Interfacial instabilities during unidirectional solidification of a binary alloy. J. Cryst. Growth, vol. 49 , no. 1, p. $13-28$.

Cox, G.F.N. and W.F. Weeks (1975) Brine drainage and initial salt entrapment in sodium chloride ice. USA Cold Regions Research and Engineering Laboratory, Research Report 354, 85 p.

Cox, G.F.N. and W.F. Weeks (1974) Salinity variations in sea ice. J. Glaciol., vol. 13 , no. 67 , p. 109-120.

Cox, G.F.N. and W.F. Weeks (1982) Equations for determining the gas and brine volumes in sea ice samples. USA Cold Regions Research and Engineering Laboratory, CRREL Report (in press).

Dayton, P.K. and S. Martin (1971) Observations of ice stalactites in McMurdo Sound, Antarctica. J. Geophys. Res., vol. 76, p. 15951599.

Dunbar, M. and W.F. Weeks (1975) Interpretation of young ice forms in the Gulf of St. Lawrence using side-looking airborne radar and infrared imagery. USA Cold Regions Research and Engineering Laboratory, Research Report 337, 41 p.

Edie, D.D. and D.J. Kirwan (1973) Impurity trapping during crystallization from melts. Ind. Eng. Chem. Fundam., vo1. 12, p. 100-106.

Eide, L. and S. Martin (1975) The formation of brine drainage features in young sea 1ce. J. Glaciol., vol. 14, no. 70, p. 137-154.

Elbaum, C. (1959) Substructures in crystals grown from the melt. Prog. Met. Phys., vol. 8, p. 203-253.

England, A.W. (1975) Thermal microwave emfssion from a scattering layer. J. Geophys. Res., vol. 80 , no. 32 , p. 4484-4496.

Evans, S. (1965) Dielectric properties of snow and ice: A review. Glaciol., vol. 5, p. 773.

Farhadieh, R. and R.S. Tankin (1972) Interferometric study of freezing of sea water. J. Geophys. Res., vo1. 77, p. 1647-1657. 
Foldvik, A. and T. Kvinge (1974) Conditional instability of sea water at the freezing point. Deep Sea Res., vol. 21, p. 169-174.

Frankenstein, G. and R. Garner (1967) Equations for determining the brine volume of sea 1 ce from $-0.5^{\circ}$ to $-22.9^{\circ} \mathrm{C}$. J. Glaciol., vol. 6 , nо. 48 , p. $943-944$.

Fujino, K. and Y. Suzuki (1959) Observations on the process of ice rind formation on the surface of still water. Low Temp. Sci., A 18, p. 149-155 (in Japanese).

Fujioka, T. and R.F. Sekerka (1974) Morphological stability of disc crystals. J. Cryst. Growth, vol. 24/25, p. 84-93.

Fukutomi, T., K. Kusunoki and T. Nagashima (1949) On the formation of crystal ice and the structure of ice crust. Low Temp. Sci., vol. 2, p. 73-76 (in Japanese).

Fukutomi, T., M. Saito and Y. Kudo (1953) Study of sea ice (the 16th report): On the structure of ice rind, especially on the structure of thin ice sheet and ice-sheet block. Low Temp. Sci., vol. 9, p. 113-123 (in Japanese).

Fung, A. (1981) Microwave scattering and emission from sea ice. Proceedings of Second Workshop on Microwave Remote Sensing of Sea Ice and Icebergs, NASA Langley Research Center.

Garrison, D. and K.R. Buck (1982) Sea ice algal communities in the Wedde11 Sea. I: Biomass distribution and the physical environment. AGU-ASLO Ocean Sciences Meeting, San Antonio (abstract to be published in EOS).

Gitterman, K.F. (1937) Thermal analysis of sea water. Trudy Solyanoy Lab. Akad. Nauk SSR, No. 15(1) (in Russian).

Glen, J.W. (1955) Comments on the paper of Professor Arakawa on the growth of ice crystals in water. J. Glaciol., vol. 2, p. 483.

Golden, K.M. and S.F. Ackley (1981) Modeling of anlsotropic electromagnetic reflection from sea ice. J. Geophys. Res (in press).

Golovkov, M.P. (1936) K petrografif 1 'da Karskogo moria (The petrography of Kara sea 1ce). Leningrad: Vsesoluzny1 Arkticheskii Institut, Trudy 60 , p. $7-40$.

Gow, A.J. and S. Epstein (1972) On the use of stable isotopes to trace the origins of ice 1n a floating ice tongue. J. Geophys. Res., vo1. 77 , no. 33 , p. 6552-6557.

Gow, A.J. and D. Langston (1977) Growth history of lake ice in relation to Its stratigraphic, crystalline and mechanical structure. USA Cold Regions Research and Engineering Laboratory, CRREL Report $77-1,24 \mathrm{p}$.

Gow, A.J. and W.F. Weeks (1977) The Internal structure of fast ice near 
Narwhal Island, Beaufort Sea, Alaska. USA Cold Regions Research and Engineering Laboratory, CRREL Report 77-29, 8 p.

Gow, A.J., S.F. Ackley, W.F. Weeks and J.W. Govoni (1982) Physical and structural characteristics of Antarctic sea ice. Third International Symposium on Antarctic Glaciology, Ohio State University, Annals Glaciol.

Gow, A.J., W.F. Weeks, J.W. Govoni and S.F. Ackley (1981) Physical and structural characteristics of sea ice in McMurdo Sound. Ant. J. U.S. (in press).

Gudmandsen, P. (1971) Electromagnetic probing of ice. In Electromagnetic Probing in Geophysics (J.R. Wait, Ed.), Boulder, Colorado: Golem Press, p. 321-338.

Hallett, J. (1960) Crystal growth and the formation of spikes in the surface of supercooled water. J. Glaciol., vol. 3, p. 698-702.

Hardy, S.C. and S.R. Coriell (1973) Surface tension and interface k1netics of ice crystals freezing and melting in sodium chloride solutions. J. Cryst. Growth, vo1. 20, p. 292-300.

Harrison, J.D. and W.A. Tiller (1963) Controlled freezing of water. In Ice and Snow - Processes, Properties, and Applications (W.D. Kingery, Ed.), Cambridge, Mass.: M.I.T. Press, p. 215-225.

Harrison, J.D. (1965) Measurement of brine droplet migration in ice. J. Appl. Phys., vol. 36 , no. 12, p. 3811-3815.

Hillig, W.B. (1958) The kinetics of freezing of ice in the direction perpendicular to the basal plane. In Growth and Perfection of Crystals (R.H. Doremus, Ed.), New York: Wiley, p. 350-359.

Hillig, W.B. (1959) Kinetics of solidification from nonmetalifc Iiquids. In Kinetics of High Temperature Processes (W.D. Kingery, Ed.), New York: Wiley, p. 127-135.

H1111g, W.B. and D. Turnbul1 (1956) Theory of crystal growth in undercooled pure liquids. J. Chem. Phys., vol. 24 , p. 914.

Hobbs, P. (1974) Ice Physics. Oxford University Press, 837 p.

Hoekstra, P., T.E. Osterkamp and W.F. Weeks (1965) The migration of liquid inclusions in single ice crystals. J. Geophys. Res., vol. 70 , no. 20 , p. 5035-5041.

Johnson, N.G. (1943) Studies av isen i Gullmarfjorden. Svenska Hydrog. - Bio1. Komm. Skr., Ny Serie: Hydrografi, 18, p. 1-21.

Jones, D.R.H. (1973) The temperature-gradient migration of 1iquid droplets through 1ce. J. Cryst. Growth, vol. 20, p. 145-151.

Jones, D.R.H. (1974) Determination of the k1net1cs of 1ce-brine Interfaces from the shapes of migrating droplets. J. Cryst. Growth, vol. 26 , p. 177-179. 
Kamb, W.B. (1959) Theory of preferred crystal orlentation developed by crystallization under stress. J. Geol., vol. 67, p. 153-170.

Katsaros, K.B. (1973) Supercooling at the surface of an arctic lead. J. Phys. Ocean., vol. 3 , no. 4, p. 482-486.

Kawamura, T. and N. Ono (1980) Freezlng phenomena at seawater surface opening in polar winter. III. Measurement of crystallographic orlentation of newly grown sea ice. Low Temp. Sc1., A(39), p. 175-180.

Kingery, W.D. and W.H. Goodnow (1963) Brine migration in salt ice. In Ice and Snow: Properties, Processes and Applications (W.D. Kingery, Ed.), Cambridge, Mass.: MIT Press, p. 35-47.

Knight, C.A. (1962a) Curved growth of ice on surfaces. J. Appl. Phys., vol. 33, p. 1808-1815.

Knight, C.A. (1962b) Migration of 11quid 1nclusions parallel to the caxis in single ice crystals: An origin for some striations. Can. J. Phys., vol. 40, p. 1681-1682.

Knight, C.A. (1962c) Polygonization of aged sea 1ce. J. Geol., vol. 70, p. 240-246.

Knight, C.A. (1962d) Studies of arctic lake ice. J. Glacio1., vol. 4, p. 319-335.

Koerner, R.M. (1963) The Devon Island expedition, 1960-64. Arctic, vol. 16 , p. 57-62.

Kohnen, H. (1976) On the dc resistivity of sea 1ce. Z. Gletsch. und Glaz., vol. 11, no. 2, p. 143-154.

Kovacs, A. and R. Morey (1978) Radar anisotropy of sea ice due to preferred azimuthal orientation of the horizontal c-axes of 1ce crystals. J. Geophys. Res., vol. 83, no. C12, p. 6037-6046.

Kovacs, A. and R.M. Morey (1980) Investigations of sea 1ce anisotropy, electromagnetic properties, strength, and under-1ce current orientation. USA Cold Regions Research and Engineering Laboratory, CRREL Report $80-20,18$ p.

Kumai, M. and K. Itagaki (1953) Cinematographic study of 1ce crystal formation in water. J. Faculty Sci., Hokkaido Univ., Ser. II, 4, p. 235-246.

Lake, R.A. and E.L. Lewis (1970) Salt rejection by sea ice during growth. J. Geophys. Res., vol. 75 , no. 3, p. 583-597.

Landauer, J.K. and H. Plumb (1956) Measurements of anisotropy of thermal conductivity of 1ce. USA Snow, Ice and Permafrost Research Establishment, Research Report 16.

Langhorne, P. (1980) Crystal anisotropy in sea ice in the Beaufort Sea. 
Proceedings, Workshop on Remote Estimation of Sea Ice Thickness, Memorial University, St. Johns, Newfoundland, C-CORE Pub. 80-5, p. 189-224.

Langhorne, P.J., J.R. Rossiter and T.E. Keliher (1980) Remote estimation of the properties of sea ice, ice core analysis, Beaufort Sea, March 1979. Memorial University, St. Johns, Newfoundland, C-CORE Pub. $80-7,172$ p.

Langleben, M.P. (1959) Some physical properties of sea 1ce. II. Can. J. Phys., vo1. 37 , p. 1438-1454.

Lewis, E.L. (1967) Heat flow through winter ice. In Physics of Snow and Ice (H. Oura, Ed.), Institute of Low Temperature Science, Hokkaido, vol. 1 , no. 1, p. 611-631.

Lewis, E.L. and R.A. Lake (1971) Sea 1ce and supercooled water. J. Geophys. Res., vol. 76 , no. 24 , p. 5836-5841.

Lofgren, G. and W.F. Weeks (1969) Effect of growth parameters on the substructure spacing in NaC1 ice crystals. J. Glaciol., vol. 8, no. 52 , p. $153-164$.

Lonsdale, K. (1958) The structure of ice. Proc. Roy. Soc. (London), vol. 247 , p. $424-434$.

Lyons, J.B., S.M. Savin, and A.J. Tambur1 (1971) Basement 1ce, Ward Hunt Ice Shelf, Ellesmere Island, Canada. J. Glaciol., vol. 10, no. 58, p. $93-100$.

Macklin, W.C. and B.F. Ryan (1966) Habits of ice grown in supercooled water and aqueous solutions. Phil. Mag., vol. 14, p. 847-860.

Malmgren, F. (1927) On the properties of sea ice. Sci. Results Norwegian North Pole Exped. "Maud", 1918-1925, vol. 1, no. 5, 67 p.

Martin, S. (1972) Ice stalactites and the desalination of sea ice. Naval Research Reviews, vol. XXV, no. 9, p. 17-26.

Martin, S. (1974) Ice stalactites: Comparison of a laminar flow theory with experiment. J. Fluid Mech., vol. 63, no. 1, p. 51-79.

Martin, S. (1979) A field study of brine drainage and oil entrapment in sea ice. J. Glaciol., vol. 22 , no. 88 , p. 473-502.

Martin, S. (1981) Frazil ice in rivers and oceans. Ann. Rev. Fluid Mech., vol. 13, p. 379-397.

Martin, S. and P. Kauffman (1974) The evolution of under-1ce melt ponds, or double diffusion at the freezing point. J. Fluid Mech., vol. 64 , no. 3 , p. 507-527.

Martin, S. and P. Kauffman (1981) A field and laboratory study of wave damping by grease 1ce. J. Glaciol., vol. 27, no. 96. 
Maxwe11, J.C. (1891) Electricity and Magnet1sm, 3rd ed., Vol. I. New York: Dover.

Maykut, G. and N. Untersteiner (1971) Some results from a time-dependent thermodynamic model of sea ice. J. Geophys. Res., vol. 76, p. 1550-1576.

Meeks, D.C., G.A. Poe and R.0. Ramseier (1974) A study of microwave emission properties of sea ice - AIDJEX 1972. Aerojet Electrosystems Company, Azusa, California, Final Report No. 1786FR-1.

Mellor, M. (1982) Mechanical behavior of sea 1ce. U.S. Army Cold Regions Research and Engineering Laboratory, CRREL Report (1n press).

Myerson, A.S. and D.J. Kirwan (1977a) Impurity trapping during dendritic crystal growth. 1. Computer simulation. Ind. Eng. Chem., Fund., vo1. 16 , no. 4 , p. 414-420.

Myerson, A.S. and D.J. Kirwan (1977b), Impurity trapping during dendritic crystal growth. 2. Experimental results and correlation. Ind. Eng. Chem., Fund., vol. 16, no. 4, p. 420-425.

Nagle, J.F. (1966) Lattice statist1cs of hydrogen bonded crystals. I. The residual entropy of 1ce. J. Math. Phys., vo1. 7, p. 1484-1491.

Nakawo, M. and N.K. Sinha (1981) Growth rate and salinity profile of first-year sea ice in the high Arctic. J. Glaciol, vol. 27, no. 96 , p. $315-330$.

Nakawo, M. and N.K. Sinha (in press) Brine layer spacing of first-year sea ice. J. Geophys. Res.

Nelson, K.H. and T.G. Thompson (1954) Deposition of salts from sea water by frigid concentration. J. Marine Res., vol. 13, no. 2, p. 166182.

Niedrauer, T.M. and S. Martin (1979) An experimental study of brine dra1nage and convection in young sea 1ce. J. Geophys. Res., vo1. 84 , no. C3, p. $1176-1186$.

Ono, N. (1965) Thermal properties of sea ice II. A method for determining the $\mathrm{K} / \mathrm{c} \rho$ value of a non-homogeneous ice sheet. Low Temp. Sci., vo1. A23, p. 177-183 (1n Japanese).

Ono, N. (1968) Thermal propertles of sea 1ce. IV. Thermal constants of sea 1ce. Low Temp. Sc1., vol. A26, p. 329-349 (in Japanese).

Owston, P.G. (1958) The structures of 1 ce $I$, as determined by X-ray and neutron diffraction analys1s. Adv. Phys., vol. 7, p. 171-188.

Ozum, B. and D.J. K1rwan (1976) Impurities in 1ce crystals grown from stirred solutions. A.I.Ch.E. Sympos. Series, vol. 72 , no. 153, p. 1.

Paige, R.A. (1966) Crystallographic studies of sea lce in McMurdo Sound, 
Antarctica. Nava1 Civil Engineering Laboratory, Technical Report $\mathrm{R} 494,31$ p.

Paige, R.A. (1970) Stalactite growth beneath sea ice. Science, vol. 167, p. $171-172$.

Paige, R.A. and R.A. Kennedy (1967) Strength studies of sea 1ce -effect of load rate on ring tensile strength. Naval Civil Engineering Laboratory, Technical Report R545, 25 p.

Patterson, M.S. (1973) Nonhydrostatic thermodynamics and its geologic applications. Rev. Geophys. Space Phys., vol. 11, p. 355-389.

Pauling, L. (1935) Structure and entropy of ice and of other crystals with randomness of atomic arrangements. J. Am. Chem. Soc., vol. 57, p. 2608-2684.

Perey, F.G.J. and E.R. Pounder (1958) Crystal orientation in ice sheets. Can. J. Phys., vol. 36, p. 494-502.

Peterson, S.W. and H.A. Levy (1957) A single-crystal neutron diffraction study of heavy ice. Acta Crystallographica, vol. 10, p. 70-76.

Petrov, I.G. (1954-55) Fiziko-mekhanicheskiye svoystva 1 tol'shchina ledyanogo pokrova (Physical and mechanical properties and thickness of ice cover). In Materialy Nablyudeniy Nauchno-Issledovatel'skoy Dreyfuyushchey Stantsii 1950-51 Goda (Observations of the Drifting Research Station of 1950-51) (M.M. Somov, Ed.), ArktIcheskiy Nauchno-Issledovate1'skiy Institut 2, Leningrad, p. 103-165.

Peyton, H.R. (1963) Some mechanical properties of sea ice. In Ice and Snow--Processes, Properties, and Applications (W.D. Kingery, Ed.), Cambridge, Mass.: MIT Press, p. 107-113.

Peyton, H.R. (1966) Sea 1ce strength. Geophysical Institute, University of Alaska Rept. UAG-182, 187 p.

Peyton, H.R. (1968) Sea ice strength - effects of load rates and salt reinforcement. In Arctic Drifting Stations (J.E. Sater, Ed.), Arctic Institute of North America, p. 197-217.

Pfann, W.G. (1958) Zone Melting, New York: Wiley, 230 p.

Poe, G., A. Stogryn and A.T. Edgerton (1972) Microwave emission characteristics of sea ice. Aerojet General Corp., Rept. 1749R-2.

Poe, G.A., A. Stogryn, A.T. Edgerton and R.0. Ramseler (1974) Study of microwave emission properties of sea ice. Aerojet General Corp., Rept. 1804FR-1.

Pounder, E.R. and E.M. Little (1959) Some physlcal properties of sea ice. I. Can. J. Phys., vol. 37, p. 443-473.

Ragle, R.H. (1962) The formation of lake ice in a temperate climate. U.S. Army Cold Regions Research and Engineering Laboratory, Research Report 107. 
Reeburgh, W.S. and M.S. Young (1982) New measurements of sulfate and chlorinity in natural sea 1ce. J. Geophys. Res. (1n press).

Richardson, C. and E.F. Keller (1966) The brine content of sea ice measured with a nuclear magnetic resonance spectrometer. J. Glaciol., vol. 6 , no. 43 , p. $89-100$.

Ringer, W.E. (1906) De Veranderinger in Samenstelling van Zeewater by Het Bevriezen. Chemisch Weeleblad, vol. 3, p. 223-249.

Rodhe, B. (1959) The Baltic ice code. Sveriges Meteorologiska och Hydrologiska Institut, Stockholm, Ser. E, No. 10, 59 p.

Rohatgi, P.K. and C.M. Adams (1967a) Freezing rate distributions during unidirectional solidification of solutions. Trans. Metall. Soc. A.I.M.E., vo1. 239 , no. 6 , p. 850-857.

Rohatgi, P.K. and C.M. Adams (1967b) Ice-brine dendritic aggregate formed on freezing of aqueous solutions. J. Glaciol., vol. 6, no. 47 , p. 663-679.

Rosenberg, A. and W.A. Tiller (1957) The relationship between growth forms and the preferred direction of growth. Acta Met., vol. 5, p. 565-573.

Rutter, J.W. and B. Chalmers (1953) A prismatic substructure formed during solidification of metals. Can. J. Phys., vol. 1, p. 15-39.

Ryan, B.F. (1969) The growth of ice parallel to the basal plane in supercooled water and supercooled metal fluoride solutions. J. Cryst. Growth, vol. 5, p. 284-288.

Ryan, B.F. and W.C. Macklin (1968) The growth of 1ce in supercooled aqueous solutions. J. Cryst. Growth, vol. 2, p. 337-340.

Salto, T. and N. Ono (1980) Percolation of sea 1ce. II. Brine drainage channels in young sea 1ce. Low Temp. Sc1., vo1. A39, p. 127-132.

Savel'ev, B.A. (1958) Izucheniyu 1'dov $v$ rayone dreyfa stantsii SP-4 v period tayaniya 1 razrushenya $1 \mathrm{kh} v 1955 \mathrm{~g}$ (Study of $1 \mathrm{ce}$ in the region of the drift of station SP-4 during melting and break-up in 1955). Problemy Severa, vol. 2, p. 47-79.

Savel'ev, B.A. (1963) Structure, composition, and properties of the ice cover of sea and fresh waters. Izd. Moskovskogo Univ., 541 p. (in Russian).

Schwarz, J. and W.F. Weeks (1977) Engineering properties of sea ice. J. Glaciol., vol. 19 , no. 81 , p. 499-530.

Schwarzacher, W. (1959) Pack-1ce studies in the Arctic Ocean. J. Geophys. Res., vo1. 64, p. 2357-2367.

Schwerdtfeger, P. (1963) The thermal properties of sea 1ce. J. Glaciol., vol. 4 , no. 36 , p. 789-807. 
Seidensticker, R.G. (1965) Comment on paper by P. Hoekstra, T.E. Osterkamp and W.F. Weeks, "The migration of liquid inclusions in single ice crystals." J. Geophys. Res., vol. 71, no. 8, p. 2180-2181.

Sekerka, R.F. (1968) Morphological stability. J. Cryst. Growth, vo1. $3 / 4$, p. $71-81$.

Sekerka, R.F., R.G. Seldensticker, D.R. Hamilton and J.D. Harrison (1967) Investigation of desalination by freezing. Office of Saline Water, Westinghouse Research Laboratories, Pittsburgh, Contract No. 14-01-0001-605, Final Report.

Seligman, G. (1949) Growth of glacier crystal. J. Glaciol., vol. 1, p. 254-268.

Serikov, M.I. (1963) Structure of Antarctic sea 1ce. Infor. Bull. Soviet Antarctic Exped., vol. 4, no. 5, p. 265-266.

Serson, H.V. (1972) Investigation of a plug of mult1-year old sea 1ce in the mouth of Nansen Sound. Defence Research Establishment, Ottawa, Technical Note $72-6,4 \mathrm{p}$.

Sharp, R.P. (1947) Sultability of ice for aircraft landings. Trans. Am. Geophys. Union, vol. 28, p. 111-119.

Shumsk11, P.A. (1955) K 1zuchenliu 1'dov severnogo ledovitogo okeana (A study of ice in the Arctic Ocean). Vestnik Akademii Nauk SSSR, 25, No. 2, p. 33-38.

Sinha, N.K. (1977) Technique for studying structure of sea 1ce. J. Glaciol., vol. 18 , no. 79 , p. 315-323.

Smith, D.D. (1964) Ice 1ithologies and structure of ice island Arlis II. J. Glaciol., vol. 5 , no. 37 , p. 17-38.

Smith, V.G., W.A. Tiller and J.W. Rutter (1955) A mathematical analysis of solute redistribution during solidification. Can. J. Phys., vol. 33 , p. $723-745$.

Stander, E. and G.A. Gidney (1980) The measurement of finite strain in sea 1 ce by impulse radar techniques. Proceedings Workshop on Sea Ice Field Measurement, Memorial University, St. Johns, Newfoundland, C-CORE Pub. No. 80-21, p. 127-164.

Stogryn, A. (1970) The brightness temperature of a vertically structured medium. Radio Science, vo1. 5, no. 12, p. 1397.

Stogryn, A. (1971) Equations for calculating the dielectric constant of saline water at $\mathrm{GHz}$ frequencies. IEEE Trans. Microwave Theory and Techniques, vol. 19 , no. 8 , p. 273.

Stratton, J. (1941) Electromagnetic Theory. New York: McGraw-Hi11, p. 563-573.

Suzuk1, Y. (1955) Observations of 1ce crystals formed on sea surface. J. Ocean. Soc. Japan, vol. 11, p. 123-126. 
Suzuki, Y. (1967) On disorder entropy of 1ce. In Physics of Snow and Ice, Institute of Low Temperature Science, Hokka1do University, Vol. 1, No. 1, p. 21-41.

Swinzow, G.K. (1966) Ice cover of an arctic proglacial lake. USA Cold Regions Research and Engineering Laboratory, Research Report 155, $43 \mathrm{p}$.

Tabata, T. (1960) Studies on the mechanical properties of sea ice V. Measurement of flexural strength. Low Temp. Sci., vol. Al9, p. 187-201.

Tabata, T. and N. Ono (1957) On the structure of sea 1ce. Low Temp. Sci., vo1. Al6, p. 197-210 (in Japanese).

Tabata, T. and N. Ono (1962) On the crystallographic study of several kinds of 1ce. Low Temp. Sci., vol. A20, p. 199-214 (in Japanese).

Taylor, L.D. and J.B. Lyons (1959) Ice structures, Angiussaq Lake, northwest Greenland. Geophysics Research Directorate, Air Force Cambridge Research Center, TN-59-461, 33 p.

T11ler, W.A. (1962) Effect of grain boundaries on solute partitioning during progressive solidification. Acta Met., vol. 1, no. 4, p. 428-437.

Tiller, W.A. (1963) Migration of a liquid zone through a solid. J. App1. Phys., vol. 34, no. 9, p. 2757-2762.

Tiller, W.A., K.A. Jackson, J.W. Rutter and B. Chalmers (1953) The redistribution of solute atoms during the solidification of metals. Acta Met., vol. 1, p. 428-437.

Tinga, W.R., W.A. Voss and D.F. Blossey (1973) Generalized approach to multiphase dielectric mixture theory. J. Appl. Phys., vol. 44, no. 9, p. 3897-3903.

Tsurikov, V.L. (1974) Statistics of salt composition in sea 1ce. Oceanology, vol. 14, no. 3, p. 360-367.

Tsurikov, V.L. (1976) Liquid Phase in Sea Ice. Moscow: Nauka, 210 p. (1n Russian).

Tsurikov, V.L. and Tsurikova, A.P. (1972) The brine content of sea ice (statement of the problem). Oceanology, vol. 12, no. 5, p. 663672 .

Turner, J.S. (1973) Buoyancy Effects in Fluids. Cambridge University Press, 367 p.

U.S. Navy Hydrographic office (1952) A functional glossary of ice terminology. Washington, D.C., 88 p.

Untersteiner, N. (1961) On the mass and heat budget of arctic sea ice. Arch. Meteorol. Geophys. Biok., vol. 12, p. 151-182. 
Untersteiner, N. (1968) Natural desalination and equilibrium salinity proftle of perennial sea 1ce. J. Geophys. Res., vol. 73, no. 4, p. 1251-1257.

Untersteiner, N, and F, Badgley (1958) Preliminary results of thermal budget studies on arctic pack 1ce during summer and autumn. In Arctic Sea Ice, U.S. National Acadeny of Sciences-National Research Council Pub. 598, p. 85-98.

Vant, M.R., R.O. Ramseler and V. Makros (1975) The complex dielectric constant of sea ice at frequencies in the range $0.1-40 \mathrm{GHz}$. J. App1. Phys., vo1. 49, no. 3, p. 1264-1280.

Vittoratos, E.S. (1979) Existence of oriented sea ice by the McKenzie Delta. In POAC 79, Trondheim, Norway, p. 643-650.

Wakatsuchi, M. (1977) Experiments on haline convection induced by freezing of sea water. Low Temp. Sci., vol. A35, p. 249-258 (in Japanese).

Walker, E.R. and P. Wadhams (1979) Thick sea-ice floes. Arctic, vol. 32 , no. 2 , p. 140-147.

Walton, D. and B. Chalmers (1959) The orlgin of the preferred orientation in the columnar zone of 1ngots. Trans. Metal. Soc. Am. Inst. Min. Met., Eng., vol. 215, p. 447-457.

Walton, D., W.A. Tiller, J.W. Rutter and W.C. Winegard (1955) Instability of a smooth solid-11quid interface during solidiffcation. J. Metals 7, Eng., vol. 215, p. 447-457.

Weeks, W.F. (1958) The structure of sea 1ce: A progress report. In Arctic Sea Ice, U.S. National Academy of Sciences-National Research Counc11, Pub. 598, p. 96-98.

Weeks, W.F. (1962) Tens1le strength of NaCl ice. J. Glaclol., vol. 4, no. 31 , p. $25-52$.

Weeks, W.F. and A. Assur (1963) Structural control of the vertical variation of the strength of sea and salt ice. In Ice and Snow Processes, Properties, and Applications (W.D. Kingery, Ed.), Cambridge, Mass.: MIT Press, p. 258-276.

Weeks, W.F. and A. Assur (1967) The mechanical properties of sea ice. USA Cold Regions Research and Engineering Laboratory, CRREL Monograph II-B3.

Weeks, W.F. and A. Assur (1969) Fracture of lake and sea ice. USA Cold Regions Research and Englneering Laboratory, Research Report 269, $77 \mathrm{p}$.

Weeks, W.F. and A.J. Gow (1978) Preferred crystal orlentations along the margins of the Arctic Ocean. J. Geophys. Res., vol. 84, no. C10, p. 5105-5121. 
Weeks, W.F. and A.J. Gow (1980) Crystal alignments in the fast ice of arctic Alaska. J. Geophys. Res., vol. 84, no. C10, p. 1137-1146.

Weeks, W.F. and G. Lofgren (1967) The effective solute distribution coefficient during the freezing of NaCl solutions. In Physics of Snow and Ice (H. Oura, Ed.), Institute of Low Temperature Science, Hokkaido, vol. 1, no. 1, p. 579-597.

Weeks, W.F. and 0.S. Lee (1958) Observations on the physical properties of sea 1ce at Hopedale, Labrador. Arctic, vol. 11, p. 134-155.

Weeks, W.F. and 0.S. Lee (1962) The salinity distribution in young sea ice. Arctic, vol. 15, p. 92-108.

Weeks, W.F. and W.L. Hamilton (1962) Petrograph1c characteristics of young sea 1ce, Polnt Barrow, Alaska. Am. Mineral., vol. 47, p. 945-961.

Weller, G.E. (1968) The heat budget and heat transfer processes in Antarctic plateau 1 ce and sea 1ce. ANARE Sclentific Reports, Series A (IV), Glaciology, Pub. No. 102, 155 p.

Wernick, J.H. (1956) Determination of diffusivities in liquid metals by means of temperature-gradient zone melting. J. Chem. Phys, vol. 25 , no. 1, p. 47-49.

Whitman, W.G. (1926) Elimination of salt froin sea water ice. Am. J. Sci., Ser. 5, vo1. 11 , no. 62,126 p.

Wilson, J.T., J.H. Zumberge and E.W. Marshall (1954) A study of ice on an Inland lake. USA Snow, Ice and Permafrost Research Estalishment, Research Report 5, 78 p.

Yen, Y.C. (1981) Review of thermal properties of snow, ice and sea 1ce. USA Cold Regions Research and Engineering Laboratory, CRREL Report $81-10,27$ p.

Zotikov, I.A., V.S. Zagorodnov and J.V. Raikovski (1980) Core drilling through the Ross Ice Shelf (Antarctica) confirmed basal freezing. Science, vol. 207 , no. 4438 , p. 1463-1465. 